\title{
General overview: European Integrated project on Aerosol Cloud Climate and Air Quality interactions (EUCAARI) - integrating aerosol research from nano to global scales
}

M. Kulmala ${ }^{1}$, A. Asmi $^{1}$, H. K. Lappalainen ${ }^{1,2}$, U. Baltensperger ${ }^{3}$, J-L. Brenguier ${ }^{4}$, M. C. Facchini ${ }^{5}$, H.-C. Hansson ${ }^{6}$ Ø. Hov ${ }^{7}$, C. D. O'Dowd ${ }^{8}$, U. Pöschl ${ }^{9}$, A. Wiedensohler ${ }^{10}$, R. Boers ${ }^{11}$, $_{\text {O } \text { Boucher }^{12, *} \text {, G. de Leeuw }}^{1,2,13}$, H. A. C. Denier van der Gon ${ }^{13}$, J. Feichter ${ }^{14}$, R. Krejci ${ }^{6}$, P. Laj ${ }^{15}$, H. Lihavainen ${ }^{2}$, U. Lohmann ${ }^{16}$, G. McFiggans ${ }^{17}$, T. Mentel ${ }^{18}$, C. Pilinis ${ }^{19}$, I. Riipinen ${ }^{1,36}$, M. Schulz ${ }^{7,20}$, A. Stohl ${ }^{21}$, E. Swietlicki ${ }^{22}$, E. Vignati $^{23}$, C. Alves ${ }^{25}$, M. Amann ${ }^{24}$, M. Ammann ${ }^{59}$, S. Arabas ${ }^{26}$, P. Artaxo ${ }^{27}$, H. Baars ${ }^{10}$, D. C. S. Beddows ${ }^{28}$, R. Bergström ${ }^{29}$, J. P. Beukes ${ }^{30}$, M. Bilde ${ }^{31}$, J. F. Burkhart ${ }^{21}$, F. Canonaco ${ }^{3}$, S. L. Clegg ${ }^{32}$, H. Coe ${ }^{17}$, S. Crumeyrolle ${ }^{33}$, B. D'Anna ${ }^{34}$, S. Decesari ${ }^{5}$, S. Gilardoni' ${ }^{23}$, M. Fischer ${ }^{35}$, A. M. Fjaeraa ${ }^{21}$, C. Fountoukis ${ }^{36}$, C. George ${ }^{34}$, L. Gomes ${ }^{4}$, P. Halloran ${ }^{12}$, T. Hamburger ${ }^{37}$, R. M. Harrison ${ }^{28}$, H. Herrmann ${ }^{10}$, T. Hoffmann ${ }^{38}$, C. Hoose ${ }^{39}$, M. Hu ${ }^{40}$, A. Hyvärinen ${ }^{2}$, U. Hõrrak ${ }^{41}$, Y. Iinuma ${ }^{10}$, T. Iversen ${ }^{7}$, M. Josipovic ${ }^{30}$, M. Kanakidou ${ }^{42}$, A. Kiendler-Scharr ${ }^{18}$, A. Kirkevåg ${ }^{7}$, G. Kiss ${ }^{43}$, Z. Klimont ${ }^{24}$, P. Kolmonen ${ }^{2}$, M. Komppula ${ }^{44}$, J.-E. Kristjánsson ${ }^{45}$, L. Laakso ${ }^{1,2,30}$, A. Laaksonen ${ }^{2,46}$, L. Labonnote ${ }^{47}$, V. A. Lanz ${ }^{3}$, K. E. J. Lehtinen ${ }^{44,46}$, L. V. Rizzo ${ }^{27}$, R. Makkonen ${ }^{1}$, H. E. Manninen ${ }^{1}$, G. McMeeking ${ }^{17}$, J. Merikanto ${ }^{1}$, A. Minikin ${ }^{37}$, S. Mirme ${ }^{35}$, W. T. Morgan ${ }^{17}$, E. Nemitz ${ }^{48}$, D. O'Donnell ${ }^{14}$, T. S. Panwar ${ }^{49}$, H. Pawlowska ${ }^{26}$, A. Petzold ${ }^{37}$, J. J. Pienaar ${ }^{30}$, C. Pio ${ }^{25}$, C. Plass-Duelmer ${ }^{50}$, A. S. H. Prévôt ${ }^{3}$, S. Pryor ${ }^{51}$, C. L. Reddington ${ }^{52}$, G. Roberts ${ }^{11}$, D. Rosenfeld ${ }^{53}$, J. Schwarz ${ }^{54}$, Ø. Seland ${ }^{7}$, K. Sellegri ${ }^{55}$, X. J. Shen ${ }^{56}$, M. Shiraiwa ${ }^{9}$, H. Siebert ${ }^{10}$, B. Sierau ${ }^{16}$, D. Simpson $^{7,60}$, J. Y. Sun ${ }^{56}$, D. Topping ${ }^{17}$, P. Tunved ${ }^{6}$, P. Vaattovaara ${ }^{46}$, V. Vakkari ${ }^{1}$, J. P. Veefkind ${ }^{11}$, A. Visschedijk ${ }^{13}$, H. Vuollekoski ${ }^{1}$, R. Vuolo ${ }^{20}$, B. Wehner ${ }^{10}$, J. Wildt ${ }^{18}$, S. Woodward $^{12}$, D. R. Worsnop ${ }^{1,2,57}$, G.-J. van Zadelhoff ${ }^{11}$, A. A. Zardini ${ }^{31,58}$, K. Zhang ${ }^{14}$, P. G. van Zyl ${ }^{30}$, V.-M. Kerminen ${ }^{2}$, K. S Carslaw ${ }^{52}$, and S. N. Pandis ${ }^{36}$

${ }^{1}$ Department of Physics, University of Helsinki, 00014 Helsinki, Finland

${ }^{2}$ Finnish Meteorological Institute, Research and Development, 00101 Helsinki, Finland

${ }^{3}$ Paul Scherrer Institut, Laboratory of Atmospheric Chemistry, Villigen PSI, Switzerland

${ }^{4}$ French Meteorological Service, 31057 Toulouse, France

${ }^{5}$ Institute of Atmospheric Sciences and Climate (ISAC), National Research Council (CNR), Bologna, Italy

${ }^{6}$ Department of Applied Environmental Science (ITM), Stockholm University, 10691 Stockholm, Sweden

${ }^{7}$ Norwegian Meteorological Institute, 0313 Oslo, Norway

${ }^{8}$ School of Physics \& Centre for Climate and Air Pollution Studies, Environmental Change Institute, National University of Ireland, Galway, Ireland

${ }^{9}$ Max Planck Institute for Chemistry, Mainz, Germany

${ }^{10}$ Leibniz Institute for Tropospheric Research, 04318 Leipzig, Germany

${ }^{11}$ Earth Observation and Climate Department/Climate and Seismology Sector, KNMI, The Netherlands

${ }^{12}$ Met Office Hadley Centre, Fitzroy Road, Exeter, Devon, EX13PB, UK

${ }^{13}$ TNO Built Environment and Geosciences, Utrecht, The Netherlands

${ }^{14}$ Max Planck Institute for Meteorology, Hamburg, Germany

${ }^{15}$ Laboratoire de Glaciologie et Géophysique de l'Environnement (LGGE), CNRS/University of Grenoble, Grenoble, France

${ }^{16}$ Institute of Atmospheric and Climate Science, ETH Zurich, Switzerland

${ }^{17}$ School of Earth, Atmospheric and Environmental Sciences, University of Manchester, Manchester, UK

${ }^{18}$ Institut fuer Energie- und Klimaforschung - Troposphaere, Forschungszentrum GmbH Jülich, 52425 Jülich, Germany

${ }^{19}$ Department of Environment, University of the Aegean, Mytilene, Greece

${ }^{20}$ Laboratoire des Sciences du Climat et de l'Environnement, Gif-sur-Yvette, France

${ }^{21}$ NILU, Norwegian Institute for Air Research, Kjeller, Norway

${ }^{22}$ Division of Nuclear Physics, Lund University, P.O. Box 118, 22100 Lund, Sweden

${ }^{23}$ European Commission, Institute for Environment and Sustainability, Climate Change and Air Quality Unit, Ispra, Italy

${ }^{24}$ IIASA, International Institute for Applied Systems Analysis, Laxenburg, Austria

${ }^{25}$ CESAM \& Department of Environment, University of Aveiro, Portugal 
${ }^{26}$ Institute of Geophysics, Faculty of Physics, University of Warsaw, Warsaw, Poland

${ }^{27}$ Institute of Physics University of São Paulo Rua do Matão, Travessa R, 187 CEP05508-090, Sao Paulo, Brazil

${ }^{28}$ University of Birmingham, Division of Environmental Health and Risk Management, Birmingham, UK

${ }^{29}$ Department of Chemistry, University of Gothenburg, 41296 Gothenburg, Sweden

${ }^{30}$ School of Physical and Chemical Sciences, North-West University, Potchefstroom, South Africa

${ }^{31}$ Department of Chemistry, University of Copenhagen, Copenhagen, Denmark

${ }^{32}$ School of Environmental Sciences, University of East Anglia, Norwich NR4 7TJ, UK

${ }^{33}$ Laboratoire de Météorologie Physique, Université Blaise Pascal, Clermont-Ferrand, France

${ }^{34}$ CNRS, UMR5256, IRCELYON, Institut de recherches sur la catalyse et l'environnement de Lyon, Villeurbanne, Université de Lyon, Lyon, France

${ }^{35}$ Airel Ltd, Tähe 4, Tartu, Estonia

${ }^{36}$ Institute of Chemical Engineering and High Temperature Chemical Processes (ICE-HT), Foundation for Research and Technology Hellas (FORTH), Patras, Greece

${ }^{37}$ Deutsches Zentrum für Luft- und Raumfahrt (DLR), Institut für Physik der Atmosphäre, Oberpfaffenhofen, Germany

${ }^{38}$ Institut für Anorganische und Analytische Chemie, Johannes Gutenberg-University, Mainz, Germany

${ }^{39}$ Karlsruhe Institute of Technology, Karlsruhe, Germany

${ }^{40}$ State Key Joint Laboratory of Environmental Simulation and Pollution Control (Peking University), College of

Environmental Sciences and Engineering, Peking University, Beijing, 100871, China

${ }^{41}$ Institute of Physics, University of Tartu, 18 Ülikooli St., Tartu, 50090, Estonia

${ }^{42}$ Environmental Chemical Processes Laboratory, Department of Chemistry, University of Crete, 71003 ,

P.O. Box 2208, Heraklion, Greece

${ }^{43}$ Air Chemistry Group of Hungarian Academy of Sciences, University of Pannonia, P.O. Box 158, 8201 Veszprém, Hungary

${ }^{44}$ Finnish Meteorological Institute, Kuopio Unit, 70211 Kuopio, Finland

${ }^{45}$ Department of Geosciences, University of Oslo, Oslo, Norway

${ }^{46}$ University of Eastern Finland, Dept. Applied Physics, POB 1627, 70211 Kuopio, Finland

${ }^{47}$ Laboratoire d'Optique Atmosphérique - Université des Sciences et Technologies de Lille/CNRS,

Villeneuve d'Ascq Cedex, France

${ }^{48}$ Centre for Ecology \& Hydrology Bush Estate, Penicuik, Midlothian, EH26 0QB, UK

${ }^{49}$ TERI Darbari Seth Block IHC complex Lodhi Road, New Delhi, 110003, India

${ }^{50}$ Hohenpeissenberg Meteorological Observatory, Deutscher Wetterdienst, Germany

${ }^{51}$ Risø National Laboratory Fredriksborgvej 399, P.O. Box 49, 4000 Roskilde, Denmark

${ }^{52}$ University of Leeds, School of Earth and Environment, Leeds, LS2 9JT, UK

${ }^{53}$ Institute of Earth Sciences, The Hebrew University of Jerusalem, Israel

${ }^{54}$ Institute of Chemical Process Fundamentals AS CR, Rozvojova 135, Prague, Czech Republic

${ }^{55}$ Laboratoire de Météorologie Physique, UMR6016, CNRS/University of Clermont-Ferrand, Clermont-Ferrand, France

${ }^{56}$ Key Laboratory for Atmospheric Chemistry, Chinese Academy of Meteorological Sciences, Beijing 100081, China

${ }^{57}$ Aerodyne Research, Inc. 45 Manning Rd, Billerica, MA 0182, USA

${ }^{58}$ Institute for Energy and Transport, Sustainable Transport Unit, JRC-European Commission, 21027 Ispra (Va), Italy

${ }^{59}$ Paul Scherrer Institut, Laboratory of Radiochemistry and Environmental Chemistry, Switzerland

${ }^{60}$ Dept. Earth \& Space Sciences, Chalmers University of Technology, Gothenburg, Sweden

*now at: Laboratoire de Météorologie Dynamique, IPSL/CNRS, Tour 45-55, Université P. et M. Curie, 4 place Jussieu, 75252 Paris Cedex 05, France

Received: 19 April 2011 - Published in Atmos. Chem. Phys. Discuss.: 24 June 2011

Revised: 24 November 2011 - Accepted: 5 December 2011 - Published: 21 December 2011 
Abstract. In this paper we describe and summarize the main achievements of the European Aerosol Cloud Climate and Air Quality Interactions project (EUCAARI). EUCAARI started on 1 January 2007 and ended on 31 December 2010 leaving a rich legacy including: (a) a comprehensive database with a year of observations of the physical, chemical and optical properties of aerosol particles over Europe, (b) comprehensive aerosol measurements in four developing countries, (c) a database of airborne measurements of aerosols and clouds over Europe during May 2008, (d) comprehensive modeling tools to study aerosol processes fron nano to global scale and their effects on climate and air quality. In addition a new Pan-European aerosol emissions inventory was developed and evaluated, a new cluster spectrometer was built and tested in the field and several new aerosol parameterizations and computations modules for chemical transport and global climate models were developed and evaluated. These achievements and related studies have substantially improved our understanding and reduced the uncertainties of aerosol radiative forcing and air quality-climate interactions. The EUCAARI results can be utilized in European and global environmental policy to assess the aerosol impacts and the corresponding abatement strategies.

\section{Introduction}

\subsection{Background}

The study of atmospheric physics and chemistry as a scientific discipline goes back to the 18 th century when the principal issue was identifying the major chemical components of the atmosphere. In the late 19th and 20th century attention turned to the so-called trace gases and aerosol particles. Recently, the importance of atmospheric aerosols to global radiation, cloud formation, and human health effects has motivated several investigations. Trace gases and atmospheric aerosols are tightly connected with each other via physical, chemical, meteorological and biological processes occurring in the atmosphere and at the atmosphere-biosphere interface (see e.g. Seinfeld and Pandis, 1998; Fowler et al., 2009). Human actions, such as emission policy, forest management and land use changes, as well as various natural feedback mechanisms involving the biosphere and atmosphere, have substantial impacts on the complicated couplings between atmospheric aerosols, trace gases, air quality and climate (Brasseur and Roeckner, 2005; Monks et al., 2009; Arneth et al., 2009; Raes and Seinfeld, 2009; Carslaw et al., 2010).

Atmospheric aerosol particles affect the quality of our life in many different ways. First of all, they influence the Earth's radiation balance directly by scattering and absorbing solar radiation, and indirectly by acting as cloud condensation nuclei (CCN) (e.g. Charlson et al., 1992). The interaction between atmospheric aerosols and climate system is the dominant uncertainty in predicting the radiative forcing and future climate (IPCC, 2007; Andreae and Rosenfeld, 2008; Myhre,
2009; Quaas et al., 2009; Isaksen et al., 2009). The effects of aerosols on temperature and precipitation patterns can be seen mainly over regional and continental scales. Secondly, aerosol particles deteriorate both human health and visibility in urban areas (Pope and Dockery, 2006; Hand and Malm, 2007; Anderson, 2009). The interactions between air quality and climate are largely unknown, although some links have been identified (e.g. Swart, 2004; Arneth et al., 2009) or even quantified (Dentener et al., 2005). Thirdly, aerosol particles modify the intensity and distribution of radiation that reaches the earth surface, having direct influences on the terrestrial carbon sink (Gu et al., 2002). Better understanding and quantifying of the above aerosol effects in the atmosphere requires detailed information on how different sources (including those related to the biosphere) and atmospheric transformation processes modify the properties of atmospheric particles and the concentrations of trace gases. It also requires the development of advanced instrumentation and methodologies for measuring and validating atmospheric composition changes and understanding key atmospheric processes (Laj et al., 2009).

The European Aerosol Cloud Climate and Air Quality Interactions project EUCAARI is an EU Research Framework 6 integrated project focusing on understanding the interactions of climate and air pollution (Kulmala et al., 2009). EUCAARI has integrated in a multidisciplinary way atmospheric processes from the nano to global scale. The project brought together several leading European research groups, state-of-the-art infrastructure and some key scientists from non-EU countries to investigate the role of aerosol on climate and air quality. Altogether 48 partners from 24 countries participated in the project. EUCAARI has established a pan-European measurement network for Lagrangian studies and four stations in developing countries. Here we present the main research achievements, improved scientific methods, and the answers to the main scientific questions and objectives of EUCAARI. We focus on the quantification of different processes related to aerosol radiative forcing of our climate. We also quantify the side effects of possible air quality directives on aerosol concentrations and present the roadmap for future analysis. All of this is possible since we have improved the general understanding of aerosol life cycle, which enabled us to improve the description of radiative forcing and different feedbacks. It also allowed us to assess aerosol effects on climate and air quality and analyze a range of abatement strategies.

We present first an overview of the main tools (Sect. 2) and results of the project (Sect. 3). In Sect. 4 we focus on our objectives and specific questions (given in Sect. 1.2). In Sect. 4 we also describe the major improvements of the description of the aerosol life cycle, which resulted in major improvements of the climate and air quality models. In Sect. 4 we also present our legacy including data banks, implementations of process-based parameterisations in chemical transport and global climate models improving their performance. 


\subsection{Mission and objectives}

Originally The EUCAARI mission and objectives were determined in 2005-2006 (Kulmala et al., 2009):

1. Reduction of the current uncertainty of the impact of aerosol particles on climate by $50 \%$ and quantification of the relationship between anthropogenic aerosol particles and regional air quality. To achieve this objective EUCAARI concentrated on the areas of greatest uncertainty to:

1. Identify and quantify the processes and sources governing global and regional aerosol concentrations.

2. Quantify the physico-chemical properties of atmospheric aerosols.

3. Quantify the feedback processes that link climate change and atmospheric aerosol concentrations with emphasis on the production and loading of natural aerosols and their precursors.

2. Quantification of the side effects of European air quality directives on global and regional climate, and providing tools for future quantifications for different stakeholders.

EUCAARI also aimed to make technological developments by improving aerosol and ion measurement techniques. This was achieved by using prototypes of new equipment in field experiments, thus providing the relevant technological trials for product development by small and medium companies (SME). EUCAARI also produced advanced aerosol and cloud models that can be used by the global and regional climate and air quality modelling communities.

EUCAARI Objective 1 was achieved by improving our understanding of atmospheric aerosol physics and chemistry. This improvement enhanced our ability to forecast shortterm regional air quality as well as to estimate the long-term aerosol effects on current and future global climate. Objective 2 facilitated the linking of the air quality and global climate change problems and provided the necessary tools for their quantification for use by different stakeholders.

The impact of EUCAARI can be measured by its ability to achieve its objectives and its contribution to (a) research, (b) technological improvements; (c) mitigation strategies and (d) solution of air pollution problems.

During project planning the consortium identified 12 key scientific topics from nanometre scale processes to the overall aerosol-cloud effect on climate. These were:

1. In-situ formation (nucleation) of aerosols.

2. Number and mass emissions of primary aerosol from natural and anthropogenic sources at urban, regional, and global scales.
3. Formation of secondary organic aerosol and the partitioning of semi-volatile compounds between the gas and aerosol phases.

4. Ageing of aerosols and evolution of their properties during their atmospheric lifetime.

5. Attribution of the different aerosol mass components in Europe to specific sources.

6. Current and future contributions of natural versus anthropogenic, and primary versus secondary sources to particle number concentrations.

7. Long-range transport of aerosol particles and their precursors from and to Europe as well as their transport within Europe.

8. Seasonal behaviour of aerosol particles in economically developing countries.

9. Air quality and local climate interactions inside and outside Europe.

10. The impact of aerosols and trace gases on cloud droplet activation, cloud lifetime, and extent (the aerosol indirect effects).

11. Interactions between the aerosol cycle, the water cycle, and the biosphere.

12. Climatic feedbacks related to anthropogenic/biosphereaerosol-cloud-climate interactions.

Highlights of EUCAARI contributions to our knowledge in these key areas are summarized in Sect. 4 and Appendix E.

\section{Scientific approach}

In order to achieve our objectives and to address the research questions we performed multidisciplinary research including both experimental and theoretical methods. Laboratory and field experiments, including development of novel instrumental techniques, provided new information about aerosol and cloud properties and processes, while developments in basic theory, simulations, and models gave us a way to integrate and compare the results in a broader context. EUCAARI utilized the European long-term aerosol observation network established by EUSAAR (European Super sites for Atmospheric Aerosol Research), and also established longterm ground-based aerosol measurements in economically growing countries in Asia, Africa, and South-America to plug significant gaps in our global aerosol observation capability. In parallel, EUCAARI performed intensive airborne measurements over Europe during May 2008. Additional details of the technical approach are given in Appendix A and references therein. 
Figure 1 shows the research chain (the "EUCAARI arrow") utilized as the backbone of EUCAARI research. It begins at the molecular scale extending to the regional and global scale. The scientific approach starts from basic theories of nucleation and chemical processes followed by models of detailed aerosol dynamic/atmospheric chemistry and vegetation-atmosphere exchange, laboratory experiments with continuous field measurements at several research stations and global-scale modelling. Understanding the highly non-linear processes related to the earth system at different spatial and temporal scales gave insights that allowed us to achieve our objectives. The main corresponding disciplines are aerosol and environmental physics and technology, atmospheric chemistry and physics, analytical chemistry, micrometeorology, climate modelling and forest ecology. This multidisciplinarity provides an opportunity to add value and gain synergy.

We have focused on those topics in the research chain where the uncertainties are largest. At small scales, we used molecular simulations (Monte Carlo and molecular dynamics) to understand nucleation and aerosol thermodynamic processes. These microscopic processes of nucleation together with condensation/evaporation and coagulation are required to understand aerosol dynamics, particle concentrations and composition. Significant advances in laboratory data and modelling techniques were needed for a number of important aerosol systems. Fundamental aerosol processes are needed to be understood in order to quantify the aerosol radiative properties and the influence of aerosols on cloud microphysics and dynamics at the scale of individual clouds. At larger scales, advances in our understanding of boundary layer meteorology were needed to understand atmospheric aerosol transport, trace gas (e.g. $\mathrm{CO}_{2}$, methane, $\mathrm{N}_{2} \mathrm{O}, \mathrm{O}_{3}, \mathrm{SO}_{2}, \mathrm{NO}_{\mathrm{x}}, \mathrm{VOCs}$ ) and water vapour exchange and deposition processes. Boundary layer studies form a link to regional-scale and global-scale processes. To simulate global climate and air quality, the most recent progress in this chain of processes was compiled, integrated and implemented into climate change and air quality numerical models.

The understanding of different processes and their inclusion in climate models is crucial. For example, if only the aerosol mass loading in the atmosphere is simulated based on emissions of precursor gases (like $\mathrm{SO}_{2}$ ) and primary emissions, the number concentration of aerosol particles and further cloud condensation nuclei $(\mathrm{CCN})$ concentration might be seriously under- or sometimes overestimated unless the size and number of particles is considered (see e.g. Spracklen et al., 2006, 2008b).

EUCAARI has built on available data from previous field campaigns and long-term measurements in order to establish global datasets. The data integration within EUCAARI involved a combination of data analysis (accuracy, consistency and representativeness), modelling and field experiments. The experimental and model data was collected in a web-based platform located at partner NILU in Norway

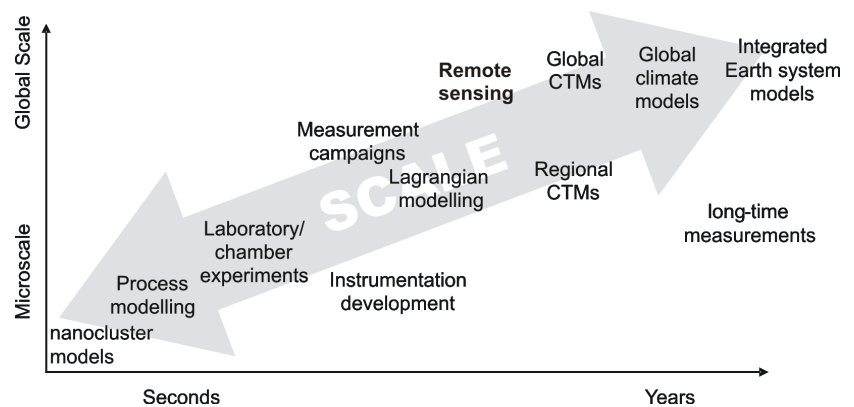

Fig. 1. The "EUCAARI arrow" or research chain connecting molecular scale processes with the global scale through integrated measurements, modeling and theory (Kulmala et al., 2009).

(ebas.nilu.no). The EUCAARI observation system combines long-term and spatially extensive surface-based measurements both in Europe and developing countries (China, India, Brazil, South-Africa), including the European network of supersites for aerosol research (EUSAAR), with satellite retrievals of key parameters. EUCAARI used west-east and north-south station-to-station networks together with Lagrangian and Eulerian airborne measurements and field measurements to quantify the effects on regional aerosol properties of emissions, aerosol formation, transformation, transport and deposition. These measurements included parameters relevant for climate change (the radiative fields in clear and cloudy skies, and their susceptibility to aerosol fields) and air quality (particulate matter (PM) mass, size-resolved aerosol chemical composition, ozone, and $\mathrm{NO}_{\mathrm{x}}$ ). During May 2008 an intensive campaign of airborne measurements over Europe was performed. During 2008-2009 a subnetwork of supersites provided higher resolution data and detailed chemical composition and extended the observations into the free troposphere.

Due the wide variety of experiments and studies done in EUCAARI, a comprehensive description of technical solutions and methodologies can not be explained fully in single document. More details are given in the EUCAARI Special Issue in the journal Atmospheric Chemistry and Physics (http://www.atmos-chem-phys.net/special_issue111.html).

Here, we present some of the key methods used in the main studies of EUCAARI. The laboratory studies focused on atmospheric nucleation, ice nucleation and secondary organic aerosol formation/ageing studies. In order to cover the time scales involved in these processes (from seconds to days), flow tubes as well as atmospheric simulation chambers of different sizes were applied. Table A1 in Appendix A. provides information about the main laboratory infrastructures used in EUCAARI. Field studies in EUCAARI used multiple stations in Europe and developing countries. Table A2 in Appendix A summarizes the main field infrastructures used in the studies. Airborne measurements in 2008 included two main airborne experiments named Intensive Cloud Aerosol 
Measurement Campaign (IMPACT) and Long-range Experiment (LONGREX). The airborne platforms are shown in Table A3 in Appendix A.

The computational methods span from simulations of the behaviour of single modules to compute rates of specific processes to Earth system models. Table A4 in Appendix A show some of the main methods used in the small scale studies, and Table A5 in Appendix A methods used in the large scale studies. The used data bases and emission inventories are described in Table A6 in Appendix A.

EUCAARI studies deployed an unprecedented array of instruments for in situ measurements. Table A7 in Appendix A shows some of the main instruments used in experiments concentrating on the current state-of-art instrumentation.

\section{Main results}

\subsection{Emissions}

\subsubsection{Size-resolved anthropogenic carbonaceous aerosols and particle number emission database for Europe}

To assess the impact of air pollution on climate, among the major knowledge gaps are size-resolved emissions of carbonaceous aerosols and particle numbers $(\mathrm{PN})$. Both have been addressed in EUCAARI (Denier van der Gon et al., 2009, 2011a, b). European emissions of anthropogenic particulate elemental carbon (EC) and organic carbon (OC) were estimated and separated in $<1 \mu \mathrm{m}, 1-2.5 \mu \mathrm{m}$ and $2.5-10 \mu \mathrm{m}$ size classes. More detailed mass particle size distributions for $\mathrm{EC}<1 \mu \mathrm{m}$ and $\mathrm{OC}<2.5 \mu \mathrm{m}$ in the range $20 \mathrm{~nm}-2.5 \mu \mathrm{m}$ by source sector was derived from the literature. Particle mass size distributions show a maximum in the range of 80$200 \mathrm{~nm}$, indicating that the carbonaceous aerosol emissions are highly relevant for long-range atmospheric transport. The emission of $\mathrm{OC}<2.5 \mu \mathrm{m}$ in Europe is dominated by the residential combustion of wood and coal. The largest sources of $\mathrm{EC}<1 \mu \mathrm{m}$ are transport (diesel use) and residential combustion. Total carbonaceous aerosol in the $\mathrm{PM}_{10}$ range for $\mathrm{Eu}-$ rope in 2005 amounts to $\sim 2000 \mathrm{kt} \mathrm{C} \mathrm{yr}^{-1}$, of which $\sim 10 \%$ is due to international shipping. For details see Table 1.

A first size-resolved anthropogenic particle number (PN) emission inventory for the reference year 2005 was compiled (Denier van der Gon et al., 2011a). The emission data base includes all particles in the size range of $10-300 \mathrm{~nm}$ and distributes the particle number emissions in 15 different size bins. The preferred approach to calculate $\mathrm{PN}$ emissions uses direct emission factors (EFs). For the key sources, such EFs were compiled from the literature with specific emphasis on road transport and residential combustion. Especially wood combustion is an uncertain source in Europe. The wood-use data have been updated and new PN emission factors have been compiled. A remarkable observation from these data is that PM emission is highly dependent on the type of wood stove with modern stoves emitting much less PM but that $\mathrm{PN}$ emissions are quite comparable. The emissions are gridded on a $1 / 8^{\circ} \times$ longitude $1 / 16^{\circ}$ latitude resolution (or approximately $7 \times 7 \mathrm{~km}$ ) using especially prepared distribution maps. Particular attention has been given to the spatial distribution of transport emission and emission due to residential combustion. An example is presented in Fig. 2.

In polluted areas, road traffic is usually the main source of particles evaluated by number. In comparison to emission factors for mass, the particle number emission factors are very poorly known. There are two sources of available information:

- Emission factors determined from laboratory chassis dynamometer studies, in which particle number emissions from engines with a range of capacities, fuels and technologies have been measured. There has been only one systematic study (the PARTICULATES project), from which data can be taken.

- Inversion of particle number concentrations measured in the field to infer the source strength of particles from a known fleet of vehicles.

Whilst the latter approach has the attraction of deriving data from actual on-road vehicles, it has the weakness that the highest level of disaggregation according to vehicle type which can be achieved is between heavy duty and light duty vehicles, and the method requires accurate knowledge of the source strength of another traffic generated pollutant such as $\mathrm{NO}_{\mathrm{x}}$. The latter demands high quality emission factor information combined with detailed knowledge of the traffic fleet composition. Whilst the former approach of deriving data from chassis dynamometer studies is superficially attractive, the measurements are sensitive to exhaust gas dilution conditions and may not replicate well between different test facilities.

A number of published studies have used the field measurement approach to estimate average emission factors for light duty and heavy duty vehicles. In some cases, the vehicle fleet composition was published and has been used to infer emission factors. In other cases, it was not, and has been reconstructed from published data on vehicle registrations and usage. By combining such data on the vehicle fleet with the laboratory determined emission factors relating to different fuels and engine technologies, fleet average emission factors can be calculated which can then be compared with those determined in the field (Beddows and Harrison, 2008).

\subsubsection{Particle number emissions from biomass burning}

Aerosol emissions from vegetation fires have a large impact on air quality and climate. Dynamic particle number (EFPN, unit: number of particles per kg of burnt fuel) and mass emission factors (EFPM, unit: mass of particles per 
Table 1. Size-differentiated EC and OC emissions (tonnes) for UNECE Europe in 2005.

\begin{tabular}{|c|c|c|c|c|c|c|}
\hline SNAP & Source sector & $\mathrm{EC}<1 \mu \mathrm{m}$ & $\mathrm{EC} 1-2.5 \mu \mathrm{m}$ & EC $2.5-10 \mu \mathrm{m}$ & $\mathrm{OC}<2.5 \mu \mathrm{m}$ & OC $2.5-10 \mu \mathrm{m}$ \\
\hline 1 & Combustion in energy industries & 2390 & 17600 & 29000 & 11200 & 2700 \\
\hline 2 & Non-industrial combustion plants & 143000 & 43000 & 50200 & 395000 & 4340 \\
\hline 3 & Combustion in manufacturing industry & 1850 & 3960 & 5460 & 9050 & 543 \\
\hline 4 & Production processes & 32300 & 3990 & 19000 & 81000 & 29000 \\
\hline 5 & Extraction and distribution fossil fuels & 1330 & 2720 & 55200 & 1430 & 6310 \\
\hline 6 & Solvent use & 0 & 0 & 0 & 0 & 0 \\
\hline 7 & Road transport (total) & 184000 & 16800 & 7800 & 104000 & 25500 \\
\hline 8 & Other mobile sources and machinery & 90200 & 4880 & 5250 & 71200 & 0 \\
\hline 9 & Waste treatment and disposal & 35200 & 1880 & 1870 & 63000 & 0 \\
\hline 10 & Agriculture & 35000 & 1010 & 2250 & 112000 & 145000 \\
\hline \multicolumn{2}{|c|}{ Total excl. international shipping* } & 525000 & 95900 & 176000 & 848000 & 214000 \\
\hline \multicolumn{2}{|c|}{ International shipping } & 79400 & 44700 & 6890 & 83700 & 0 \\
\hline
\end{tabular}

* Deviations in the summed totals are due to rounding of the source sector contributions.

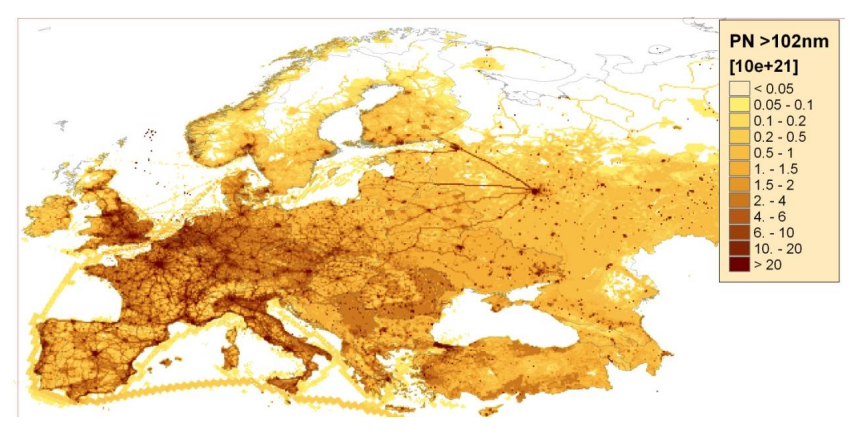

Fig. 2. Emission of particle numbers from 100-300 nm in Europe for the year 2005 (Denier van der Gon et al., 2009).

$\mathrm{kg}$ of burnt fuel) as well as characteristic carbon monoxide (CO)-referenced emission ratios (PN/CO, PM/CO) were determined from experimental data (Janhall et al., 2009). For the particle number emission factor of vegetation fires, we found no dependence on fuel type and obtained the following parametrization as a function of modified combustion efficiency (MCE):

$\mathrm{EFPN}=34 \times 10^{15} \times(1-\mathrm{MCE}) \mathrm{kg}^{-1} \pm 10^{15} \mathrm{~kg}^{-1}$

with regard to dry fuel mass. For the fine particle mass emission factors (EFPM) we obtained (86$85 \times \mathrm{MCE}) \mathrm{g} \mathrm{kg}^{-1} \pm 3 \mathrm{~g} \mathrm{~kg}^{-1}$ as an average for all investigated fires; $(93-90 \times \mathrm{MCE}) \mathrm{g} \mathrm{kg}_{4} \mathrm{~g} \mathrm{~kg}^{-1}$ for forest; (67-65 $\times$ MCE) $\mathrm{g} \mathrm{kg}^{-1} \pm 2 \mathrm{~g} \mathrm{~kg}^{-1}$ for savanna; (63$62 \times \mathrm{MCE}) \mathrm{g} \mathrm{kg}^{-1} \pm 1 \mathrm{~g} \mathrm{~kg}^{-1}$ for grass (Janhall et al., 2009). For the PN/CO emission ratio we obtained an average of (34 \pm 16$) \mathrm{cm}^{-3} \mathrm{ppb}^{-1}$ exhibiting no systematic dependence on fuel type or combustion efficiency. The average PM/CO emission ratios were $(0.09 \pm 0.04) \mathrm{g} \mathrm{g}^{-1}$ for all investigated fires; $(0.13 \pm 0.05) \mathrm{g} \mathrm{g}^{-1}$ for forest; $(0.08 \pm 0.03) \mathrm{g} \mathrm{g}^{-1}$ for savanna; and $(0.07 \pm 0.03) \mathrm{g} \mathrm{g}^{-1}$ for grass. These results were based on a rather limited amount of experimental data and should be complemented by additional measurements. Nevertheless, the presented parameterizations represent the current state of knowledge and appear sufficiently robust for exploring the influence of vegetation fires on aerosol particle number and mass concentrations in regional and global model studies.

\subsubsection{Particle emissions from oceans}

Marine aerosols comprise the largest natural source of particulate matter globally. A critical review of the production of aerosol from the ocean shows the current status of knowledge, including extension of the source function to particles as small as $10 \mathrm{~nm}$, new insights in the production mechanisms and the contribution of organic matter to the sea spray aerosol composition (de Leeuw et al., 2011a). Although the enrichment of primary marine aerosol with organics compared to the average sea-water composition has been known for decades, before O'Dowd et al. (2008) this organic fraction had not been included in a source function. This EUCAARI contribution provides global emission inventories for number, mass and organic enrichment fraction of primary marine aerosol and presents a scheme to calculate these parameters online in chemical transport models. The combined organic-inorganic sea-spray source function combines $10 \mathrm{~m}$ wind speed, chlorophyll- $a$ concentrations and sea-spray source function to produce a size-resolved emission of number, mass and water insoluble organic matter enrichment as a function of the wind speed and chlorophyll-a concentration. A key finding of this research is that the organic enrichment is observed in submicron aerosol sizes.

\subsection{Aerosol microscale processes}

In this section we summarise new aerosol process understanding obtained during EUCAARI combining theory, 
process models and laboratory experiments with field observations.

\subsubsection{Nucleation and growth}

The most important technical achievement of the EUCAARI nucleation studies was the development of new instruments for measuring sub- $3 \mathrm{~nm}$ particle populations, along with the extensive application of these instruments in both the laboratory and the field measurements. One of these instruments is the Neutral cluster and Air Ion Spectrometer (NAIS; Kulmala et al., 2007a; Manninen et al., 2009a, b), and a more sophisticated version of it suitable for airborne operations at different altitudes (Mirme et al., 2010).

All the scientific results obtained during EUCAARI indicate that sulphuric acid plays a central role in atmospheric nucleation (Kerminen et al., 2010). However, also vapours other than sulphuric acid are needed to explain the nucleation and the subsequent growth processes of particles, at least in continental boundary layers. Organic vapours are seen to participate at least in the growth of freshly formed particles.

Both field and laboratory measurements demonstrate that the nucleation rate scales to the first or second power of the nucleating vapour concentration(s). This agrees with the few earlier field observations, but is in stark contrast with the predictions of classical thermodynamic nucleation theories. However, the recent laboratory experiments show somewhat higher power dependence on sulphuric acid. The average formation rates of 2-nm particles were found to vary by almost two orders of magnitude between the different EUCAARI field sites, whereas the formation rates of charged 2-nm particles varied very little between the sites. Overall, our observations are indicative of frequent, yet moderate, ion-induced nucleation usually outweighed by much stronger neutral nucleation events in the continental lower troposphere.

The most concrete outcomes of the nucleation studies are the new semi-empirical nucleation rate parametrizations for neutral and ion-induced nucleation based on field observations, along with updated aerosol formation parametrizations (see Sect. 3.4.3.8).

\section{Laboratory experiments}

Homogeneous nucleation experiments with various mixtures of sulphuric acid, water, ammonia, amines and organic vapours were made in three laboratories by using two different flow tubes (IfT in Leipzig, Finnish Meteorological Institute) and an environmental smog chamber (Paul Scherrer Institute). The conducted $\mathrm{H}_{2} \mathrm{SO}_{4}-\mathrm{H}_{2} \mathrm{O}$ nucleation experiments resolved the apparent discrepancies between most earlier experiments is largely a measurement artifact arising from the high sensitivity of the measured "nucleation rate" to the temporal and spatial profile of the gaseous $\mathrm{H}_{2} \mathrm{SO}_{4}$ concentration inside the measurement device and the detection efficiency of the instrument used to measure nucleated particles (Sipilä et al., 2010). The new $\mathrm{H}_{2} \mathrm{SO}_{4}-\mathrm{H}_{2} \mathrm{O}$ nucleation experiments are in line with EUCAARI field observations both predicting a slope between about 1 and 2 in a plot of the nucleation rate versus gaseous $\mathrm{H}_{2} \mathrm{SO}_{4}$ concentration. Experiments with different inlet $\mathrm{NH}_{3}$ concentrations showed that the presence of $\mathrm{NH}_{3}$ increased slightly the mean diameter of nucleated particles, as well as their total number concentration. The enhancing effect of $\mathrm{NH}_{3}$ addition on the nucleation was found to be more pronounced under drier conditions. The presence of tert-butylamine enhanced nucleation rates more than $\mathrm{NH}_{3}$ under similar conditions (Berndt et al., 2010). A series of photo-oxidation experiments in the presence of 1,3,5trimethylbenzene (TMB), $\mathrm{NO}_{\mathrm{x}}$ and $\mathrm{SO}_{2}$ at various mixing ratios showed that the measurement data can only be explained with a dependence of the nucleation rate on both sulphuric acid and a nucleating organic compound (Metzger et al., 2010).

The UEF Kuopio plant chamber was used in experimental studies of nucleation and growth resulting from oxidation of VOC's emitted by Scots pine and Norway spruce seedlings. It was found that ozonolysis products of the VOCs are more efficient than $\mathrm{OH}$ products in causing new particle growth (Hao et al., 2009). On the other hand, the new particle formation rates were several hundred times higher in the $\mathrm{OH}$ experiments compared with the ozonolysis experiments. This is in agreement with findings in the Jülich Plant chamber where $\mathrm{OH}$ radicals are needed to initiate particle formation at $\mathrm{ppb}$ VOC and atmospheric ozone levels (Mentel et al., 2009). The studies in both plant chambers suggest that at organics participated in the nucleation. Jülich observed linear relations between VOC concentration and nucleation rate. Kuopio showed that even if trace amounts of $\mathrm{SO}_{2}$ had been present - the modelled peak $\mathrm{OH}$ concentration was $1.07 \times 10^{6}$, and it is not likely that sulphuric acid would have been formed enough to produce the observed particle formation rate of $360 \mathrm{~cm}^{-3} \mathrm{~s}^{-1}$ without any contribution from the organics. In a later set of experiments (Hao et al., 2011) the ozonolysis products were somewhat surprisingly found to be less volatile than the $\mathrm{OH}$ products.

Laboratory experiments on the effect of electric charge (both negative and positive) on the heterogeneous nucleation probability were performed at University of Vienna (Winkler et al., 2008). The experiments showed that when the saturation ratio of the vapour responsible for heterogeneous nucleation (here n-propanol) is gradually increased, the negatively-charged particles or clusters will activate first, then the positively-charged ones, and finally also the neutral ones. This kind of behaviour was evident in the sub- $4 \mathrm{~nm}$ size range, and the effect was more pronounced for smaller particle sizes.

\section{Atmospheric nucleation mechanism}

In practically all lower-tropospheric environments, naturally charged particles, called also air ions, were found to have 
an almost persistent and narrow mode of cluster ions, close to the mobility diameter of $1 \mathrm{~nm}$ (e.g. Hõrrak et al., 2008; Hirsikko et al., 2011 and the references therein). The aircraft measurements made during the LONGREX experiment as well as the ground based-measurements at high elevation sites revealed that this cluster ion mode can be seen in the free troposphere (Mirme et al., 2010; Boulon et al., 2010). The first quantitative estimates on the concentrations of neutral sub-3 nm particles were obtained for both the continental boundary layer (Kulmala et al., 2007a; Lehtipalo et al., 2009) and the free troposphere (Mirme et al., 2010). The concentrations of neutral sub-3 nm particles seem to exceed those of similar-size charged particles in the lower troposphere (Manninen et al., 2010). During the LONGREX aircraft measurements, concentrations of neutral particles in the diameter range $2-10 \mathrm{~nm}$ were, on average, roughly two orders of magnitude larger than those of charged particles throughout the tropospheric column (Mirme et al., 2010). First observations of large scale particle production in the open ocean were detected (O'Dowd et al., 2010).

The EUCAARI field measurements indicate that sulphuric acid plays a central role in atmospheric nucleation. On the other hand, both field measurements and laboratory experiments showed that vapours other than sulphuric acid are needed to explain the aerosol formation process. Such vapours are very likely of organic origin, at least in the continental boundary layer. The in situ UFO-TDMA field measurements showed that oxidized organics dominate the fresh particle growth processes in a European polluted environment (San Pietro Capofiume, Italy) too, in addition to previously observed organics dominance in the boreal forest region. The field data indicate that the atmospheric nucleation rate scales to the first or second power of the gaseous $\mathrm{H}_{2} \mathrm{SO}_{4}$ concentration or, more generally, of the nucleating vapour concentrations.

The field measurements brought plenty of new insight into the role of ions in atmospheric nucleation (Laakso et al., 2007; Kerminen et al., 2007; Gagné et al., 2008, 2010; Manninen et al., 2010; Mirme et al., 2010; Boulon et al., 2010). The contribution of charged particles to the total formation rate of 2-nm particles was usually found to be well below $10 \%$, but it showed substantial temporal variability both during a nucleation event and between the different event days. In general, our observations are indicative of frequent, yet moderate, ion-induced nucleation usually outweighed by much stronger neutral nucleation in the continental lower troposphere. No evidence on the enhanced role of ion-induced nucleation in the upper free troposphere, as suggested by some theoretical studies, was obtained from our aircraft measurements, although a higher contribution of ioninduced nucleation is found at high altitude sites compared to low altitude sites (Manninen et al., 2010; Boulon et al., 2010).

\section{Quantum chemical calculations}

By using quantum chemical methods, atmospherically relevant molecular clusters were studied, with the final aim of elucidating the molecular mechanism behind observed atmospheric nucleation. Quantum chemical calculations provide evaporation rates, or equivalently formation free energies, of different clusters that can be involved in nucleation. Evaporation rates are needed to assess the stability of various clusters and to identify the pathways through which clusters nucleate. The evaporation rates of a wide variety of clusters were calculated, ranging from clusters containing only sulphuric acid to clusters containing complex molecules like amines or large organic acids. Our main findings can be summarized as follows: (i) ammonia can enhance neutral sulphuric acidwater nucleation to some extent, but has a smaller role in corresponding ion-induced nucleation (Ortega et al., 2008), (ii) dimethylamine enhances neutral and ion-induced sulphuric acid-water nucleation in the atmosphere more effectively than ammonia (Kurtén et al., 2008; Loukonen et al., 2010), (iii) some of the organic acids resulting from monoterpene oxidiation can form very stable clusters with sulphuric acid, being good candidates to explain the pool of neutral clusters found in field measurements, and (iv) organosulphates can be involved in ion-induced nucleation.

\section{Future needs}

Although our understanding on atmospheric nucleation has enhanced substantially during EUCAARI, several issues requiring further research can be identified. Firstly, it is unclear whether atmospheric nucleation is dominated by a single nucleation pathway, or whether multiple different mechanisms are competing with each other. Secondly, we have not yet resolved the relative importance of kinetic and thermodynamic factors controlling the atmospheric nucleation rate. Thirdly, the identity and role of organic vapours in the nucleation process are still unknown. Finally, although our results suggest ion-induced nucleation to be of minor significance in continental boundary layers, this may not be the case in the free troposphere or above the oceans.

In order to address the remaining issues and scientific questions, we need to find out how the nucleation rate is connected with the chemical composition, physical properties, evaporation rates and dynamics of the smallest atmospheric clusters. Getting such information requires further advances in both experimental tools and theoretical approaches. These include construction and application of highly sensitive and selective instruments capable of operating at the sub- $2 \mathrm{~nm}$ size range, making laboratory experiments at highly-controlled conditions (e.g. Kirkby et al., 2011), developing a new generation of kinetic molecularscale models, and using various theoretical approaches relying on both quantum chemistry and classical thermodynamics. 


\subsubsection{BSOA formation and OA partitioning}

Results from EUCAARI show that the yields of biogenic secondary organic aerosol (BSOA) from emissions of Boreal and Mediterranean trees were between 5 and $10 \%$, independent of the monoterpene mixture (Mentel et al., 2009; Lang-Yona et al., 2010; Buchholz et al., 2011), whereas Hao et al. (2011) found a somewhat broader range for the yields $(1.9-17.7 \%)$. The formed particle mass and number concentration increased linearly with increasing monoterpene concentrations in accordance with the analysis of Boreal field data by Tunved et al. (2008). Based on this result, climate warming of a few degrees leading to increasing monoterpene emissions will enhance future BSOA formation. Via direct and indirect aerosol effects this will contribute to the negative feedback as postulated by Kulmala et al. (2004a). Monoterpene emissions of Mediterranean tree species are stronger dependent on temperature (Lang-Yona et al., 2010; Staudt and Bertin, 1998), leading to stronger BSOA formation in the Mediterranean compared to Boreal regions for the same degree of warming. However, the coupling of increasing monoterpene emissions and enhanced BSOA formation is diminished, if with the warming relatively more isoprene is emitted. The presence of isoprene suppressed the nucleation as well as the formation of mass of BSOA (Kiendler-Scharr et al., 2009b). The effect of stress-induced emissions caused by droughts, heat waves, or nutrition deficits in a changing climate still needs to be investigated. Moreover, we observed indications that stress-induced emissions have the potential to enhance SOA formation but also to suppress particle formation (Mentel et al., 2011).

EUCAARI included a complete set of chamber experiments of aerosol aging, where the main results showed an increase of the $\mathrm{O} / \mathrm{C}$ ratio of aged aerosol and good agreement between different methodologies of organic aerosol analysis. A set of models and chemical mechanisms have been developed that enable a consistent description of the chemical transformation and aging of organic aerosol components under a wide range of different conditions. Studies of surface chemistry, physics and laboratory studies of aerosol aging, including a wide variety of modeling, measurements and experiments are detailed in Appendix B.

\subsubsection{Ice nucleation experiments}

In terms of the ability of aerosols to act as ice nuclei (IN), significant progress was made. Ice nucleation in supercooled water clouds with temperatures between 0 and $-35^{\circ} \mathrm{C}$ can be initiated in four different ways: deposition nucleation, immersion freezing, condensation freezing and contact freezing.

Deposition nucleation refers to the direct deposition of vapour onto an ice nucleus. It requires that the saturation ratio with respect to ice exceeds 1 . Deposition nucleation is important for cirrus clouds, when vapour is deposited for instance onto mineral dust particles that act as IN. Deposition nucleation does not seem to be important for mixedphase clouds, because LIDAR observations revealed that liquid clouds are required before ice crystals form via heterogeneous freezing mechanisms (Ansmann et al., 2008). Immersion freezing refers to freezing that is initiated from within the droplet. It requires that the IN is fully immersed in the droplet when the droplet reaches a temperature at which it can freeze. Obviously, the liquid phase requires saturation with respect to water. Sometimes condensation freezing is distinguished from immersion freezing. It is thought that condensation freezing refers to a different pathway such that the IN enters ambient conditions supersaturated with respect to water only at low temperatures at which heterogeneous freezing of the forming droplet is likely. In that way, the ice crystal can form in the liquid phase, but at the interface between the forming droplet and the vapour phase. This has been shown theoretically to be energetically more favourable than forming an ice crystal on a fully immersed IN (Djikaev, 2008). Condensation freezing can be observed in laboratory studies on deposition nucleation when the relative humidity exceeds water saturation (Welti et al., 2009). However, condensation freezing is very difficult to be unambiguously distinguished from other ice nucleation mechanisms in an experiment. Therefore, it is still subject of ongoing research to what extent condensation freezing is fundamentally different from immersion freezing. Contact freezing refers to the collision of an IN with a supercooled cloud droplet. It requires saturation with respect to water.

We have built devices to perform experiments on all four modes of ice nucleation. The continuous flow diffusion chamber ZINC (Zurich Ice Nucleation Chamber) can be used to study ice nucleation in the deposition and condensation mode in the laboratory (Stetzer et al., 2008; Welti et al., 2009) and the portable version PINC (Portable Ice Nucleation Chamber, PINC) can be used to study ice nucleation in the deposition and condensation mode in the field (Chou et al., 2011). The design of ZINC and PINC was based on Rogers et al. (1988) except that the cylindrical walls were replaced by plane-parallel walls in order to optically distinguish between liquid droplets and ice crystals (Nicolet et al., 2010).

In addition, we built a chamber for immersion freezing (Lüönd et al., 2010). Here we could not follow any design as most immersion freezing experiments were done with droplets immersed in emulsions containing oil (e.g. Zuberi et al., 2002; Marcolli et al., 2007) or based on wind tunnel studies of levitated droplets of the size of drizzle drops (e.g. Diehl et al., 2002). Both are not representative of typical atmospheric conditions. Our immersion freezing device (IMCA = Immersion Mode Cooling Chamber) is comparable to the one simultaneously built in Leipzig (Niedermeier et al., 2010). IMCA is also a continuous flow diffusion chamber (CFDC) designed such that first the aerosol particles are activated as cloud droplets. This ensures that there is only 
one single aerosol particle inside each droplet and therefore, IMCA mimics conditions similar to those found in the atmosphere. The droplets are then cooled down and ice formation can occur inside ZINC. This approach will enable the comparison of deposition/condensation freezing with immersion freezing.

Cloud droplets formed on soluble aerosol particles can only freeze homogeneously. Accordingly, the data for immersion freezing of ammonium sulphate particles show an onset of freezing close to $235 \mathrm{~K}$ and a steep increase of the frozen fraction with decreasing temperature. The measurements with immersed kaolinite particles clearly show that the droplets freeze at higher temperatures, indicating that freezing occurred heterogeneously, i.e. kaolinite particles act as IN. We could also observe droplets to freeze at slightly higher temperatures (around $2 \mathrm{~K}$ for a frozen fraction of $50 \%$ ) if the particle diameter is increased from $200 \mathrm{~nm}$ to $800 \mathrm{~nm}$. The slope of the frozen fraction with decreasing temperature is less steep for heterogeneous freezing than for homogeneous freezing. This suggests that in terms of heterogeneous ice nucleation, IN surfaces can not be described appropriately by assuming all particles to have equal and uniform surface properties (Lüönd et al., 2010; Hartmann et al., 2011). These findings can be important for the initiation of precipitation in numerical models, as a small fraction of aerosol particles acting as IN is sufficient to initiate precipitation. Therefore, the measurements suggest that kaolinite particles might initiate precipitation at temperatures significantly higher than if the first ice crystals nucleate homogeneously.

\subsubsection{CCN formation and cloud droplet activation}

Laboratory experiments in a controlled laboratory environment were carried out on single component, binary and ternary particles to investigate the effect of organic molecules with different properties on cloud droplet activation. Frosch et al. (2010) investigated the ability of oxo-dicarboxylic acids to act as cloud condensation nuclei and Kristensson et al. (2010) addressed the cloud droplet activation of aminoacids with limited solubility. Frosch et al. (2011) studied the combined effect of inorganic salts and organic acids. Prisle et al. $(2008,2010)$ investigated the effect of surface active organic molecules on cloud droplet activation and found that it is important to account correctly for partitioning of the surfactant molecules between the bulk and surface of the growing droplet to match measured critical supersaturations.

Laboratory experiments of CCN activity of biogenic secondary organic aerosols generated in smog chambers were performed by Asa-Awuku et al. (2009) and Engelhart et al. (2008, 2010). The SOA becomes more CCN active in all cases due to continued reactions with the $\mathrm{OH}$ radical (Engelhart et al., 2008; Asa-Awuku et al., 2009). The water uptake of organics could be modeled using kappa-Köhler theory following Petters and Kreidenweis (2007) applying a kappa value of $\sim 0.1$, which is consistent with other recent laboratory and field studies of (secondary) organic aerosol hygroscopicity and CCN activity (Gunthe et al., 2009; Shinozuka et al., 2009; King et al., 2010; Dusek et al., 2010; Roberts et al., 2010; Pöschl et al., 2010, 2011, and references therein).

A synthesis paper is in progress focusing on parametrizations describing the activation of ambient and SOA particles that can be used in global models (Sierau et al., 2011). This paper also combines $\mathrm{CCN}$ measurements in the laboratory with those in the field during EUCAARI. Herein, extensive and intensive $\mathrm{CCN}$ parameters compiled from the exceptionally broad data set from CCN measurements that were carried out at locations all over the world, including longterm as well as intensive field studies, will be statistically analysed and reported as monthly, daily and/or hourly mean values to account for seasonal, weekly, and diurnal pattern. The overall kappa-variability will be inferred and discussed in context with the effective average kappa of $0.3 \pm 0.1$ and $0.7 \pm 0.2$ as estimated by Andreae and Rosenfeld (2008) for the continental and marine background aerosol, respectively. The former value has recently been superseded by $0.3 \pm 0.2$ (Pringle et al., 2010) which seems still fairly well constrained with regard to cloud droplet formation (Reutter et al., 2009; Arabas and Pawlowska, 2010, 2011). Kappa deduced from the $\mathrm{CCN}$ data (i.e. measured in the supersaturated regime) will be further compared with kappa deduced from Hygroscopicity Tandem Differential Mobility Analyser (HTDMA) data measured under subsaturated conditions (Swietlicki et al., 2011). Moreover, measured CCN activity for secondary organic aerosol (SOA) from real tree emissions of boreal and Mediterranean trees as measured at the Jülich Plant Atmosphere Chamber will be related to the $\mathrm{CCN}$ activity parameters obtained from the field stations in Hyytiälä, FI, and Finokalia, GR, respectively.

\subsection{Aerosol characterization}

\subsubsection{Long-term field observations in Europe}

Development of an observing capacity suited to follow and understand atmospheric composition changes and to account for regional specificities is a primary objective of EUCAARI. Sustained long-term observations of short-lived species of atmospheric importance outside of the few policy-regulated variables have, in fact, been crucially missing in Europe. Monitoring of species essential to climate and air quality studies was left to quasi-independent initiatives of scientists contributing to collection and analysis of atmospheric data, resulting in difficulties to assess data quality, access and intercompare data sets. Limited availability of long time-series of atmospheric parameters, and in particular aerosol related species, over Europe was a major obstacle for the validation of satellite observations and chemical transport model evaluation. Recent initiatives to integrate information on aerosol chemical and physical properties (Putaud et al., 2004; Van 


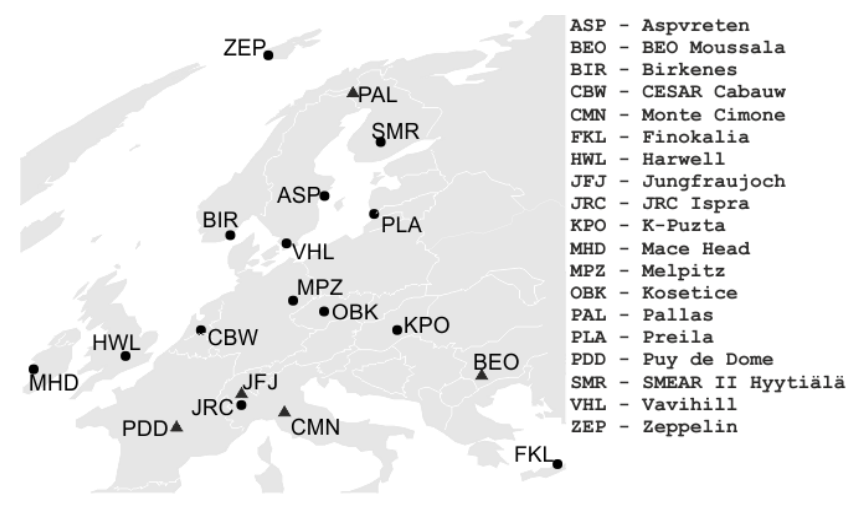

Fig. 3. Stations and station codes of EUSAAR stations used in EUCAARI (adapted from Asmi et al., 2011).

Dingenen et al., 2004) represent a first attempt to provide a synthetic view of aerosols over Europe. However, these studies were mostly based upon data provided on a voluntary basis and, for the major part, derived from campaign-based initiatives rather than long-term observations. A limitation of past work was also the absence of coordinated control on data quality, not available at that time in Europe. Recent intercomparison exercises performed in Europe indeed demonstrated the need for improving standardization of operating procedures for many aerosol measurements (Kahnert et al., 2004; Cavalli et al., 2010).

EUCAARI, in a joint effort with the EU-funded Integrated Infrastructure Initiative EUSAAR (European Super sites for Atmospheric Aerosol Research), provided the framework for the first pan-European coordinated initiative on aerosol observations. By the end of the EUCAARI project, the network provided the most comprehensive record of aerosol observation ever produced in Europe. In addition to basic aerosol variables as recommended by Global Atmospheric Watch (GAW) (namely aerosol absorption and scattering coefficients, aerosol number and size, aerosol chemistry), observations were expanded to provide the change in particle size with relative-humidity using novel Hygroscopicity Tandem Differential Mobility Analyzer techniques (Duplissy et al., 2008; Fors et al., 2009; Massling et al., 2010), atmospheric ion size distribution using novel EUCAARI-developed ion spectrometers (Manninen et al., 2010), and size-segregated chemistry using aerosol mass spectrometers (Prévôt et al., 2011). Not all measurements, in particular the more advanced ones, were performed for the whole EUCAARI period but rather during intensive observing periods that took place in the Spring and Autumn of 2008 and Winter of 2009. For the first time, all groups worked together to ensure similar procedures and methodologies. A number of metrology papers from EUSAAR activities have been recently submitted/published providing the data quality framework for EUCAARI (Cavalli et al., 2010; Collaud-Coen et al., 2010; Mueller et al., 2009; Wiedensohler et al., 2011).
EUCAARI and EUSAAR measurements provided a panEuropean view of aerosol properties (Fig. 3, Asmi et al., 2011). A first observation relates to the large variability of aerosol properties encountered over Europe. This is largely due to the geographical location of observing stations representing different climates and environment, although significant variability is also observed for single stations. An integration of measurements over such an extended network leads to simplifications in particular related to station representativeness. Overall, the most suited categorization of sites related to particle variability appears to be a mix between the categorization by Henne et al. (2010) and the more classical geographical classification (Asmi et al., 2011). The concept of catchment area (the area in which the surface fluxes are creating detectable and significant signals at the site) seems to apply well to a number of sites located in the plains of Central and Western Europe (KPO, OBK, CBW, JRC, MPZ for example). At these sites, even if some may be classified as rural according to air base classification, aerosol physical parameters and in particular the smallest particle range (below $50 \mathrm{~nm}$ ) are clearly influenced by a regional catchment that varies from 50 to a few hundred $\mathrm{km}$. Stations under this situation have in common the following features:

- To a first approximation, the dynamics of aerosol number concentration are driven by large catchment area for particles with particle diameter $d_{\mathrm{p}}>100 \mathrm{~nm}$ as opposed to a typically smaller area for the smallest particles. The particles regional background is therefore ranging from 2000 to $3000 \mathrm{~cm}^{-3}$. According to Van Dingenen et al. (2004) this concentration range is associated to a particle mass ranging from 10 to $20 \mu \mathrm{g} \mathrm{m}^{-3}$. Considering that most particles are in the sub- $2.5 \mu \mathrm{m}$ range, the quality objective for $\mathrm{PM}_{2.5}$ of $20 \mu \mathrm{g} \mathrm{m}^{-3}$ by 2015 is a very optimistic target.

- A fairly constant particle number concentration throughout the year. The change in boundary layer height appears to be compensated by a more intense secondary particle formation during summer months.

- Elevated number concentrations of particles generally over $3000 \mathrm{~cm}^{-3}$ and up to $7000 \mathrm{~cm}^{-3}$ (JRC in the Po Valley-Italy) on an annual basis for particles with sizes approximately larger than $30 \mathrm{~nm}$.

- The elevated background of particles somehow hides the diurnal cycle of particles which stays fairly constant.

- The ratio between particles with $30 \mathrm{~nm}<d_{\mathrm{p}}<100 \mathrm{~nm}$ and $d_{\mathrm{p}}>100 \mathrm{~nm}$ rarely exceeds 2 , but is always higher than unity (Asmi et al., 2011). The dynamics of the smallest particles seems to be more easily explained in models by including a substantial particle formation rate in the boundary layer (Spracklen et al., 2010; Merikanto et al., 2009). However, the link between sub-50 $\mathrm{nm}$ to the larger super- $100 \mathrm{~nm}$ particles, which are generally 
involved in cloud formation is not direct and involves processes that are outside the 48-h catchment area. This is confirmed by model work of Spracklen et al. (2008b) and Merikanto et al. (2009) showing that CCN concentrations are fairly insensitive to large changes in the BL nucleation intensity. Clearly, data are still missing in the sub- $15 \mathrm{~nm}$ range. Results from the EUSAAR intercomparison experiments showed that DMPS/SMPS instruments are at present not suited to provide a coherent framework below $15 \mathrm{~nm}$ (Wiedensohler et al., 2011). However, NAIS/AIS/BSMA measurements have shown to be able to give reasonable and significant results on new particle formation (Manninen et al., 2010).

- Measurements of hygroscopic properties confirm the difference in origin of the sub- $30 \mathrm{~nm}$ particles with respect to particles with $d_{\mathrm{p}}>100 \mathrm{~nm}$. However, this is based on a limited number of stations. More hygroscopic particles, characterized by high hygroscopic growth factor $(\mathrm{HGF}=1.5)$ which are internally mixed between evolved SOA and inorganic material constitute most of the super- $100 \mathrm{~nm}$ fraction. On the contrary, below $30 \mathrm{~nm}$ particles are generally less hygroscopic (HGF 1.3) and result from freshly formed particles. The seasonal variability of the HGF also agrees with the weaker SOA contribution to the super- $100 \mathrm{~nm}$ particles (lower HGF) (Swietlicki et al., 2011).

- There is no simple feature explaining optical properties at stations of Central and Western Europe. Different mass absorption coefficients and chemical composition lead to more variability in comparing absorption and scattering coefficients than for the number concentration. Differences in energy production and in the automobile fleet may explain the variability.

- A classification of aerosol properties under the conditions encountered at stations like CBW, KPO, MPZ, OBK or JRC (see Fig. 3) can be performed without considering the air mass origin but rather considering first a very large regional catchment area driving optical properties and the larger particle properties (CCN concentrations in particular), and a smaller catchment area driving the more variable sub- $50 \mathrm{~nm}$ particles, of which a still unknown fraction directly arises from direct particle emissions.

- For these stations, the strong difference between boundary layer characteristics and the air aloft leads to a strong decoupling between aerosol parameters (such as Angström coefficient or single scattering albedo) retrieved in-situ and using sun photometers (Kinne et al., 2011). In addition, the insitu measurements of the optical properties are usually performed under dry conditions, for comparison with remote sensing techniques they need to be corrected for their dependences on the relative humidity (Zieger et al., 2011).
Stations located at elevated sites (JFJ, MTC, BEO, PDD) also present some common features. These stations have been obviously placed at those sites to provide a more regional view of aerosol properties. There, the local catchment area, as defined by Henne et al. (2010), has in fact, much less influence on the variability of the aerosol parameters. The driving factors explaining observed changes are related to both long-range transport (air mass origin) and station altitude. The station altitude and its surrounding topography control thermally-driven upslope/downslope flows which are a common feature of all mountain sites. Characteristics of the mountain sites are:

- Strong seasonal variability, in particular for sites located above $2000 \mathrm{~m}$. This is clearly due to the stronger influence of thermal winds during mid-spring to mid-autumn with resulting advection of boundary the layer air. This is not exclusively linked to slope winds but may also result from an increased boundary layer thickness for medium altitude sites such as PDD in France or Hohenpeissenberg or Schauinsland in Germany. This explains a large fraction of the higher aerosol concentrations in summer months with respect to winter periods.

- At sites strongly affected by thermal winds, a strong bias is introduced if the local dynamics is not accounted for. The thickness of the thermally-driven air mass is rather limited (a few hundred meters) and the station for a fair amount of time may not represent the regional background, but rather air from lower levels. Venting boundary layer air by mountain topography is not well represented in regional models and is an efficient way to transport air pollutants into the free troposphere.

- The interface between polluted air from the BL and the FT air was found to be the location for nucleation events. This is observed at mountain stations (Venzac et al., 2009; Boulon et al., 2011) but also during airborne measurements above central Europe (Crumeyrolle et al., 2010). This is clearly an additional source of small particles to the FT.

- The particle number concentration is a function of station height decreasing down to a couple of hundred particles per $\mathrm{cm}^{3}$ for the highest EU station of JFJ. This corresponds to mass concentrations of approximately 5 to $10 \mu \mathrm{g} \mathrm{m}^{-3}$ during summer and 2.5 to $5 \mu \mathrm{g} \mathrm{m}^{-3}$ in winter for stations right above $1000 \mathrm{~m}$, and concentrations below $5 \mu \mathrm{g} \mathrm{m}^{-3}$ in summer and below $2 \mu \mathrm{g} \mathrm{m}^{-3}$ in winter above $2000 \mathrm{~m}$.

- The relative contributions by organic material, inorganic species and elemental carbon do not seem to be height dependent to a first approximation. The fraction of organic material remains at all sites close to $50 \%$. 
- Within EUCAARI, new information was made available from HGF measurements at high altitude sites. Our results show that the long-range component of aerosol sampled at high altitudes $(>2000 \mathrm{~m})$ is internally mixed with HGF close to 1.4 at $90 \%$ for $75 \mathrm{~nm}$ particles (Kammermann et al., 2010). At lower altitudes, aerosol properties are driven by injection from the BL at regional scale and features that are described for the site in Central/Western European plains are still valid. The aerosol is composed of several modes with the more hygroscopic mode having a HFG of around $1.5 \pm 0.1$ for $110 \mathrm{~nm}$ particles at $\mathrm{RH}=90 \%$, and the less hygroscopic mode around $1.2 \pm 0.1$ for the same conditions. The number fraction of particles in each hygroscopic mode is variable but the more hygroscopic mode seems to dominate in winter, likely for the same reasons as for BL sites.

- The optical properties of particles at high altitude sites follow the features of particles number concentrations with marked diurnal and seasonal variations. The absorption and scattering coefficients are larger in summer leading to larger extinction coefficient without significant changes in the single scattering albedo.

- Contrary to BL sites, in situ measurements performed at high-elevation stations seem to provide a fairly good representation of the atmospheric column, at least on a monthly average basis (provided the in situ measurements are corrected for humidity effects). This is confirmed by the general agreement between optical properties derived from sun-photometers and in-situ measurements.

A third category of stations are those in the Nordic/Baltic countries stations (ASP, BIR, PAL, PLA, SMR and VHL). They can be differentiated from the Central/Western European BL stations mainly by the generally lower concentrations of aerosol particles and gases as well as the presence of a higher proportion of particles with $d_{\mathrm{p}}<100 \mathrm{~nm}$. The lower concentrations might be explained by the specific locations of the Nordic stations, often chosen far away from urbanized areas in particular for the Finnish stations. The occurrence of frequent new particle formation events explain the higher fraction of particles with diameter less than $30 \mathrm{~nm}$ with respect to more continental BL sites. The seasonal variability is not well marked at these Nordic stations. A larger variability at BIR results from changing source regions during summer rather than from a change in BL height. The single Baltic station within EUSAAR shows distinct differences with respect to other Nordic stations, with considerably higher concentrations. The Baltic area is possibly the interface between the polluted central European BL and the cleaner Nordic area. Similarly, the Zeppelin station in the Svalbard demonstrates very specific variability due to the Arctic haze phenomena in Spring and Summer. Hygroscopic growth measurements in the Nordic station of VHL are also somewhat intermediate between the internally mixed free tropospheric aerosol and the multi-mode or less hygroscopic modes encountered in the Central European plains.

The European network also includes single stations that cannot be classified into a specific category. The marine stations FKL and MHD do not show the expected similarities based on their geographical location within the marine BL. This is due to the fact that their average aerosol levels and composition reflect also local and regional influence. It also shows that aerosol processes taking place at regional scale modify the atmospheric composition leading to difficulties in defining typical marine aerosol parameters in Europe.

The hypothesis that aerosol properties (size, hygroscopicity) may be estimated based on their evolution during transport is very difficult to test using long-term measurements (Crumeyrolle et al., 2011). This evolution can only be followed during airborne campaigns, which are limited in time and space. The regional context can be addressed by indicators similar to those listed by Henne et al. (2010).

The bias between model and measurements is much higher for in-situ observations (both positive and negative) than for the integrated column (AERONET) measurements. This is due to the fact that AERONET observations are less sensitive to local variability but also that they are not well suited for regional air quality forecasting. Direct comparison of just absolute values is at present of limited use for the testing of the transport and transformation components of CTMs as most of the model variability derives from emission inventories. Andrews et al. (2011) derived some interesting secondary parameters such as Ångstrom coefficient versus single scattering albedo that may be more discriminating for testing model/observation discrepancies. Asmi et al. (2011) have also performed a synthesis and data reduction on aerosol number concentrations required for direct model/measurements comparisons.

\subsubsection{Long-term field observations outside Europe}

Detecting atmospheric trends of key atmospheric compounds requires long ( $>10 \mathrm{yr}$ ) high quality records. Such datasets are rare in Europe, and nonexistent in many parts of World.This crucial lack of data is a limiting factor for many applications, including forecasting atmospheric composition changes. Tools developed at the EU level to improve provision and access to high quality atmospheric data have been applyied within the international collaborating framework of EUCAARI.

In cooperation with partners from universities and research institutes in China, India, Brazil, and South Africa, longterm aerosol measurements were performed to obtain additional insights into the physical, optical and chemical particle properties in these important areas. We carefully selected the observation sites in these four countries to be representative for the regional atmospheric aerosol. This activity completes 
efforts of EU scientists to develop and sustain monitoring activities of short-lived species in developing and emerging countries (see for example Zhang et al., 2011; Henne et al., 2008; Bonasoni et al., 2008, 2010). In this section, we highlight findings from the EUCAARI measurements in these four countries.

In China, we performed measurements at a regional site in the North China Plain $150 \mathrm{~km}$ northeast of Beijing. In India, we chose a site $30 \mathrm{~km}$ from Delhi in a highly polluted nonurban area. In South-Africa, we performed measurements in a clean savannah area as well in the polluted area east of Johannesburg. Finally, we characterized the aerosol over the Amazonian Basin near Manaus in Brazil.

\section{South Africa}

EUCAARI obtained the longest data series of aerosol optical properties and number size distributions in continental Africa. We found that over the background savannah, nucleation and particle growth takes place in more than $80 \%$ of the days (Laakso et al., 2008; Vakkari et al., 2011). The observed particle formation and growth rates (Vakkari et al., 2011) were among the highest observed (Kulmala et al., 2004b). Comparisons with regional vegetation maps and emission inventories clearly show that particle growth is related to biogenic organic vapors whereas formation is dominated by sulfur compounds.

At the station Elandsfontein east of Johannesburg, the light absorption measurements revealed an annual cycle of black carbon (Laakso et al., 2010). In the industrial area around Elandsfontein, black carbon results from industrial activities as well as from domestic burning and natural fires. The peak concentration during the local winter is due to wild fires combined with increased domestic small scale burning.

On a regional scale, meteorology of the area is characteristically strongly layered (Garstang et al., 1996). These layers trap emissions at different levels. The aerosol emission from large natural fires may be injected to higher altitudes. These layers are clearly visible in vertically resolved aerosol profiles, but significantly complicate the interpretation of satellite observations.

The observations in South Africa have significantly increased knowledge on levels, sources and dynamics of atmospheric aerosol particles. Domestic burning and natural wildfires pose a significant threat to human health, whereas acidic particulate matter, combined with gaseous compounds from industrial activities may seriously affect local agriculture. In the context of climate change, high black carbon concentrations may result in significant local heating of the lower atmosphere.

\section{China}

The Chinese GAW-site Shangdianzi, at which the EUCAARI measurements took place, is influenced by two different types of air masses. From the South, highly polluted air is transported from the North China Plain to the site, while from the North, cleaner continental air is observed. During periods of northerly winds, particle formation occurred on 205 out of 565 days in 2008 and 2009 (Shen et al., 2011).

Particle formation occurred in the morning with a maximum average number concentration of $18000 \mathrm{~cm}^{-3}$ around noon. At midnight, the number concentration decreased due to coagulation to approximately $3000 \mathrm{~cm}^{-3}$. The mean particle growth rate was $3.8 \mathrm{~nm} \mathrm{~h}^{-1}$ and the mode diameter reached $80-100 \mathrm{~nm}$ at midnight. The mean mass growth rate was $2.6 \mu \mathrm{g}\left(\mathrm{m}^{-3} \mathrm{~h}\right)$ and the mean mass concentration reached $45 \mu \mathrm{g} \mathrm{m}^{-3}$ at midnight when assuming a particle density of $1.5 \mathrm{~g} \mathrm{~cm}^{-3}$. The mean number concentration of particles $d_{\mathrm{p}}>100 \mathrm{~nm}$ was between 5000 and $6500 \mathrm{~cm}^{-3}$ throughout the day. The mean $\mathrm{PM}_{1}$ mass concentration varied from 70 to $90 \mu \mathrm{g} \mathrm{m}^{-3}$ during the day.

Lidar measurements revealed that the top of the aerosol layer was around $900 \mathrm{~m}$ above ground in all seasons, only slightly higher during the summer months. Frequently, elevated aerosol layers were observed, especially during winter and spring. A mean aerosol optical depth (AOD) of 0.95 was observed for air masses arriving from the North China Plain. In contrast, the mean AOD was about 0.42 for northerly air masses.

\section{India}

Aerosol measurements in Gual Pahari, India, were performed from December 2007 to January 2010. The seasonal variation of the aerosol characteristics was very distinct in Gual Pahari (Hyvärinen et al., 2011a). The highest concentrations were observed during the winter and the lowest ones during the rainy season. The average monsoon-time mass concentrations of $\mathrm{PM}_{10}, \mathrm{PM}_{2.5}$, and black carbon (BC) were 55$70 \%$ lower than the pre-monsoon average concentrations, having a linear relationship with the total local rainfall during the monsoon season. The average $\mathrm{PM}_{10}$ mass concentration (at STP conditions) was $216 \mu \mathrm{g} \mathrm{m}^{-3}$ and the average $\mathrm{PM}_{2.5}$ concentration was $126 \mu \mathrm{g} \mathrm{m}^{-3}$. A high percentage (4-9\%) of the $\mathrm{PM}_{10}$ mass consisted of $\mathrm{BC}$, indicating strong anthropogenic influence. The percentage of $\mathrm{BC}$ was higher during the winter and according to the diurnal pattern of the $\mathrm{BC}$ fraction, the peak occurred during active traffic hours. The rainy season decreased the average fraction of particle mass in the $\mathrm{PM}_{2.5}$ size range.

The diurnal variation of the aerosol properties was much dependent on the prevailing season, even though outside the rainy season the general characteristics were rather similar. Figure 4 illustrates the PM behaviour during different seasons. Maximum concentrations occurred in the morning around 07:00-08:00, because of the low boundary layer height and the morning traffic in the area. The warm day time temperatures initiated convective mixing, which is visible as a minimum in the diurnal PM mass data. The afternoon 


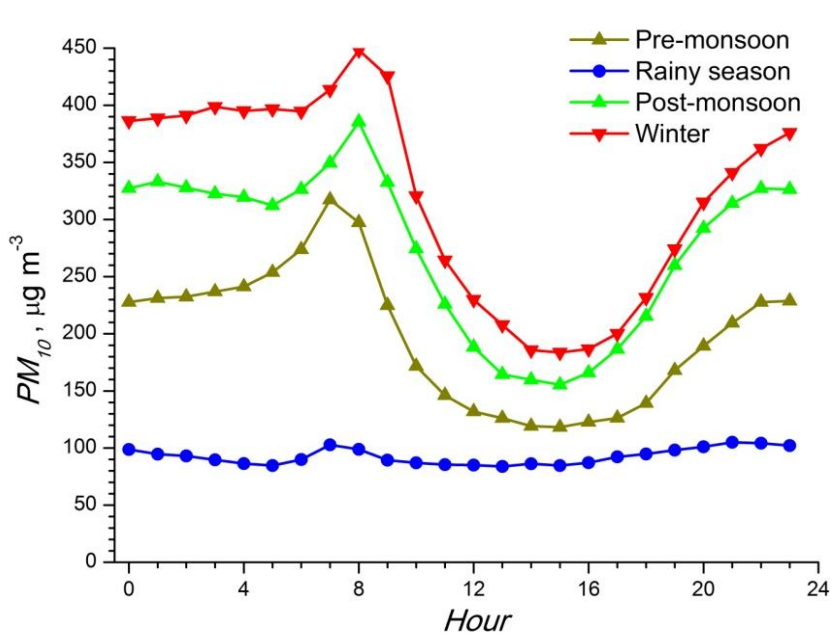

Fig. 4. Diurnal variation of the $\mathrm{PM}_{10}$ mass during different seasons in the Indian EUCAARI site.

concentration was more than $50 \%$ lower compared to the morning values. Another maximum in mass concentration was observed in the evening due to traffic and reduction of the boundary layer height. During the strong daytime mixing, the fraction of particles smaller than $1 \mu \mathrm{m}$ decreased.

New particle formation events were observed frequently at Gual Pahari. The decreased condensation sink due to convective mixing and dilution was the key factor enabling the new particle formation. Apparently, the vapor source rate in Gual Pahari was very high, because nucleation events were observed in over $60 \%$ of the measurement days. The particles grew rapidly reaching the Aitken and accumulation mode size thus contributing considerably to the aerosol mass concentration. In November, fewer particle formation events were observed, as the low night- and day-time temperatures resulted in weaker natural convection and a higher condensation sink.

Vertical profiles of aerosol properties were measured for more than one year (Komppula, 2010; Hyvärinen et al., $2011 \mathrm{~b}$ ). The vertical profiles of backscatter, extinction, and lidar ratio and their variability during each season were analyzed. The measurements revealed that the aerosol layer was on average highest in spring $(5.5 \mathrm{~km})$. In summer, the vertically averaged (between $1-3 \mathrm{~km}$ ) backscatter and extinction coefficients had the highest average values. Aerosol concentrations were slightly higher in summer compared with other seasons. The autumn showed the highest lidar ratio and a high extinction-related Ångström exponent, indicating the presence of smaller absorbing particles. The winter had the lowest backscatter and extinction coefficients, but the extinction-related Ångström exponent was the highest.

\section{Brazil}

Aerosol measurements were performed at a pristine Amazonian forest site near Manaus. We highlight here the seasonal variation of the optical and physical aerosol properties. The scattering coefficients ranged between 1 and $600 \mathrm{Mm}^{-1}$ at $450 \mathrm{~nm}$, while absorption ranged between 1 and $25 \mathrm{Mm}^{-1}$ at $637 \mathrm{~nm}$. A strong seasonal behavior was observed, with higher aerosol mass concentrations during the dry season (July-November) compared to the wet season (DecemberJune). During the wet season, the single scattering albedo calculated from our measurements ranged from 0.90 to 0.99 , whereas during the dry season, it ranged from 0.75 to 0.95 . Although the site is remote, it receives the influence of regional biomass burning emissions during the dry season. Also, measurements of aerosol elemental composition indicate events of long range transport of African dust to the Amazonian forest site. These trans-continental sources of particles affect the optical properties of the natural aerosol population, with implications to the regional climate and to the forest nutrient cycle.

Measurements of submicrometer number size distributions indicated only a few events of new particle formation and subsequent growth along three years of measurements. From wet to dry season, integrated number concentrations increased approximately by a factor of 3 . The shape of the particle number size distribution also changed. During the wet season, the Aitken mode $(\sim 30-100 \mathrm{~nm})$ was prominent, suggesting the presence of secondary aerosol, most likely originated from the condensation of biogenic volatile organic compounds to the particle phase. In contrast, during the dry season the accumulation mode $(100-500 \mathrm{~nm})$ dominates the number size distribution, indicating the presence of primary biomass combustion and/or aged aerosol.

In Fig. 5 monthly averages of particle number size distributions are shown. The black curve represents the mean of all seasons, while the upper and lower curves are monthly averages of the dry and wet season, respectively. During the dry season, the Amazonian biomass burning aerosol dominates the number size distribution, while the concentrations are low during the wet season.

The number size distribution, light scattering and absorption coefficient data are the first long-term aerosol in-situ measurements ever performed in Amazonia, elucidating the differences between the biogenic aerosol population and the anthropogenic and long-range transport influences.

Lidar measurements were performed from January to November 2008 to obtain vertical aerosol profiles (Althausen et al., 2009) in Amazonia, determining the backscatter coefficient (wavelength: $355 \mathrm{~nm}, 532 \mathrm{~nm}, 1064 \mathrm{~nm}$ ), the extinction coefficient $(355 \mathrm{~nm}$ and $532 \mathrm{~nm})$ and the depolarization ratio $(355 \mathrm{~nm})$. Furthermore, microphysical properties such as the effective radius and the volume concentration as well as the single scattering albedo were retrieved using the inversion algorithm by Ansmann and Müller (2005). The aerosol 


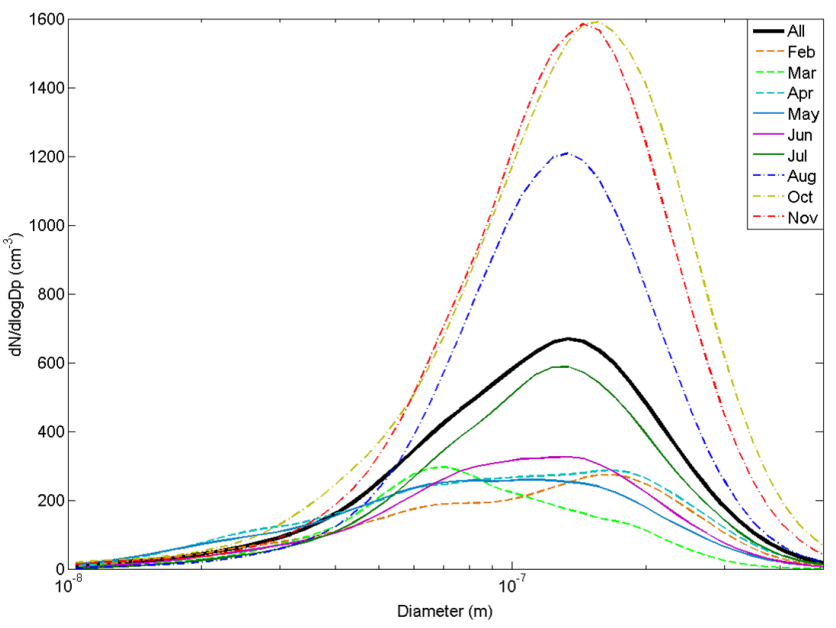

Fig. 5. Seasonal behaviour of the particle number size distribution in the Brazilian EUCAARI site. The black curve represents the mean of all seasons. The upper and lower curves are the averages of the dry and wet season, respectively.

optical depth (AOD) was derived by integrating the vertical extinction coefficient profiles.

A wide variety of aerosol conditions with a complex vertical aerosol layer structure were observed. During the wet season, clean conditions occurred occasionally with an AOD $(532 \mathrm{~nm})$ less than 0.03 . This low AOD value is in the order of the lowest values measured for remote marine conditions (Andreae, 2009) and one of the lowest values ever measured on a continent. Beside such clean conditions, frequent intrusions of Saharan mineral dust and African biomass burning aerosol were observed (Ansmann et al., 2009). The mineral dust fraction in these African aerosol plumes was usually below $50 \%$. The biomass burning aerosol from Africa seems to be as important as the Saharan dust in terms of trans-continental transport. During the dry season, Amazonian biomass burning dominated the optical aerosol properties with AODs up to $0.55(532 \mathrm{~nm})$. One major finding from the dry season observations is that virtually no cleaning due to short showers was observed.

The lidar measurements performed during EUCAARI were the first long-term observations of the vertical aerosol structure in Amazonia ever. It was also the first time that a multi-wavelength-Raman lidar was operated in the Amazon Basin.

\subsubsection{Source apportionment of organic aerosol}

Organic aerosol components (OA) account for a large mass fraction of the European aerosol, and accurate quantification, source apportionment and model descriptions are necessary in order to determine their effect on the radiative balance and air quality. The importance of biogenic sources and their response to climate change and air quality policy measures is not yet adequately quantified, but is likely to be significant. The main accomplishments of EUCAARI in this area have been:

- A large mass fraction of the European aerosol is organic, and a large fraction of that carbonaceous aerosol is modern carbon (i.e. deriving from non-fossil fuel sources).

- A new comprehensive European AMS data set, which was analyzed by positive matrix factorization (PMF) and further supported by HNMR data, provided detailed information on the different sources of OC at urban and rural sites, including biomass burning aerosol, fossilfuel POA, and oxidized organic aerosol (OOA). The latter fraction, both freshly-produced and aged typically comprised the largest fraction of OA. The origin of these oxidized components remains uncertain but can be considered as an upper limit for the total SOA contribution. The reconstructed carbon budget for selected stations indicates that most of such OOA must be apportioned to modern carbon sources.

- Major sources to modern carbon in Europe are wood combustion and secondary biogenic OA. The latter includes not only the products of terpenes oxidation, but also amines, which were found to characterize a variety of environments (Po Valley, Crete, Boreal forest). Since their source strengths are expected to vary in response to climate change, these sources of modern carbon may constitute important feedback mechanisms in the climate system.

- Both global and regional OA model parameterizations were developed. Secondary OA formation via multiphase reactions was shown to be an important contributor to global background OA.

- The comprehensive OA data set acquired within EUCAARI offers a unique opportunity to evaluate OA models on a wide range of spatial and temporal scales, and will be valuable beyond the EUCAARI timeframe.

The wide variety of co-supporting methodologies and their results are detailed in Appendix C. Figure 6 shows the source apportionment for TC for Hyytiälä, SPC and Melpitz, based on the different methods used $\left({ }^{14} \mathrm{C}, \mathrm{NMR}, \mathrm{AMS}\right)$. AMS HOA was approximated as fossil-fuel POA. Although there is an uncertainty due to the unknown modern fractions of EC for these stations, the carbon budget indicates that the sum of the OOA classes having no clear source characterization must actually be apportioned to modern carbon, but for the single classes we cannot exclude important contributions from fossil fuel carbon. 

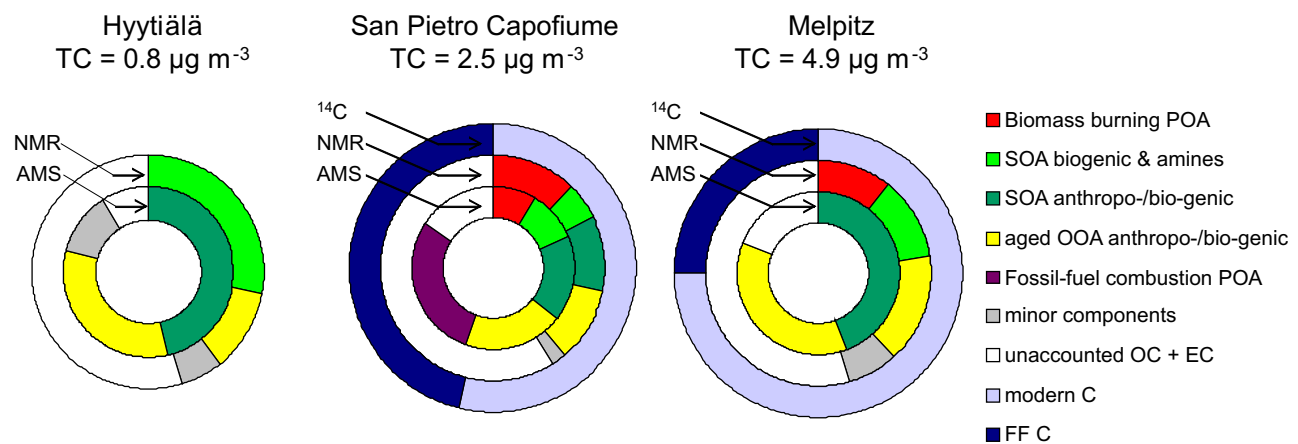

Fig. 6. Source apportionment for TC for Hyytiälä, SPC and Melpitz, based on the different methods used ( ${ }^{14} \mathrm{C}, \mathrm{H}-\mathrm{NMR}$, AMS). "Biomass burning POA" are AMS "BBOA" and NMR factors correlated to biomass burning tracers (levoglucosan). "SOA biogenic \& amines" include AMS and NMR factors for amines, and the NMR factor for terpene SOA (Finessi et al., 2011b). "SOA anthropo-/bio-genic" include semivolatile organic compounds determined by AMS (SV-OOA) of unspecified anthropogenic or biogenic origin; or NMR factors for oxygenated WSOC compounds of unspecified origin. "Aged OOA anthropo-/bio-genic" stand for low-volatility organic compounds determined by AMS (LV-OOA) of unspecified anthropogenic or biogenic origin, or NMR factors for oxygenated WSOC showing spectral profiles characteristic of humic-like substances (HULIS). "Fossil-fuel combustion POA" are approximated to AMS hydrocarbon-like compounds (HOA). All concentrations are calculated on a carbon basis. A circular arc of $360^{\circ}$ refers to the average total carbon $(\mathrm{TC}=\mathrm{OC}+\mathrm{EC})$ concentration at each site.

\subsubsection{Field observations of organic aerosol ageing}

During EUCAARI, the atmospheric transformation of OA was studied during 30 ground-based field experiments using AMS and other OA characterization techniques, providing a unique European data set of OA "types", defined by spectral fingerprints (and chemical composition) reflecting both sources and chemical ageing. Main results of the analysis of these measurements are:

- a new European phenomenology of submicron aerosol chemical composition based on time-resolved mass spectrometric (AMS) measurements;

- a first European phenomenology of "organic aerosol types", defined by spectral fingerprints from both AMS and HNMR spectroscopies (Decesari et al., 2011a);

- LV-OOA (low volatility oxygenated organic aerosol), which are end-products of OA ageing, were associated by H-NMR analysis to HULIS-containing aerosols, and are the most common constituents of the European regional continental polluted background under clear sky and stable meteorological conditions (from May 2008 IOP).

An overview of how the various H-NMR and AMS source types correspond to each other is shown in Fig. 7. The AMS data are plotted in the space spanned by the organic mass fractions of $m / z 44$ versus $m / z 43$ (Ng et al., 2010). Extensively aged $\mathrm{OA}$ is found in the upper apex of the blue triangle (high organic mass fraction of $m / z 44$ ), while freshly emitted $\mathrm{OA}$ is typically found at the base of it. The larger diversity of compositions observed for fresh OOA reflects the multiple fingerprints of anthropogenic (e.g. biomass burning) and biogenic (e.g. terpene SOA) sources, while the aged OOA exhibits a consistent composition dominated by carboxylic acids. H-NMR analysis highlights a sharp contrast between the composition of OOA in the lower left corner of the triangle (samples from the Po Valley) and that of samples from regional background stations (Mace Head, Montseny) which fall in the upper corner of the diagram. The former are dominated by aliphatic chains, poorly functionalized alkyl groups, amines, aromatic and alcohols (originating from wood burning emissions), while the functional group composition of the background stations is characterized by a variable amount of aromatic groups and by very functionalized aliphatic groups lacking of methylenic chains, hence pointing to HULIS. In the centre of the triangle, compositions of "atypical HULIS" are also found, which are interpreted as OOA of intermediate ageing state and are found at some polluted stations (Barcelona, Cabauw). On the other hand, H-NMR analysis identifies HULIS also in samples not characterized by extensive ageing (Melpitz), therefore missing a full overlap with the AMS categorization for OOA. Reasons for this discrepancy can be inherent to the methodologies: H-NMR characterization reflects more the structure of the backbone of the organic molecules and their functionalization degree rather than their actual oxidation state, therefore looking at the ageing processes with a different perspective compared to AMS. An alternative explanation is that in environments, such as Melpitz, the less oxidized OOA are accounted for by waterinsoluble compounds, which were not analyzed by H-NMR spectroscopy in this study. 


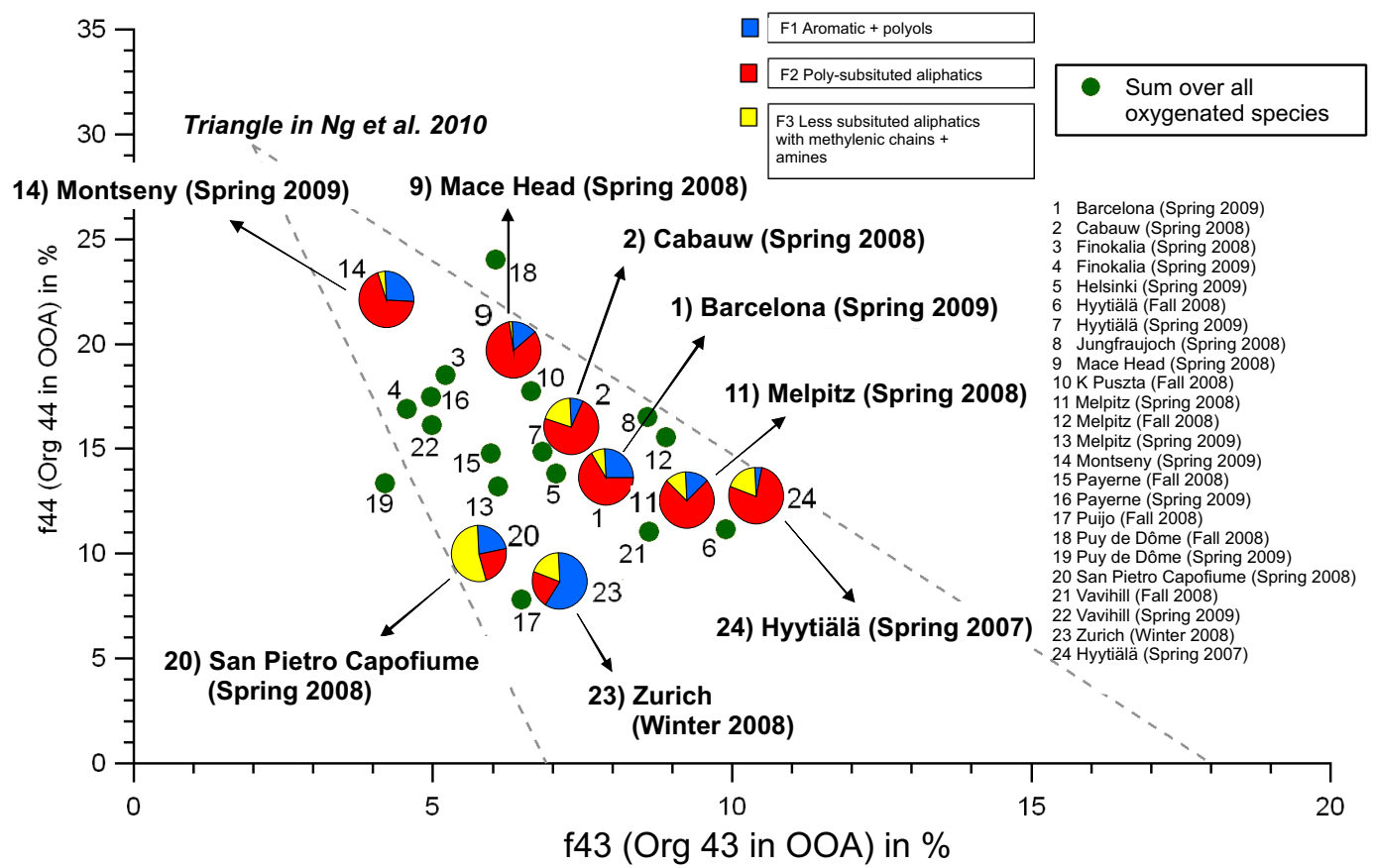

Fig. 7. Average H-NMR compositions from various EUCAARI campaigns compared to the corresponding AMS fingerprints for oxidized organic aerosols. NMR compositions are expressed as relative proportions of main WSOC chemical classes derived by factor analysis: Factor 1 ("Aromatic + polyols") is associated with fresh biomass burning sources, Factor 2 ("Poly-substituted aliphatics") are associated with atmospheric humic-like substances (HULIS), while Factor 3 includes minor components, such as amines. The AMS composition for OOA is shown as a function of the abundance of carbonyl (mass fragment $\mathrm{m} / \mathrm{z} 43$ ) and carboxyl (mass fragment $\mathrm{m} / \mathrm{z}$, 44) functional groups (Ng et al., 2010).

\subsubsection{Results of the intensive observation period}

\section{Particulate pollution over Europe under anticyclonic conditions}

During the EUCAARI-LONGREX campaign in May 2008 the DLR Falcon and FAAM BAe-146 research aircraft were deployed to measure microphysical, chemical and optical properties of atmospheric aerosol over Europe throughout the tropospheric column. The first half of May 2008 was characterized by the occurrence of a well developed, blocking anticyclonic system, which enabled the development of a very stable boundary layer over central Europe (Hamburger et al., 2011). Reduced horizontal wind velocities averaging below $7 \mathrm{~m} \mathrm{~s}^{-1}$ at low levels and the stable vertical layering of the lower troposphere resulted in high total particle number concentration over the continent. The airborne measurements of aerosol number concentrations discussed by Hamburger et al. (2011) show a "C-shaped" vertical structure for particles with $d_{\mathrm{p}}>10 \mathrm{~nm}$ (Fig. 8) with considerable day-to-day (flight-to-flight) variability throughout the tropospheric column. Boundary layer aerosol number concentrations ranged from 5000 to 20000 particles $\mathrm{cm}^{-3}$ in polluted regions to around 1000-2000 particles $\mathrm{cm}^{-3}$ in rather remote areas. A significant number of freshly formed particles have been de- tected during many flights (Crumeyrolle et al., 2010). Accumulation mode particles $\left(d_{\mathrm{p}}>150 \mathrm{~nm}\right)$ accounted typically for approximately for $10-20 \%$ of the aerosol population. A rather strong gradient between high number concentrations inside the boundary layer and the much cleaner free troposphere was characteristic for the high pressure conditions, whereas the contrast was clearly weakened after passage of frontal systems later on.

Almost undisturbed transport of continental anthropogenic pollutants to remote regions can occur. This process was observed for instance around 14 May 2008, contributing to about $90 \%$ of fairly high aerosol optical depths (AOD) over the Atlantic south west of Ireland (Fig. 9). Closure of optical aerosol properties determined from the High Spectral Resolution Lidar (HSRL) and the in situ aerosol optical aerosol spectrometers carried on the Falcon was successfully obtained for this case (Hamburger et al., 2011). Furthermore, the AOD as retrieved from satellite observations (here PARASOL; averaged AOD $0.31 \pm 0.03$ for the box marked in Fig. 9b) could be validated against the HSRL measurement (averaged AOD $0.36 \pm 0.05$ along the flight track in Fig. 9b) 

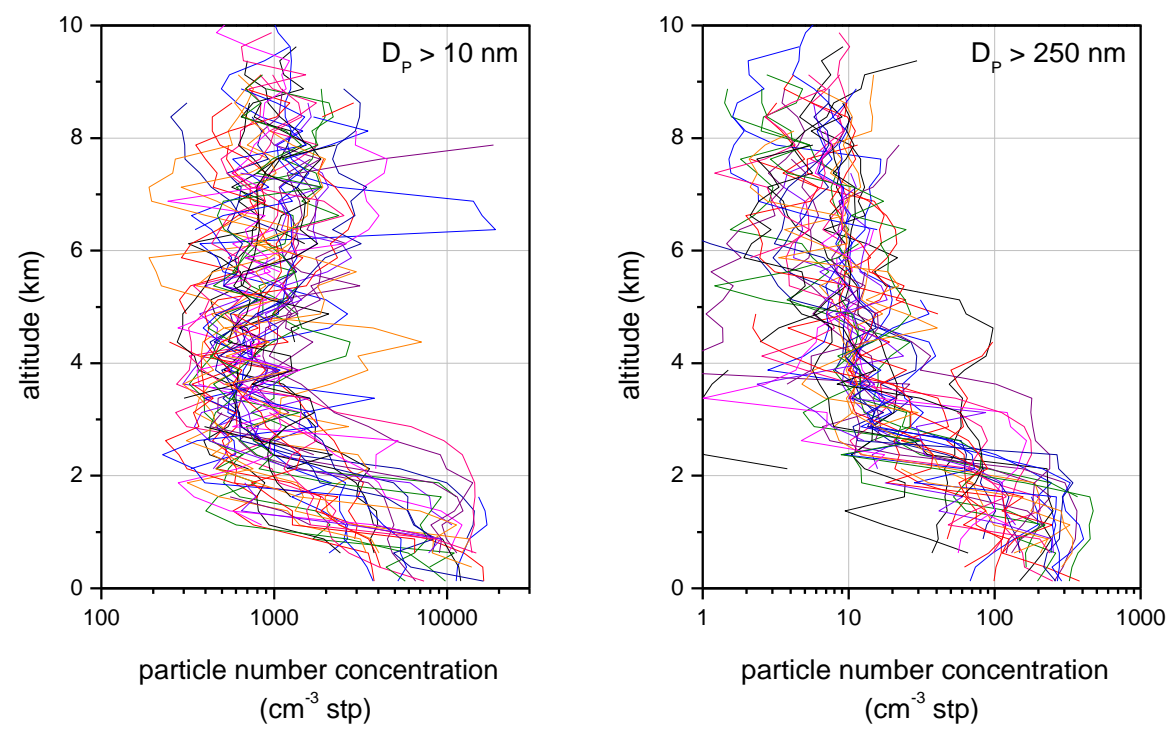

Fig. 8. Vertical distribution of aerosol particles $>10 \mathrm{~nm}$ (left panel) and $>250 \mathrm{~nm}$ (right panel) over Europe during May 2010 from 43 individual vertical profiling missions with the DLR Falcon aircraft, measured by condensation and optical particle counters (see Hamburger et al. (2011) for details). In-cloud data are excluded. Number concentration refers to standard conditions (STP) $273 \mathrm{~K}$ and $1013 \mathrm{hPa}$.
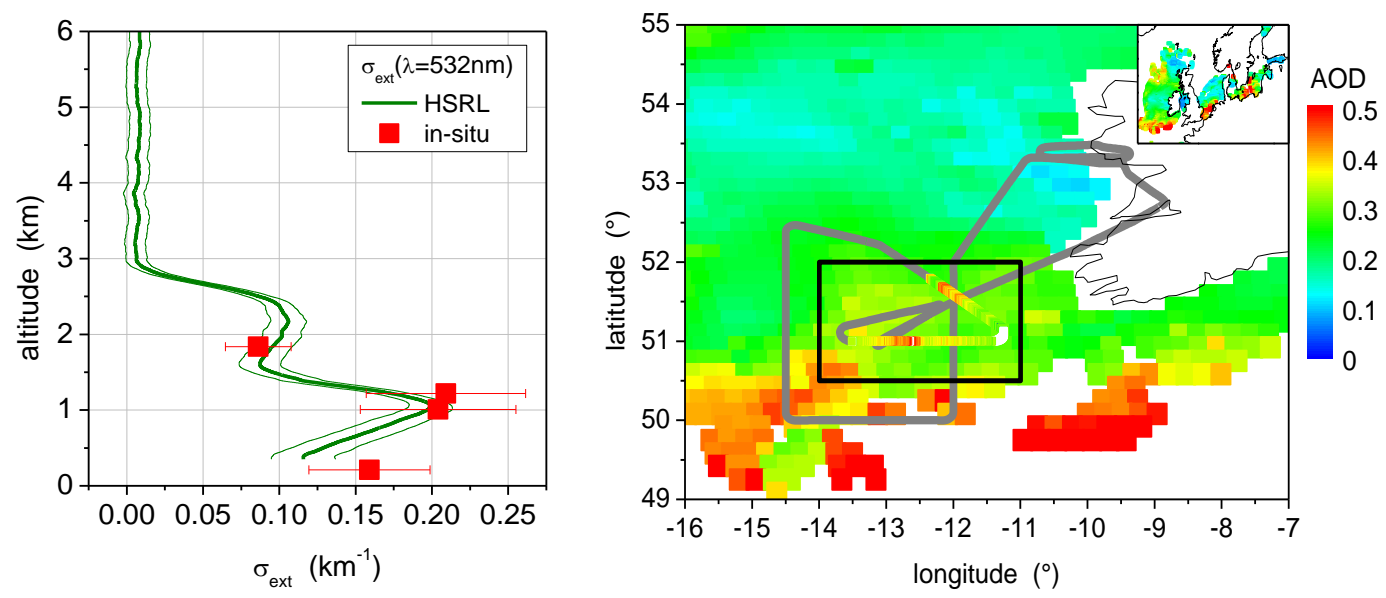

Fig. 9. Long-range transported central European pollution observed over the Atlantic off the west coast of Ireland on 14 May 2008 . (a) Averaged vertical profile of the aerosol scattering coefficient as measured by High Spectral Resolution Lidar (HSRL; green line) and derived from the in situ particle size distribution measurements (square symbols) on board the DLR Falcon. (b) Map of aerosol optical thickness (AOD) at $532 \mathrm{~nm}$ wavelength retrieved from satellite (PARASOL) and HSRL measurements colour coded, where available, on the Falcon flight track.

\section{Sub-micron aerosol chemical composition}

The spatial distribution of sub-micron aerosol chemical composition has been characterized based upon airborne measurements in the planetary boundary layer across Europe (Morgan et al., 2010b). Downwind of major source regions total submicron mass loadings from the AMS exceeded $15 \mu \mathrm{g} \mathrm{m}^{-3}$ with organic aerosol (OA) and ammonium nitrate being the dominant chemical components, contributing 20$50 \%$ each to the non-refractory mass. OA dominates over sulphate over most of Europe, with OA concentrations typically 1.3-2.5 times greater than that of sulphate. A positive matrix factorisation analysis of the OA component was conducted, revealing the dominance of oxidised organic aerosol (OOA) over hydrocarbon-like organic aerosol (HOA), which is consistent with previous literature (Jimenez et al., 2009; Zhang et al., 2007) as well as with the ground-based data. An empirical estimate based upon previous research indicated that HOA contributes less than $15 \%$ to the OA burden. Two separate OOA components were identified; one 
representing an aged-more oxidised organic aerosol and another representing fresher-less oxidised organic aerosol. OA data can be viewed as a continuum with a progression from a less oxidised, more-volatile component to a highly oxidised, less-volatile component. This progression was observed to occur as a function of the distance from source, with more oxidised components dominating further downwind. Ammonium nitrate dominates in North-Western Europe where the emissions of $\mathrm{NO}_{\mathrm{x}}$ and ammonia reach their maximum.

Airborne measurements revealed complex partitioning of the semi-volatile aerosol components in the planetary boundary layer. Measurements revealed an increase in secondary aerosol mass with an increasing altitude in the boundary layer, causing an increase of the aerosol direct radiative forcing (Morgan et al., 2010a). Specifically, in-situ measurements in the vicinity of a ground-based measurement site at Cabauw, the Netherlands, showed that ammonium nitrate was the dominant chemical component aloft, while at the ground OA dominated. Furthermore, the fractional contribution to the sub-micron aerosol mass of ammonium nitrate increased with height in the boundary layer. This was primarily attributed to partitioning of semi-volatile gas phase precursors to the particle phase at reduced temperature and enhanced RH, a phenomenon which has been observed previously in California (Neuman et al., 2003). By comparing the optical properties measured on the aircraft with coincident measurements from the ground, a strong enhancement in the aerosol optical depth (AOD) and direct forcing was shown to occur when taking into account the additional mass associated water uptake and hence scattering caused by the partitioning phenomenon. Consequently, the radiative impact of anthropogenic aerosols is likely to be severely underestimated in Europe, where ammonium nitrate and OA are major components of the sub-micron aerosol burden. Such increases in AOD and radiative forcing have major implications for regional weather and climate, particularly as semivolatile compounds are often not included in global and regional aerosol models.

\section{Black carbon}

The EUCAARI airborne IOP delivered also first measurements of refractory black carbon (rBC) in the lower troposphere on a European scale (McMeeking et al., 2010). Averaged $\mathrm{rBC}$ mass concentrations in the boundary layer $(<3 \mathrm{~km})$ ranged from roughly $300 \mathrm{ng} \mathrm{m}^{-3}$ in near-urban regions to $50 \mathrm{ng} \mathrm{m}^{-3}$ in background environments. The rBC mass concentrations increased from the East to the West during a period dominated by easterly flow, although fraction of submicron mass was between $0.5-3 \%$ and displayed a weak geographic dependence. Mass concentrations in the boundary layer were more than a factor of 10 higher than in the lower free troposphere, decreasing on average from about $100 \mathrm{ng} \mathrm{m}^{-3}$ to $5 \mathrm{ng} \mathrm{m}^{-3}$.

\section{Airborne CCN and cloud property measurements}

During EUCAARI, simultaneous observations of cloud condensation nuclei and lidar extinction profiles, as well as simultaneous ground-based and airborne $\mathrm{CCN}$ concentrations measurements provided the opportunity to quantify the vertical distribution of CCN. Results from the groundbased/airborne intercomparison based on data from the intensive measurement period at Cabauw, Netherlands, in May 2008 , indicate that CCN measurements on the ground often over-estimate the concentrations at levels where clouds form. During the clean background conditions when the air masses originated from the North Sea and cloud bases were relatively low, the boundary layer was well mixed and $\mathrm{CCN}$ concentrations at the ground resembled those at cloud base. The difference between ground-based and airborne measurements is especially important at higher concentrations associated with local pollution, when boundary layer mixing timescales are greater than the timescales for transport. Ground-based and airborne lidar observations detect multiple aerosol layers, provide insight to boundary layer mixing and are useful tools to investigate the relationships between ground-based and airborne measurements.

\section{Lagrangian parcel model simulations}

Lagrangian parcel model simulations were carried out to assess the closure among the aerosol and cloud-droplet measurements carried out on board the SAFIRE ATR-42 during the IMPACT campaign. The physicochemical aerosol characteristics measured below cloud base are used for initializing an air parcel model. The model covers detailed treatment of the evolution of aerosol size spectrum and predicts the shape of the spectrum of activated cloud droplets. The evolution of the spectrum is driven by changes in humidity that are in turn caused by adiabatic displacement of the air parcel. Results of multiple simulations performed using different vertical velocities were matched with the measured vertical wind speed spectrum to obtain statistics of droplet-spectrum parameters. The predicted statistics were compared with the in-situ measurements made just above the cloud base using the FSSP-100 cloud-droplet size spectrometer on 13 and 15 May (Arabas and Pawlowska, 2010). The result of that study is hoped to help a creation of a novel parametrization of the activation process in cloud models with detailed description of microphysics. A novel approach for solving the evolution of particle spectrum in an air-parcel model was developed for the purpose of this study (Arabas and Pawlowska, 2011, model code released with the paper).

Analysis of vertical velocity statistics on different levels in the atmosphere and statistics of cloud micro-physical parameters (cloud droplet number concentration, liquid water content, cloud droplet radius) were performed (Fig. 10). That information has been used in the evaluation of the droplet activation model developed at the University of Warsaw (Arabas 

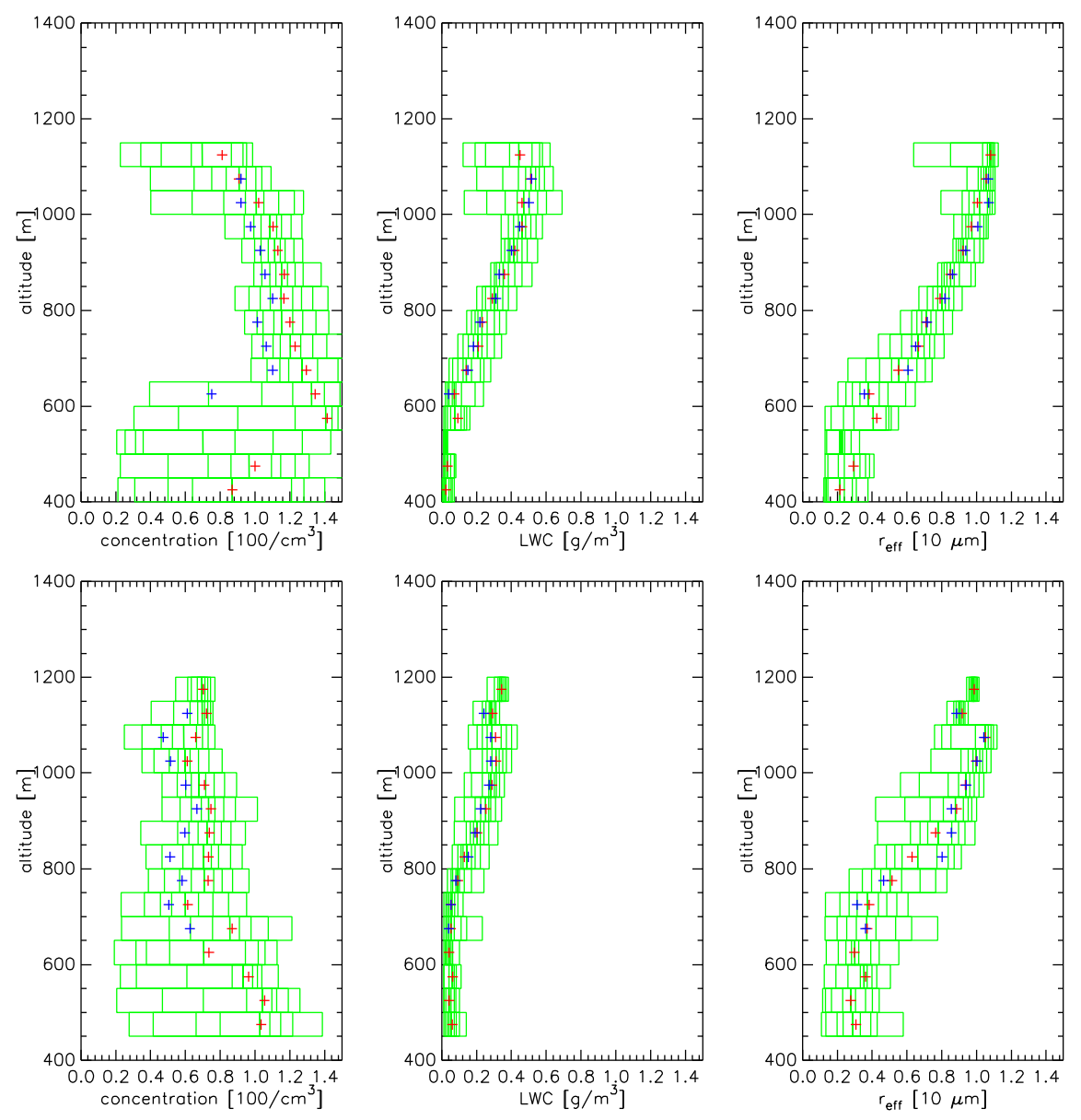

Fig. 10. Statistics of cloud droplet spectrum plotted as a function of altitude for two research flights (RF51 - upper row, and RF52 - lower row) on 15 May above the North Sea in a Sc layer. A cumulative distribution of cloud droplet number concentration, liquid water content and effective radius on each level is represented by a set of 7 percentiles $(1 / 8,2 / 8,3 / 8,4 / 8,5 / 8,6 / 8$ and $7 / 8)$ using vertical bars. The analysis carried out separately for regions with a positive $(w>0)$ and negative $(w<0)$ vertical velocity shows median valuse marked by a green $(w<0)$ and red $(w>0)$ crosses.

and Pawlowska, 2011). Statistics of vertical velocity have been used also in the CAM-Oslo GCM model (Hoose et al., 2010a).

Profiles derived from the aircraft data taken during the flight on 15 May over the North Sea (RF51) were used to initialize Large Eddy Simulations (LES). Simulation was run using the Eulerian version of the EULAG model (www. mmm.ucar.edu/eulag) that solves anelastic equations with a 2-moment microphysics scheme that predicts liquid water mixing ratio and cloud droplet concentration. To study the process of turbulent mixing in clouds, the microphysics scheme was improved. In the original version of the scheme, the mixing scenario is determined by a single parameter, which is assumed to be constant in space and time during the simulation. To include in the model the variability of the mixing scenario in clouds, we took advantage of the direct numerical simulations (DNS) results (Andrejczuk et al.,
2009). Results from these simulations suggest that a simple relationship exists between the ratio of the time scales of droplet evaporation and turbulent homogenization and the slope of the mixing line on the diagram representing the relative change of the droplet concentration versus the change of the droplet radius cubed. To calculate the ratio of the time scales two new variables were added to model: the scale (or width) of cloudy filaments and the fraction of cloud air in the grid box.

The IMPACT stratocumulus case was used to compare the models with new 2-moment microphysics scheme and with the traditional 2-moment scheme (assuming homogenous or extremely inhomogenous mixing for entire simulation). Results from all simulations are in relatively good agreement with experimental data. The cloud water profiles show a bilinear structure, with different slopes in the layer between 400 and $600 \mathrm{~m}$, and the layer above $700 \mathrm{~m}$. This might 
suggest a layer of cumuli beneath the stratocumulus growing into the stratocumulus deck. The differences between models are insignificant. This is what one might expect because homogeneity of mixing should not affect bulk cloud properties such as cloud water and cloud fraction profiles. It is not true for the mean droplet number concentration where differences between models should be important.

\section{LES simulations}

High resolution Large Eddy Simulation (LES) studies are important in our effort to understand cloud processes. Data derived from the North Sea case studies provide excellent material for the initialization of LES models that were used to simulate the PBL-cloud formation and evolution. Development of these models now include (a) $\mathrm{CCN}$ parametrization, (b) the option to study in-depth the various mixing scenario's of the clouds with ambient [overlying air], (c) inclusion of the observed aerosol chemical and physical properties. A parametrization testbed has been used to compare the output from LES models to that from larger scale Single Column Models that are reduced versions of full scale 3-D regional/global climate models.

\section{Radiative closure}

Our results from IMPACT sub-campaign show that a detailed model of the effects of aerosols on atmospheric radiation is able to capture the observed radiative signatures at the surface with a high degree of accuracy. This suggests that an accurate modelling of the direct aerosol radiative effect in global climate models is within reach provided that the global and regional distribution of aerosols is known.

The focus in this work was on the radiation budget of stratocumulus clouds. To study this complex system, an atmospheric model capable of computing three dimensional cloud fields is needed. This requires high spatial and temporal resolution at large domain sizes. The gpuASAM model developed at the IfT in Leipzig uses graphical processing units (GPU) to provide the necessary computing power. It is a three dimensional atmospheric model with a two moment microphysics based on Seifert and Beheng (2006). With that it is possible to study the effects of different CCN concentrations on cloud structures. The model was evaluated using simple test cases (Bryan and Fritsch, 2002) but also some more complex GCSS test cases (BOMEX, DYCOMS). It is capable of producing three-dimensional cloud fields even with features like open and closed cell structures, at computation times of several hours using one GPU. More GPU's can be combined to enhance domain size or increase model resolution. With this new model large eddy simulations of cloud fields became possible on ordinary desktop computers or even on notebooks. In future, using actual high-end GPU servers, it will be possible to do these calculations in a forecast mode for example to accompany field measure- ments. The produced three dimensional cloud fields are good input fields for usage in more sophisticated radiation transfer models, but none of these are currently implemented in the model framework.

\subsection{Regional and global aerosol and clouds}

\subsubsection{Satellite data}

EUCAARI used satellite data to understand regional and global variations of aerosol and cloud properties, and aerosol-cloud interactions. The resulting aerosol and cloud information on regional and global scales was used in process, transport and effects studies in support of the assessment of air quality and climate. The observations were made using experimental state-of-the-art space-borne instruments (MODIS, AATSR, PARASOL, OMI, Cloudsat, CALIPSO and MSG SEVIRI) (see de Leeuw et al., 2011b). This required the development of new methods/algorithms and the improvement of existing ones to improve the quality of retrieved aerosol and cloud parameters and the retrieval of new parameters by optimum utilization of the technical characteristics of the available instruments. Tools have been developed to visualize and analyse combined data sets. The analysis focused on the EUCAARI campaigns LONGREX and IMPACT, on the distributions and effects over Europe and around the EUCAARI sites in China, India and South Africa, and on regional, global and seasonal variations of aerosol and cloud properties and radiative effects. Retrieval results were analyzed and inter-compared to improve their quality and the understanding of the retrieval products. Aerosol optical depth (AOD) and Fine Mode Fraction (FMF) were compared with independent ground-based and airborne measurements as well as with model results. These comparisons served to evaluate both the retrieval and the model outcomes. Cloud properties retrieved from satellite observations show the effects of aerosols on cloud microphysical and optical properties and the evolution of clouds as well as information on cloud phase, which leads to better understanding of cloud properties and effects.

Satellite-based instruments provide information on the spatial distribution of atmospheric constituents on regional to global scales (Burrows et al., 2011). Of particular interest for EUCAARI was the retrieval of aerosol and cloud properties using radiometers or lidar systems. Satellite-retrieved aerosol and cloud properties provide information on atmospheric processes and especially on aerosol-cloud interactions and radiative effects of clouds through their macroscopic and microphysical properties. The current status of the retrieval of cloud properties has been described by Kokhanovsky et al. (2011). The current status of the retrieval of aerosol properties over land has been described by Kokhanovsky and de Leeuw (2009) and de Leeuw et al. (2011b). The validation of aerosol retrieval is described in Piters et al. (2011). Together these publications provide a 
good overview of the instruments and algorithms used in EUCAARI to provide aerosol information from space. Aerosol and cloud properties have been retrieved using instruments flying on sun-synchronous satellites as well as on geostationary satellites. The former provide information on a global scale within one to a few days, the latter provide information on part of the globe but with temporal resolution of multiples of $15 \mathrm{~min}$.

\section{Satellite detection of aerosols}

Aerosol retrieval products over Europe are available from AQUA/MODIS, PARASOL, OMI, and the CALIOP lidar, all flying in the A-Train constellation, as well as AATSR (on ENVISAT) and SEVIRI (on MSG, geostationary). For all instruments algorithms have been further developed and improved.

The AATSR dual view algorithm was further developed and improved (Kolmonen et al., 2011). Results for 2008 are shown in Fig. 11. Global aerosol retrieval results on the aerosol optical depth (AOD) over land were compared with ground-based AERONET (Holben et al., 1998) AOD data. This comparison showed where the algorithm provides good and less good results, with the latter needing further development (Kolmonen et al., 2011). For the determination of the aerosol altitude using data from a passive sensor, a new approach has been developed that uses the oxygen A-band of POLDER (Dubuisson et al., 2009). The method provides insight into the vertical distribution of aerosol on a global scale. A new approach for the retrieval of aerosol optical thickness above clouds from merged POLDER and MODIS observations has been developed by Waquet et al. (2009). The method provides a new perspective for studying aerosol properties and radiative forcing in the presence of underlying clouds. The OMI multi-wavelength aerosol algorithm (OMAERO product) has been developed (Torres et al., 2007) to retrieve the aerosol optical thickness and a best fitting aerosol type. The single scattering albedo, the layer height and the size distribution associated with the best fitting aerosol type are provided. OMAERO aerosol products have been improved by the use of the surface albedo climatology from OMI over land (Kleipool et al., 2008) in the retrieval algorithm to account for surface effects on the radiation measured at the top of the atmosphere. Further OMAERO improvement is expected from combining the MODIS-AQUA cloud screening with the OMI data, in order to improve the cloud screening for OMAERO. MODISAQUA and OMI are both part of the A-Train satellite constellation and the two sensors observe the same area within $10 \mathrm{~min}$.

Apart from the aerosol optical thickness and the aerosol type retrieval, the OMAERO product also produces the Aerosol Absorbing Index (AAI). The AAI is not a geophysical parameter, but an indicator of the presence of elevated layers of absorbing aerosol, such as desert dust or biomass

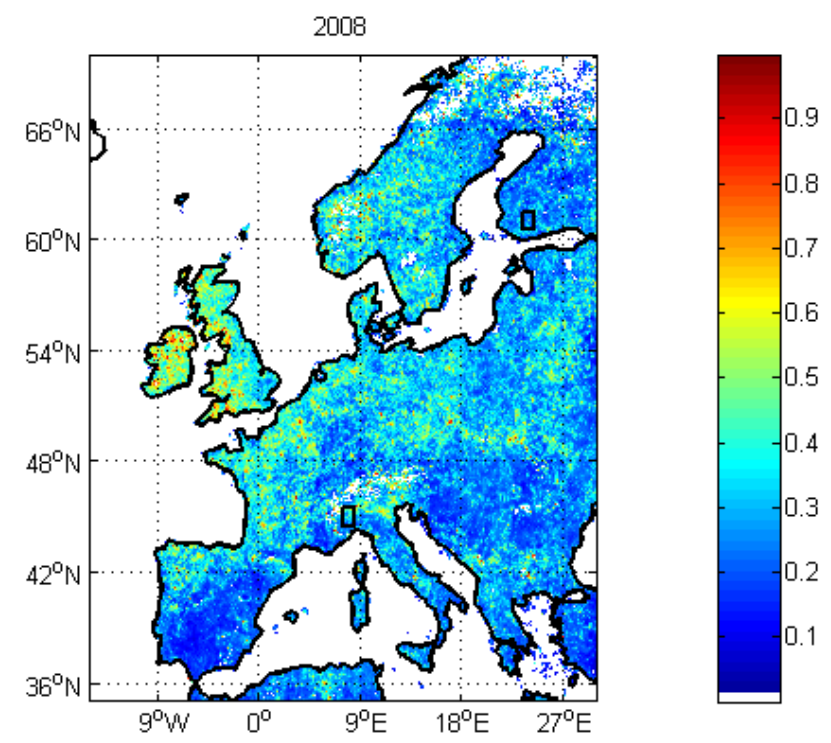

Fig. 11. AOD at $555 \mathrm{~nm}$ over Europe, as an aggregate of the individual data for the whole year 2008. White areas (e.g. over the Alps) indicate the absence of data.

burning plumes. The multi-year OMI AAI data series show the inter-annual variability of this parameter. A unique new result is the retrieval of the AOD above clouds from merged POLDER and MODIS observations (Waquet et al., 2009). It provides a new perspective for studying aerosols properties and radiative forcing in the presence of underlying clouds.

\section{Satellite detection of clouds}

A study on the information content analysis of Multi-viewing polarization measurements for liquid cloud microphysical retrievals by Labonnote et al. (2011) showed that the physics governing the radiative transfer in clouds is relatively well known, whereas the impact of model uncertainties and instrument noise in the information content of an observing system is not as clear. The study further showed that there is potentially more information than only the two first modes of the size distribution (effective radius and effective variance) in such measurements. It might be possible to retrieve the entire shape of the size distribution depending of the angular resolution and the signal to noise ratio of the instrument.

MODIS and POLDER cloud fraction, cloud optical thickness and cloud phase as well as seasonal variations and spatial distribution of high, middle and low, ice/liquid cloud fractions have been compared by Zhang et al. (2010) and Zeng et al. (2010). Seasonal variations and spatial distribution of high, middle and low, ice/liquid cloud fractions have been compared and analyzed. The impact of microphysical model uncertainties on cloud optical thickness retrievals and subsequent errors on the estimate of ice cloud radiative forcing has been quantified. 
An algorithm has been developed to retrieve an improved cloud top phase product using POLDER/PARASOL and MODIS/AQUA (Riedi et al., 2007). The resulting product provides a semi-continuous confidence index ranging from confident liquid to confident ice instead of the usual discrete classification of liquid, ice, mixed or simply unknown phase clouds.

A sophisticated method using a variational technique has been developed to retrieve cloud size distribution parameters (effective radius and effective variance) from multiviewing/spectral polarized measurements (Labonnote et al., 2009). Due to the data used (polarization) this microphysical information primarily comes from cloud top and is mainly sensitive to narrow size distribution (e.g. small effective variance).

The OMI effective cloud fraction represents the cloud influence on the reflectance, not a geometric coverage. The OMI effective cloud fraction has been validated against the MODIS/Aqua cloud optical thickness (Sneep et al., 2006). The MODIS instrument uses thermal infrared radiation to determine the cloud (top) pressure. OMI uses reflected sunlight close to the $\mathrm{O}_{2}-\mathrm{O}_{2}$ absorption band at $477 \mathrm{~nm}$ and yields a pressure near the mid-level of the cloud. The clouds observed near 40 degrees latitude are probably a multi-layer cloud deck (cirrus over water clouds) where MODIS observes the top layer, and OMI the bottom layer. Model comparisons have shown that the cloud pressure retrieved by OMI is near the mid-level of the cloud. This is very different from the cloud pressure derived in the thermal infra-red, where a cloud top is found. Comparisons with CloudSat have confirmed this behaviour (Sneep et al., 2008).

\section{Performance criteria and trend analysis of satellite aerosol observations}

A new scoring system has been introduced to quantify the performance of MISR and MODIS satellite sensor retrieval products for aerosol optical depth (AOD). Based on comparisons to highly accurate ground-based sun-photometer data of AERONET here stratified into 25 regions and 12 months, scores for bias and variability are assigned. These regional and temporal sub-scores are then combined into single annual global overall scores. MODIS (0.61) and MISR (0.58) global annual scores are at the top of available multi-annual AOD data-sets. Both data-sets (based on multi-annual statistics) score even better than the usually well behaved multimodel median (0.58). MODIS scores better over oceans and MISR scores better over land. Another aspect of this new scoring is the diagnostics, which allows tracing poor retrieval performance back to failure at temporal and spatial sub-scales. Such analysis for instance suggests that MODIS suffers from retrieval issues over continents in midlatitudes during winter (possibly due to sub-pixel snow) and that MISR suffers from retrieval issue at high latitudes (certainly related to MISR's relatively poor temporal sampling).
Differences in scores at these sub-scales allow the identification of regional and seasonal retrieval strengths and help in making more objective choices when picking one retrieval over another.

\subsubsection{Natural vs. anthropogenic contribution to aerosol number concentrations}

\section{Global particle number concentrations with GLOMAP}

Model runs on the global impact of secondary particle formation on $\mathrm{CN}$ (condensation nuclei, i.e. measured particle numbers) and $\mathrm{CCN}$ (cloud condensation nuclei) numbers were conducted with the global CTM GLOMAP (Spracklen et al., 2006, 2008b, 2010; Merikanto et al., 2009, 2010). The computational schemes based on linear or square dependence on sulphuric acid for boundary layer (BL) nucleation (developed within EUCAARI, Sect. 3.2.1 and Kulmala et al., 2006; Sihto et al., 2006; Spracklen et al., 2006; Kerminen et al., 2010) were used and the binary homogeneous nucleation in the upper troposphere was also accounted for (Merikanto et al., 2009). The model runs with a global focus were conducted using pre-existing inventories for particulate emissions, while in the model runs concentrating on the European domain the particle number emission inventories developed in EUCAARI were used.

The results suggested that the primary emissions can reproduce the spatial variation of the particle number concentrations on a global scale (Spracklen et al., 2010). A clear influence of secondary particle formation on the total $\mathrm{CN}$ numbers was seen particularly on the seasonal behavior of particle number concentrations (Spracklen et al., 2010). The results reported by Merikanto et al. (2010) suggest that on average about $75 \%$ of predicted global surface level number concentrations of $d_{\mathrm{p}}>3 \mathrm{~nm}$ particles had originated from nucleation. Over the continents BL nucleation is the primary source of these nucleated particles, whereas near the equator a large contribution from upper tropospheric nucleation is predicted (Fig. 12) (Merikanto et al., 2010).

Merikanto et al. (2010) concluded that $45 \%$ of global low-level cloud $\mathrm{CCN}$ at $0.2 \%$ supersaturation are secondary aerosol derived from nucleation (ranging between 30-50\% taking into account uncertainties in primary emissions and nucleation rates), with the remainder from primary emissions. Boundary layer nucleation and emissions of biogenic organics are coupled, when looking at their effect on CCN numbers. On average the forest emissions increase boreal CCN by a factor of 2 (Spracklen et al., 2008a). However, in a run without nucleation the forest emissions increase $\mathrm{CCN}$ only by a factor of 1.5 The contribution of biogenic SOA formation to total aerosol mass, on the other hand, was estimated using a physico-chemical box model applied in a Lagrangian manner over Scandinavia (Tunved et al., 2008). A recently-developed parametrization for the aerosol mass 
A: Totol $\mathrm{CN}$

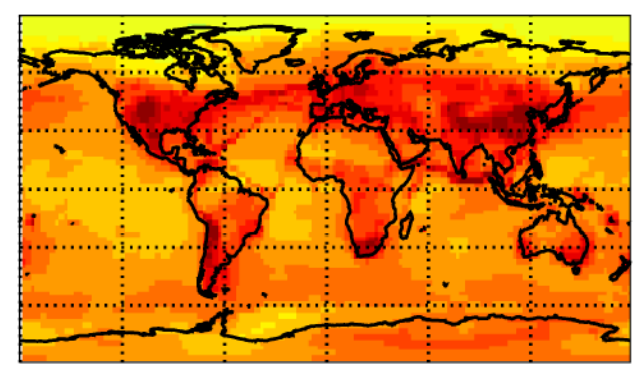

$110100100010000 \mathrm{~cm}^{-3}$

C: CN from UTN

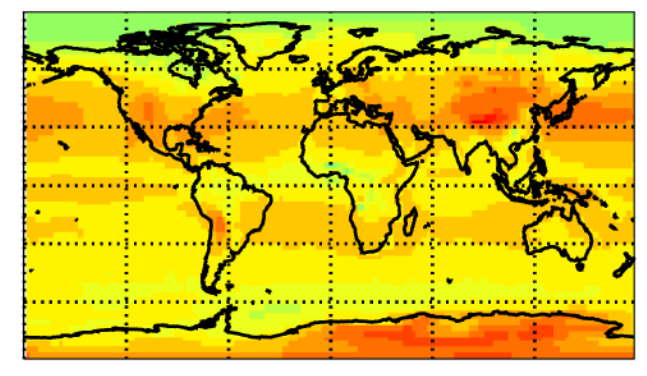

$110100100010000 \mathrm{~cm}^{-3}$
B: $\mathrm{CN}$ from Primories

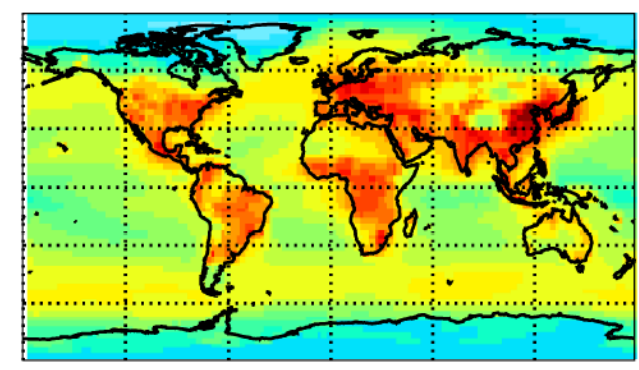

$110100100010000 \mathrm{~cm}^{-3}$

$D: C N$ from $B L N$

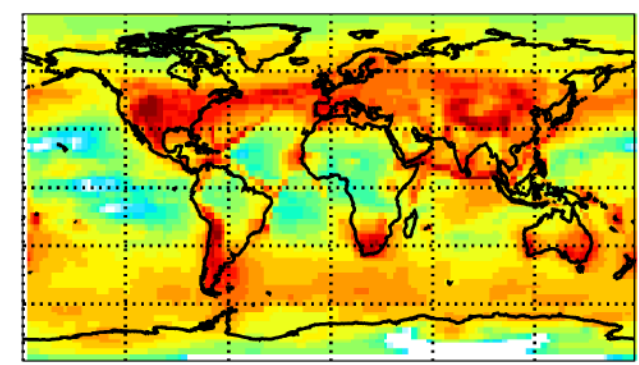

$110100100010000 \mathrm{~cm}^{-3}$

Fig. 12. Ground level total particle (above $3 \mathrm{~nm}$ in diameter) average concentrations of (a) all particles (sum of panels b, c and d); (b) primary particles; (c) nucleated particles entrained from upper troposphere; (d) particles nucleated in the boundary layer, as predicted with GLOMAP (published in Merikanto et al., 2009).

yield from biogenic terpenes was used (see also Tunved et al., 2006). It was demonstrated that the forest itself could produce up to $200 \mathrm{CCN}$ per $\mathrm{cm}^{3}$ on average over Scandinavia. Model runs comparing global CCN, cloud droplet numbers (CDN) and cloud reflectivity in 1850 and 2000 were conducted with GLOMAP. The results indicate that the global impact of nucleation on the 1850-to-2000 change in cloud reflectivity is small (few percent) but regionally it may be as high as $50 \%$ and can be either positive or negative (see Fig. 13 and Merikanto et al., 2010). These results suggest that boundary layer nucleation is important in the first indirect forcing calculations on a regional scale.

GLOMAP predictions of particle number over Europe were compared to aircraft and ground-based measurements recorded during the May 2008 EUCAARI intensive campaign and Long Range Experiment (LONGREX) by Reddington et al. (2011). It was found that the spatial distributions of campaign-mean number concentrations $>50 \mathrm{~nm}$ $\left(N_{50}\right)$ and $>100 \mathrm{~nm}\left(N_{100}\right)$ dry diameter were well captured by the model $\left(R^{2}>0.8\right)$ and the normalised mean bias was also small ( $-18 \%$ for $N_{50}$ and $1 \%$ for $\left.N_{100}\right)$ if a small emission size was assumed for primary carbonaceous particles, as used by AEROCOM (Dentener et al., 2006). Number con- centrations of particles $<50 \mathrm{~nm}$ dry diameter $(N<50)$ were substantially underpredicted at most ground sites unless an empirical mechanism was included to simulate BL nucleation. Comparisons with aircraft observations were consistent with these findings. The results of a $\mathrm{t}$-test showed that by including BL nucleation, a statistically significant difference between modelled and observed $N<50$ was removed at roughly half the ground sites. Including BL nucleation increased simulated $N_{50}$ and $N_{100}$ over Europe by $\sim 10-40 \%$ and $\sim 5-20 \%$ respectively, depending on the mechanism and on the emission size of primary particles. However, within the uncertainty of the observations and accounting for the uncertainty in the size of emitted primary particles, BL nucleation made a statistically significant contribution to $\mathrm{CCN}$ sized particles $\left(d_{\mathrm{p}}>50 \mathrm{~nm}\right)$ at less than a quarter of the ground sites. Despite testing several empirical parametrisations for BL nucleation (including new parametrisations developed within EUCAARI, Paasonen et al., 2010), the agreement between hourly time series of modelled and observed nucleation events in this period was fairly poor. From this 1-month intensive European dataset it was not possible to determine a reliable estimate of the fraction of $\mathrm{CCN}$-sized particles from primary and secondary sources, although the 
$\Delta$ Rc with BLPF, full year
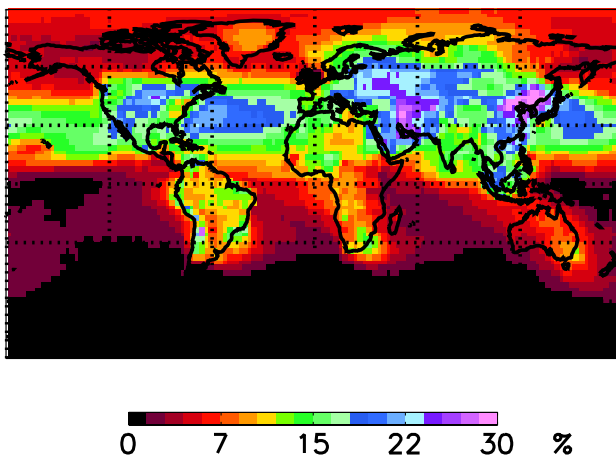

$\Delta$ Rc with BLPF, Summer
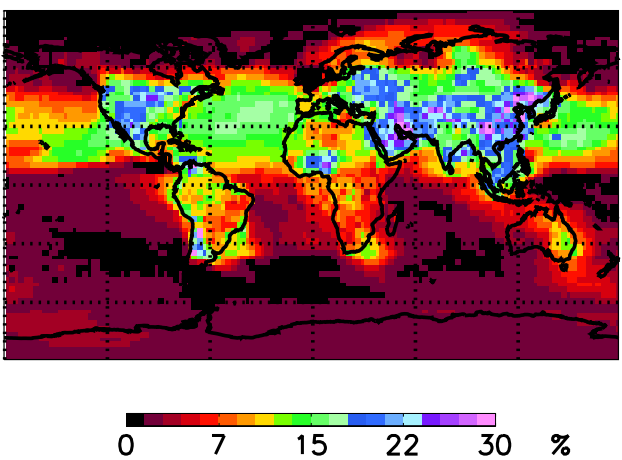

$\Delta R$ c without BLPF, full year
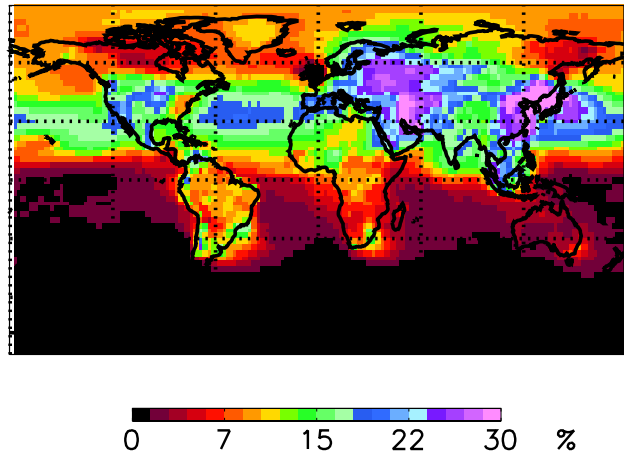

$\Delta R c$ without BLPF, Summer
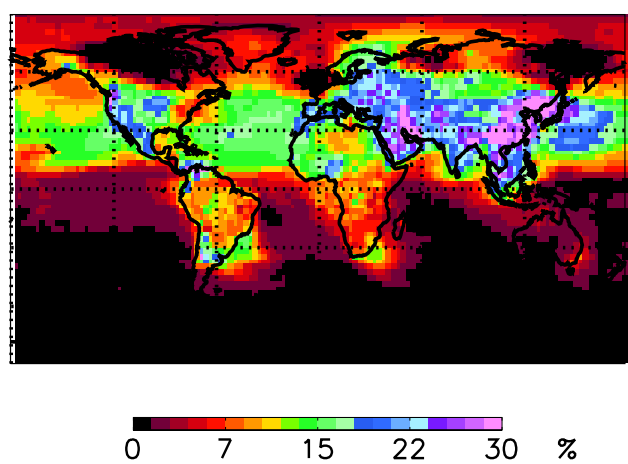

Fig. 13. The 1850-2000 change in cloud albedo with and without boundary layer particle formation (BLPF) at 300-1000 $\mathrm{m}$ above ground level, as predicted with GLOMAP. Results are shown for an initial albedo $R_{\mathrm{C}}=0.35$ assuming cloud updraft velocity $w=0.4 \mathrm{~m} \mathrm{~s}{ }^{-1}$ (published in Merikanto et al., 2010).

size of primary emitted particles was shown to be a major source of uncertainty.

\section{Global particle number concentrations with ECHAM5-HAM}

The global climate model ECHAM5-HAM (Stier et al., 2005) was modified to improve the representation of new particle formation in the boundary layer. The effect of nucleation on cloud droplet number was studied with the modified version of the model by Makkonen et al. (2009, see Fig. 14). In these runs the simple particle formation scheme introduced in EUCAARI (see also Sihto et al., 2006) was implemented together with a model of condensation of biogenic organics, which are able to contribute particle growth. Comparisons to observations indicated that simple nucleation scheme used in the study is a promising way to improve the ECHAM5-HAM model towards the average values observed over different locations.
European number concentrations with PMCAMx-UF and GLOMAP using emission inventories developed in EUCAARI

The regional 3-D-model PMCAMx-UF was developed (Jung et al., 2008), and its first tests were conducted for the Eastern United States for which input data such as emission inventories were readily available (Jung et al., 2010). The model simulates the aerosol number (from $1 \mathrm{~nm}$ to $10 \mu \mathrm{m}$ ) and mass distributions for a variety of chemical components, with a spatial resolution of $36 \mathrm{~km} \times 36 \mathrm{~km}$ and temporal resolution of one hour. To test the impact of boundary layer nucleation on aerosol number, the model allows the user to select among several different nucleation parametrisations, including the ones developed in EUCAARI (Sihto et al., 2006; Paasonen et al., 2010). Furthermore, a version of PMCAMxUF simulating the European domain was developed, and the newly-developed anthropogenic particle inventory (see Sect. 3.1) was implemented (Fountoukis et al., 2011b). Figure 15 shows the average predicted total number concentration of particles larger than $3 \mathrm{~nm}\left(N_{3}\right), 50 \mathrm{~nm},\left(N_{50}\right)$, and $100 \mathrm{~nm}\left(N_{100}\right)$ for the ground level for May 2008. The major nucleation areas are in the S-SE of Europe. The maps 

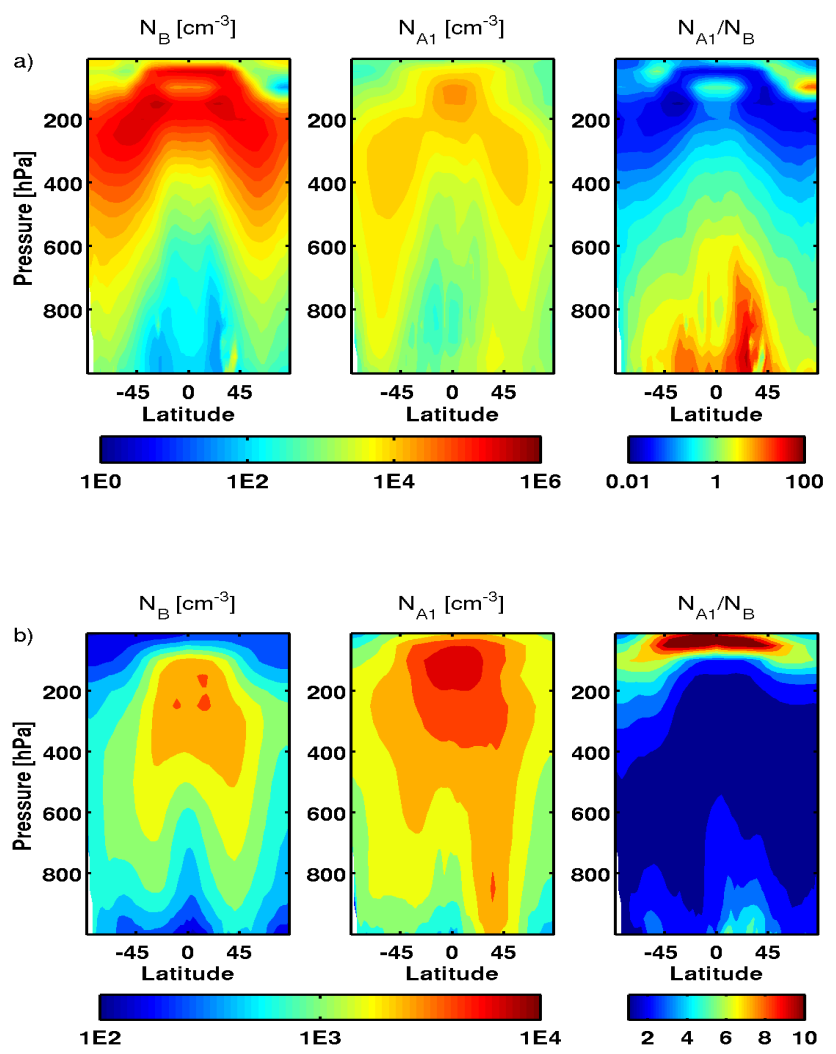

Fig. 14. Annual zonal average concentrations $\left(\mathrm{cm}^{-3}\right.$ STP $(1013.25 \mathrm{hPa}, 273.15 \mathrm{~K})$ ) of (a) nucleation mode aerosol number; (b) sum of Aitken mode number concentration: centre ones experiment A1 (using activation nucleation in addition to the standard binary nucleation) as predicted by the GCM ECHAM5-HAM; and right panels show the ratio of the yearly averages for experiments $\mathrm{B}$ (only binary nucleation) and A1. Notice the different color scales between figures (published in Makkonen et al., 2009).

of average $N_{50}$ and $N_{100}$ concentration fields have in general similar features, while the spatial distribution of $N_{3}$ is quite different. The average ground concentrations over the whole modelling domain are predicted to be 6667,1465 , and $390 \mathrm{~cm}^{-3}$ for $N_{3}, N_{50}$, and $N_{100}$, respectively. Additional simulations were performed for the same period with (1) nucleation turned off to study the secondary contribution to particle number concentrations; (2) anthropogenic $\mathrm{SO}_{2}$ and primary aerosol emissions reduced with $50 \%$, respectively, to study the anthropogenic impact on aerosol particle number concentrations. Corresponding simulations were conducted with GLOMAP using the same nucleation parameterisations, EUCAARI-developed emission inventories, and meteorological fields.

The evaluation of the anthropogenic particle number emission inventories developed in EUCAARI (Sect. 3.1.1) is an important contribution to the assessment of the anthropogenic impact on atmospheric aerosol numbers in the European boundary layer. These emission inventories were imple- mented in PMCAMx-UF and GLOMAP, and comparisons between the predicted particle number concentrations against observations at the EUCAARI field sites during the Intensive Observation periods in May 2008 and March 2009 were conducted to evaluate the performance of the inventories. The results indicate that the models performed relatively well in both capturing the levels of particle number concentrations and size distributions, as well as their temporal variation (see Fig. 16, for the comparison for $N_{50}$ in May 2008).

The average impact of secondary particle production by nucleation on average number concentrations of particles larger than $3 \mathrm{~nm}\left(N_{3}\right)$ and $50 \mathrm{~nm}\left(N_{50}\right)$ in Europe, and their sensitivity to $50 \%$ reductions in anthropogenic $\mathrm{SO}_{2}$, primary particle and biogenic VOC emissions are depicted in Table 2. The estimates are based on the PMCAMx-UF and/or GLOMAP simulations. The results suggest, in line with the previous global model studies (Merikanto et al., 2010), that a considerable fraction of $>3 \mathrm{~nm}$ and $>50 \mathrm{~nm}$ aerosol and $\mathrm{CCN}$ number concentrations are of secondary origin. The number concentrations also seem to be relatively insensitive to potential emission reductions. The impacts of the emission reductions on the size distribution are notable: while reducing $\mathrm{SO}_{2}$ emissions will reduce number concentrations in all size classes, primary aerosol emission reductions will have the largest impact on $>50 \mathrm{~nm}$ particles. According to predictions with GLOMAP, the similar behavior is predicted for the impact of VOC emissions. It should be noted, however, that large uncertainties exist in the role of organic compounds and therefore in the role of VOCs - in defining the lifetimes and size distributions of atmospheric aerosol populations.

\section{Observed changes in particle formation due $\mathrm{SO}_{2}$ emission reductions}

In order to study the effects of past $\mathrm{SO}_{2}$ emission reductions on small particle concentrations via possible reduction in new particle formation, we examined two long term dataseries of aerosol size distributions recorded in Melpitz, Germany, in 1996-1997 and in 2003-2006 (Hamed et al., 2010). Between the two periods, $\mathrm{SO}_{2}$ concentrations decreased on average by $65 \%$. This decrease was accompanied by a $45 \%$ decrease in the frequency of new particle formation events, and a $68 \%$ decrease in the average new particle formation rate. Examination of the various factors affecting sulfuric acid concentrations (i.e. $\mathrm{SO}_{2}$ concentration, intensity of solar radiation, and the condensation sink) allowed us to conclude that the $\mathrm{SO}_{2}$ reductions were indeed the reason in the decreased new particle formation. However, the growth rate of the freshly formed particles increased by $22 \%$ between 1996-1997 and 2003-2006, resulting in increased likelihood of the new particles to grow to sizes above $100 \mathrm{~nm}$. Therefore, and rather counterintuitively, the production of $100 \mathrm{~nm}$ (and larger) particles origination from new particle formation events was increased in the 2003-2006 period compared to 1996-1997, although new particle formation 

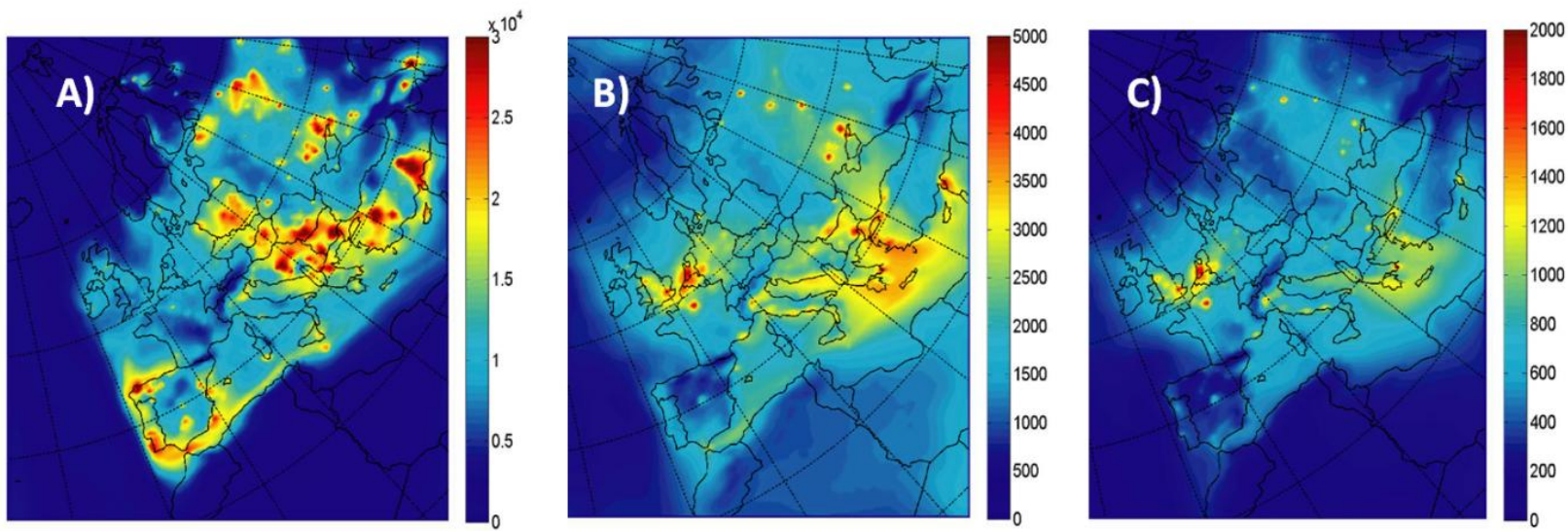

Fig. 15. The average number concentrations $\left(\mathrm{cm}^{-3}\right)$ at the ground level above (A) $3 \mathrm{~nm},(\mathbf{B}) 50 \mathrm{~nm}$, and (C) $100 \mathrm{~nm}$ as predicted by the regional CTM PMCAMx-UF for 1-29 May 2008 simulation (Fountoukis et al., 2011b).
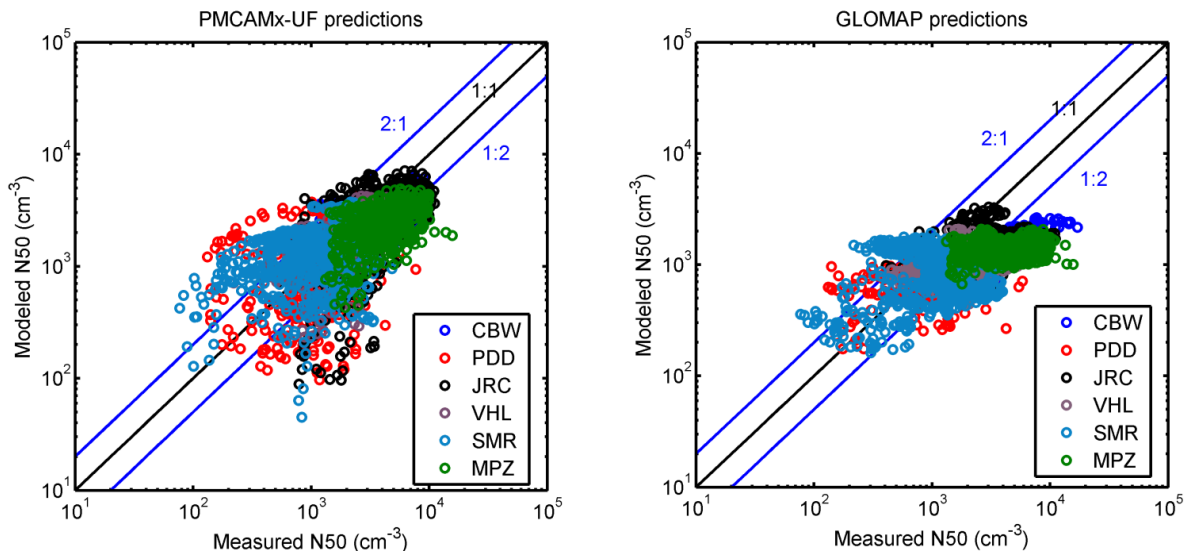

Fig. 16. Comparison of measured and modeled (PMCAMx-UF, left; GLOMAP, right) number concentrations of particles larger than $50 \mathrm{~nm}$ during May 2008 in a selection of EUCAARI field stations (see Fig. 3 for explanations of the letter codes for the stations). The model runs have been conducted using the nucleation parametrisations and primary aerosol emission inventories developed in EUCAARI.

itself decreased. The reason for the increased growth rate may have to do with increased emissions of biogenic VOC's as the new particle formation day temperatures were on average clearly higher in 2003-2006 than in 1996-1997.

\section{From primary vs. secondary to natural vs. anthropogenic contributions to particle number concentrations}

Summarizing, the importance of anthropogenic emissions as compared with natural aerosol background to the aerosol loading in atmosphere was one of the core questions of EUCAARI. To address this question for atmospheric aerosol number concentrations, it is crucial to unravel the fraction of particles with primary as compared with secondary origin - the former having primarily anthropogenic sources over the European continent, and the latter being typically a complicated mixture of both natural and anthropogenic components. We studied the sources of atmospheric aerosol particle numbers with global and regional models, equipped with the state-of-the-science parameterisations for secondary aerosol formation and primary aerosol number emission inventories - both developed within EUCAARI. The main results of these studies are:

1. Nucleation is a major source of aerosol particle number concentrations, and usually several tens of percents of sub-micron aerosol particles have originated from condensation of atmospheric vapours - thus being of secondary origin. As a rough approximation one could estimate that about half of aerosol particles in terms of their total number concentration in the European boundary layer have originated from nucleation.

2. Secondary aerosol formation is a combination of both natural and anthropogenic influence: while anthropogenic sulfate emissions are a major factor governing formation of new particles, natural emissions of 
Table 2. Impact of nucleation and emission reductions on particle number concentrations in Europe. Where available, the values represent the average of PMCAMx-UF and GLOMAP. Otherwise the numbers are based on one of the models only.

\begin{tabular}{lcrrr}
\hline & Relative increase due to nucleation (\%) & \multicolumn{2}{c}{ Relative PN change for 50\% reduction in emissions } \\
\cline { 2 - 4 } & & $\mathrm{SO}_{2}(\%)$ & Primary PN $(\%)$ & VOC $(\%)$ \\
\hline$N_{3}$ & 263 & -15 & -8 & 3 \\
$N_{50}$ & 63 & -12 & -15 & -8 \\
\hline
\end{tabular}

biogenic organic vapours play an important role in defining the aerosol size distributions and the climatic impact of aerosols. Our results suggest that the anthropogenic contribution (both primary and secondary) is dominating in the most parts of Europe, the biogenic component being of less importance. However, halving $\mathrm{SO}_{2}$ and anthropogenic primary particle emissions (see Table 2) would result in reductions of the order of $20 \%$ on the total particle number concentrations which might suggest that the natural aerosol production might compensate somewhat for the reductions in the anthropogenic aerosol production.

3. Air quality-driven reductions of global anthropogenic $\mathrm{SO}_{2}$ emissions are likely to decrease the cooling effect of aerosols during the next hundred years - due to their impact on secondary aerosol formation. This effect is likely to overwhelm the potential changes in natural emissions of aerosol precursors.

It is important to mention that impact of different air qualitydriven reduction scenarios are still associated with a lot of uncertainty

\subsubsection{Parameterisations of processes}

Due to the required long computing time complex processes usually need simplification before they can be implemented in global and regional models. These simplifications should still represent the full processes from the physical and/or chemical point of view. Therefore they need extensive testing before their results can be trusted. The EUCAARI project produced quality controlled parameterizations and investigated the accuracy of essential assumptions used in the models. Key results of this work are:

1. The role of a minimum in cloud droplet number concentration assumed in models was quantified, thus reducing the sensitivity of the estimated aerosol first indirect effect to this arbitrary choice.

2. The parameterization of the cloud updraft velocity was improved, allowing a better determination of the activation of aerosol particles to cloud droplets.
3. Ice nucleation parameterizations were tested and improved with emphasis on the role of bioaerosols in atmospheric ice nucleation in mixed-phase clouds.

4. The treatment of boundary layer was improved. The new description allows better results for relation between Liquid Water Path and Aerosol Optical Depth.

5. The description of stratocumuli thickness was improved.

6. An improved scheme for $\mathrm{CCN}$ activation was developed filtering numerical artifacts.

7. A parameterization of surface partitioning was developed that can be included in large-scale models.

8. New nucleation parameterizations were developed, evaluated and tested. The existing parameterization for aerosol formation was updated.

9. The relative accuracies and differences between modaland bin-descriptions of the aerosol size distribution were evaluated.

\section{Cloud droplet number concentration}

Some global aerosol-climate models impose a lower bound to cloud droplet number concentration (CDNC) or aerosol concentrations. Typical values of this lower bound range between 5 and $40 \mathrm{~cm}^{-3}$. In the pre-industrial era very low aerosol concentrations were not as uncommon as they are today. A constraint on the CDNC influences simulated clouds strongly and in a non-physical way. The common practice of prescribing a lower bound on the droplet number concentration is avoided in CAM-Oslo. Hoose et al. (2009) showed that arbitrary lower bounds on the droplet concentration lead to suppression of the simulated first indirect effect (from $-1.9 \mathrm{~W} \mathrm{~m}^{2}$ up to $-0.6 \mathrm{~W} \mathrm{~m}^{2}$ ), especially over oceans. Constraining aerosol concentration instead of droplet concentration has a weaker effect on the change in short-wave cloud forcing and can be considered physically more correct, because global aerosol-cloud models lack some aerosol species like primary biological particles or non-desert dust. 


\section{Cloud updraft velocity}

The parametrization of the in-cloud updraft velocity, which determines the activation of aerosol particles to cloud droplets, has been the subject of model studies and comparison to observations from the EUCAARI-IMPACT campaign (Hoose et al., 2010a). The onset of the WegenerBergeron-Findeisen process in mixed-phase clouds is also related to the distribution of in-cloud updraft velocity. Therefore the updraft velocity parametrization has also an influence on the simulated 1st indirect effect in mixed-phase clouds (Lohmann and Hoose, 2009). Updraft velocity is a critical parameter in cloud formation, because it determines how many CCN are activated. GCMs cannot resolve the updrafts, so they need to be parametrized. In the CAM-Oslo model, a parametrization from Abdul-Razzak and Ghan (2000) is used, calculating the probability density function (PDF) of the vertical velocity in each grid box, and relating the width $\left(\sigma_{\mathrm{w}}\right)$ of the PDF to the eddy exchange coefficient that is given by the turbulence scheme. Comparing the obtained values of $\sigma_{\mathrm{w}}$ from the model with various observations, e.g. EUCAARI-IMPACT data (Cabauw), a rather poor agreement has been found, and in particular an underestimation on cloudy days.

Based on these results, a new parametrization has been derived, in which an additional term, proportional to LWC (liquid water content) is added to the formulation of $\sigma_{\mathrm{w}}$. The physical idea behind this is that clouds not only depend on updrafts for their formation, they also produce turbulence via two mechanisms: cloud top cooling and latent heat release. In fact it has been known for many years that in marine stratocumulus, it is the cloud top cooling that is the main source of turbulence in the boundary layer, and it is precisely that turbulence which transports moisture from the surface to the cloud base, thereby maintaining the cloud.

With the new formulation, the agreement between the model-predicted $\sigma_{\mathrm{w}}$ and the observed $\sigma_{\mathrm{w}}$ is greatly improved. When the new formulation is tested in the CAM-Oslo model, it yields an overall $36 \%$ increase in cloud droplet number, significantly reducing the model negative bias.

\section{Ice nucleation on biological and mineral dust particles}

Global model simulation of bacterial, fungal spore and pollen with the CAM-model showed that simple bioaerosol emission parametrisations can reproduce average measured concentrations. The modelled average bioaerosol contribution to heterogeneous ice nucleation in mixed-phase clouds is very small. If they are present in high enough concentrations (significantly higher than the climatological concentrations simulated in this study), they might trigger glaciation of clouds at warmer temperatures and lower altitudes than in their absence (Hoose et al., 2010b).

Most assessments of the aerosol first indirect effect so far only deal with $\mathrm{CCN}$ influencing cloud droplet formation.
While some climate models calculate ice nucleation from natural and anthropogenic aerosols, so far they have only used quite simple, empirical parametrizations. In order to reduce the uncertainty associated with the aerosol indirect effect, a new parametrization of heterogeneous ice nucleation has been developed, in which the ice nucleation rates and their temperature dependence are derived from classical nucleation theory and laboratory data (Hoose et al., 2010c). The parametrization treats three types of IN: mineral dust, soot and primary biological aerosol particles (PBAP: bacteria, pollen and fungal spores). This is the most detailed parametrization of heterogeneous ice nucleation developed so far in any global climate model.

Multi-year simulations were carried out with the CAMOslo model, using the new parametrization. Comparing simulated IN concentrations to observations using the airborne CFDC instrument shows generally good agreement over the whole temperature range from $0^{\circ}$ to $-40^{\circ}$. It was found that mineral dust accounts globally average of $77 \%$ of the ice crystal nucleation in mixed-phase clouds, followed by with soot at $23 \%$, while the PBAP contribution is much less than $1 \%$. Even when rather extreme assumptions are made on the nucleation ability of PBAP, their contribution remains small. Hence, our results do not support earlier suggestions in the literature of a large contribution from biological particles to ice nucleation (Christner et al., 2008; Prenni et al., 2009). However, we do not rule out a significant role of such particles in certain areas and at certain times.

With the new ice nucleation scheme in place, the simulated aerosol indirect forcing is reduced by about $25 \%$ compared to simulations that do not treat ice nuclei. The reduction is caused by a reduced lifetime effect, as anthropogenic soot stimulates the freezing of supercooled water. Precipitation release is much more efficient when ice crystals are present, and therefore the freezing stimulates precipitation, which is the opposite of the Albrecht effect in warm clouds.

\section{Improvements of boundary layer parametrization}

The ECHAM5 model uses a turbulent kinetic energy (TKE)scheme, which simulates the cloud top fluxes in function of the local turbulence. It reproduces relatively well the clear convective and stratocumulus topped boundary layers in a quite high resolution model (e.g. Duynkerke and Driedonks, 1987). Nevertheless, a new version of the boundary layer including a parametrisation of cloud-top entrainment in the stratocumulus regions has been included in ECHAM5 (ENTR). The standard version (STD) includes turbulent diffusion on non-conserved variables. The highest values of TKE in ENTR are more in the range of measurements (between 0.1 and $0.5 \mathrm{~m} \mathrm{~s}^{-1}$ ) than the huge values in STD. Although using the new scheme the relation between Liquid Water Path and Aerosol Optical Depth becomes closer to the satellite measurements it is still not enough as the observations show a negative slope of all the variables for 
AOD $>0.2$. Nevertheless, the explicit entrainment reduces the sensitivity of LWP to AOD on a global scale as well.

\section{Improved description of stratocumuli thickness}

It has been observed that stratocumuli are too shallow to be well represented in the standard vertical grid of models like ECHAM5. To better simulate these low clouds without increasing the vertical resolution tremendously, two levels are added dynamically wherever a stratocumulus could form. More precisely, the thickness of the stratocumulus is found following the approach presented in Grenier and Bretherton (2001), and a new grid containing 2 more levels based on it is defined. The algorithm which computes the cloud top and the vertical thickness of the stratocumulustopped boundary layer in ECHAM5 and defines the new grid has been implemented. The method allows the existence of stratocumuli in the right place in the GCM with a reasonable pressure for the inversion (cloud top).

\section{Supersaturation simulation to reduce spurious CCN activation}

$\mathrm{CCN}$ activation is among the shortest time scale processes in cloud physics and effective prediction of the number of activated CCN requires time steps that are not feasible in models. Supersaturation prognostic schemes show spurious peaks leading to unrealistic activation. A new scheme has been developed, tested in a parcel model and implemented in 3-D Large Eddy Simulation framework (CNRM), based on advection of supersaturation, even thought supersaturation is not a conservative variable. Combined with the supersaturation prognostic derived from heat and moisture, the scheme allows filtering numerical artifacts and it provides an accurate prediction of $\mathrm{CCN}$ activation. It has been extensively tested in a parcel model against explicit calculation of supersaturation at a $0.01 \mathrm{~s}$ time resolution. Implemented in a 3-D LES framework to simulate cumulus and stratocumulus clouds, it appears very efficient at suppressing spurious $\mathrm{CCN}$ activation at cloud boundaries.

\section{Surface partitioning of surface active compounds}

Simplified descriptions for surface partitioning of surface active compounds in liquid droplets were developed (Prisle et al., 2010; Raatikainen and Laaksonen, 2011). These parametrizations are computationally affordable and can be applied in regional-scale and global-scale models.

\section{Nucleation and aerosol formation rate parametrizations}

Several parametrizations related to modelling atmospheric aerosol formation were derived. We concentrated on developing semi-empirical ones, in which the nucleation rate is assumed to follow a simple power-law dependence on the gaseous sulphuric acid (and organic vapour) concentration
(Riipinen et al., 2007a; Paasonen et al., 2010). Data from 12 European field sites with different types of air ion and cluster spectrometer measurements were used to derive a semi-empirical parameterization for ion-induced nucleation (Nieminen et al., 2011).

Direct application of nucleation rate parameterisations in large-scale models is not possible, or at least not desirable because of the numerical cost. For this reasons, an updated parametrisation that relates the the apparent formation rate of particles at any diameter to the nucleation rate was derived (Lehtinen et al., 2007). This parametrization was developed further to take into account the nuclei self-coagulation (Anttila et al., 2010). All these parametrizations are readily applicable in large-scale atmospheric models.

\section{Modal vs. sectional model intercomparison}

A modal aerosol model was evaluated in the GLOMAP model against a more comprehensive section or "bin" model. GLOMAP-mode simulates the aerosol size distribution using several log-normal modes while GLOMAP-bin uses 20 size sections. GLOMAP was run at $2.8^{\circ}$ resolution for $1 \mathrm{yr}$ using both mode and bin schemes. Particle size distributions have been compared for 12 distinct regions around the world. The modal and bin schemes agree very well at most sizes, although there tends to be some overprediction of particle concentrations in the nucleation mode of the modal model. Aerosol optical depth has also been evaluated against MODIS and AERONET observations. Both models are in close agreement but differ by approximately the same amount from the retrieved size distributions. It was therefore concluded that there are general adjustments to make to the aerosol model, rather than a specific issue with the simpler modal model. Global cloud condensation nuclei have been evaluated against a collection of $\mathrm{CCN}$ measurements compiled from several field campaigns. There is reasonable agreement in the model versus observations (with a lot of scatter). But again the difference between the bin and modal schemes is smaller than the difference between model and the observations. Modal aerosol schemes are a computationally efficient but nonetheless accurate way of simulating the aerosol size distribution, optical properties and $\mathrm{CCN}$ concentrations on a global scale. Thus EUCAARI model comparisons show that the microphysical treatment in state of the art climate models is now sufficiently well developed to be able to capture many of the details of the aerosol properties on a global scale.

\subsubsection{Air quality}

The role of aerosols in European air quality was one of the major foci of EUCAARI. We have improved a regional Chemical Transport Model (PMCAMx) and used it together with the emission inventories developed in the project to 

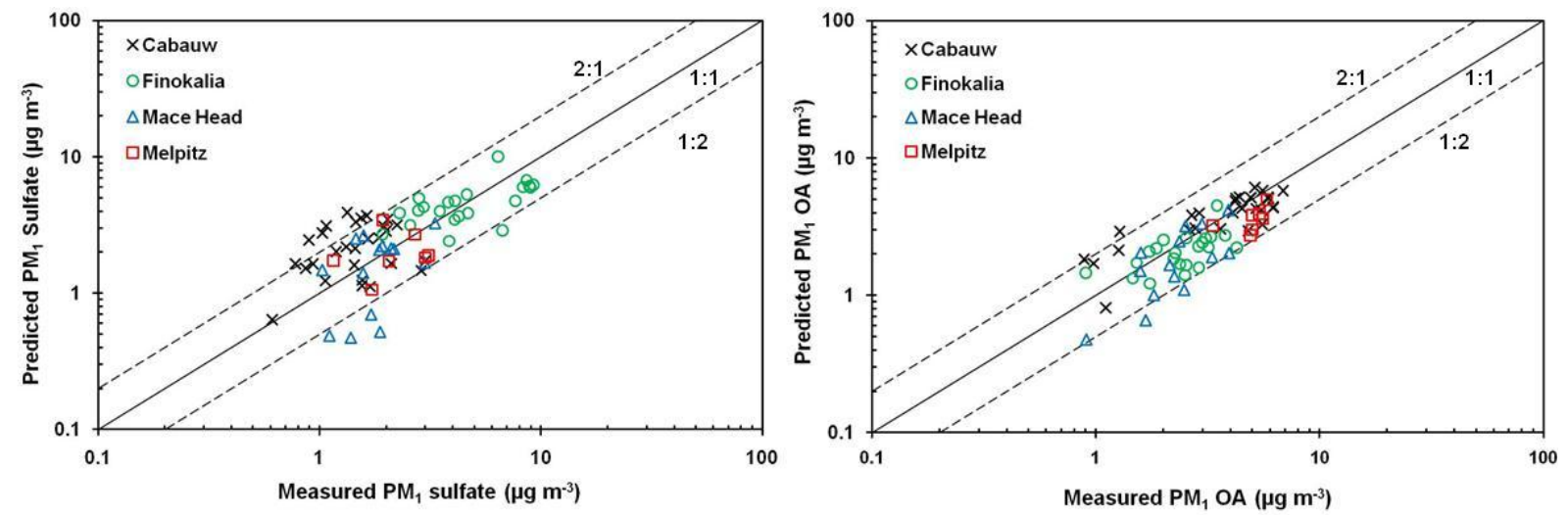

Fig. 17. Comparison of predicted versus observed $\mathrm{PM}_{1}$ sulphate and organic aerosol concentration $\left(\mu \mathrm{g} \mathrm{m}^{-3}\right)$ from 4 measurement stations during the EUCAARI May 2008 campaign. Each point corresponds to a 24-h average value. Also shown the 1:1, 2:1 and 1:2 lines. Observed data represent AMS measurements.

evaluate our understanding of the sources and atmospheric processing of fine PM in Europe. Major findings include:

The carbonaceous aerosol emissions of EUCAARI together with the new organic aerosol module used in PMCAMx based on the volatility basis set approach resulted in very good agreement with measured organic aerosol concentrations on the European continent (Fig. 17). There is evidence that the residential woodburning emissions in at least some regions (e.g. Sweden, East Germany, Switzerland) are significantly underestimated. Also the wintertime emissions of ammonia are probably overestimated by a factor of 3 or so.

The reduction in ammonia emissions is one of the most effective ways to reduce aerosol mass concentrations in Europe. Reduction in $\mathrm{NO}_{x}$ is also effective, but might lead to higher ozone levels. Reduction in $\mathrm{SO}_{2}$ emissions will reduce particulate air pollution especially in the Eastern Mediterranean area. Reduction of organic aerosol concentrations is a lot more challenging and will require reductions of gas and aerosol emissions from transportation and biomass burning.

Besides PMCAMx also EMEP MSC-W chemical transport model was used (see Appendix D).

\section{Evaluation of current understanding of regional fine PM in Europe}

During EUCAARI, the organic and inorganic aerosol modules of PMCAMx were improved (Fountoukis et al., 2011a) and the resulting model (called PMCAMx-2008) was applied for the first time in Europe. The domain consisted of the whole European continent, and extended from the Atlantic Ocean to the Middle East and from the North Pole to North
Africa. The results of the model were compared against measurements during the May 2008 EUCAARI intensive campaign both at ground level and aloft. The comparison of the model predictions with the ground measurements in four measurement stations is encouraging. The model reproduces more than $86 \%$ of the daily averaged data and more than $77 \%$ of the hourly data within a factor of 2 , for both $\mathrm{PM}_{1}$ OA and sulphate respectively (Fig. 17).

The model tends to predict relatively flat diurnal profiles for $\mathrm{PM}_{1} \mathrm{OA}$ in many areas, both rural and often urban, in agreement with the available measurements. The model performance against the high time resolution airborne measurements at multiple altitudes and locations is as good as its performance against the ground level hourly measurements (Fig. 18). There is no evidence of missing sources of OA aloft over Europe. The major sources of OA during the summer are predicted to be photo-oxidation of biogenic VOCs and anthropogenic Intermediate Volatility Compounds (IVOCs) and evaporated primary organic aerosols.

The highest predicted concentrations for fine sulphate are seen over the Mediterranean region while organic matter is predicted to be the dominant $\mathrm{PM}_{1}$ species in central and northern Europe (Fig. 19). The model predicts low levels of fresh POA and a ubiquity of oxygenated species in organic aerosol, which is predicted to be predominantly composed of SOA of biogenic origin.

PMCAMx was also evaluated against the EUCAARI measurements at the ground level during the winter intensive period of February/March 2009. Measurements from the field stations in Barcelona, Cabauw, Finokalia, Helsinki, Hyytiälä, Mace Head, Melpitz, Payerne, Puy de Dome and Vavihill. While the performance of the model for sulfate and organic aerosol in most areas was quite good, ammonium nitrate levels were overpredicted. Sensitivity analysis indicated that this was probably due to an overestimation of the wintertime ammonia emissions. A uniform reduction of these emissions 

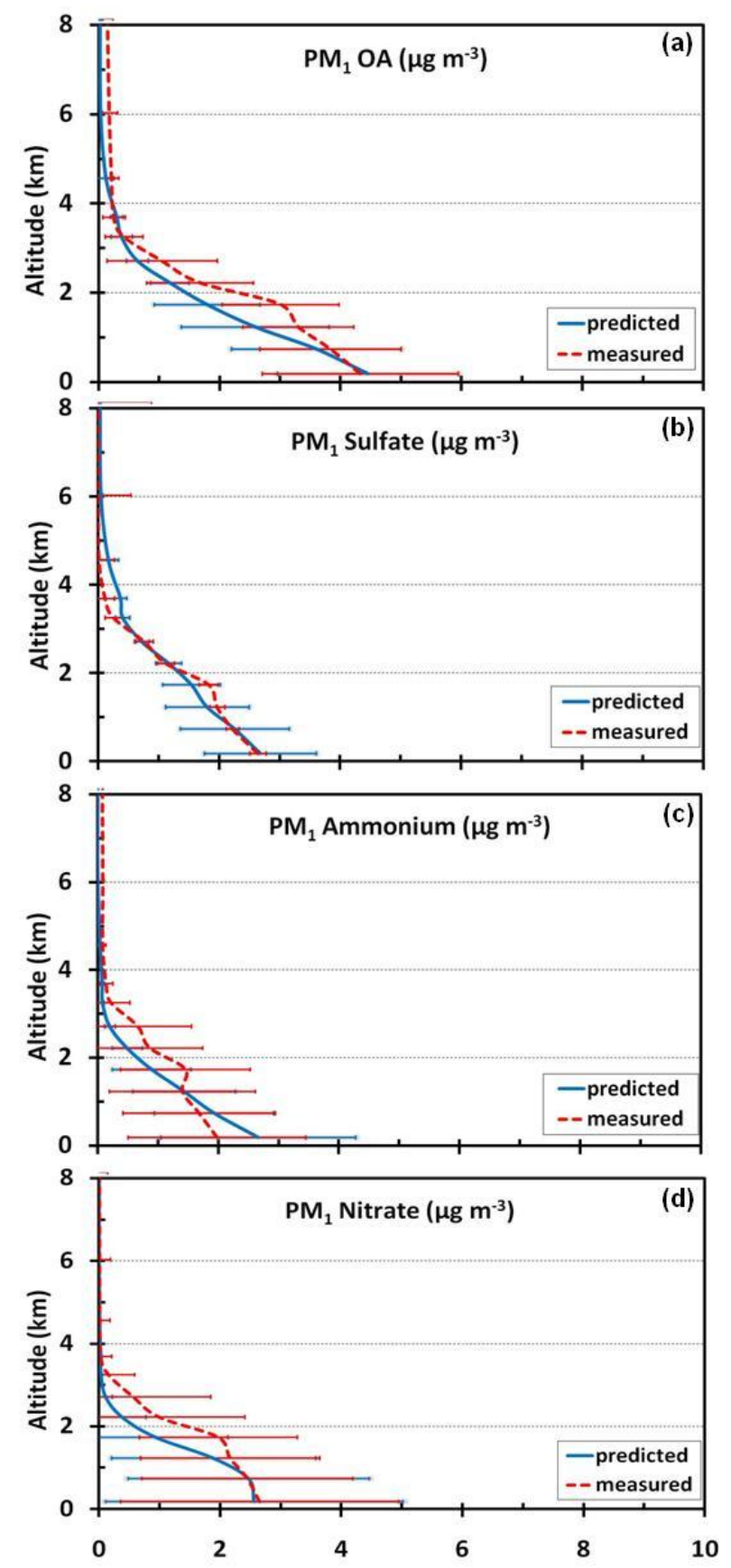

Fig. 18. Comparison of predicted (PMCAMx) vs. observed (AMS) vertical profiles of aerosol chemical composition averaged over the entire EUCAARI-LONGREX campaign for $\mathrm{PM}_{1}$ (a) organics, (b) sulfate, (c) ammonium and (d) nitrate. The horizontal bars indicate one standard deviation for each $500 \mathrm{~m}$ altitude bin mean value.

resulted in significant improvement of the performance of the model. A second problem was the serious undeprediction of organic aerosol levels in Melpitz, Payerne and Vavihill suggesting an underestimation of the residential wood burning emissions in these areas.

\section{Sensitivity of fine PM to emissions}

We performed a series of emissions sensitivity runs to quantify the responses of the concentrations of fine PM to the changes of emissions of sulphur dioxide, oxides of nitrogen, anthropogenic VOCs, and ammonia. In these tests we examined the effects of uniform reductions of the emissions of $\mathrm{NH}_{3}, \mathrm{NO}_{\mathrm{x}}, \mathrm{POA}$, anthropogenic VOCs and $\mathrm{SO}_{2}$ by $50 \%$. The differences in composition and concentration of the fine PM in Europe result in different spatial reductions of the fine PM levels. Reductions in ammonia emissions are one of the most promising strategies for the areas with the highest PM levels during the late spring period investigated. For example a $50 \%$ reduction in ammonia emissions is predicted to result in a $16 \%$ reduction of the $\mathrm{PM}_{2.5}$ levels in downtown London during that month (Table 2). Reductions in $\mathrm{NO}_{\mathrm{x}}$ emissions would also result in significant reductions in $\mathrm{PM}_{2.5}$ levels; however they will be accompanied by increases in ozone levels in these areas according to the model predictions. Reductions in $\mathrm{SO}_{2}$ emissions will be helpful across Europe and will represent a significant reduction of the fine PM especially in the Eastern Mediterranean.

\subsubsection{Aerosols and climate}

The present-day direct and first indirect radiative forcings by atmospheric aerosols have been updated using a combination of model, satellite and other ancillary data. In this chapter, unless specifically mentioned otherwise, we mean by aerosol "indirect effect" the aerosol first indirect effect (or cloudalbedo effect).

EUCAARI model results and sensitivity studies, done within EUCAARI with an offline radiative transfer model, suggest that a central estimate for the total direct aerosol forcing is not more negative than $-0.45 \mathrm{~W} \mathrm{~m}^{-2}$. This is substantially less than the upper limit estimate of $-0.9 \mathrm{~W} \mathrm{~m}^{2}$ by the IPCC AR4. The best estimate for the 1st indirect forcing is $-0.7 \pm 0.5 \mathrm{~W} \mathrm{~m}^{2}$, which can be compared the the first indirect forcing estimate of -0.3 to $-1.8 \mathrm{~W} \mathrm{~m}^{2}$ by the IPCC AR4.

Different aerosol and aerosol precursor emission scenarios reflecting possible future control strategies for air pollution have been simulated with a global climate atmospheric chemistry model (ECHAM5-HAM). When stringent air pollution control measures are implemented worldwide, the present-day negative total aerosol top-of-the-atmosphere aerosol radiative forcing will be reduced by $50 \%$ by 2030 . The net effect of increasing GHG concentrations and lower aerosol concentrations is a global annual mean equilibrium temperature increase is predicted to be $2.2 \mathrm{~K}$, as compared with the temperature increase of $1.2 \mathrm{~K}$ due to increasing GHG concentrations alone. As aerosols strongly impact surface forcings, the consequences for precipitation increases associated with global warming are even stronger. These 

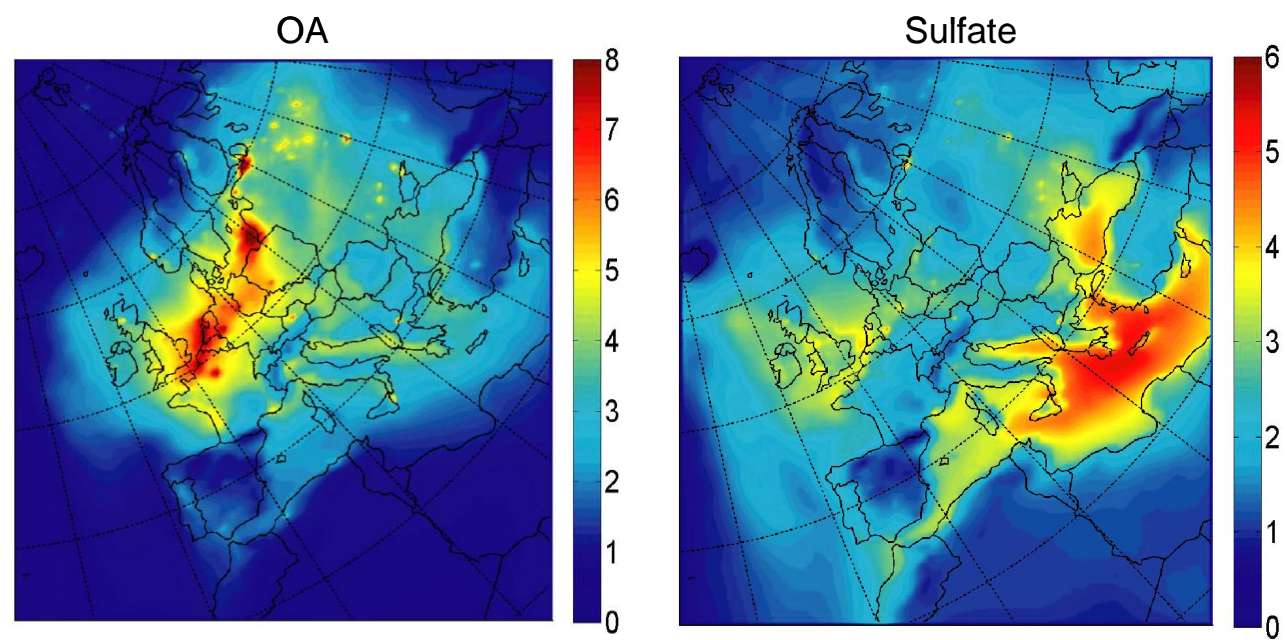

Fig. 19. Ground-level concentration predictions averaged over the entire simulation period (1-29 May 2008) for $\mathrm{PM}_{2.5}$ total organic aerosol and sulphate (in $\mu \mathrm{g} \mathrm{m}^{-3}$ ). Different scales are used.

results highlight the potential impact of future air pollution mitigation strategies on climate.

The performance of the improved EUCAARI global atmospheric chemistry models has been evaluated against preexisting and also the new EUCAARI observational datasets. The simulation of absorbing aerosols above cloud has been identified as a major cause of the discrepancies among models. Simulated total optical depth shows considerable low bias especially in South-East Asia and the biomass burning dominated regions in South America and South Africa. The model bias in South-East Asia has decreased with the new IPCC emissions used in the EUCAARI models, but considerable discrepancy still exists for South Africa and South America. A zonally-averaged comparison to AERONET derived column absorption exhibits considerable bias in several models. Mass absorption coefficients, dust contributions to measured total absorption, sampling bias of AERONET and emission uncertainties were identified as major reasons for the documented bias.

\section{Estimated aerosol direct effect on climate}

The fourth assessment report of the Intergovernmental Panel on Climate Change struggled in assessing the aerosol direct effect on climate. The vast majority of the results suggests now that aerosol on a global annual average exerts a cooling on the Earth-Atmosphere-System (see discussion in Haywood and Schulz, 2007). However, there was a discrepancy between observational-based estimates at or near $-1.0 \mathrm{~W} \mathrm{~m}^{2}$ and model-based estimates near $-0.4 \mathrm{~W} \mathrm{~m}^{2}$. Since then several independent studies of EUCAARI partners have explored details responsible for this discrepancy. These studies demonstrate that more negative estimates of observation-based approaches are most likely incorrect. These observation-based approaches involve many assump- tions and approximations, most of which introduce a negative bias:

- aerosol optical depth (AOD) of most satellites retrievals may be biased high;

- the anthropogenic fraction is uncertain since it is only part of the fine mode attributable aerosol optical depth;

- the switch from clear- to all-sky is not a linear function of the cloud-fraction (as absorbing aerosols above clouds can exert a warming impact on climate) (Schulz et al., 2006);

- areas over desert (regions of potential warming) are not well characterized by satellite based aerosol observations;

- albedo uncertainties are still important, e.g. the MODIS surface albedo product does not consider snow-cover and the range used in models varies largely (Stier et al., 2007).

Bellouin et al. (2008) demonstrated that just by using an improved year 2002 AOD data-set of MODIS (with less snow contamination at high latitudes) and improved assumptions for the fine-mode fraction, the best estimate is reduced from near approximately $-1.0 \mathrm{~W} \mathrm{~m}^{2}$ to near $-0.65 \mathrm{~W} \mathrm{~m}^{2}$. This estimate still may be biased high, due to choices for surface albedo, AOD, clear-sky to all-sky ratio and assumptions on missing AOD information over desert regions. In fact, sensitivity studies performed by the EUCAARI partners demonstrate that direct cooling in access of $-0.45 \mathrm{~W} \mathrm{~m}^{2}$ is highly unlikely. The use of quasi-global sun-/sky photometer data of AERONET, which define not only AOD but also simultaneous information on aerosol absorption and size (without making a-priori assumptions), suggests a $-0.2 \mathrm{~W} \mathrm{~m}^{2}$ aerosol 
direct cooling (Kinne, 2011). This value is identical to the average from AEROCOM models (Schulz et al., 2006), in which however contributions from nitrate and anthropogenic dust are missing. Altogether, this may suggest that there is less model-data discrepancy.

\section{Estimated aerosol indirect effect on climate}

Although many different types of interactions between aerosols and clouds have been suggested, IPCC AR4 only considered the cloud albedo effect of warm clouds, and for that effect alone a wide uncertainty range of -0.3 to $-1.8 \mathrm{~W} \mathrm{~m}^{-2}$ was given, cancelling anywhere from $12 \%$ to $69 \%$ of the radiative forcing from well-mixed greenhouse gases. EUCAARI has contributed a better understanding and a narrowing of this uncertainty range. For instance, we investigated the implications for the aerosol first indirect effect of using lower bounds for cloud droplet number concentration of aerosol number concentration (CDNC), which are being used in many climate models. We found (Hoose et al., 2009) that the use of such lower bounds on CDNC leads to a suppression of the simulated first indirect effect from $-1.9 \mathrm{~W} \mathrm{~m}^{2}$ to $-0.6 \mathrm{~W} \mathrm{~m}^{2}$, depending on what threshold is chosen. The suppression is strongest over oceans where CDNC is low. This means that a rather arbitrary and sometimes poorly justified choice of a threshold value has a huge impact on the simulated aerosol first indirect effect.

In Iversen et al. (2010) this was further elaborated by estimating the impact on the equilibrium climate response of direct and the warm-cloud first indirect aerosol effects by adding a "background" level of cloud droplets. The added background cloud droplet number concentration (CDNC) were $3 \mathrm{~cm}^{-3}$ over oceans and the Antarctica and $17 \mathrm{~cm}^{-3}$ over continents. The effect on the estimated global equilibrium 2-m temperature response to anthropogenic aerosol forcing was a reduction from -2.09 to $-1.50^{\circ} \mathrm{C}$, while the global equilibrium precipitation response was reduced from $-5.7 \%$ to $-4.5 \%$.

We have also investigated the influence on the simulated indirect effect of a prognostic treatment of ice crystal concentrations (Storelvmo et al., 2008) and ice nucleation by natural and anthropogenic particles (soot). Hoose et al. (2010c) found a reduction in the simulated aerosol indirect effect by about 10 to $26 \%$. The reduction is mainly caused by a reduced lifetime effect due to anthropogenic soot (glaciation effect). This is because soot particles stimulate the freezing of supercooled water, thereby stimulating the release of precipitation from the clouds. The net effect is a reduction in cloud lifetime.

Several EUCAARI models have contributed to the study by Quaas et al. (2009) where a model based range for the first indirect effect was established, considering constraints from satellite observations of cloud droplet number concentration and liquid water path. An estimate obtained by scaling simulated clear and cloudy-sky forcings with estimates of anthropogenic and satellite-retrieved $N_{\mathrm{d}}$-AOD regression slopes, respectively, yields a global cloudy-sky (aerosol indirect effect) estimate of $-0.7 \pm 0.5 \mathrm{~W} \mathrm{~m}^{-2}$.

\section{Sensitivity of climate models to aerosol nucleation}

Studies (e.g. Spracklen et al., 2006; Merikanto et al., 2009; Kazil et al., 2010) indicate that nucleation of new particles from the gas phase is an important source of cloud condensation nuclei. A realistic simulation of new particle formation in the planetary boundary layer has been problematic in the past. Recently, it has been found that observed nucleation can be explained by sulphuric acid or by both sulphuric acid plus organic species (Sipilä et al., 2010; Metzger et al., 2010; Paasonen et al., 2010). Earlier, models were based upon a range of other assumptions, now known to be incorrect.

ECHAM5-HAM was used with varying emission environments of years 1750, 2000 and 2100 to assess the effect of nucleation on indirect aerosol forcing (Makkonen et al., 2011). Forcing was calculated as radiative flux perturbation. According to the results, the effect of nucleation is clearly visible in present-day climate: including nucleation in the model increases the present-day indirect forcing from $-0.27 \mathrm{~W} \mathrm{~m}^{2}$ to $-1.16 \mathrm{~W} \mathrm{~m}^{2}$. In simulations without nucleation, aerosol number concentrations are a result of primary emissions only. A strong decrease is seen in the indirect aerosol forcing when moving to year 2100, relating to a decrease in both anthropogenic $\mathrm{SO}_{2}$ emissions and primary emissions. Two additional experiments were performed to see the effect of potentially rising future emissions of biogenic VOCs and oceanic DMS. Even with the high-level of elevation in emissions ( $+50 \%$ BVOCs or $+10 \%$ DMS), the natural emissions cannot counteract the cooling from the strong decrease in anthropogenic emissions.

\section{Air quality and climate}

Specific economic sectors and/or source regions emit a wide variety of climate relevant gases and particles, influencing climate and air quality. This includes emissions of greenhouse gases, chemical species that affect the oxidation capacity of the atmosphere and the concentrations of ozone and methane, and aerosol particles or aerosol precursors. Most of the studies so far assessed the climate impact of specific chemical components (e.g. carbon dioxide, sulphate particles etc.). However, the different climate effects add non-linearly and thus interactions between warming and the water and aerosol cycles have to be taken into account. For the purpose of climate protection and improvement of air quality, we applied a more integrative approach assessing the total climate effect of gaseous and particulate emissions from a specific economic sector. Additionally, we have to take into account that the implementation of air quality measures affects the climate system as well. 
Table 3. Predicted $\mathrm{PM}_{2.5}$ Concentrations Reduction in Selected Cities for May 2008.

\begin{tabular}{llllll}
\hline City & \multicolumn{4}{c}{ Reduction in $\mathrm{PM}_{2.5}\left(\mu \mathrm{g} \mathrm{m}^{-3}\right)$ for a $50 \%$ Emissions Reduction } \\
\hline & $\mathrm{SO}_{2}$ & $\mathrm{NO}_{\mathrm{x}}$ & VOCs & $\mathrm{POA}$ & $\mathrm{NH}_{3}$ \\
London & $1.1(4.2 \%)$ & $2.9(11 \%)$ & $0.8(3.1 \%)$ & $0.7(2.6 \%)$ & $4.0(16 \%)$ \\
Paris & $1.3(6.1 \%)$ & $1.4(6.7 \%)$ & $0.2(1 \%)$ & $1.9(8.9 \%)$ & $0.8(4.2 \%)$ \\
Athens & $1.0(10 \%)$ & $0.4(3.5 \%)$ & $0.1(0.8 \%)$ & $0.2(1.7 \%)$ & $0.6(6.1 \%)$ \\
Marseille & $0.7(3.7 \%)$ & $1.1(6 \%)$ & $0.3(1.3 \%)$ & $0.5(2.5 \%)$ & $2.3(12 \%)$ \\
Ruhr & $1.1(10 \%)$ & $1.7(15 \%)$ & $0.1(1 \%)$ & $0.2(1.8 \%)$ & $0.7(6.4 \%)$ \\
\hline
\end{tabular}

Different aerosol and aerosol precursor emission scenarios reflecting possible future control strategies for air pollution have been applied in the ECHAM5-HAM model coupled to a mixed-layer ocean model to simulate the resulting effects on the Earth's radiation budget and climate. Two opposing future mitigation strategies for the year 2030 have been used: one in which emission reduction legislation decided in countries throughout the world are effectively implemented (current legislation; CLE 2030) and one in which all technical options for emission reductions are being implemented independent of their cost (maximum feasible reduction, MFR). The importance of the combined industrial and power generation sector on the one hand have been assessed and domestic and transport related emission on the other hand. In addition, regional experiments have been performed to evaluate the influence aerosol emissions from Europe and Asia have on other world regions. A number of sensitivity studies address the non-linear chemical and microphysical couplings in the context of these scenarios (Kloster et al., 2008, 2009).

CAM-Oslo coupled to a slab ocean model was used to estimate interactions between GHG-driven and anthropogenic aerosol-driven global changes under various assumptions (Iversen et al., 2010), Anthropogenic aerosols largely counteract the effects of increased $\mathrm{CO}_{2}$, even though there are significant exceptions for precipitation in the subtropics and in the southern extra-tropics. Increased $\mathrm{CO}_{2}$ shortens the atmospheric residence time of aerosols and aerosol precursors due to increased precipitation amounts in major anthropogenic air pollution emission regions. This reduction is estimated to be larger for present-day ( 2000) aerosol emissions than it would have been if aerosols had been maintained at preindustrial levels $(\sim 1850)$. The climate effects of aerosols are thus reduced by the $\mathrm{CO}_{2}$-increase. Since the two effects largely counteracts each other, this feedback may potentially cause a non-linear reinforcement of the $\mathrm{CO}_{2}$ driven global changes when reduction protocols for aerosols and precursors are implemented.

When more stringent air pollution abatements are implemented worldwide, utilizing the presently available most advanced control technologies, the present-day negative total aerosol top-of-the-atmosphere radiative forcing will be strongly reduced (by $50 \%$ ) by 2030 (Iversen et al., 2010). As a consequence, climate change thereafter will be controlled to a larger extent by changes in greenhouse gas emissions. The temperature response of increasing GHG concentrations and reduced aerosol emissions leads to a global annual mean equilibrium temperature response of $2.18 \mathrm{~K}$. When aerosols will be only abated in the Industry and Power Plant sector, whereas the Domestic and Transport sectors stay with currently enforced regulations, the temperature response is $1.89 \mathrm{~K}$. In contrast, a maximum feasible abatement only applied in the Domestic and Transport sector, leads to a smaller temperature response of $1.39 \mathrm{~K}$. Increasing GHG concentrations alone lead to a temperature response of $1.20 \mathrm{~K}$. Our study thus highlights the huge potential impact of future air pollution mitigation strategies on climate and supports the need for urgent GHG emission reductions. As aerosols strongly impact surface forcings and have thus a high hydrological sensitivity, the consequences for precipitation increases associated with global warming are even stronger. GHG and aerosol forcings are not independent as they both affect and are influenced by changes in the hydrological cycle.

\section{Model intercomparisons}

The aerosol direct radiative effect has been shown to be associated with considerable model diversity (Schulz et al., 2006) and thus uncertainty in the 4thAR IPCC total radiative forcing uncertainty for present day. Uncertainty in the computation of the direct effect is due to several factors involved, among which dominate the vertical distribution of the aerosol (Schwarz et al., 2010), the relative position and interaction of clouds and aerosols (Quaas et al., 2009), the amount of aerosol absorption (Koch et al., 2009), the anthropogenic aerosol load, humidity growth and possibly also details of the radiative transfer calculation itself. It is thus of interest to compare new EUCAARI model simulations to earlier pre-EUCAARI results. Such comparison is possible for the models (ECHAM, CAM-Oslo and INCA) which have been further developed and changed considerably from the earlier AEROCOM phase I. The GLOMAP and HadGem models did not participate in earlier AEROCOM phase I experiments. All GCM models have developed new coupled aerosol climate model versions with changed resolutions and atmospheric host models. This has involved changes to the 
model environment beyond the aerosol model structure. Differences in performances are then difficult to track down to individual aerosol process formulation, because several changes were in effect at the same time of the model structure. Model improvement with respect to the selected observational datasets of relevance is fair for several parameters and models.

The new observational datasets that became available in the EUCAARI framework and from other sources make several characteristics, successes and biases of the EUCAARI global aerosol model exercise apparent, with direct consequences for an improved direct aerosol forcing estimate. The error in the vertical distribution of the aerosol (as evaluated against CALIOP vertical extinction profiles) above the industrial regions of the Northern Hemisphere is probably not so much an error in the form of the profile, but rather an error in absolute aerosol loads and column optical depth. The average European vertical profile for 2008 (annual and May) and the simulated contributions from aerosol species as well as humidity growth serves as an example here. The role of absorbing aerosols above cloud is identified as one factor of important differences between models and sensitivity simulations are performed in the INCA model to identify the contribution from just that fraction of the aerosol to total aerosol forcing.

Total optical depth is a crucial parameter for the direct radiative effect of the aerosol. Simulated total optical depth shows considerable low bias especially in South-East Asia and the biomass burning dominated regions in South America and South Africa. The model bias in South-East Asia has decreased with the new IPCC emissions used in the EUCAARI models, but considerable discrepancy still exists for South Africa and South America. Surface observations from EUSAAR/EUCAARI on dry aerosol extinction and absorption coefficients confirm such findings on independent grounds.

Aerosol absorption due to black carbon and brown carbon is a major uncertainty for the direct aerosol forcing. A zonally averaged comparison to AERONET derived column absorption exhibits considerable bias in several models. The underestimate goes only partially along with simultaneous underestimates in total aerosol optical depth, suggesting that especially the black carbon fraction is underestimated in several model simulations. Mass absorption coefficients, dust contributions to measured total absorption, sampling bias of AERONET and emission uncertainties are identified as major reasons for the documented bias in modelling.

\subsection{Feedback processes and interactions}

A number of anthropogenic perturbations are being applied to the climate system since pre-industrial times through changes in atmospheric composition, land use, and other changes. These perturbations are known as radiative forcings. The climate system responds to these perturbations through a series of changes called feedbacks in order to return to some equilibrium. A lot of research has focused on understanding and quantifying the feedbacks of the physical climate system (Arneth et al., 2010); however the development of Earth System models has revealed the importance of biogeochemical feedbacks. The EUCAARI project has focused on climate feedbacks involving natural and anthropogenic aerosols.

An important task of EUCAARI was to quantify the uncertainties in the various interactions between aerosols and the Earth system as one important aspect of the overall biogeochemical feedbacks. EUCAARI reviewed and assessed the role of aerosols in climate and Earth system feedbacks (Carslaw et al., 2010) and quantified the magnitude of feedback loops involving natural and anthropogenic aerosols. Available observations and model studies suggest that the regional radiative perturbations are potentially several Watts per square metre due to changes in natural aerosol emissions in a future climate. The review produced new estimates of the direct radiative effect due to aerosol feedbacks related to dust, dimethyl-sulphide (DMS) from marine biota, wildfires and terrestrial biogenic secondary organic aerosol. Taking into account only the direct radiative effect of changes in the atmospheric burden of natural aerosols, and neglecting potentially large effects on other parts of the Earth system, a global mean radiative perturbation approaching $1 \mathrm{~W} \mathrm{~m}^{-2}$ is possible by the end of the century. The level of scientific understanding of the climate drivers, interactions and impacts was assessed as very low.

EUCAARI has pushed our understanding a bit further concerning biogenic SOA, marine DMS and dust, and has also studied the effect of climate change on sea spray particle emissions and their radiative effect. This was done through the use of three Earth System models including aerosols and their couplings to other components of the Earth System.

\subsubsection{Climate Change impact on global aerosol cycling}

Climate change experiments have been performed to analyse the change in atmospheric cycling of both natural and anthropogenic aerosols through changes in temperature, humidity, precipitation, convection and oxidant concentrations (HadGEM2-ES, Rae et al., 2007). We found that, when oxidants alone are changed, the global total sulphate burden decreases by approximately $3 \%$, due mainly to a reduction in the $\mathrm{OH}$ burden. When climate alone is changed, our results show that the global total sulphate burden increases by approximately $9 \%$; we conclude that this is probably attributable to reduced precipitation in regions of high sulphate abundance. When both oxidants and climate are changed simultaneously, we find that the effects of the two changes combine approximately linearly.

The HadGEM2-ES model includes interactive sources and sinks of aerosols, coupled to the tropospheric chemistry scheme through interactive oxidants, and coupled to the 
marine carbon cycle through emissions of DMS and deposition of dust. Nitrate aerosols have also been added to the default HadGEM2-ES climate model as it is an important aerosol species in some regions. Interactive biogenic emissions and a simple secondary organic aerosol scheme have been added in a research version of HadGEM2-ES.

The MPI Hamburg coupled climate model version used in EUCAARI is based on the atmospheric model ECHAM6 middle atmosphere version with the extension to gasphase chemistry (MOZART3) and aerosol physics (HAM2) merged with the most recent carbon cycle model system (MPI-OM, HAMMOC, JS-BACH). The aerosol module HAM (Stier et al., 2005) has been extended by a scheme for the treatment of SOA (O'Donnell, 2009). The time integration of the nucleation and condensation schemes has been improved and different nucleation schemes have been implemented and tested (Kazil et al., 2008). HAM2 includes additionally a new impaction and below cloud scavenging scheme. The new two-moment cloud physics (Lohmann et al., 2007) enables a more physically based treatment of aerosol-cloud interactions. The new model version includes also source models for marine sources of DMS and biogenic sources of VOC.

The IPSL model includes the LMDZ atmospheric model (Hourdin et al., 2006) and several ESM components. Two model versions were used to study the aerosol-climate feedbacks: the standard IPSL coupled model, which uses precalculated aerosol mass fields and the interactive IPSL-AER aerosol-climate model, which is using offline pre-calculated oxidant fields. The latter includes interactive sources and sinks of dust and sea salt aerosols, coupled to biogeochemistry through emissions of DMS. Dust deposition of iron is read in into the NEMO-PISCES module as forcing. Biogenic VOC emissions are also pre-calculated for present day conditions from the land-biosphere model ORCHIDEE. Several control keys have been implemented into the model to investigate the trajectory of the climate in the model with/without the radiative aerosol effects, with/without nudging the synoptic meteorology, with/without prescribed aerosol optical properties. The comparisons between the different model versions have shown that the radiative forcing due to aerosols differs within $30 \%$ and makes the models comparable, despite differences in complexity.

The global CAM-Oslo model version used in EUCAARI includes an aerosol life-cycling scheme for sea-salt, dust, sulphate, black and organic carbon. The sulphur chemistry relies on prescribed oxidants. Through tabulations that takes into account sulphate-nucleation, condensation, coagulation and processes in liquid cloud droplets, the aerosol optical and water-activation properties are implicitly described with 44 size-bins (Seland et al., 2008), and aerosol interactions with clear-air radiation and warm cloud microphysics are parametrized. The model was coupled to a slab ocean for estimations of equilibrium climate sensitivity (Kirkevåg et al., 2008) and was used for EUCAARI for estimating inter- actions between GHG-driven changes and changes caused by anthropogenic aerosols (Iversen et al., 2010). The sensitivity of the equilibrium climate sensitivity and with respect to selected uncertain aerosol assumptions was also estimated.

\subsubsection{Climate feedbacks involving natural secondary organic aerosols}

The global aerosol-climate model ECHAM5-HAM has been extended with a suite of parametrizations that describe the complete life cycle of secondary organic aerosols, starting from emission of the precursor gases, proceeding through the chemical formation of condensible species, the partitioning of those species between the aerosol and gas phases, the microphysics of the aerosol phase and finally to the sink processes that remove both gases and aerosols from the atmosphere (O'Donnell et al., 2011). The model treats primary and secondary, organic and inorganic aerosols, prognostically resolves their composition, size distribution and mixing state, and computes their impact on both the shortwave and longwave radiation budget. The model is coupled to the ECHAM5-HAM double-moment cloud scheme that calculates cloud droplet number concentration and mass concentration as prognostic variables as functions of (inter alia) aerosol properties. The model thus contains the elements necessary for estimation of the effects of SOA on radiation and on liquid water clouds. To the second end, a global model of vegetation emissions of precursor gases has been implemented and linked to the aforementioned SOA extension to the ECHAM5-HAM model. As an alternative, the option to use externally-generated sources of biogenic emission data has been added, making it possible to use the output of, for example, a dynamic vegetation model as input to the SOA module. With these tools, biosphere-atmosphere interactions via biogenic emissions have been investigated in a number of simulations, both in the present atmospheric state, and in hypothetical atmospheric states, that are conceived to examine interactions between anthropogenic activities, biogenic emissions and climate.

Different biogenic emission models were employed, one an empirically-based model lacking any $\mathrm{CO}_{2}$ response, the other a dynamic vegetation model with leaf process-based calculation of emissions includes $\mathrm{CO}_{2}$ concentration in its calculation of biogenic emissions. Both models were used to drive the SOA model in two different climate states, one present day, and one warmer climate state, each climate state being constrained on the large scale by fixed sea surface temperatures. The warmer climate state used SRES scenario A2 $\mathrm{CO}_{2}$ levels, and sea surface temperatures previously calculated for that scenario by the coupled ECHAM5/MPI-OM atmosphere-ocean model in the context of IPCC AR4 scenario runs. When driven with the empirically based emission model, the SOA model, in common with published studies, predicts a large increase in biogenic SOA in the warmer 
climate state (O'Donnell, 2009), however this requires further studies.

\subsubsection{Climate feedbacks involving DMS and sulphate production}

HadGEM2-ES was used to study a feedback that links climate-driven changes in terrestrial dust production, iron stimulated (or limited) marine-biological growth changes, oceanic DMS production, and climate change. As observed in the contemporary ocean, HadGEM2-ES simulates iron limitation of phytoplankton growth in the Pacific Ocean. Coupling between the deposition of dust from the atmosphere and oceanic iron concentrations within HadGEM2$\mathrm{ES}$, allows modification of iron limitation in response to terrestrial land-use change or drying events, increasing wind intensity, or changes in wind direction. Atmospheric $\mathrm{CO}_{2}$ concentrations were increased by $1 \%$ each year, following the IPCC CMIP5 experimental protocol. This drives in increase in dust production, and subsequently iron deposition in the North Pacific. The increase in dust deposition progressively alleviates surface ocean iron limitation throughout the experiment. Increased photic zone iron concentration stimulates two changes; firstly, overall phytoplankton production is enhanced, partially offsetting the background decline in primary production occurring due to increased surface water stratification limiting the upward movement of macro-nutrients (in this case nitrogen), secondly, the higher affinity for iron demonstrated by the diatom phytoplankton group relative to the non-diatom group initiates a population shift towards diatoms. The ecosystem shift will result in a relative increase in carbon drawdown (due to the faster sinking rate of the larger diatom functional type), but also since the model's DMS scheme allows DMS production by only the non-diatom phytoplankton type (Halloran et al., 2010), a relative increase in DMS emissions. Although from a global temperature standpoint this feedback is likely to be of minor importance, since the land-based warming which initiates the observed chain of events is spatially separated from the DMS-driven surface ocean (relative) cooling, it can be hypothesised that this feedback will act to intensify monsoon processes in landmasses neighbouring iron-limited ocean basins.

We have also compared some of the results with earlier results from the ECHAM5 model. DMS emissions increase in UM, but decrease in ECHAM, although, the effect on sulphate aerosol is negligible compared with anthropogenic changes. Such opposite responses were also reported in the Carslaw et al. (2010) review, so it is important to understand why two models can differ so fundamentally. Differences between models are large, often exceeding the differences between historical and future simulation for one model. Surface temperatures are similar in both models, but the pattern of warming in ECHAM is more inhomogeneous than in UM, with more warming in the Northern Hemisphere and less in the Southern. $10 \mathrm{~m}$ windspeeds, which drive DMS sea-toair flux, are broadly similar in both models, but are higher in ECHAM in the Southern Ocean. Changes - both positive and negative - are larger in ECHAM than the UM. Mixed layer depth (MLD) is much greater in ECHAM than the UM in the Southern Ocean and North Atlantic. Whilst the UM MLD is almost unchanged over time, the ECHAM MLD is significantly reduced, particularly in those areas where it was highest, though it remains greater them UM MLD in those regions. Ocean DMS concentrations are higher in the UM than ECHAM: $25 \%$ in $1860-1889$ and $50 \%$ in 2060 2089 in the global mean. The change is caused mainly by a drop in ECHAM concentrations particularly at high latitudes and near the equator, while UM global mean values increase very slightly, with some increases at high latitudes, but with some decreases in equatorial regions. In both cases patterns of emission change follow those of DMS ocean concentration change. $\mathrm{SO}_{2}$ and sulphate loads are different in the two models, but in each case are dominated by anthropogenic emissions. The pattern of sulphate loading shows negligible contributions from DMS. In conclusion, there are different mechanisms in action in the two models and the changes in DMS are too small to induce a significant feedback in present-day conditions.

\subsubsection{Climate feedbacks involving natural dust and sea-salt production}

Jones et al. (2007) investigated the change in the burden of the natural primary aerosols (sea-salt and mineral dust) in climate change experiments. These changes are purely in response to the anthropogenic aerosol/ $\mathrm{CO}_{2}$ changes, as no alterations to the emission schemes for natural aerosols were made in these experiments (vegetation cover was also kept constant). The changes at low latitudes are dominated by mineral dust, while those at high latitudes are due to seasalt. The changes in dust burden show complex patterns of increases and decreases, with some areas of increase immediately adjacent to areas of decrease. Such complex distributions of changes are to be expected given the highly variable nature of dust emission (Woodward, 2001): whereas one might explain the changes in the dust plume over the Arabian Sea in terms of the change in wind speed over the horn of Africa, the same explanation does not hold for the plume extending over the Atlantic. These results indicate that changes in dust production in this major source region are in general more strongly affected by changes in soil moisture content than in wind speed in this model. Further investigations using HadGEM2-ES showed that the $\mathrm{CO}_{2}$ fertilisation contributes to change soil moisture in semi-arid regions, but not in arid and hyper-arid regions, through an increase in the shrub cover. This results in a decrease in dust emissions over these regions.

Turning to the changes in sea-salt, these appear more straightforwardly related to changes in sea-ice fraction and 
$10 \mathrm{~m}$ wind speed, which govern the area available for sea-salt production and the amount of sea-salt produced respectively. These changes in sea-ice and the corresponding decreases in wind speed (possibly related to the increased roughness length over sea-ice) lead to a reduction in sea-salt around the sea-ice edges in these experiments. The Carslaw et al. (2010) review highlighted recent work of the Leeds group showing that decadal trends in wind speed in parts of the Southern Hemipshere may have led to more than $20 \%$ changes in CCN between the 1980s and 2000. These changes are likely to have induced changes in clouds and a negative feedback on climate.

CEA-LSCE has further shown that the temporal variability in dust deposition has little impact on the ocean productivity. However, long term changes in dust deposition are demonstrated to have the potential to exhibit a considerable change to oceanic ecosystems (Aumont et al., 2008).

\section{Discussion and conclusions}

\subsection{Main achievements}

In 2006 when planning the EUCAARI project we realized that the baseline for the uncertainty in aerosol radiative forcing was typically greater than $100 \%$, and for some aerosol components even much higher. Furthermore, the regional scale forcing can be significantly greater than the global average values, as can be uncertainties. As a whole, the contributions of various aerosol sources, the role of primary and secondary particulate matter to the ambient aerosol concentrations over Europe were largely unknown. Therefore we performed studies presented in this overview using methods presented in Sect. 2 and obtaining results presented in Sect. 3. Kulmala et al. (2009) described a set of 12 key questions of EUCAARI. The answers of the project to these key research questions are included in Appendix E.

\subsubsection{Aerosols and climate: reducing uncertainty}

Our first objective was the reduction of the uncertainty (2006 level) of the impact of aerosol particles on climate by $50 \%$ and quantification of the relationship between anthropogenic aerosol particles and regional air quality. To achieve this objective EUCAARI concentrated on the areas of greatest uncertainty to:

a. identify and quantify the processes and sources governing global and regional aerosol concentrations;

b. quantify the physico-chemical properties of atmospheric aerosols;

c. quantify the feedback processes that link climate change and atmospheric aerosol concentrations with emphasis on the production and loading of natural aerosols and their precursors.
Answers to the points (a), (b) and (c) are given in Sect. 3. Answers related to point (a) are mainly considered in Sects. 3.1 and 3.2 where both natural and anthropogenic sources, along with various formation and transformation mechanisms are considered and in Sect. 3.4 where modeled regional and global distributions and concentration fields are presented. Answers related to point (b) are given in Sects. 3.2 and 3.3. In Sect. 3.3, the most comprehensive set of physico-chemical aerosol properties are reported, not only extensively over Europe but also in some key developing countries, using the most advanced instrumentation and techniques available. In particular, significant advances were made in quantifying the organic fraction of the atmospheric aerosol. Answers related to point (c) are given in Sects. 3.4 and 3.5 primarily with respect to biogenic SOA, natural dust and the marine sulphate cycle. Our achievements towards a $50 \%$ reduction in the uncertainty associated with aerosol radiative forcing is outlined below.

The First Assessment Report (FAR) IPCC report was published in 1990, after which it was followed by the second (SAR) in 1995; the third (TAR) in 2001; and the fourth (AR4) in 2007. At the beginning of the assessment reports, the uncertainty related to aerosol forcing increased as both a better knowledge of aerosol properties and sources emerged as well as an increasing number of aerosol species and processes were implemented in the climate models. It was not only until the AR4 in 2007 that the uncertainty started to get reduced as seen in Table 4 and in Fig. 20.

In 1990/1992 the assessment report authors concluded that the effect for (the then) current emission levels, averaged over the Northern Hemisphere, corresponded to a negative forcing at the Earth's surface of about $1 \mathrm{~W} \mathrm{~m}^{-2}$, with about a factor of two uncertainty. This was comparable (but of opposite sign) to the forcing due to anthropogenic $\mathrm{CO}_{2}$ $\left(+1.5 \mathrm{~W} \mathrm{~m}^{-2}\right)$. In addition to the direct effect on climate of sulphate aerosols, there was an indirect effect - via changes in $\mathrm{CCN}$ and cloud albedo - which tended to act in the same direction (i.e. towards a cooling) with a magnitude that has not yet been reliably quantified (Charlson et al., 1990 and 1992; Kaufman et al., 1991). In the AR4, the range of estimates for the direct effect spanned $-0.8 \mathrm{~W} \mathrm{~m}^{-2}$ while the indirect effect spanned $-1.5 \mathrm{~W} \mathrm{~m}^{-2}$. For the direct effect, this represents a reduction in span of plausible results from ca $1.4 \mathrm{~W} \mathrm{~m}^{-2}$ (SAR), ca $2.7 \mathrm{~W} \mathrm{~m}^{-2}$ (TAR) to $0.8 \mathrm{~W} \mathrm{~m}^{-2}$ (AR4), while in between these three reports no reduction in span was found for the indirect effect; however, the SAR only handled sulphate aerosol while the AR4 handled many more aerosol species. It should be noted that the range for the indirect effect was $(-) 2 \mathrm{~W} \mathrm{~m}^{-2}$ in the TAR.

Preliminary analysis from EUCAARI model analyses of the direct radiative forcing by the aerosols ranges from -0.049 and $-0.311 \mathrm{~W} \mathrm{~m}^{-2}$. In Quaas et al. (2009) several additional global models were used to derive the direct $\left(-0.4 \pm 0.2 \mathrm{~W} \mathrm{~m}^{-2}\right)$ and indirect effect $\left(-0.7 \pm 0.5 \mathrm{~W} \mathrm{~m}^{-2}\right)$ radiative forcings for atmospheric aerosols. We caution that 
the EUCAARI results are only from the three models participating in the project, and more complete and comparable results will be available later for IPCC AR5 analyses.

The interactions and feedbacks between aerosols and clouds, aerosols/clouds and climate, as well as air pollution and climate are many and intricate. The study of them requires a multidisciplinary approach. The research chain concept has to be followed to develop a deeper science understanding. Comparing number and mass we are able to find out several good research chains which we can utilize (a) nucleation/emissions - parametrisations - regional and global model results, (b) comparison of (a) with 2008-2009 ground base data and comparison with satellite data, and (c) vapour pressures - SOA formation - emissions - regional and global models, comparison like in (b).

One example of the used research chain is given in Fig. 21. That figure shows the main processes and parameters which contribute to the indirect radiative climate forcing of aerosols. It summarizes the interplay of meteorological and dynamical parameters with microphysical and chemical parameters of aerosols and clouds that lead to changes in cloud optical depth and thus to radiative climate forcing, i.e. the first indirect effect of aerosols on climate (Twomey effect). Table 5 provides quantitative estimates for the relative uncertainties and sensitivities of individual parameters and their effect on the uncertainty of cloud optical depth (Heintzenberg and Charlson, 2009). It can be seen that following EUCAARI, the uncertainty in many of the key parameters in the aerosol-cloud system are reduced by $50 \%$, for example, the hygroscopicity parameter kappa, updraft velocities, $\mathrm{CCN}$ concentrations, etc.

\subsubsection{Air quality and climate}

Our second objective was to quantify the side effects of European air quality directives on global and regional climate, and to provide tools for future quantifications for different stakeholders. Our answer to this objective is given in Sects. 3.4 and 3.6. The interconnections between climate change and air quality are clearly significant.

Future climate predictions were conducted for the Special Report on Emissions Scenarios (SRES) A1B and the interactions between air quality and climate change was evaluated for the years 1950-1959, 2000-2009 and 2040-2049. The climate induced variability, or variability due to meteorology between years within each decade gives rise to variability in the annual average of the surface $\mathrm{PM}_{2.5}$ concentrations of typically $10 \%$. The 2040s generally have the highest concentrations of $\mathrm{PM}_{2.5}$, consistent with the previous conclusion that the $\mathrm{PM}_{2.5}$ lifetime increases under the 2040s climate when it is much drier and warmer around the Mediterranean. The differences in annual average $\mathrm{PM}_{2.5}$ concentrations between the decades are also typically $10 \%$. The exception here is BSOA and BSOA precursors, where the difference between the decades is larger than $10 \%$ as the source func- tion for BSOA is temperature-dependent, with larger emissions as temperature rises.

For emission scenarios, the following four scenarios were used: Frozen legislation (FLE), reference case with Current Legislation (CLE), sustainable policy with CLE, sustainable policy with SLE. The difference in annual average $\mathrm{PM}_{2.5}$ concentrations are much larger when the emission changes are taken into account compared to when only meteorological changes were taken into account. This shows that the climatology of $\mathrm{PM}_{2.5}$ and its composition for the coming decades can be expected to be largely controlled by the emission changes, while the climate changes mainly will affect the level of biogenic secondary organic pollutants forcing them to go up. Emission changes dominate over the effect of intradecadal climate variability in annual average surface $\mathrm{PM}_{2.5}$ concentrations over the EMEP domain including its chemical components. The ranking of the scenario results for the 2040s also follow the ranking of the emissions, with the highest concentrations for the FLE case, followed by the reference case with CLE, sustainable policy with CLE and sustainable policy with SLE. The results of the two latter scenarios are very close, as are also the emissions for these two scenarios. The latter two scenarios result in the order of $40 \%$ reduction in $\mathrm{PM}_{2.5}$ mass while FLE scenario results in a marginal increase in $\mathrm{PM}_{2.5}$.

In terms of specific emissions reductions, the reduction in ammonia emissions is one of the most effective ways to reduce aerosol mass concentrations in Europe. Reduction in $\mathrm{NO}_{\mathrm{x}}$ is also effective for PM, but might lead to higher ozone levels. Reduction in $\mathrm{SO}_{2}$ emissions will reduce particulate air pollution especially in the Eastern Mediterranean area. Reduction of organic aerosol concentrations is a lot more challenging and will require reductions of gas and aerosol emissions e.g. from transportation and biomass burning.

\subsection{Policy relevance}

The development of policy strategies generally has often built on a bottom-up process starting in basic research that provided the scientific knowledge needed to address questions of societal importance. Applied research was then developed to find answers to these questions. The policy strategies for robust mitigation programmes were developed through the interaction of policy making bodies and applied researchers. The Convention on Long-Range Transport of Air Pollution and the IPCC are successful examples using such a process to include science into policy making.

EUCAARI focused mainly on basic research concerning processes on all scales aiming at a new generation of air quality and climate models based on sound physical and chemical understanding of processes influenced by atmospheric aerosols and gases. EUCAARI contributed new and/or enhanced understanding of processes from micro to global scale, leading to the improvement of models (including EMEP) that are crucial in developing policies. The 
Table 4. Aerosol forcing according to different IPCC reports: Forcing ( $\mathrm{W} \mathrm{m}^{2}$ ), BB = Biomass Burning aerosols, FF $=$ Fossil Fuel burning aerosols.

\begin{tabular}{lll}
\hline & Aerosol direct & Aerosol indirect (first indirect) \\
\hline SAR: & $-0.5(0.1$ to -1.3$)$ sulfate $+\mathrm{BB}+\mathrm{FF}(\mathrm{EC})$ & $(-0.0$ to -1.5$)$ sulfate only \\
TAR: & $-0.6(0.5$ to -2.2$)$ SAR+dust+FF(OC) & $(-0.0$ to -2.0$)$ all aerosols \\
AR4: & $-0.5(-0.1$ to -0.9$)$ all aerosols & $-0.8(-0.3$ to -1.8$)$ all aerosols \\
EUCAARI: & $-0.2(-0.05$ to -0.31$)$ all aerosols & $-0.7(-0.2$ to -1.2$)$ all aerosols \\
\hline
\end{tabular}
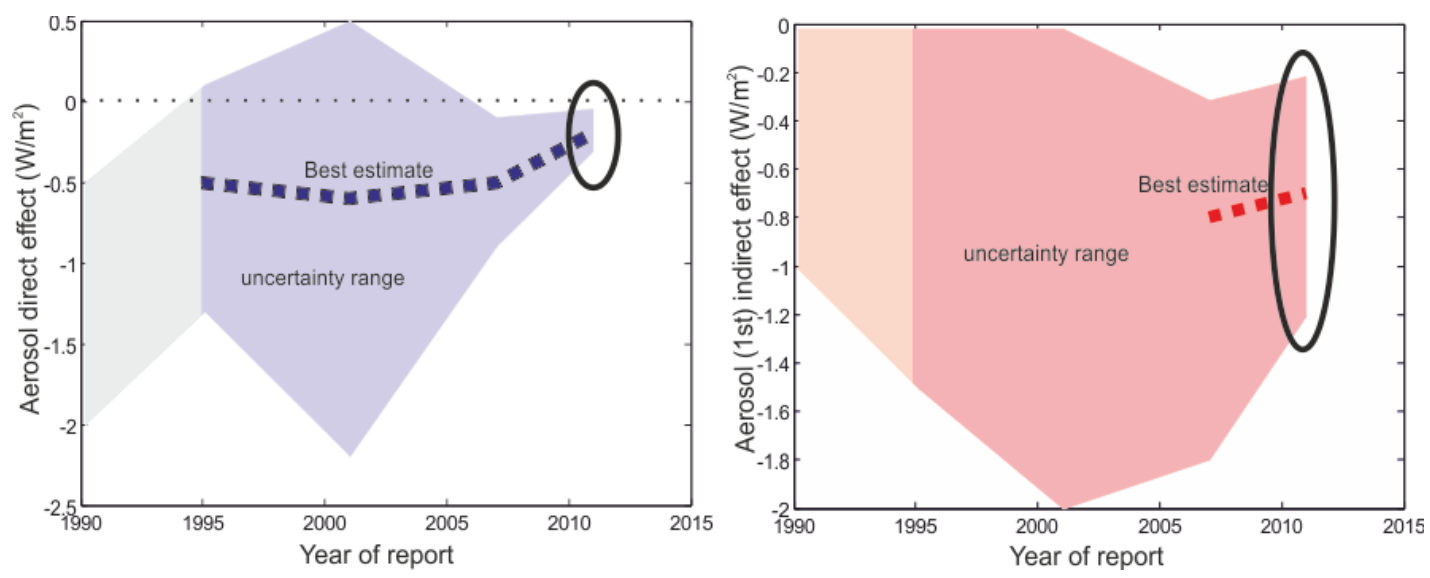

Fig. 20. The upper and lower limit and the best estimate for radiative forcing based on IPCC results and our own estimate denoted by 2010 for direct effect (left) and for 1st indirect effect (right).

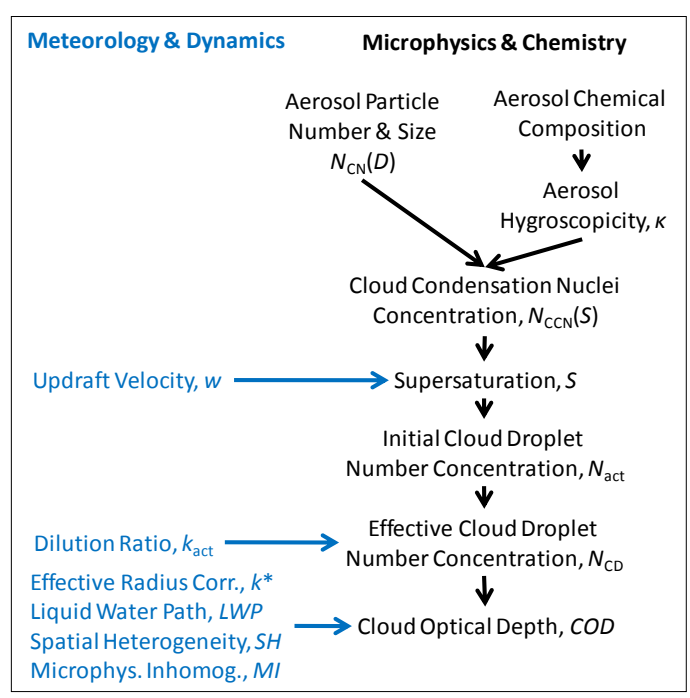

Fig. 21. Major processes and parameters contributing to the first indirect effect of aerosols on climate (Twomey effect).

improvements have already affected the policy work and will do so for at least the next $5 \mathrm{yr}$ period. Through its strategy EUCAARI has moved basic research closer to the policy work.

\subsubsection{Updated emissions inventories and their evaluation}

A major contribution of EUCAARI was the creation of the first ever inventory of number resolved particle emissions for Europe (see Sect. 3.1 and Denier van der Gon et al., 2009). Most emission databases express the emissions in terms of mass, while modern regional and global models need a size resolved input as particle size is decisive in most aerosol dynamic processes, particularly concerning the impacts on climate. Therefore, size-resolved particle emission information is needed in order to connect policies related to climate and air quality. The lack of information on particle sizes means that most models have included assumptions about the particle size distribution, which has been shown in EUCAARI to be a major source of uncertainty in regional aerosol assessments (Reddington et al., 2011). Introduction of size resolved emissions will give a unified input to all models and facilitate more transparent model comparisons. Another crucial improvement is the chemical speciation of PM emissions as the chemistry strongly influences particle behaviour. EUCAARI made a new inventory of European elemental carbon (EC) and organic carbon (OC) emissions. EC and OC are important components of $\mathrm{PM}_{10}$ and $\mathrm{PM}_{2.5}$ and are important particulate components affecting human health and climate. In line with the PN emission inventory, a size-distribution for 
Table 5. Range, variability, uncertainty, and relative sensitivity estimates for major parameters describing the first indirect effect of aerosols on climate (Twomey effect).

\begin{tabular}{|c|c|c|c|c|c|c|}
\hline \multirow[t]{2}{*}{ Parameter } & \multirow[t]{2}{*}{ Effective Range } & \multirow[t]{2}{*}{ Varia-bility Factor } & \multicolumn{2}{|c|}{$\begin{array}{l}\text { Relative Uncertainty } \\
\qquad(d \mathrm{X} / \mathrm{X}=d \ln \mathrm{X})\end{array}$} & \multicolumn{2}{|c|}{$\begin{array}{c}\text { Relative Sensitivity } \\
(d \ln Y / d \ln X=(d Y / Y) /(d X / X))\end{array}$} \\
\hline & & & Pre-EUCAARI & Post-EUCAARI & & \\
\hline Aerosol Hygroscopicity, $\kappa$ & $0.1-1.0$ & 10 & 1 & 0.5 & $1 / 3$ & $d \ln N_{\mathrm{CCN}} / d \ln \kappa$ \\
\hline Aerosol Particle Number \& Size, $N_{\mathrm{CN}}(D)\left(\mathrm{cm}^{-3}\right)$ & $10^{2}-10^{4}$ & 100 & 2 & 1 & 1 & $d \ln N_{\mathrm{CCN}} / d \ln N_{\mathrm{CN}}$ \\
\hline CCN Concentration, $N_{\mathrm{CCN}}\left(\mathrm{cm}^{-3}\right)$ & $10^{1}-10^{4}$ & 1000 & 2.3 & 1.2 & 1 & $d \ln N_{\mathrm{act}} / d \ln N_{\mathrm{CCN}}$ \\
\hline Updraft velocity, $w\left(\mathrm{~m} \mathrm{~s}^{-1}\right)$ & $0.5-20$ & 40 & 2 & 1 & 1 & $d \ln S / d \ln w$ \\
\hline Supersaturation, $S(\%)$ & $0.1-1$ & 10 & 3 & 2 & 1 & $d \ln N_{\text {act }} / d \ln S$ \\
\hline Initial Cloud Droplet Number Concentration, $N_{\mathrm{act}}\left(\mathrm{cm}^{-3}\right)$ & $10^{1}-10^{3}$ & 100 & 7.3 & 4.2 & 1 & $d \ln N_{\mathrm{CD}} / N_{\mathrm{act}}$ \\
\hline Dilution Ratio, $N_{\mathrm{CD}} / N_{\mathrm{act}}$ & $0.4-0.9$ & 2 & 1 & 0.3 & 1 & $d \ln N_{\mathrm{CD}} / d \ln k_{\mathrm{act}}$ \\
\hline Effective Cloud Droplet Number Conc., $N_{\mathrm{CD}}\left(\mathrm{cm}^{-3}\right)$ & $10^{1}-10^{3}$ & 100 & 8.3 & 4.5 & $1 / 3$ & $d \operatorname{lnCOD} / d \ln N_{\mathrm{CD}}$ \\
\hline Effective radius correction, $k^{*}$ & $0.5-1$ & 2 & 0.3 & 0.1 & $1 / 3$ & $d \operatorname{lnCOD} / d \ln k^{*}$ \\
\hline Spatial heterogeneity, $\mathrm{SH}$ & $0.1-1$ & 10 & 1 & 1 & $1 / 5$ & $d \operatorname{lnCOD} / d \operatorname{lnSH}$ \\
\hline Microphys. inhomogeneity, MI & $0.1-1$ & 10 & 1 & 1 & $1 / 5$ & $d \operatorname{lnCOD} / d \ln \mathrm{MI}$ \\
\hline Liquid Water Path, LWP $\left(\mathrm{g} \mathrm{m}^{-2}\right)$ & $20-400$ & 20 & 1 & 1 & $5 / 6$ & $d \operatorname{lnCOD} / d \operatorname{lnLWP}$ \\
\hline Cloud Optical Depth, COD & & & 4.1 & 2.8 & & \\
\hline
\end{tabular}

the major source categories was provided to the modellers. Effective EC mitigation strategies and scope for regulations have been recently discussed at a regional and global level e.g. UNEP and EMEP (UNEP, 2011; ECE, 2010). Errors and uncertainties in the emission estimates propagates into the modelling results on air quality and climate. Further the mitigation strategies generally focus on emission reductions making the negotiations focused on finding the most cost effective reduction strategy (see Fig. 22). Accurate emission data are thus fundamental to developing the best possible abatement program.

Aerosol source apportionment was based on about 30 field campaigns all over Europe with most advanced instrumentation and shows the strong presence of organic components dominating the fine aerosol. The major fraction is modern carbon coming from biogenic emissions and biomass combustion (Prévôt et al. 2011). The biomass combustion contribution is strongly varying with season and site. Application of the new emission inventory in the PMCAMx model reveals inconsistencies in the emission database, such as too low wood combustion emissions in Sweden and Eastern Europe, calling for a review of the national emission reports. Preliminary analyses of the new emissions in the GLOMAP global aerosol model show reasonable agreement with EUSAAR observations at some locations, but overall discrepancies between models and observations are still considerable at many other locations in Europe, in particular for high altitude sites and Scandinavia.

\subsubsection{Atmospheric composition: new findings of importance for policy development}

Efforts are now focused on establishing an integrated air quality and climate mitigation policy. One major air quality issue is the health effects caused by particles (Pope and Dockery, 2006). The risk estimates recommended by the World Health Organisation (WHO) are based on $\mathrm{PM}_{10}$ or
$\mathrm{PM}_{2.5}$. Even though some particle components may be associated with higher risks there is no recommendation due to insufficient epidemiological evidence. Several investigations suggest that exposure to combustion particles is associated with higher health effect risks (Hoek et al., 2002). In EUCAARI, extensive efforts have been made to unravel the organic chemistry of aerosol particles, thereby facilitating a more mechanistic chemical process description in the models, which from a policy point of view is important for a better understanding of the contribution of the different sources, natural and anthropogenic, to the total aerosol load. A major coordinated effort was launched in cooperation with EMEP together with the observational network EUSAAR and extended with highly specialized instrumentation such as the Aerosol Mass Spectrometers at about 10 sites in three monthlong campaigns. The aim was to collect detailed data on how emissions mix with and age with pre-existing aerosol and how these particles interact with clouds. Several research aircrafts were deployed in a major airborne measurement campaign (Roberts et al., 2011). The extensive database of detailed information on the atmospheric composition, especially the organic components, is instrumental in developing an accurate quantitative description of the anthropogenic contribution to PM (Nemitz et al., 2011).

Short-lived climate forcing components (SLCF) such as black carbon, sulphate, organic carbon, ozone and methane affect the climate significantly. Abatement of air pollution is associated with considerable costs but also major savings in health and ecosystem effects. However, as major greenhouse gas emission originates from the same sources as air pollutants, a coordinated abatement strategy is needed. Such a strategy needs to balance reductions of cooling and warming SLCFs and therefore focuses on limited number of sources but when done hand in hand with $\mathrm{CO}_{2}$ reductions helps to achieve climate targets. However, the uncertainties are considerable because the indirect effects of aerosols on clouds are not included, and the focus is in radiative forcing rather 


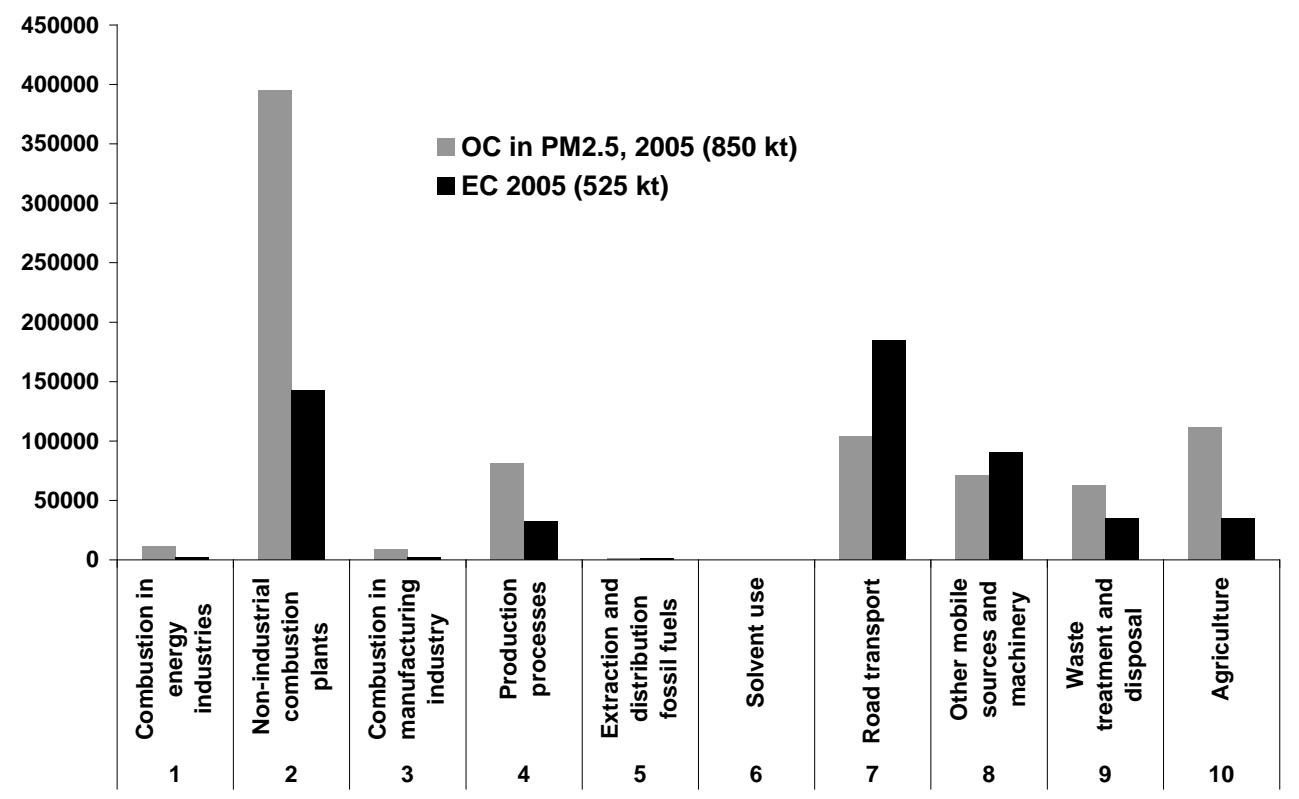

Fig. 22. EC and OC annual emission (tonnes) for Europe in 2005 by source sector.

than the climate response itself. The present total aerosol forcing is not well known, giving a large uncertainty in the quantification of the actual temperature increase at double $\mathrm{CO}_{2}$ concentration (Schwartz et al., 2010; Hansson, 2010). The atmospheric concentrations of these components and the chemical composition of the particles strongly affect not only their radiative properties but also the potential for cloud droplet formation. EUCAARI, partly through the use of data from infrastructure network such as EUSAAR, has put major efforts into analysing concentrations and properties of importance for calculations of the aerosol total forcing effect (see e.g. Swietlicki et al., 2008; Asmi et al., 2011). The distribution of the different chemical components over the particle size distribution and thus their influence on the particle properties are most important for the total effect of the given compounds. Long term measurements of the particle size distribution have been performed all over Europe in collaboration with EUSAAR, extended by EUCAARI to 4 international sites in Africa, India, China and Brazil. Further EUCAARI undertook a major month-long campaign including measurements of chemically resolved size distributions. In total the major achievements on measuring the chemical composition and properties influencing climate forcing have affected and will continue to affect the policy development as it will give a much stronger basis for estimating the effect of emission reductions.

Coupled photochemistry and aerosol microphysics simulations for the period 1980-2005 using the aerosolchemistry-climate model ECHAM5-HAMMOZ have been performed, to assess the understanding of long-term changes and inter-annual variability of the chemical composition of the troposphere, and in particular of ozone and sulphate concentrations. In order to separate the impact of the anthropogenic emissions and meteorology on atmospheric chemistry, two model experiments have been compared, driven by the same ECMWF re-analysis data, but with varying and constant anthropogenic emissions, respectively (Pozzoli et al., 2011). The model analysis indicates an average increase of $1 \mathrm{ppbv}$ in global average surface ozone concentrations due to anthropogenic emissions, but this trend is largely masked by natural variability ( $0.63 \mathrm{ppbv})$, corresponding to $75 \%$ of the total variability ( $0.83 \mathrm{ppbv})$. Regionally, annual mean surface $\mathrm{O}_{3}$ concentrations increased by 1.3 and $1.6 \mathrm{ppbv}$ over Europe and North America, respectively, despite the large anthropogenic emission reductions between 1980 and 2005. Global average sulphate surface concentrations are largely controlled by anthropogenic emissions. Globally natural emissions are an important driver determining the AOD (Aerosol Optical Depth) variations, regionally AOD decreased by $28 \%$ over Europe, while it increased by $19 \%$ and $26 \%$ in East and South Asia. The global radiative perturbation calculated in our model for the period 19802005 was rather small.

\subsubsection{Model development, new parametrizations, feedback processes and evaluations}

The basic foundation of EUCAARI is implementing scientifically investigated parametrization of processes into mechanistic models. The climate is controlled by a very complex web of processes on all scales, from the nano to the global scale, interacting with each other. Simultaneous studies of 
these processes aiming at improving our understanding will improve models considerably. In AR4 the uncertainty in climate sensitivity due to poorly quantified aerosol processes results in a very large uncertainty in global mean temperatures in a double $\mathrm{CO}_{2}$ climate (Schwartz et al., 2010). Obviously this uncertainty gave considerable difficulty in setting generally acceptable abatement goals.

As the atmospheric particle size distribution is strongly dependent on the formation of new particles in the atmosphere, i.e. nucleation, EUCAARI focused on the crucial question of how the natural particle formation, growth and ageing processes are affected by anthropogenic emissions, and thus how changes in emissions will affect climate forcing. EUCAARI has put emphasis on both warm and cold clouds, investigating how different properties affect the cloud droplet or ice nuclei formation, all in an attempt to get better estimates of the indirect effects as well of their contribution to the total uncertainty (e.g. Hoose et al., 2010a). Feed-back processes in the interaction between the atmosphere and the natural ecosystem and/or the natural oceans in a changing climate have been investigated using models updated with new parametrizations developed in EUCAARI (e.g. Collins et al., 2010).

An evaluation process of regional and global aerosol models was developed to document modelling progress made during EUCAARI. A platform was developed, which helps constructing successful modelling studies within EUCAARI and outside of the consortium, making a link to the international AEROCOM model inter-comparison. This initiative allows a quantification of actual uncertainties in our prediction of aerosol impact on climate and air quality. Benchmark test tools were developed and applied to analyse model biases with respect to processes that govern aerosol concentrations and physico-chemical properties of the aerosol.

Upgrading an operational model requires significant effort including scientific investigations and evaluation of the effects of changes on the general performance of the model. Thus the full upgrading of the operational models has been lagging behind. The just started AR5 in the IPCC process stops the upgrading processes of the operational models for a period of $2 \mathrm{yr}$ for the IPCC simulations. This delays the implementation of new parametrizations and the upgrading based on EUCAARI results for a period of approximately 2 yr.

\subsubsection{Developing and evaluating policy strategies}

Several scenarios were developed in EUCAARI in which available technical and non-technical reduction measures of short lived climate forcing components and air pollutants were combined to find the best integrated strategy for cobeneficial climate and air quality mitigation. The developed approaches were used in the UNEP Integrated Assessment of Black Carbon and Tropospheric Ozone (UNEP, 2011) and were the basis for work in the Arctic Council Task Force and the Arctic Monitoring and Assessment (AMAP) Expert Group to assess the climate effects on the Arctic. Developments to identify the contribution to air pollution as well as radiative forcing from individual member states in the OECD was also made within the EUCAARI, which have been used in the work within different task forces and expert committees in EMEP/CLRTAP.

A first assessment, performed within EUCAARI showed that balanced reduction strategies of short-lived climate forcers and atmospheric pollutant can enhance the climate mitigation and simultaneously improve air quality (see also Fig. 23). A baseline was developed based on current and planned emission regulation for the period 2000-2030. Three control scenarios adding well known standard reduction measures on $\mathrm{BC}$ and methane were investigated together with one scenario were maximum feasible reductions were applied on all substances involved.

During 2010 UNEP performed an assessment of BC and ozone that recently was published using the same scenarios (www.unep.org/dewa/). The evaluation by two GCMs (GISS and ECHAM) found the global temperature increase could be reduced by about $0.5^{\circ}$ from 2030 and onwards with the suggested measures, at the same time considerable improvements in adverse health and ecosystem effects were achieved.

Similarly, runs with ECHAM using IIASA air quality mitigation scenarios were made with the following air quality mitigation scenarios: Current Legislation Emissions (CLE), Maximum Feasible Reductions (MFR) and CLEMFR where the MFR was applied for Europe and CLE for the rest of the world. When the MFR scenario is applied only to Europe the study shows a substantial warming effect and increase in precipitation. But these effects are almost double, both over Europe and globally, when the MFR scenario is adopted globally. In the case of CLEMFR the temperature response in Europe is $+2.2^{\circ} \mathrm{C}$ while in the case of MFR the temperature increase in Europe is $4.1^{\circ} \mathrm{C}$. It is the difference in reduction of $\mathrm{SO}_{2}$ emissions that causes this fairly large difference in global climate response. The global temperature response in 2030 due to the greenhouse gas emissions in both scenarios was found to be about $1.2^{\circ} \mathrm{C}$.

The development of the EMEP model has facilitated a first implementation of forcing as an element in the Greenhouse Gas and Air Pollution Interactions and Synergies (GAINS) model. This allows the use of GAINS for an integrated assessment of climate and air quality, in order to develop cost effective and thus co-beneficial mitigation strategies for climate and air quality. The development also facilitates evaluation of Europe's influence on the global air quality and climate. The investigated scenarios were found to significantly affect the climate of the whole of the Northern Hemisphere. The different member states' contributions to the climate effect in Europe vary to some extent with their geographical location while the Arctic rim countries have a larger effect on the Arctic compared to the European countries further south. Climate change does affect air quality, but it was 


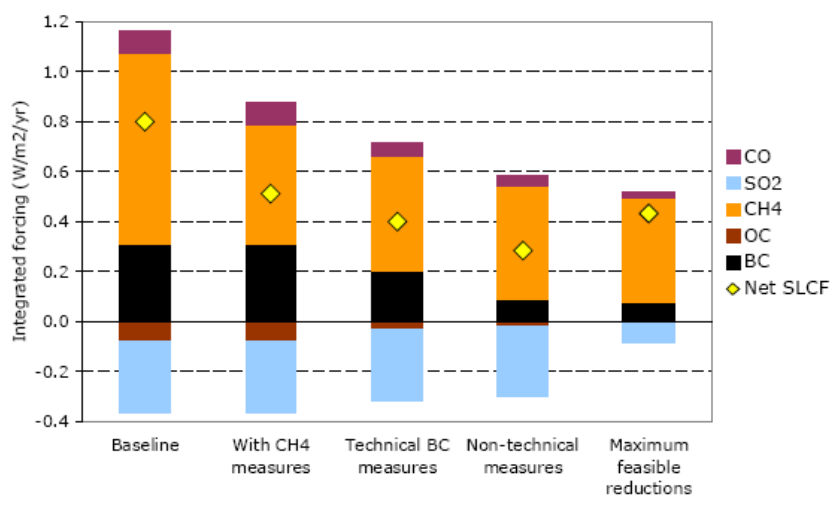

Fig. 23. Radiative forcing (integrated over $100 \mathrm{yr}$ for the baseline, three control scenarios and the MFR on Air Quality regulation, global assessment by substance (UNEP, 2011).

found that air quality mitigation scenarios will give a clearly significantly better and noticeable improvement inair quality in spite of the variations induced by climate change and natural variability in the climate.

EUCAARI has already had an considerable effect on the production of key documents for the policy process, developing new air quality and climate mitigation policies, e.g. the UNEP report, answering the most pertinent, relevant and most recent policy related questions. In this work only some of the new developments in relevant knowledge and implementations of that in the models have been used. One reason for this is the limited duration of EUCAARI making it impossible to actually fully implement all new parametrizations in the operational models in the course of the project itself. Also, the complexity both in terms of organization and the science content of current climate modelling research and as well as the supporting operational infrastructure does not facilitate a systematic implementation of the model improvements that may arise from new parametrizations developed through EUCAARI and subsequent operational use for policy development, implementation and monitoring.

\subsection{Impact}

EUCAARI had and will continue to have a significant impact on atmospheric aerosol and climate research, on aerosol measurement technologies and techniques, on knowledge transfer, and on mitigation strategies relating to air pollutionclimate change interactions. The scientific impact has mainly described in Sect. 3 and also partly in Sect. 4.1. The EUCAARI legacy is described in Sect. 4.4; however, the main impact has come via quantification the effect of aerosols on the planet's radiative balance to understand future climate change (see Sect. 4.1.). As an underpinning and critical issue, during EUCAARI, the integration of European atmospheric research, with a particular focus on aerosols, air pollution, atmospheric composition and climate change has improved over and above the sum of the individual parts of the programme. This underpinning paves the way for more critically and informed research and assessments into the future.

From a technological perspective, EUCAARI has developed new aerosol measurement instruments and has deployed some of the most complex research instruments world-wide in, more or less, an operational manner. Such instruments include the cluster spectrometer, deployed over extended periods at numerous sites including airborne platforms (Mirme et al., 2010). Besides the aforementioned instrument, several new instrumental techniques have been developed and utilized in filed and laboratory studies (see Sect. 2) with annual observation of different properties of atmospheric aerosol having been performed at between 12-24 different sites to different degrees. The measurements additionally include, size distribution measurements (Asmi et al., 2011), hygroscopicity of atmospheric aerosols (Swietlicki el al., 2011), optical properties, and significantly aerosol mass spectrometer (AMS) measurements (e.g. the longest world-wide record of high-resolution AMS measurements were enabled at Mace Head, Ireland, where they continue to date since May 2008). In summary, EUCAARI has moved highly complex and labour-intensive aerosol measurement techniques from research mode to close-to-operational measurements delivering important data, previously lacking, to stakeholders.

In terms of knowledge transfer, the list is too exhaustive to be listed in this document, but includes extensive workshops, seminars, winter and summer schools as well as daily mentoring of graduate students and post doctoral researchers from Europe but also a number of developing countries and other regions around the world. More than $230 \mathrm{Ph} . \mathrm{D}$. students have been involved in EUCAARI.

EUCAARI has produced more than 420 papers published in peer reviewed literature by 31 March 2011 ( 9 of them in Nature or Science). EUCAARI outcome has disseminated also via (i) EUCAARI-platform, (ii) meetings, conferences, web pages, publications, reports and (iii) different networks.

The baseline in global air pollution point of view was that information was very sparse in 2006 in 3rd world countries. EUCAARI set up a ground-site measurement network in developing countries and ensured the continuity of the work by providing a special training program for the scientists representing developing countries. In practice, EUCAARI covered the polluted regions in China and South Africa as well as the Amazon area in Brazil and rural areas in India. These regions extended EUCAARI to different ecosystems and economic areas, providing a useful reference for evaluating European conditions, and they are valuable for the design of control strategies at the local, national and European level, providing also information for international negotiations. The reduction in uncertainty regarding the aerosol role in climate change allows the EU to achieve a better balance between sustainable economic development and minimal environmental impacts. The involvement of developing 
countries in the EUCAARI consortium was important both for the quantification of the pollution effects on a global scale but also for helping these countries to develop practical solutions to pollution problems.

The improved understanding of regional aerosol concentrations and emissions applies directly for the planning of the European mitigation strategies estimating the cost-efficiency of future emission controls, and the risk-analysis of longterm investments. In EUCAARI we have provided more informed tools compared to this previously existing, to perform an improved pollution-impact assessment with a particular emphasis on atmospheric aerosols. However, while the EUCAARI advances are significant, there is a still long road ahead to assess future climate change and interactions with air quality. The complexity of atmospheric aerosols, and their interactions with clouds, going forward, are still highly complex and warrant significant investment into the future.

Health effects due to air pollution and the potential damage from climate change are probably the two most important environmental problems facing the EU. EUCAARI has quantified the contributions of different anthropogenic and natural sources to the $\mathrm{PM}_{10}, \mathrm{PM}_{2.5}$, and ultrafine particle concentrations. Additionally, EUCAARI provided new information on particle hygrosopicity and composition, along with the source apportionment. The project quantified the responses of the aerosol concentrations to changes in emissions of particles and their precursors within and outside Europe. The EUCAARI data base provides knowledge on regional aerosol loadings, hygroscopicity (related to dose of the exposed population) and composition (related to toxicity of the particles) and estimates of how much of the loading is due to long-range transport. EUCAARI also contributed the scientific requirements relating to the European Thematic strategy on Air Pollution, where it was stated that it is necessary to reduce the uncertainties in (i) the knowledge about the sources of PM including their physical and chemical characterization, and whether they are of natural or anthropogenic origin. (ii) the formation of secondary aerosols and how different sources contribute, (iii) the role of long-range transport including intra-hemispheric and global transport for the aerosol load over e.g. Europe; (iv) the links between air pollution and climate change; and (v) the modelling and monitoring of air pollution.

The developed models and knowledge on sources and emission scenarios came directly in to use in providing assessments evaluating the possibilities of co-beneficial measures improving air quality simultaneously mitigating climate change. These assessments have and certainly will affect ongoing policy in e.g. the National Emission Cellings Directive with in the Convention of Long-Range Transboundary Air Pollution (CLRTAP).

EUCAARI has during its four year made considerable advances on all scales of science and made it useful in the policy for better air quality and mitigating climate change.

\subsection{Legacy and future research needs}

EUCAARI leaves a legacy to be used in future projects and investigations. The key issue is EUCAARI way of integrating individual efforts to join efforts from process level understanding to global scientific and socio-etal problems. The legacy contains advanced models from process level understanding to global climate models (see EUCAARI arrow Fig. 1), new developed and tested instruments, emission inventories, data banks etc. The data banks include e.g. atmospheric nucleation data from 12 different sites, data from Intensive Observation Period (IOP), size distribution data obtained in co-operation with EUSAAR, hygroscopicity data etc.

During EUCAARI, leading European groups started to work together more systemically than ever before. 48 partners had common objectives and their work 48 months towards fulfilling those objectives. During the project several benefits from supradisciplinary work have been seen. E.g. experimentalists and modellers start to work together. The real use of EUCAARI arrow is a big benefit and shows the power of joint work in all scales. This legacy will hopefully continue into future projects.

EUCAARI established a data exchange protocol (a) to ensure rapid dissemination of data and results within the project consortium, (b) to protect the data ownership of the contributing scientists and (c) to ensure that project data are preserved and made available after the end of the project. All measurement data had to be submitted to a central database (http://ebas.nilu.no), which is shared with EUSAAR and other projects, so that the EUCAARI data became part of a large established database system containing data from multiple research campaigns and monitoring activities. Some of these data are publicly available while for others the access is restricted. As of now, the database contains data from the 1970s up to 2010. It is essential that links established between the data production and storage system and the users developed within the EUCAARI framework is maintained for future studies.

Furthermore, EUCAARI supported the interpretation of EUCAARI and EUSAAR data by running a Lagrangian particle dispersion model, FLEXPART (Stohl et al., 2005), in backward mode from all EUCAARI and EUSAAR measurement data points. Backward modelling products for the years 2006-2010 are available for these locations: Aspvreten, BEO Moussala, Birkenes, Cabauw, Finokalia, Harwell, Junfraujoch, JRC-Ispra, K-puszta, Mace Head, Melpitz, Montseny, Mt. Cimone, Kosetice, Pallas, Puy de Dôme, Preila, Hyytiälä, Vavihill, as well as for Capo Fiume and Barcelona. Furthermore, products are available for all EUCAARI airborne observations. All products are freely available at http://transport.nilu.no/projects/eucaari/ and are also linked via the EUCAARI database.

In future it is good to continue from EUCAARI achievements. It will be important to find out 
- key processes and thermodynamics related to ice nucleation and both ice and mixed phase clouds;

- thermodynamics of key aerosol systems;

- better parametrisations to include new process understanding in global and regional models;

- effect of climate stress on vegetation and secondary aerosol formation-properties;

- interlinks between biospheric and anthropogenic aerosols and their precursors;

and to perform

- pollutant impact assessments, based on both aerosol mass and number concentrations;

- continuous and comprehensive measurements including aerosol, reactive trace gases and greenhouse gases at the same supersites;

- maintenance and extension of the observation network outside of the European political boundaries, in collaboration within strong international partnership;

- develop more detailed emissions inventories;

and to include

- EUCAARI findings in future air quality directives.

One of very important future research topic with a certain policy relevance is the quantification of the side effects of possible air quality directives on aerosol concentrations. Actually the roadmap for future analysis is to (1) obtain regional size segregated mass and number concentration using EUCAARI/EUSAAR data plus EUCAARI model results, (2) perform model runs using the emissions related or given by air quality directives, (3) analyse the results and (4) give assessments based on the results.

\subsection{Summary}

The EU-FP6 EUCAARI project (2007-2010) is an Integrated Project (IP) of the 6th Framework Programme of the European Commission. The goals of EUCAARI are to quantify the effect of aerosols on cloud, climate and air quality interactions, to understand future climate change, and to develop strategies and implementation plans for global air quality monitoring. EUCAARI is a consortium of 48 partners coordinated by the University of Helsinki. The project has been motivated by the urgent need to quantify the effect of aerosols on our planet's radiative balance to understand future climate change. The uncertainty in aerosol radiative forcing has been typically greater than $100 \%$ and for some aerosol components it is more than $200 \%$.
The project was organized into elements studying the emission and formation of aerosols, their evolution and transformation during their atmospheric lifetime and their impact on clouds. This approach maximized the integration of methodologies and scales and ultimately our understanding of the effects of aerosols on air quality and climate. Groundbased, aircraft and satellite measurements were integrated with existing data to produce a global consistent dataset with the highest possible accuracy. The EUCAARI intensive measurement campaign in May 2008, was designed around simultaneous airborne measurements together with measurements from several "super-site" stations around Europe. Furthermore, during EUCAARI, a hierarchy of new-generation models was developed based on the results of the laboratory and theoretical investigations. This new research concept of "all scales research chain" was the basis of the EUCAARI mission. The EUCAARI work followed several research chains, in which small-scale models were used to interpret measurements and then integrated in to regional air quality and global climate models. In the end of the project this new knowledge was incorporated in policy-orientated models to analyze climate change and air quality for a range of global emission scenarios using updated economic and technological information.

One crucial task of EUCAARI was the quantification of the impact of aerosols and trace gases on clouds. The influence of aerosols on clouds depends on particle properties and cloud microphysics as well as on meteorological conditions. Before EUCAARI, the uncertainties related to aerosol properties were similarly high as those related to cloud microphysics and meteorology. Synthesizing the EUCAARI and related studies results, the uncertainty of key parameters in aerosol properties (aerosol particle hygroscopicity, size distribution, number concentration, etc.) and cloud microphysics (dilution ratio, effective radius, etc.) was reduced by about $50 \%$. New formulations of turbulence in global models derived from EUCAARI observations give much better agreement with observations, yielding an overall $36 \%$ increase in predicted cloud droplet number concentrations and significantly reducing the model negative bias. With regard to climate modeling and air quality, aerosol properties and cloud microphysics appear now, after EUCAARI, well constrained relative to the uncertainties of meteorological conditions.

EUCAARI focused on the scientific questions related to aerosols with the greatest uncertainty at all relevant scales; from nanometers to global scale, from milliseconds to tens of years. The resulting improved understanding of the aerosol life cycle enabled us to also improve significantly the corresponding climate and air quality models. An example of such an improvement is the partitioning of complex organic compounds between the gas and the particulate phase. The work was based on laboratory experiments focusing on the micro scale. New models were then developed which greatly reduced the complexity of the organic aerosol (OA) 
partitioning problem to the point where they can be included in global OA models.

EUCAARI developed a set of new emission inventories and scenarios for Europe. For example the particle number emission inventory developed for Europe within EUCAARI is the first of its kind in the world. These inventories together with new knowledge on long-range transport of aerosol pollution provide valuable tools for air pollution policy making. The EUCAARI conclusions are also valuable inputs for future European air quality directives. Based on EUCAARI results the reduction in ammonia emissions is one of the most effective ways to reduce aerosol mass concentrations in $\mathrm{Eu}-$ rope. Reduction in $\mathrm{NO}_{\mathrm{x}}$ is also effective, but might lead to higher ozone levels in several areas. Reduction in $\mathrm{SO}_{2}$ emissions will reduce particulate air pollution especially in the Eastern Mediterranean area. Reduction of organic aerosol concentrations is a lot more challenging and will require reductions of gas and aerosol emissions from transportation and biomass burning.

EUCAARI has also performed measurements, which provide new insights of the role of different types of aerosols on air quality and climate. EUCAARI has made significant progress in understanding the formation of biogenic secondary organic aerosol (BSOA). It has now shown that a large fraction of the OA in Europe is of modern origin, for which the main sources are BSOA (boreal forests), biomass burning and primary biogenic aerosol particles. These compounds have also been shown to contribute to the growth of newly formed particles into cloud condensation nuclei and are therefore important for the indirect radiative forcing. All these sources are expected to respond to climate change, although we are presently unable to gauge accurately the strength of the multitude of feedback mechanisms involved.

The large-scale interactions between air quality and climate have been largely unknown, although some links have been identified or even quantified. EUCAARI results highlight the potential impact of future climate change on air pollution and vice versa.

Good quality long-term data sets of physical, chemical, and optical characteristics of aerosols are rare. Long-term data sets are needed to estimate the effect of emission reductions and underpin European strategy on air pollution. EUCAARI leaves a legacy of data and advanced aerosol and cloud computer codes, which are available via the EUCAARI Platform (http://transport.nilu.no/projects/eucaari/). The EUCAARI database, hosted by the Norwegian Institute for Air Research (NILU), builds on the efforts of the EMEP program and utilizes the developments of EU-FP6 infrastructure project EUSAAR (European Supersites for Atmospheric Aerosol Research). The construction of the European Research Area for the atmospheric science will require in the future that the strong connections between science and infrastructure programs be maintained. The database contains observation data of atmospheric chemical composition and physical properties in a common format. It also makes avail- able transport modelling products (Lagrangian particle dispersion model FLEXPART) suitable for the identification of source regions of measured aerosols for the case studies. In order to expand the European activities of aerosol monitoring EUCAARI has built new field stations outside Europe: in polluted regions in China and South-Africa, in Amazon area in Brazil and rural areas in India. This selection of sites provides useful reference for evaluating European conditions and providing information for international negotiations.

EUCAARI contributed to expand the European activities of aerosol monitoring outside Europe: in polluted regions in China and South-Africa, in Amazon area in Brazil and rural areas in India. This selection of sites not only provides useful reference for evaluating European conditions and information for international negotiations but it also strengthened the positioning of Europe as an attractive place for advanced education in the atmospheric science. Support of the European Commission for extending long-term observing network in emerging and developing countries outside of Europe is an essential and unique contribution to Global Climate Observing System (GCOS).

The most important technical achievement of EUCAARI was the development of a new prototype of cluster spectrometer for measuring sub- $3 \mathrm{~nm}$ size particle and cluster ion concentrations and thus allowing us to follow the initial steps of growth of new aerosol particles. This breakthrough will enable Europe to take a leading role in developing and applying environmental technologies and mobilize all stakeholders in the area of air pollution management.

In order to efficiently disseminate and ensure the continuity of EUCAARI measurement techniques, use of the instrumentation and running of the new stations the project has organized several workshops and training events for young scientist as an integral part of the research activity. EUCAARI has clearly strengthened the European research community working in different disciplines of aerosol research: physics, chemistry, meteorology and biology. The project has also set up the stage for further studies such as the continued development of global and regional models using EUCAARI findings and also the incorporation of its results in future air quality directives.

\section{Appendix A} Details of methodologies used, related to 2.
scientific approach 
Table A1. Laboratory infrastructures used in EUCAARI.

\begin{tabular}{|c|c|c|c|c|}
\hline Methodology & Description & Scale & Reference & Used in \\
\hline FMI Laminar flow-tube & $\begin{array}{l}\text { Homogenous nucleation } \\
\text { experiment tube }\end{array}$ & Nanoscale & Brus et al. (2010) & Nucleation and growth \\
\hline IfT Atmospheric pressure flow-tube & $\begin{array}{l}\text { Homogenous nucleation } \\
\text { experiment tube }\end{array}$ & Nanoscale & $\begin{array}{l}\text { Berndt et al. (2005); } \\
\text { Sipilä et al. (2010) }\end{array}$ & Nucleation and growth \\
\hline \multicolumn{5}{|l|}{ Vienna Size Ananlysing Nucleation } \\
\hline Chamber & Expansion Chamber & Nanoscale & Winkler et al. (2008) & $\begin{array}{l}\text { Heterogeneous nucleation, } \\
\text { cluster activation, } \\
\text { condensation growth }\end{array}$ \\
\hline Zurich Ice Nucleation Chamber (ZINC) & Ice Nucleation Chamber & Nanoscale & Stetzer et al. (2008) & Ice nucleation \\
\hline Portable ice nucleation chamber (PINC) & Ice Nucleation chamber & Nanoscale & Chou et al. (2010) & Ice nucleation \\
\hline $\begin{array}{l}\text { Immersion mode cooling chamber } \\
\text { (IMCA) }\end{array}$ & Ice Nucleation chamber & Nanoscale & Niedermeier et al. (2010) & Ice nucleation \\
\hline JPAC Juelich Plant atmosphere chamber & $\begin{array}{l}\text { Two temperature controlled, con- } \\
\text { tinuously stirred flow reactors, } \\
\text { housing the plants and the photo- } \\
\text { chemical studies. }\end{array}$ & Microscale & $\begin{array}{l}\text { Mentel et al. (2009); } \\
\text { Kiendler- } \\
\text { Scharr et al. (2009a, b); } \\
\text { Lang-Yona et al. (2010) }\end{array}$ & $\begin{array}{l}\text { SOA formation and } \mathrm{OA} \\
\text { partitioning }\end{array}$ \\
\hline $\begin{array}{l}\text { PSI Environmental smog } \\
\text { chamber }\end{array}$ & Temperature controled $27-\mathrm{m}^{3}$ & & & \\
\hline Teflon bag with artificial lights & Nanoscale & $\begin{array}{l}\text { Paulsen et al. (2005); } \\
\text { Duplissy et al. } \\
\text { (2008); } \\
\text { Metzger et al. (2010); } \\
\text { Chirico et al. (2010) }\end{array}$ & $\begin{array}{l}\text { Nucleation and growth; } \\
\text { aging of SOA and of } \\
\text { combustion emissions }\end{array}$ & \\
\hline $\begin{array}{l}\text { SAPHIR Simulation of } \\
\text { Atmospheric PHotochemistry In a large } \\
\text { Reaction Chamber }\end{array}$ & $\begin{array}{l}\text { Long-term photo-chemical age- } \\
\text { ing of BSOA formed from a } \\
\text { representative mixture of Boreal } \\
\text { BVOCs }\end{array}$ & Microscale & $\begin{array}{l}\text { Bohn et al. (2005); } \\
\text { Rohrer et al. (2005); } \\
\text { Wegener et al. (2007); } \\
\text { Spindler (2010); Buch- } \\
\text { holz (2010) }\end{array}$ & $\begin{array}{l}\text { SOA formation and } \mathrm{OA} \text {; } \\
\text { partitioning }\end{array}$ \\
\hline UEF Kuopio plant chamber & A $6 \mathrm{~m}^{3}$ teflon chamber where & & & \\
\hline $\begin{array}{l}\text { VOC's from a plant enclosure are mixed } \\
\text { with oxidants }\end{array}$ & Nano/microscale & $\begin{array}{l}\text { Hao et al. (2009); } \\
\text { Hao et al. (2011) }\end{array}$ & $\begin{array}{l}\text { Nucleation and growth, } \\
\text { SOA formation }\end{array}$ & \\
\hline
\end{tabular}

Table A2. Field infrastructures used in EUCAARI.

\begin{tabular}{|c|c|c|c|c|}
\hline Methodology & Description & Scale & Reference & Used in \\
\hline Shangdianzi Station station & $\begin{array}{l}\text { Station in China, near } \\
\text { Beijing }\end{array}$ & Regional: China & Shen et al. (2011) & Long term measurements outside Europe \\
\hline \multicolumn{5}{|l|}{ Elandsfontein station and } \\
\hline Botsalano & Station in South Africa & $\begin{array}{l}\text { Regional: South } \\
\text { Africa }\end{array}$ & $\begin{array}{l}\text { Laakso et al. (2010); } \\
\text { Collett et al. (2010) }\end{array}$ & Long term measurements outside Europe \\
\hline EUSAAR station network & 24 stations in Europe & Regional: Europe & Philippin et al. (2009) & $\begin{array}{l}\text { Intensive measurement period, Ground } \\
\text { based measurements inside Europe }\end{array}$ \\
\hline Gual Pahari station & $\begin{array}{l}\text { Station in India, near New } \\
\text { Delhi }\end{array}$ & Regional: India & Hyvärinen et al. (2010) & Long term measurements outside Europe \\
\hline Manaus station & Station in Amazon Basin & Regional: Brazil & Martin et al. (2010) & Long term measurements outside Europe \\
\hline Hohenpeissenberg & Station in Germany & Regional & Fricke et al. (2007) & $\begin{array}{l}\text { Intensive measurement period, Ground } \\
\text { based measurements inside Europe }\end{array}$ \\
\hline $\begin{array}{l}\text { CESAR site (part of } \\
\text { EUSAAR) }\end{array}$ & Station in Netherlands & Local/Regional & $\begin{array}{l}\text { Russchenberg et al. } \\
(2005)\end{array}$ & Intensive measurement period \\
\hline $\begin{array}{l}\text { SMEAR II (part of } \\
\text { EUSAAR) }\end{array}$ & Station in Finland & Local/Regional & $\begin{array}{l}\text { Hari and } \\
\text { Kulmala (2005) }\end{array}$ & $\begin{array}{l}\text { Atmospheric nucleation studies, Biomass } \\
\text { burning experiment }\end{array}$ \\
\hline $\begin{array}{l}\text { Jungfraujoch (Part of } \\
\text { EUSAAR) }\end{array}$ & $\begin{array}{l}\text { Station in Switzerland (free } \\
\text { troposphere): }\end{array}$ & Regional Europe & $\begin{array}{l}\text { Kammermann et al. } \\
(2010) \text {; } \\
\text { Fierz-Schmidhauser } \\
\text { et al. (2010); Juranyi et } \\
\text { al. (2010) }\end{array}$ & $\begin{array}{l}\text { Long-term measurements, Intensive } \\
\text { measurement period }\end{array}$ \\
\hline $\begin{array}{l}\text { Puy de Dôme (Part of } \\
\text { EUSAAR) }\end{array}$ & $\begin{array}{l}\text { Station in Central France } \\
\text { (free troposphere/Boundary } \\
\text { layer) }\end{array}$ & Local/Regional & $\begin{array}{l}\text { Venzac et al. (2009); } \\
\text { Sellegri et al. (2003) }\end{array}$ & $\begin{array}{l}\text { Long-term measurements, Intensive } \\
\text { measurement period }\end{array}$ \\
\hline
\end{tabular}


Table A3. Airborne infrastructures used in EUCAARI.

\begin{tabular}{|c|c|c|c|c|}
\hline Methodology & Description & Scale & Reference & Used in \\
\hline ATR-42 SAFIRE & Aerosol-cloud interactions & Regional & Crumeyrolle et al. (2010) & $\begin{array}{l}\text { Aerosol and cloud } \\
\text { characterization, IOP }\end{array}$ \\
\hline BAe-146 FAAM & Aerosols, boundary layer, lower FT & Regional & (McMeeking et al. (2010); Morgan et al. (2010a, b) & Aerosol characterization, IOP \\
\hline DLR Falcon & Aerosols, free troposphere, lidar remote sensing & Regional & Hamburger et al. (2011) & Aerosol characterization, IOP \\
\hline IfT Helicopter & Aerosols, clouds, and radiation, boundary layer & Local & Wehner et al. (2010); Henrich et al. (2010) & $\begin{array}{l}\text { Aerosol characterisation Inten- } \\
\text { sive measurement period, IOP }\end{array}$ \\
\hline NERC Dornier 228 & Cloud characterization, remote sensing & Regional & http://arsf.nerc.ac.uk/ & Cloud characterisation IOP \\
\hline
\end{tabular}

Table A4. Main computational methods used in EUCAARI (small scale).

\begin{tabular}{|c|c|c|c|c|}
\hline Methodology & Description & Scale & Reference & Used in \\
\hline Ion-UHMA & Ion-Particle interaction simulations & Local & Leppä et al., 2009 & Nucleation \\
\hline PRA kinetic model framework & $\begin{array}{l}\text { Universally applicable rate equations and pa- } \\
\text { rameters for mass transport and chemical re- } \\
\text { actions at the surface and in the bulk of } \\
\text { aerosol particles }\end{array}$ & Nanoscale & $\begin{array}{l}\text { Pöschl et al. (2007) } \\
\text { Ammann and Pöschl (2007) }\end{array}$ & Aerosol transformation \\
\hline K2-SURF, K2-SUB KM-SUB & $\begin{array}{l}\text { Modular kinetic flux models of particle } \\
\text { chemistry }\end{array}$ & Nanoscale & $\begin{array}{l}\text { Shiraiwa et al. (2009, 2010); } \\
\text { Pfrang et al. (2010) }\end{array}$ & Organic aerosol ageing \\
\hline Benchmark thermodynamic model & $\begin{array}{l}\text { The state-of-the-science multicomponent ac- } \\
\text { tivity coefficient code }\end{array}$ & Microscale & Clegg et al. (2008b) & Thermodynamics \\
\hline Equilibrium absorptive partitioning & Method to calculate aerosol partitioning & Microscale & Barley et al. (2009) & Thermodynamics \\
\hline Absorptive partitioning evaluator & $\begin{array}{l}\text { automated methodology for evaluation of } \\
\text { the sensitivities of absorptive partitioning to } \\
\text { vapour pressure and activity coefficient esti- } \\
\text { mation }\end{array}$ & Microscale & McFiggans et al. (2010) & Thermodynamics \\
\hline SALSA, ECHAM-SALSA & $\begin{array}{l}\text { Sectional multicomponent aerosol micro- } \\
\text { physics code for large scale applications }\end{array}$ & Microscale, global scale & $\begin{array}{l}\text { Kokkola et al. (2008); } \\
\text { Bergman et al. (2011). }\end{array}$ & Aerosol dynamics \\
\hline Quantum mechanics calculation & Simulations of nanocluster behaviour & nanoscale & Kurten et al. (2008) & Nucleation \\
\hline Hygroscopicity distribution concept & $\begin{array}{l}\text { Data analysis and simulation of aerosol par- } \\
\text { ticle properties and mixing state with regard } \\
\text { to CCN activation }\end{array}$ & & $\begin{array}{l}\text { Su et al. (2010); } \\
\text { Reutter et al. (2011) }\end{array}$ & $\begin{array}{l}\text { Secondary organic } \\
\text { aerosol formation }\end{array}$ \\
\hline Adaptive method of lines & $\begin{array}{l}\text { Multi-component aerosol condensational } \\
\text { growth and CCN activation }\end{array}$ & microscale & Arabas and Pawlowska (2011) & $\mathrm{CCN}$ activation \\
\hline
\end{tabular}

Table A5. Main computational methods used in EUCAARI (large scale).

\begin{tabular}{|c|c|c|c|c|}
\hline Methodology & Description & Scale & Reference & Used in \\
\hline CAM-Oslo & $\begin{array}{l}\text { global community atmospheric model. with } \\
\text { aerosol lifecycling with parameterized size- } \\
\text { distributions and interactions with clouds } \\
\text { and radiation, coupled to a slab-ocean model }\end{array}$ & Global & $\begin{array}{l}\text { Boville et al. (2006); Iversen et } \\
\text { al. (2010); } \\
\text { Kirkevåg et al. (2008); Seland } \\
\text { et al. (2008); } \\
\text { Hoose et al. (2009) }\end{array}$ & $\begin{array}{l}\text { Interactions between aerosol-driven climate } \\
\text { effects with } \mathrm{CO}_{2} \text {-driven Equilibrium Cli- } \\
\text { mate Sensitivity Modelling, Model inter- } \\
\text { comparison }\end{array}$ \\
\hline ECHAM5-HAM & $\begin{array}{l}\text { Global community Earth System Model, } \\
\text { including the modal aerosol microphysics } \\
\text { scheme M7 (Vignati et al., 2004) and water- } \\
\text { and ice-cloud-aerosol interactions }\end{array}$ & Global & $\begin{array}{l}\text { Roeckner et al. (2003); Stier et } \\
\text { al. (2005); } \\
\text { Lohmann et al. (2007); Makko- } \\
\text { nen et al. (2009); Kazil et } \\
\text { al. (2010) }\end{array}$ & $\begin{array}{l}\text { Natural vs anthropogenic origin of aerosol } \\
\text { particles, climate projections, Earth system } \\
\text { feedbacks, Model intercomparison }\end{array}$ \\
\hline GLOMAP & Global aerosol chemical transport model & Global & $\begin{array}{l}\text { Spracklen et al. (2006); Mann } \\
\text { et al. (2010) }\end{array}$ & $\begin{array}{l}\text { Natural vs. anthropogenic origin of aerosol } \\
\text { particles, Modelling, Model intercomparison }\end{array}$ \\
\hline HadGEM2-ES & Climate and Earth system model & Global & $\begin{array}{l}\text { Collins et al. (2010), Jones } \\
\text { et al. (2007); Bellouin et } \\
\text { al. (2008) }\end{array}$ & $\begin{array}{l}\text { Natural vs. anthropogenic origin of aerosol } \\
\text { particles, climate projections, Earth system } \\
\text { feedbacks }\end{array}$ \\
\hline TM4-ECPL & $\begin{array}{l}\text { 3-dimensional chemistry transport model } \\
\text { with coupled gas/aerosol chemistry }\end{array}$ & Global & $\begin{array}{l}\text { Myriokefalitakis et al. (2008, } \\
\text { 2010, 2011) } \\
\text { Kanakidou et al. (2008) }\end{array}$ & $\begin{array}{l}\text { Natural vs. anthropogenic origin of aerosol } \\
\text { particles, Modelling OA multiphase chem- } \\
\text { istry }\end{array}$ \\
\hline TM5 & Chemistry- Transport model & Global & Krol et al. (2005) & Interaction with policy \\
\hline IPSL-INCA & Climate model & Global & $\begin{array}{l}\text { Textor et al. (2006); } \\
\text { Schulz (2007); } \\
\text { Balkanski et al. (2006) }\end{array}$ & Model intercomparison \\
\hline $\begin{array}{l}\text { European scale EMEP } \\
\text { model, }\end{array}$ & $\begin{array}{l}\text { Community regional and global chemical } \\
\text { transport model }\end{array}$ & $\begin{array}{l}\text { primarily regional }(10-50 \mathrm{~km}) \text {, } \\
\text { but local }(5 \mathrm{~km}) \text { and global pos- } \\
\text { sible }\end{array}$ & Simpson et al. $(2007,2011)$ & $\begin{array}{l}\text { Air quality modelling, for policy support to } \\
\text { EU and UNECE. Natural and anthropogenic } \\
\text { aerosols. }\end{array}$ \\
\hline FLEXPART & $\begin{array}{l}\text { Atmospheric trajectory and particle disper- } \\
\text { sion model }\end{array}$ & Regional & Stohl et al. (2005) & $\begin{array}{l}\text { Natural vs anthropogenic origin of aerosol } \\
\text { particles, Modelling }\end{array}$ \\
\hline PMCAMx-2008 & Three dimensional chemical transport model & Regional & Gaydos et al. (2007) & Modelling \\
\hline CALM & Lagrangian transport model & Local to regional & Tunved et al. (2010) & $\begin{array}{l}\text { Natural vs anthropogenic origin of aerosol } \\
\text { particles, new particle formation }\end{array}$ \\
\hline PMCAMx-UF & Regional chemical transport model & Regional & Jung et al. (2008) & $\begin{array}{l}\text { Natural vs. anthropogenic origin of aerosol } \\
\text { particles }\end{array}$ \\
\hline $\begin{array}{l}\text { Number-emissions pre- } \\
\text { processor for Chemical } \\
\text { Transport Models }\end{array}$ & Module for emission scaling & Regional & Pierce et al. (2007) & Emissions pre-processing \\
\hline
\end{tabular}


Table A6. Databases and inventories used in EUCAARI.

\begin{tabular}{|c|c|c|c|c|}
\hline Methodology & Description & Scale & Reference & Used in \\
\hline $\mathrm{PM}_{0.3}$ inventory & $\begin{array}{l}\text { A further size split in the CEP- } \\
\text { MEIP } \mathrm{PM}_{1} \text { inventory }\end{array}$ & Regional & Visschedijk et al. (2004) & \\
\hline EBAS data base & $\begin{array}{l}\text { Comprehensive observation data } \\
\text { base }\end{array}$ & Global & Philippin et al. (2009) & Data bank \\
\hline Emission inventories & $\begin{array}{l}\text { Spatially distributed emissions of } \\
\text { air pollutants and PM precursors }\end{array}$ & Regional & Denier van der Gon et al. (2010) & \\
\hline Optical properties & $\begin{array}{l}\text { Aeronet/GAW/SKYNET } \\
\text { photometers }\end{array}$ & Global & $\begin{array}{l}\text { Dubovik et al. (2002); } \\
\text { Holben et al. (2001) }\end{array}$ & Model evaluation \\
\hline $\begin{array}{l}\text { Particle Number (PN) } \\
\text { emission factors }\end{array}$ & $\begin{array}{l}\text { Literature derived PN emission } \\
\text { factors for key sources comple- } \\
\text { mented with } \mathrm{PM}_{0.3} \text {-to-number } \\
\text { conversions for sources with no } \\
\text { PN emission data }\end{array}$ & Regional & Denier van der Gon et al. (2009) & Emissions \\
\hline IIASA GAINS & $\begin{array}{l}\text { Particulate matter (PM) invento- } \\
\text { ries }\end{array}$ & Regional & $\begin{array}{l}\text { Kupiainen and Klimont (2007); } \\
\text { http://gains.iiasa.ac.at }\end{array}$ & Emissions \\
\hline $\begin{array}{l}\text { Carbonaceous emission } \\
\text { inventory }\end{array}$ & $\begin{array}{l}\text { New inventory on } \\
\text { European carbonaceous aerosol }\end{array}$ & Regional & $\begin{array}{l}\text { Denier van der Gon et al. (2011a, } \\
\text { in prep.) }\end{array}$ & Emissions \\
\hline $\begin{array}{l}\text { Particle number emission } \\
\text { inventory } \\
\text { Vapour pressure compilation and } \\
\text { evaluation of vapour pressure } \\
\text { estimation techniques }\end{array}$ & $\begin{array}{l}\text { New inventory of European parti- } \\
\text { cle number emissions } \\
\text { Evaluation of vapour pressure } \\
\text { predictive techniques against }\end{array}$ & Regional & $\begin{array}{l}\text { Denier van der Gon et al. ( } 2011 \mathrm{~b} \text {, } \\
\text { in prep.) }\end{array}$ & Emissions \\
\hline available measurements & Microscale & Barley and McFiggans (2010) & Thermodynamics & \\
\hline Gridded satellite products & Gridded POLDER, MISR, & & & \\
\hline $\begin{array}{l}\text { MODIS and OMI aerosol } \\
\text { products }\end{array}$ & Global & $\begin{array}{l}\text { Deuze et al. (2000); } \\
\text { Levy et al. (2010); } \\
\text { Kahn et al. (2009) }\end{array}$ & Satellite retrievals & \\
\hline
\end{tabular}

Table A7. Critical instrumentation used in EUCAARI.

\begin{tabular}{|c|c|c|c|c|}
\hline Methodology & Description & Scale & Reference & Used in \\
\hline APCI-MS & $\begin{array}{l}\text { On-line atmospheric pressure chemical ionization MS- } \\
\text { MS (analysis of particulate organics) }\end{array}$ & In-situ & Warscheid et al. (2003) & Secondary organic aerosol formation. \\
\hline $\begin{array}{l}\text { AMS (Aerodyne Aerosol Mass Spectrometer) q-AMS, } \\
\text { c-ToF-AMS, HR-ToF-AMS }\end{array}$ & $\begin{array}{l}\mathrm{PM}_{1} \text { composition, organic aerosol sources, fingerprints, } \\
\text { and oxidation state }\end{array}$ & In-situ & $\begin{array}{l}\text { Jayne et al. (2000); } \\
\text { De Carlo et al. (2006); } \\
\text { Drewnick et al. (2005); } \\
\text { Jimenez et al. (2009) }\end{array}$ & $\begin{array}{l}\text { Secondary organic aerosol formation; Natural vs. } \\
\text { anthropogenic origin of aerosol particles, Chemi- } \\
\text { cal Ageing of secondary aerosols, photoenhancment } \\
\text { studies }\end{array}$ \\
\hline $\begin{array}{l}\text { ANAIS Airborne Neutral cluster and Air Ion } \\
\text { Spectrometer }\end{array}$ & Measures particles and clusters also below $3 \mathrm{~nm}$ & In-situ & Mirme et al. (2010) & Nucleation; Airborne experiments \\
\hline $\begin{array}{l}\text { API-TOF (Atmospheric Pressure Interface Time of } \\
\text { Flight Mass Spectrometer) }\end{array}$ & Composition of atmospheric ions & In-situ & $\begin{array}{l}\text { Junninen et al. (2010); } \\
\text { Ehn et al. (2010) }\end{array}$ & Nucleation \\
\hline${ }^{14} \mathrm{C}$ & Carbon-14 analyses & Filter & Szidat et al. $(2006,2007)$ & Natural vs. anthropogenic origin of aerosol particles \\
\hline CPCB Condensation Particle Counter Battery & Measures particles below $3 \mathrm{~nm}$ & In-situ & Kulmala et al. (2007b) & Nucleation \\
\hline Direct measurements of $\mathrm{OH}$ radicals & $\begin{array}{l}\text { DOAS long path absorption, absolute method to deter- } \\
\text { mine OH concentrations }\end{array}$ & In-situ & Schlosser et al. (2007) & OH-dose in secondary organic aerosol ageing studies \\
\hline $\begin{array}{l}\text { CCNC } \\
\text { Cloud Condensation Nuclei Counter }\end{array}$ & Measures $\mathrm{CCN}$ number concentration & In-situ & Roberts and Nenes. (2005) & $\begin{array}{l}\text { Secondary organic aerosol formation, intensive mea- } \\
\text { surement period, ground based measurements inside } \\
\text { Europe, long term measurements outside Europe, air- } \\
\text { borne experiments, cloud characterisation IOP }\end{array}$ \\
\hline AP-CIMS & Direct measurements of $\mathrm{H}_{2} \mathrm{SO}_{4}$ and $\mathrm{OH}$ & In-situ & $\begin{array}{l}\text { Berresheim et al. (2000); } \\
\text { Paasonen et al. (2010); } \\
\text { Petäjä et al. (2009) }\end{array}$ & Nucleation \\
\hline H-NMR & Functional group analysis of water-soluble $\mathrm{OC}$ & In-situ & Decesari et al. $(2007,2010 \mathrm{~b})$ & Natural vs. anthropogenic origin of aerosol particles \\
\hline H-NMR and LC-MS & Analysis methods for filter samples & filter samples & $\begin{array}{l}\text { Kiss et al. (2003); } \\
\text { Müller et al. (2011) }\end{array}$ & $\begin{array}{l}\text { HULIS detection and speciation in SOA formation } \\
\text { and ageing }\end{array}$ \\
\hline HPLC/ESI-TOFMS & Sensitive analysis method for gas and filter samples & In-situ & Kahnt et al. (2011) & Speciation in secondary organic aerosol formation \\
\hline Ion-DMPS & Measures particles and ions & In-situ & Laakso et al. (2007) & Nucleation \\
\hline $\begin{array}{l}\text { KEMS Knudsen Effusion Mass } \\
\text { Spectrometry }\end{array}$ & Vapour pressure measurement & In-situ & $\begin{array}{l}\text { Booth et al. (2009, 2010, 2011a (in } \\
\text { prep.), 2011b) }\end{array}$ & Thermodynamics \\
\hline $\begin{array}{l}\text { NAIS (Neutral cluster and Air Ion } \\
\text { Spectrometer) }\end{array}$ & $\begin{array}{l}\text { Neutral cluster and ion concentrations and size } \\
\text { distribution }\end{array}$ & In-situ & Kulmala et al. (2007a) & Nucleation; Intensive measurement period \\
\hline Nano-CPCs & Measures particles below $3 \mathrm{~nm}$ & In-situ & $\begin{array}{l}\text { Sipilä et al. }(2008,2009) \text {; } \\
\text { Vanhanen et al. (2011) }\end{array}$ & Nucleation \\
\hline TDMA system with laminar flow tube & $\begin{array}{l}\text { Evaporation rates of particles at different } \mathrm{RH} \text {; Vapour } \\
\text { pressure measurement }\end{array}$ & In-situ & $\begin{array}{l}\text { Riipinen et al. (2006); } \\
\text { Bilde et al. (2003); } \\
\text { Riipinen et al. (2006); } \\
\text { Koponen et al. (2007) }\end{array}$ & Thermodynamics \\
\hline UFO-TDMA & Ultrafine particle organic fraction detection & & Vaattovaara et al., 2005 & Nucleation \\
\hline
\end{tabular}




\section{Appendix B}

\section{Modelling and experiments of thermodynamics and ageing of organic aerosols, related to Sect. 3.2.2}

The ageing of BSOA from typical Boreal forest emissions during a day-night-day cycle in the SAPHIR chamber was correlated to the $\mathrm{OH}$ dose. Ageing was manifested as a distinctive increase of the $\mathrm{O} / \mathrm{C}$ ratio in the particles and a change in the condensation growth of the particles, indicating the photo-chemical formation of condensible material. Factor analysis of the AMS times series (PMF, Ulbrich et al., 2009) revealed that in the long term BSOA accumulates in a final factor (group of species) with the kinetic characteristics of a product which is formed with $\mathrm{OH}$ and has no significant chemical losses. Interestingly, this factor has an O/C-ratio of 0.75 and shows the same concentration profile as 3-methyl-1,2,3-butanetricarboxylic acid (3-MBTCA, Zhang et al., 2010), as measured simultaneously by APCIMS (Müller, 2010; Müller et al., 2011). 3-MBTCA was shown before to represent a unique biogenic aging marker formed by $\mathrm{OH}$-radical oxidation of semivolatile oxidation products (Müller, 2010; Müller et al., 2011; Szmigielski et al., 2007). Three other factors have the characteristics of intermediate products, with either ozonolysis or $\mathrm{OH}$ reactions as a source and $\mathrm{OH}$ reactions acting as a sink. In sum they represent the semi-volatile organic aerosol fraction with $\mathrm{O} / \mathrm{C}<0.5$ (Jimenez et al., 2009). Tracers like hydroxy pinonic acid and pinic acid correlate with the intermediate factors quite well (Müller, 2010). The correlation between tracers and AMS factors was surprisingly good as the molecular tracers represented only a very small mass fraction of the factors (Mentel et al., 2011). The time dependent ratio of the tracers pinic acid/3-MBTCA and pinonic acid/3-MBTCA indicated that the aerosol aged for about $30 \mathrm{~h}$ had similar characteristics as that observed in field studies in boreal forests (Müller, 2010; Müller et al., 2011). Analysis of 16 filter samples by H-NMR spectroscopy provided confirmation of the changing composition of BSOA with photochemical ageing. Factor analysis showed that the variability in H-NMR composition can be reduced to two or three components, with one characteristic of fresh SOA and exhibiting a maximum during the ozonolysis experiments, and the other two factors being produced by reaction with $\mathrm{OH}$ and being enriched in aged samples. This is in strikingly good agreement with the AMS results (Finessi et al., 2011a). H-NMR and APCI-MS analysis indicated that the original cyclic structure of the first-generations products of $\alpha$-pinene, $\beta$-pinene and carene oxidation is retained in fresh SOA. There the oxidation proceeded first on the lateral chains, while aged BSOA are largely depleted of methylated cyclic structures indicating that a more thorough oxidation has occurred. ESI-LCMS and LC-APCI-MS (both in negative mode) analyses revealed numerous dicarboxylic acids already in the first day of chamber experiments in agreement with the online APCI-MS observations in SAPHIR. Periodic spectral lines $(\Delta m / z=14)$ in a range between $\mathrm{m} / \mathrm{z} 300$ to 800 with maximum intensity around $m / z, 350$ and 550 increased when sesquiterpenes were present. The complexity, periodicity and the wide range of ions resembled those of humic-like substances found in rural aerosol although the maximum in ambient samples was around $\mathrm{m} / \mathrm{z}$ 250-300 (Kiss et al., 2003). UV and Visible absorption of the samples were in accordance with HULIS formation.

In the analysis of the particle-phase with respect to carbonyls, a series of carbonyl group containing oxidation products was identified in the filter samples from Boreal mixture experiments. Among these, the elemental composition of $\mathrm{C}_{15} \mathrm{H}_{24} \mathrm{O}_{4}$ (MW 268) was identified as a sesquiterpene oxidation product based on the number of carbons. The relative intensity of this compound decreased dramatically after the photochemical aging process, suggesting photochemical degradation of this compound in the particle phase. In the experiment with $50 \mathrm{ppb}$ VOC load no significant change in the carbonyl compound concentrations originating from the monoterpenes (pinonaldehyde and endolim) in the particlephase was observed for these experiments. On the other hand, much higher concentrations of pinonaldehyde and endolim were observed after the photochemical aging process in the experiment with higher VOC loads of $100 \mathrm{ppb}$ and the corresponding aging experiment, indicating the continuous production of pinonaldehyde and endolim during the photochemical aging process in presence of higher VOC level. When no sesquiterpenes are present in the VOC mixture, lower concentrations of pinonaldehyde and endolim are observed in the particle phase than the comparable experiment with sesquiterpenes, indicating that sesquiterpenes react fast with $\mathrm{OH}$ radicals acting as an $\mathrm{OH}$ radical scavenger in these experiments.

CCN measurements of the aged particles showed an effective hygroscopicity parameter $\kappa$ of $0.1 \pm 0.02$ (Buchholz, 2010). This is in agreement with the average $\kappa$ of $0.08 \pm 0.03$ for the BSOA from Mediterranen and Boreal tree species (Bucholz, 2010) and with results of CCN field measurements of SOA particles in tropical as well as in mid-latitude environments (Gunthe et al., 2009; Dusek et al., 2010; Pöschl et al., 2010). With regard to the $\mathrm{CCN}$ properties of organic and mixed organic-inorganic aerosol particles, measurement data analyses and sensitivity studies using the new hygroscopicity distribution concept and cloud parcel model suggest that a simple $\kappa$-Köhler model approach can be used for efficient approximation and prediction of CCN concentrations in the atmosphere (Gunthe et al., 2009; Reutter et al., 2009; Pöschl et al., 2010; Su et al., 2010).

Photo-enhanced aging was observed in terms of different observables: Soot, humic acids and proxy components of biomass burning aerosols showed enhanced uptake of nitrogen dioxide and ozone under UV-A or visible light (Stemmler et al., 2007; Monge et al., 2010; Zelenay et al., 2011; Sosedova et al., 2011). The initial step is energy, electron 
or hydrogen atom transfer from a partially oxidized organic precursor (which thereby gets oxidized) to an acceptor, catalyzed by an activated chromophore as a photosensitizer. This drives direct production of radicals, e.g. singlet oxygen (Styler et al., 2009), $\mathrm{O}_{2}^{-}$or $\mathrm{O}_{3}^{-}$(D'Anna et al., 2009), which then react further with the organic substrate or hydrolyse to $\mathrm{HO}_{2}$ and $\mathrm{OH}$, respectively. In the case of $\mathrm{NO}_{2}$ as acceptor, this leads to release of HONO to the gas phase, which is a precursor of $\mathrm{OH}$ there. In terms of particle aging, this photochemistry leads to enhanced rates for the initial oxidation process but also initiates secondary, radical chain reactions that lead to high molecular weight products (Rouviere et al., 2009). Depending on the substrate the hydrophilicity of organic surfaces changes, which is important for $\mathrm{CCN}$ activation of organic particles (Nieto-Gligorovski et al., 2008; Zelenay et al., 2011). Related to these effects, on inorganic substrates, similar photochemistry supports renoxification of nitrate lost through heterogeneous reaction of $\mathrm{HNO}_{3}$ with mineral dust (Vlasenko et al., 2009) via its photocatalytic reduction induced by titanium and iron oxides (Ndour et al., 2009a, b). Similar to the case of HONO above, these light induced reactions also feed back to gas-phase chemistry (Monge et al., 2010b).

A set of models and chemical mechanisms have been developed that enable a consistent description of the chemical transformation and aging of organic aerosol components under a wide range of different conditions, including a a kinetic double-layer surface model (K2-SURF) and a chemical master mechanism (Shiraiwa et al., 2009); a kinetic doublelayer model coupling aerosol surface and bulk chemistry (K2-SUB), in which mass transport and chemical reactions in the particle are represented by a reacto-diffusive flux (Pfrang et al., 2010); and a kinetic multi-layer model (KM-SUB) that explicitly resolves mass transport and chemical reaction at the surface and in the particle bulk (Shiraiwa et al., 2010). The formation and effects of amorphous solid phases in organic aerosol particles were investigated in laboratory and field experiments conducted in parallel to the model development (Mikhailov et al., 2009; Virtanen et al., 2010; Shiraiwa et al., 2011a; Pfrang et al., 2011; Koop et al., 2011). Moreover, studies employing the new models provided unprecedented insights into the the molecular mechanisms and kinetics of aerosol-ozone interactions. They showed that longlived reactive oxygen intermediates (ROIs) are formed. The ROIs explain and resolve apparent discrepancies between earlier quantum mechanical calculations and kinetic experiments. They play a key role in the chemical transformation and adverse health effects of toxic and allergenic air particulate matter, such as soot, polycyclic aromatic hydrocarbons and proteins. Moreover, ROIs may contribute to the coupling of atmospheric and biospheric multiphase processes (Shiraiwa et al., 2011b).

Following the method described in (Riipinen et al., 2006), temperature dependent sub-cooled liquid and solid state vapour pressures and enthalpies of vaporisation for malonic, succinic, glutaric and adipic acid (Riipinen et al., 2007b; Koponen et al., 2007) and vapour pressues of dried oxosuccinic, 2-oxoglutaric, 3-oxoglutaric and 4-oxopimelic acids (Frosch et al., 2010) have been derived from evaporation rate of binary aqueous or dried particles using the TDMA technique. Furthermore, uncertainties in inorganic/organic interactions in aqueous succinic acid/ $\mathrm{NaCl}$ system have been explored using evaporation rates of the ternary mixed particles (Zardini et al., 2010). We also studied solid state vapour pressure from a levitated single organic crystal using optical techniques (an application to succinic acid can be found in Zardini et al., 2009).

Booth et al. (2009) reported vapour pressures for oxalic, malonic, succinic, glutaric and adipic acids measured by KEMS. Further vapour pressures and enthalpies and entropies of sublimation have been reported for the substituted dicarboxylic acids 2-methyl- and 2hydroxy-malonic acid, 2-methyl-, 2-methyl-1,2-hydroxy-, 2-hydroxy-, 2,3-dihydroxy-, 2-amino- and 2-keto-succinic acid, 2-methyl-, 3-methyl-, 3-carboxylic-3-hydroxy-, 2amino-, 2-keto- and 3-keto-glutaric acid (Booth et al., 2010). Similarly, measurements of cyclic aliphatic compounds $(1,1-$ cyclopropane-, 1,1-cyclobutane-, 1,2-cyclopentane- and 1,3and 1,4-cyclohexane-dicarboxylic acids, levoglucosan and cis-pinonic acid; Booth et al., 2011b) and mono- and di-substituted aromatic compound (phthalic-, isophthalic-, terephthalic-, vanillic-, syringic- and p-anisic acids and nitrocatechol) vapour pressures and enthalpies of sublimation have been made (Booth et al., 2011a).

The best estimation techniques for vapour pressure estimation not requiring properties at the critical point were evaluated against available literature data (Barley et al., 2010a). It was clearly demonstrated that the combination of the boiling point and vapour pressure estimation methods of Nannoolal et al. (2004 and 2008 respectively) had the best skill in predicting the vapour pressures of low volatility multifunctional organic compounds as known to occur in the atmosphere. Several vapour pressure estimation methods have been further evaluated against the newly measured values, reaffirming the skill of the Nannoolal et al. $(2004,2008)$ method, but highlighting a number of substantial discrepancies, even in the best techniques.

A reformulated molar absorptive partitioning model (Barley and McFiggans, 2010) has been used to evaluate the sensitivity of the total predicted mass, component O:C ratios, molar masses, volatilities and aerosol properties (densities, GF, CCN, forcing) to estimated properties. The sensitivities to vapour pressure are much greater than to component activity coefficient irrespective of whether the initialisations are randomly generated or predicted using a near-explicit model of oxidative VOC degradation (McFiggans et al., 2010; Barley et al., 2011; Topping et al., 2011a). The sensitivities are increased when trying to represent the complex multicomponent mixture by fewer components. This leads to a requirement to more accurately represent the volatility of, and 
interactions between, all components with increasingly simple representations.

Suitably initialised and constrained, the predictions from equilibrium absorptive partitioning can be compared with suitable ambient measurements where available. At its broadest and most direct, this would be the mole fraction of all components with molecular identification. Such mass balanced characterisation is not practical and the total OA mass, averaged according to $\mathrm{O}: \mathrm{C}$ ratio, molar mass spectrum, volatility distribution and relative POA/SOA contributions are accessible to comparison. Across a broad range of organic vapour and OA mass initialisations, the first four of the above metrics are predicted to fall in a relatively narrow range using the best available property estimation techniques. These metrics have been compared from absorptive partitioning predictions and literature-reported field measurements using output from the near-explicit MCM model (Bloss et al., 2005; Jenkin et al., 2003). Further comparison of this range with ambient measurements emerging from EUCAARI can be used to evaluate limitations with the equilibrium approach and discrepancies used to provide guidance for use of models incorporating the partitioning module developed.

The hybrid Partial Derivative Fitted Taylor Expansion (PD-FiTE) framework was introduced for inorganic compounds by Topping et al. (2009) and for organic compounds by Topping et al. (2011b), the latter based on the sensitivities described in Barley et al. (2011). PD-FiTE is a reduced complexity generalised thermodynamic framework for calculating activity coefficients in solution using optimised parameters to describe component interactions with improved computational performance and comparable accuracy to more complete thermodynamic models. A methodology for the automated generation, optimisation and benchmark evaluation of PD-FiTE has been developed based on the best available property estimation techniques from the sensitivity evaluations described above. Code can be generated to include any number of organic and inorganic compounds to accommodate the chemical mechanism of the host model. All component activities and vapour pressures over particles of given component mole fractions are calculated at the input $\mathrm{RH}$ and temperature. Though the skill in reproducing SOA loading will obviously be determined by the ability of the oxidation mechanism to produce the SOA precursors, PD-FiTE will ensure that minimal error is introduced in the thermodynamic calculation.

The state-of-the-science multicomponent activity coefficient code published on the E-AIM website (http://www.aim. env.uea.ac.uk/aim/aim.php/) was developed as the benchmark code for evaluation of the activity coefficients in the partitioning module. Combination of inorganic and organic activity coefficients was implemented (Clegg et al., 2008b) as well as user specification of organic compounds/surrogate properties and vapour pressure estimation. The E-AIM model can now calculate densities (Clegg and Wexler, 2011a, b) and particle surface tensions (Dutcher et al., 2010) and reference thermodynamic data for inclusion of amines (Ge et al., 2011) has been compiled.

PD-FiTE compares well with E-AIM for inorganic components $\left(\mathrm{H}^{+}-\mathrm{NH}_{4}^{+}-\mathrm{Na}^{+}-\mathrm{SO}_{4}^{2-}-\mathrm{HSO}_{4}^{-}-\mathrm{NO}_{3}^{-}-\mathrm{Cl}^{-}\right)$at $298 \mathrm{~K}$ and for organic components for various example mechanisms. Comparisons are presented in Topping et al. (2009) and Topping et al. (2011b) for inorganics and organics respectively. The linear additive framework readily allows inclusion of organic components with the interaction between inorganic and organic components where appropriate data exists.

The first version of a partitioning module has been incorporated into a coupled model of gaseous photochemistry and explicit multicomponent aerosol microphysics (Topping et al., 2009, 2011b), demonstrating its stability, accuracy and efficiency. The explicit incorporation of the representation of mass transfer into the non-equilibrium treatment of aerosol transformation allows investigation of the roles of kinetic limitations (through, for example, condensed phase diffusion in highly viscous amorphous solid particles) or enhancements (through condensed phase reactions, rapidly forming less volatile components from more volatile ones). This is not possible using equilibrium partitioning treatments.

\section{Appendix C}

\section{Method-specific results of aerosol source apportionment related to Sect. 3.3.3}

\section{C1 Modern/fossil carbon}

The analysis of the ${ }^{14} \mathrm{C} /{ }^{12} \mathrm{C}$ ratio in aerosol samples collected at various locations across Europe indicates that a major fraction of the organic aerosol mass originates from sources of modern carbon. The fraction of modern carbon $\left(f_{\mathrm{M}}\right)$ in TC (total carbon) for the time of year for which ${ }^{14} \mathrm{C}$ data was available at the sites were going from north to south, for Vavihill (SE) $74 \%$, Melpitz (DE) $75 \%$, K-puszta (HU) $78 \%$, San Pietro Capofiume (IT) $54 \%$, and Ispra (IT) $52 \%$. For the background site at Montseny outside Barcelona (ES) samples from two seasons were analyzed for ${ }^{14} \mathrm{C}$ in $\mathrm{OC}$ and EC separately. The fraction of modern carbon $\left(f_{\mathrm{M}}\right)$ in these Montseny samples were for OC: $60-83 \%$ in winter and 71$93 \%$ in summer. The $f_{\mathrm{M}}$ for EC was much lower, $25-46 \%$ in winter and $23 \%$ in summer. These values clearly indicate the importance of sources of modern carbon in European background continental air, most notably biomass combustion sources and biogenic SOA. A clear annual variability in the carbon $f_{\mathrm{M}}(\mathrm{TC})$ was observed at the Ispra site in northern Italy, with $f_{\mathrm{M}}=90 \%$ in winter and $f_{\mathrm{M}}=50 \%$ in summer. Residential wood combustion for heating purposes clearly has a major impact on the organic wintertime aerosol at Ispra (Gilardoni et al., 2011). At Montseny (ES) and Vavihill in 
Southern Sweden (Genberg et al., 2011), $f_{\mathrm{M}}$ was more constant over the year. The $f_{\mathrm{M}}$ were high also at two urban sites studied. In Barcelona, OC- $f_{\mathrm{M}}$ was $51-73 \%$ in winter and $41-83 \%$ in summer. Again, $f_{\mathrm{M}}(\mathrm{EC})$ was considerably lower with $11-24 \%$ in winter and 5-20\% in summer. At an urban site in Zürich, $f_{\mathrm{M}}(\mathrm{TC})$ was $69-94 \%$ in winter.

Ceburnis et al. (2011) showed, by utilising combinations of dual carbon isotope analysis, conclusive evidence of a dominant biogenic organic fraction to organic aerosol over biologically active oceans. In particular, the NE Atlantic, which is also subjected to notable anthropogenic influences via pollution transport processes, was found to contain $80 \%$ organic aerosol matter of biogenic origin directly linked to plankton emissions.

Other OA complementary analytical techniques show that the major sources of modern OA are combustion and burning of biomass in winter and biogenic POA (primary OA) and SOA in summer. All of these have source strengths that are expected to vary in response to climate change. Since $\mathrm{OA}$ is a major component of the sub-micrometer aerosol over Europe, these sources of modern carbon may constitute important feedbacks mechanisms in the climate system.

\section{C2 Aerosol mass spectrometer (AMS) datasets}

A unique OA data set was obtained from 30 AMS campaigns across Europe conducted within the EMEP/EUCAARI framework, mainly from three coordinated campaigns in April/May 2008, September/October 2008 and February/March 2009. The AMS data was acquired at 17 sites around Europe: Auchencorth/Bush (GB), Harwell/Chilbolton (GB), Hyytiälä (FI), Puijo (FI), Helsinki (FI), Vavihill (SE), Cabauw (NL), Jungfraujoch (CH), Payerne (CH), Melpitz (D), Puy de Dome (FR), San Pietro Capofiume (IT), Finokalia (GR), Mace Head (IE), Barcelona (ES), Montseny (ES), K-puszta (HU).

The AMS data clearly show that a large mass fraction of the sub-micrometer aerosol mass in Europe is organic. The average OA concentrations ranged from $1 \mu \mathrm{g} \mathrm{m}^{-3}$ at elevated sites to $8 \mu \mathrm{g} \mathrm{m}^{-3}$ in downtown Barcelona. Organic mass fractions (in (non-refractory $\mathrm{PM}_{1}$ ) range between $20 \%$ to $60 \%$. Temporal variability is typically high at each site.

Positive Matrix Factorization (PMF) was used to examine the OA nature and ageing state, and to identify OA sources. The OA PMF analysis of the 30 AMS data sets yielded 1- to 4-factor PMF solutions, with 2 and 3 factors being most common. The most frequently observed OA component was for all cases OOA (oxygenated OA), followed by HOA (hydrocarbon-like, more fresh OA), BBOA (biomassburning OA), and in one case (Finokalia, Crete) amine-like OA. In Barcelona, the only real city site in this compilation, an additional cooking factor was identified. OOA as derived from the PMF analysis is probably mostly SOA, and dominated OA mass (55-100\% of total OA). POA (if defined as $\mathrm{HOA}$ and $\mathrm{BBOA}$ ) ranged between $0 \%$ (observed in many datasets) and $45 \%$ (Barcelona) of OA. In several data sets affected by biomass combustion and burning, the AMS PMF apportionment of BBOA (biomass-burning OA) agreed well with that derived from levoglucosan analysis on filter samples. Most sites and data sets showed a clear diurnal variability for the various OA PMF factors. As an example, the continental polluted site Melpitz, had the highest concentrations of LV-OOA (low-volatility OOA) during the afternoon hours (mixing down of aged residual air from aloft), a maximum in SV-OOA (semi-volatile OOA) during night (partitioning from gas to particle phase at lower nighttime temperatures), a biomass burning OA maximum in late evening due to residential wood combustion, and HOA peaking during the morning rush hours.

Attempts were also made to estimate the nitrate mass fraction that could be ascribed to organic nitrates, based on unitmass and high resolution AMS data. Average concentrations ranged from below detection limit at remote and elevated sites to $1.6 \mu \mathrm{g} \mathrm{m}^{-3}$ in San Pietro Capofiume. The fraction of sub-micrometer nitrate that was estimated to be non- $\mathrm{NH}_{4} \mathrm{NO}_{3}$ ranged from $20 \%$ to $60 \%$ with typical values around $30 \%$.

\section{C3 Gas Chromatography-Mass Spectrometry - organic tracers}

Analyses of organic tracers using GC-MS analysis of filter samples were used for OA source apportionment at five background sites on a campaign basis (Hyytiälä, San Pietro Capofiume, K-puszta, Melpitz, and Montseny). n-Alkanes and polycyclic aromatic hydrocarbons (PAH) in aerosols were chemically characterized, along with source attribution based on the carbon preference index (CPI), the ratios between the unresolved and the chromatographically resolved aliphatics (U/R), the contribution of wax $n$-alkanes from plants (WNA $\left.=\mathrm{C}_{n}-\left[\mathrm{C}_{n+1}+\mathrm{C}_{n-1}\right) / 2\right]$ ) and diagnostic ratios of PAH. For two other European sites, Vavihill (background site in southern SE) and Ispra (IT), OA source apportionment was performed for a full seasonal cycle on less extensive OA data sets.

The presence of petroleum residues was confirmed by the low CPI values and high ratio of resolved to unresolved aliphatic components, particularly in Hyytiälä and San Pietro Capofiume. The input of primary biogenic sources was significant in K-puszta and Melpitz, where $60 \%$ and about $50 \%$, respectively, of the total $n$-alkanes were attributable to plant waxes. This biogenic contribution represented only 15 and $23 \%$ of the total $n$-alkanes found in the boreal and Mediterranean aerosol, respectively. Diagnostic ratios between PAH suggest that vehicular emissions and biomass burning also influence the aerosol constitution in the Hungarian site. Long range transport of air masses contributed with anthropogenic components to the atmospheric aerosol in the boreal forest. In spite of transboundary pollution, Hyytiälä registered the lowest hydrocarbon levels among all locations. 
Aliphatic and aromatic hydrocarbons in samples from San Pietro Capofiume reveal that both vehicular and industrial emissions are major sources influencing the diurnal pattern of concentrations. The average benzo(a)pyrene equivalent concentration (BaPE) concentrations obtained for every EUCAARI site were far lower than the mandatory limit value $\left(1 \mathrm{ng} \mathrm{m}^{-3}\right)$.

The organic characterization of submicron aerosols from Barcelona, Zürich and Montseny pointed out that traffic is one of the main sources in the urban locations. CPI values close to 1 for the aliphatic fraction of the Montseny aerosol suggest that the anthropogenic input may be associated with the transport of aged air masses from the surrounding industrial/urban areas, which superimpose the local hydrocarbons with biogenic origin. Aerosols from the urban area of Zürich presented a much higher PAH content, and BaPE concentrations sometimes exceeding the mandatory limit. Besides traffic, residential wood burning was found to be another dominant emission source contributing to the atmospheric aerosol at the Swiss urban location, confirming the results obtained by AMS for Zurich and in general in Central Europe during winter (Lanz et al., 2008, 2010).

\section{C4 Nuclear Magnetic Resonance (NMR) spectroscopy}

H-NMR spectroscopy was employed for the off-line analysis of fine aerosol samples (Decesari et al., 2007) collected at the six European sites in 2008-2009, in parallel with AMS measurements. The evaluation of the HNMR data used positive matrix factorization (PMF) techniques and other chemometric methods (Decesari et al.,2011b). Factor analysis was applied to NMR spectral datasets for the following field sites: Hyytiälä, San Pietro Capofiume, Mace Head, Cabauw, Melpitz, K-puzsta, Zürich, and Barcelona-Montseny.

The analysis of the NMR spectra by factor analysis provided a split between four factors: (1) biomass burning products, showing a spectrum containing levoglucosan, but also other polyols and abundant aromatic compounds; (2) biogenic SOA generated by vegetation emissions (terpenes); (3) organic aerosol generated by compounds formed by the degradation of biological material (e.g. alkylamines); and (4) more generic HULIS-like OOA type, with oxidized aliphatic moieties and a smaller contribution from aromatics. The NMR biomass burning factor concentration in the Po Valley correlated well with the concentration of wood burning tracers (levoglucosan) and are also positively correlated with the AMS factors for fresh and aged biomass burning products. The biogenic SOA source type appeared for the March-April 2007 campaign in the Hyytiälä boreal forest site. A high degree of similarity was found between this spectrum and that of biogenic SOA formed from terpene oxidation in the reaction chambers of PSI and FZJ. The amine source type was also found at Hyytiälä. These findings suggest that biogenic organic aerosols in the boreal forest originate from at least two independent sources: condensation of amines and the oxidation of reactive terpenes, with the first process being relatively more important in the low aerosol concentration regime. These results are important since they offer a possible method by which biogenic SOA can be accurately apportioned (Finessi et al., 2011b).

\section{Appendix D}

\section{Organic aerosol modeling in the regional scale related to Sect. 3.4.5}

The EMEP MSC-W chemical transport model (Simpson et al., 2007, 2011) is a key tool for policy support within both the LRTAP Convention and the European Union Clean Air for Europe Programme (CAFE). Improved predictions of especially the organic aerosol component (OA) of PM are urgently required to support these policy fora, as OA typically accounts for $10-40 \%$ of $\mathrm{PM}_{10}$ in Europe.

In order to improve the EMEP MSC-W chemical transport model, the SOA module (Simpson et al., 2007, 2011) has been extended by incorporating a new organic aerosol (OA) scheme based on the Volatility Basis Set (VBS) approach (Robinson et al., 2007). For primary organic aerosol (POA) emissions, the EUCAARI anthropogenic carbonaceous aerosol emission inventory (Denier van der Gon et al., 2010; Visschedijk et al., 2009, Sect. 3.1) was used, which includes improved estimates of residential wood combustion and has high spatial resolution $\left(1 / 8^{\circ} \times 1 / 16^{\circ}\right)$.

The VBS scheme has recently been introduced to help models cope with the wide range of aerosol concentrations and the ongoing oxidation of semi-volatile organics in the atmosphere. VBS models are computationally efficient and are therefore interesting candidates for 3-D modelling. However, they are sensitive to assumptions regarding emissions, the (semi-) volatility of anthropogenic VOC-emissions, and chemical ageing of SOA. Given the lack of theoretical constraints on these SOA models, and general difficulties with the understanding of SOA, comparison and indeed calibration of the model against observational data is essential before models such as EMEP can be used for reliable policy guidance.

The OA model outputs from these and other set-ups have been compared to measurement data and especially source-apportionment results from several European campaigns, including EUCAARI. As discussed in more detail in Bergström et al. (2011), the model performance varies between stations. It seems clear that the VBSPAPS version overestimates OC in summer at most locations. The VBS-PAPS model assumes partitioning of POA emissions, and includes gas phase ageing of both anthropogenic and biogenic SOA as well as POA. This version uses an order of magnitude slower OH-reaction rate for SOA $\left(4 \times 10^{-12} \mathrm{~cm}^{3}\right.$ molecule $\left.^{-1} \mathrm{~s}^{-1}\right)$ than for POA. The other VBS model versions give lower OC concentrations, closer 
to observed levels. For the winter months, all model versions give similar (fairly low) OC concentrations. For two of the measurement sites, Ispra and Illmitz, the EMEP VBS models underestimate winter and early spring concentrations of OC severely. Similar under predictions were noted also in earlier versions of the EMEP OA model (Simpson et al., 2007), and were then shown to result from problems with significant contributions of wood-burning to OA.

Residential wood combustion was shown to be a major source of wintertime OA at Ispra in northern Italy (Gilardoni et al., 2011) in Oslo and a nearby background site in southern Norway (Yttri et al., 2011a, b), as well as at Vavihill in southern Sweden (Genberg et al., 2011). Despite these congruent observations, it is not possible to say at this stage if such contributions are a local problem or reflect more widespread problems with the wood-burning inventories.

\section{Appendix E}

\section{Answers to specific problems described in chapter 1 and also in Kulmala et al. (2009)}

\section{E1 In-situ formation (nucleation) of aerosols}

The most important technical achievement in the nucleation area was the development of new instruments for measuring sub- $3 \mathrm{~nm}$ particle populations, along with the extensive application of these instruments in both laboratory and field studies. These instruments include the Neutral cluster and Air Ion Spectrometer (NAIS, Kulmala et al., 2007a), Ion-Differential Mobility Particle Sizer (Laakso et al., 2007), Condensation Particle Counter Battery (Kulmala et al., 2007b), various other CPC techniques (Sipilä et al., 2008; Vanhanen et al., 2011), and the Atmospheric Pressure Interface Time of Flight Mass Spectrometer (API-ToF-MS, Junninen et al., 2010; Ehn et al., 2010).

Ion spectrometers were continuously operated for roughly a full year at 13 field sites during the EUCAARI Intensive Observation Period (IOP) (Manninen et al., 2010), and the air-borne version of the NAIS was used in the EUCAARI long range experiment (Mirme et al., 2010). Based on NAIS measurements, we obtained the first quantitative estimate of the concentrations of neutral sub- $3 \mathrm{~nm}$ particles in the continental boundary layer (Kulmala et al., 2007a) and the free troposphere (Mirme et al., 2010). The concentrations of neutral sub- $3 \mathrm{~nm}$ particles exceed those of charged particles in the same size range in the lower troposphere (Lehtipalo et al., 2009; Manninen et al., 2010). The average formation rates of 2-nm particles were found to vary by almost two orders of magnitude between the different EUCAARI sites, whereas the formation rates of charged 2-nm particles varied very little between the sites (Manninen et al., 2010). Overall, our observations are indicative of frequent, yet moderate, ion-induced nucleation usually outweighed by much stronger neutral nucleation events in the continental lower troposphere.

All the scientific results obtained during EUCAARI indicate that sulphuric acid plays a central role in atmospheric nucleation (Kerminen et al., 2010; Sipilä et al., 2010). However, also vapours other than sulphuric acid are needed to explain the nucleation and the subsequent growth particle processes. Candidate vapours include various organic compounds and very likely also ammonia or amines (Berndt et al., 2010; Paasonen et al., 2010). Field and laboratory data demonstrate that the nucleation rate scales to the first or second power of the nucleating vapour concentration(s) (Riipinen et al., 2007a; Metzger et al., 2010; Paasonen et al., 2010; Sipilä et al., 2010). This finding agrees with the few earlier field observations, but is in stark contrast with classical thermodynamic nucleation theories.

By using different quantum mechanics methods, atmospherically relevant molecular clusters were studied to elucidate the molecular mechanism behind observed atmospheric nucleation. Our main findings from quantum chemical calculations were that: (i) ammonia can enhance neutral sulphuric acid-water nucleation to some extent, but has a smaller role in corresponding ion-induced nucleation (Ortega et al., 2008), (ii) dimethylamine enhances neutral and ion-induced sulphuric acid-water nucleation in the atmosphere more effectively than ammonia (Kurtén et al., 2008; Loukonen et al., 2010), (iii) some of the organic acids resulting from monoterpene oxidiation can form very stable clusters with sulphuric acid, being good candidates to explain the pool of neutral clusters found in field measurements, and (iv) organosulphates can be involved in ion-induced nucleation.

A major outcome of the EUCAARI nucleation studies is the new semi-empirical nucleation rate parametrizations for neutral and ion-induced nucleation based on field observations (Riipinen et al., 2007a; Paasonen et al., 2010; Nieminen et al., 2010). These parametrizations, while compatible with the atmospheric measurements made during the EUCAARI project, probably need further refinements to become more accurate at varying atmospheric conditions, especially at conditions encountered outside the continental boundary layer. Refining the existing parametrizations requires additional field and laboratory measurement data, such as those coming from the on-going CLOUD experiment (Kirkby et al., 2011).

Direct application of nucleation rate parametrizations is not possible, or at least not desirable, in large-scale modelling frameworks (see Kerminen et al., 2010). As a result, an additional aerosol formation rate parametrization is needed. In EUCAARI, the existing and widely-applied aerosol formation rate parametrization by Kerminen and Kulmala (2002) was further improved (Lehtinen et al., 2007; Anttila et al., 2010). 
E2 Number and mass emissions of primary aerosol from natural and anthropogenic sources at urban, regional, and global scales

Emission inventories for primary particle mass, the distribution of organic and elemental carbon and anthropogenic aerosol particle number emission inventories were developed for Europe within EUCAARI. In particular, the particle number emission inventories developed for Europe were the first of their kind in the world. (see Sect. 3.1, Johansson et al., 2008; Denier van der Gon et al., 2011).

The particle number emissions in Europe are dominated by sub-micron particles. The most important anthropogenic sources of these particles vary considerably depending on country and region: while in the EU countries transport makes about half of the fine particle emissions, in non-EU parts of Europe industrial processes along with residential and commercial combustion dominate the fine particle emission inventories. Fossil fuel production, on the other hand, is not a relevant source of fine particles in any parts of Europe.

Emissions from diesel engines dominate the transportrelated particle number emissions. The particle number emissions from residential combustion are dominated by coal burning emissions, whereas wood burning dominates the particulate mass emissions. A remarkable feature of residential coal burning is the large amount of very fine $\mathrm{PN}(<25 \mathrm{~nm})$ which is related to the sulfur content of the fuel. The transport-related emissions are highest in the densely populated Central and Western Europe, the Moscow region standing out as a single hotspot outside Central Europe. Emissions from road-transport in Eastern Europe are much more allocated to urban centers than in the Western or Central Europe. Particle number emissions from residential combustion are concentrated in Eastern Europe, particularly Poland, Czech Republic, Slovakia, Ukraine and former Yugoslavian countries.

\section{E3 Formation of secondary organic aerosol and the partitioning of semi-volatile compounds between the gas and aerosol phases}

Since the onset of EUCAARI in January 2007, there has been substantial progress regarding our ability to describe the formation of secondary organic aerosol and the partitioning of semi-volatile compounds between the gas and aerosol phases. In 2007, most models seriously underestimated the regional-scale concentrations of secondary organic aerosols (Volkamer et al., 2006) while often overestimating the concentrations of primary organic particulate matter. This deficiency was in part remedied by the realization that a large fraction of the primary organic aerosol (POA) may indeed be semi-volatile, evaporating partially during the rapid dilution that takes place when fresh combustion emissions enter the atmosphere. These semi-volatile gas-phase compounds are subsequently oxidized in the atmosphere and, to a large extent, partition back to the particle phase as oxidized organic compounds (Robinson et al., 2007). The result is that OA mass is shifted from the immediate vicinity of the POA sources - often urban - to further downstream, thus increasing the OA concentrations on a regional scale. For all but the initial oxidation steps, it is evident that, in order to handle OA in regional and global scale models, it is necessary to simplify the complexity of OA, including the POA volatility behaviour and SOA formation and gas-particle partitioning.

Several OA models, also those within EUCAARI (PMCAMx and EMEP) have been updated using the volatility basis set (VBS) concept (Donahue et al., 2006). Alternative descriptions to simplify the wide range of OA properties have been proposed, such as that by Kroll et al. (2011) that uses average oxidation state versus carbon number, that of Pankow and Barsanti (2009) that maps OA according to polarity and carbon number and that of Donahue et al., 2011) (the 2-D VBS) in which the SOA volatility and O/C ratio span a space wherein all SOA can be categorized.

EUCAARI has also contributed to the improvement of our description of OA and SOA formation by providing a model framework for the gas-particle partitioning of semi-volatile $\mathrm{OA}$. The modules that were developed reduce the complexity of the OA partitioning problem, even to an extent where they can be included in global OA models. The OA can be mapped onto a variety of simplified OA spaces, such as O/C ratio versus molecular weight or those described above. In addition, the framework can be used to predict a wide range of important $\mathrm{OA}$ properties $(\mathrm{O} / \mathrm{C}$ ratio, molar mass, volatility, density, hygroscopic growth, $\mathrm{CCN}$ activity) that are directly verifiable against laboratory and field measurements. This ability is essential for the evaluation of the codes. The modules that were developed within EUCAARI offer a link that did not previously exist, between the explicit reaction kinetics as described by the Master Chemical Mechanism and various OA descriptions of reduced complexity.

Another important EUCAARI contribution is the progress with respect to the formation of biogenic SOA. EUCAARI has shown that a large fraction of the OA in Europe is of modern origin, for which the main sources are BSOA, biomass burning and primary biogenic aerosol particles. All these sources are expected to respond to climate change, although we are presently unable to gauge the strength of the multitude of feedback mechanisms involved. For instance, laboratory studies showed that BSOA production from monoterpene precursors increased with temperature, which may constitute a climate cooling effect (negative feedback). On the other hand, increased isoprene emissions, which are to be expected at raising temperatures, was demonstrated to hinder the formation of new particles, which may instead be a positive feedback mechanism (Kiendler-Scharr et al., 2009b). The identification of specific BSOA molecular markers that are representative of various stages of BVOC ageing offers a direct way to apportion the SOA to its various sources and, perhaps even more important, to estimate the state of OA 
ageing that can be compared to other methods, such as those offered by the AMS and HNMR techniques. Another important aspect of SOA formation that received further attention during EUCAARI is the multiphase oxidation reactions. Myriokefalitakis et al. (2011) performed the first global modelling study that explicitly parametrized and evaluated the impact of multiphase chemistry on organic aerosol formation, in particular through oxalic acid formation. Their results have been supported by extensive comparison with observations and demonstrated that multiphase reactions in the global atmosphere can produce significant amounts of water soluble organic aerosol (5-10 $\mathrm{Tg}-\mathrm{C} \mathrm{yr}^{-1}$ of oxalate).

\section{E4 Ageing of aerosols and evolution of their properties during their atmospheric lifetime}

EUCAARI field measurements suggested that chemical aging of OA reduces its volatility of OA by approximately 2 or more orders of magnitude compared to fresh laboratorygenerated monoterpene SOA (Lee et al., 2010). Field measurements suggest that the atmospheric ageing of OA over Europe drives the OA to a state with an almost constant AMS mass spectrum (Hildebrandt et al., 2010) and a fairly narrow range of hygroscopic properties.

Aging of aerosols modifies all properties of aerosols and occurs mostly via coagulation, condensation, or sedimentation. Concerning inorganic aerosols, condensation mainly relates to the condensation of sulfuric acid (through oxidation of $\mathrm{SO}_{2}$ ) and nitric acid (through oxidation of $\mathrm{NO}_{\mathrm{x}}$ ), where the latter typically requires the presence of $\mathrm{NH}_{3}$. While the formation of inorganic aerosols is understood rather well, the condensation of organic components is much less known. An important mechanism in the latter case is the evaporation gas phase reaction - condensation cycle, as outlined in the answer to question D.3.

Aging of organic compounds may occur either by functionalization, fragmentation, or oligomerization (Jimenez et al., 2009). Functionalization and fragmentation mainly occur in the gas phase, while oligomerization is likely to proceed largely in the aqueous phase and produces HULIS (humiclike substances). Functionalization will increase the oxidation state and decrease the volatility. Fragmentation will increase both oxidation state and volatility, and will ultimately lead to $\mathrm{CO}_{2}$. These conflicting rates are currently not well described, although various estimates can be evaluated and constrained in OA models using the VBS approach. Oligomerization will decrease the volatility, with marginal positive or negative changes in the oxidation state, depending on the actual mechanism. Oligomerization may also be accelerated by photoenhancement (Rouviere et al., 2009) or by cloud processing (Michaud et al., 2009). The actual rates of all these oligomerization mechanisms are still poorly known, but the model framework will in the future have to incorporate the rates at which this oligomerization proceeds, including their relative importance compared to functionalization and fragmentation.

EUCAARI has identified specific BSOA molecular markers that are representative of various stages of BVOC ageing. BSOA ages related to the experienced $\mathrm{OH}$ dose, leading eventually to highly oxidized compounds. BSOA observed in chambers is characterized by 2-4 different ageing states, which can be mapped to the two OOA classes observed in the atmosphere (Jimenez et al., 2009) and related to certain molecular markers like pinic acid or 3-MBTCA. Overall, the ageing processes over 2-3 days lead to a mass increase and more persistent organic aerosols with increased hygroscopicity. The ratios of such markers characterize the BSOA age, applicable in field studies. They also offer a way to apportion the SOA to its various sources and, perhaps even more important, to estimate the state of OA ageing that can be compared to other methods, such as those offered by the AMS and HNMR techniques.

In the $f_{44}$ vs. $f_{43}$ space of AMS fragments ( $\mathrm{Ng}$ et al., 2010) the OOA (which mostly represents SOA in the absence of considerable amounts of biomass burning aerosol) spans a characteristic triangle, where fresh SOA is found at the bottom and moves upwards during aging. The larger diversity of compositions observed for fresh OOA reflects the multiple fingerprints of anthropogenic (e.g. biomass burning) and biogenic (e.g. terpene SOA) sources, while the aged OOA exhibits a consistent composition dominated by humic-like substances (HULIS) and related compounds. Each area can be related to H-NMR spectra obtained by simultaneous sampling during various EUCAARI campaigns, where the latter can be tentatively interpreted to correspond to the various AMS OA source types.

Low-volatility oxidized organic aerosol (LV-OOA, which includes the HULIS fraction) is the end-product of OA ageing, and is found in the upper apex of the triangle. It is the most common constituent of the European regional continental polluted background under clear sky and stable meteorological conditions (from May 2008 IOP).

\section{E5 Attribution of the different aerosol mass components in Europe to specific sources}

The sources of sulphate, nitrate, ammonium, sodium, chloride, and crustal elements are relatively well understood in Europe so EUCAARI focused on OA and EC sources. OA is the most important component of fine PM in Europe (with the exception of Southeast Europe). A large fraction of this OA (more than half in most areas and seasons) is of modern origin, for which the main sources are biogenic SOA and biomass burning. Biogenic SOA dominates during the summer, while residential biomass burning is the major modern OA source during the winter.

The most important anthropogenic primary OA source according to the EUCAARI European inventory is nonindustrial combustion followed by agriculture and road 
transport. Significant contributions to primary OA emissions are also made by production processes, other mobile sources and machinery and waste treatment and disposal. However, most of this POA is rapidly transformed to oxidized OA through atmospheric chemistry. POA concentrations are very low in Europe outside the major urban areas. Wood burning emissions appear to be underestimated in at least some European countries.

Road transport and non-industrial combustion are the two major EC emission sources followed by other mobile sources. Significant contributions to the EC levels are also made by production processes, waste disposal and agricultural sources.

The reduction in ammonia emissions is one of the most effective ways to reduce aerosol mass concentrations in $\mathrm{Eu}-$ rope. Reduction in $\mathrm{NO}_{\mathrm{x}}$ is also effective, but might lead to higher ozone levels. Reduction in $\mathrm{SO}_{2}$ emissions will reduce particulate air pollution especially in the Eastern Mediterranean area. Reduction of organic aerosol concentrations is a lot more challenging and will require reductions of gas and aerosol emissions from transportation and biomass burning.

\section{E6 Current and future contributions of natural versus anthropogenic, and primary versus secondary sources to particle number concentrations}

The contributions of primary versus secondary and natural versus anthropogenic contributions to particle number concentrations have been studied with models simulating atmospheric transport and composition in both European and global scales (Jung et al., 2008; Spracklen et al., 2010; Merikanto et al., 2009, 2010; Fountoukis et al., 2011b).

The particle number concentrations are typically dominated by sub-micron particles, and a large fraction, usually several tens of percents, of these particles have originated from condensation of atmospheric vapours (Spracklen et al., 2006; Makkonen et al., 2009; Merikanto et al., 2009; Jung et al., 2010; Spracklen et al., 2010). Typically roughly every second aerosol particle in the European boundary layer is of secondary origin. This highlights the need for combined emission inventories and regulations for gas phase compounds and aerosol particles, instead of treating them as separate and non-interactive constituents of the atmosphere.

Because of the large contribution of secondary particles, the natural and anthropogenic contributions to particle number concentrations are difficult to quantify exactly. We have shown that often both natural (e.g. biogenic organic compounds) and anthropogenic (e.g. sulphuric acid or anthropogenic organics) vapours participate in the formation of secondary aerosol particles (Spracklen et al., 2008b; Metzger et al., 2010). While anthropogenic sulphate emissions are a major factor governing formation of new particles, natural emissions of biogenic organic vapours play an important role in defining the aerosol size distributions and the climatic impact of aerosols. Indications on the sensitivity of particle number concentrations to anthropogenic and natural gas emissions can be obtained with model studies (Spracklen et al., 2008a; Makkonen et al., 2011). The results suggest that a decrease of $50 \%$ in $\mathrm{SO}_{2}$ emissions will result in a moderate $(15-20 \%)$ decrease in particle number concentrations in all size classes (see Kerminen et al., 2010 and Sect. 3.2.1). A corresponding reduction in primary particle emissions, on the other hand, would have only a minor effect on the smallest particles or total number concentrations, but a moderate one (around $20 \%$ ) on the particles larger than $100 \mathrm{~nm}$ in diameter. Additionally, we have shown that biogenic organic emissions from vegetation are an important factor driving the concentrations of climate-relevant aerosols over remote continental regions. Spracklen et al. (2008a) found that inclusion of biogenic emissions from forests roughly doubled the climate-relevant aerosol number concentrations over the boreal region.

To assess the effect of air quality regulations on particle number concentrations, the effect of primary particle emissions along with secondary particle formation on global particle number in pre-industrial, present and future conditions (years 1850, 2000 and 2100 - using the IPCC scenario A1B) was studied (Makkonen et al., 2011). It was found that the future air quality improvements are likely to considerably decrease aerosol number concentrations and thus the cooling effect of aerosols on climate. According to these first results, the probability that any reasonable changes in natural emissions could counteract this effect is very small (Tunved et al., 2008).

Although our results shed light on the sensitivity of aerosol number concentrations to anthropogenic pollutants and natural emissions, the future forecasts are challenging due to the multitude of atmospheric processes affecting the modelling results. This highlights the need to maintain and possibly extend the provision of long-term data for atmospheric composition and gas-aerosol distributions (Reddington et al., 2011).

Overall, EUCAARI has shown clearly that particle formation processes from anthropogenic and natural gaseous precursors are a major source of cloud drop-forming aerosol over Europe. The process needs to be accurately described in climate models so that the link between climate and air quality can be established reliably. EUCAARI therefore provides a clear plan for the future development of regional and global air quality and climate models.

\section{E7 Long-range transport of aerosol particles and their precursors from and to Europe as well as their transport within Europe}

Birmili et al. (2008) showed that dust emissions in the southern Ukraine during a drought can cause very high $\mathrm{PM}_{10}$ concentrations (between 200 and $1400 \mu \mathrm{g} \mathrm{m}^{-3}$ ) over Central Europe. While such strong long-range transport events are probably not very frequent, this shows that dust transport 
models need to account for this dust source, in addition to the more frequently studied Saharan dust events. Saharan dust has been shown repeatedly to be an important source of coarse-mode particles $\left(\mathrm{PM}_{10}\right)$ in Southern Europe (e.g. Pikridas et al., 2010). However, it was also shown that the concentrations of sub-micron particles $\left(\mathrm{PM}_{1}\right)$ on Crete are lowest in marine air masses and highest in air masses transported from the Balkans, Turkey and Eastern Europe (Pikridas et al., 2010), showing that the export of pollution from Eastern Europe can influence large areas of the Mediterranean and likely beyond.

Transport of aerosol pollution from Eastern Europe also affects Scandinavia. Virkkula et al. (2010) found that the highest values of the aerosol light absorption coefficient at a remote site in Finland were associated with transport of air masses from Eastern Europe. Furthermore, Saarikoski et al. (2008) have shown that long-range transport can play a role even in urban areas in Scandinavia. They found that $24 \%$ of the OC found in Helsinki can result from long-range transport into the urban area, including a contribution from agricultural or wild fires.

During the EUCAARI-LONG Range EXperiment (EUCAARI-LONGREX), a sustained anticyclonic situation over Central Europe caused accumulation of aerosol pollution in the boundary layer and its subsequent export to the west and north-west (Hamburger et al., 2011). This allowed studying both the accumulation as well as the export of aerosol pollution from Europe and the changes in chemical composition occurring en route. Substantial amounts of pollution were observed by aircraft far downwind of continental Europe, with OA and ammonium nitrate being the major constituents of the sub-micron aerosol burden (Morgan et al., 2010a). Refractory black carbon concentrations were enhanced, too (McMeeking et al., 2010). At Mace Head on the Irish west coast, large differences were found between marine air masses arriving from the west and European polluted air masses arriving from the east. While organic matter dominated the sub-micron aerosol mass in the European pollution outflow, sulphate was dominant in the marine air masses. While polluted-continental aerosol concentrations were of the order of $3000 \mathrm{~cm}^{-3}$, background marine air aerosol concentrations were between $400-600 \mathrm{~cm}^{-3}$. Recirculation in the high-pressure system during EUCAARI-LONGREX also caused the return of some of the exported pollution from the North Atlantic into Northern Europe (Hamburger et al., 2011).

In summary, EUCAARI has shown that long-range transport of aerosol pollution from Central and Eastern Europe can exert a large influence in the Mediterranean, over the North Atlantic and over Scandinavia. On the other hand, Central Europe is influenced by long-range transport of dust from the Sahara but occasionally also from Eastern Europe, and is also influenced by transport of biomass burning plumes.

\section{E8 Seasonal behaviour of aerosol particles in economically developing countries}

South-Africa: the seasonal variation of the aerosol near Johannesburg is significantly affected by domestic and biomass burning especially during the dry and cold winter season. Furthermore, the aerosol fine and coarse mass concentrations showed clear seasonal variation. $\mathrm{PM}_{2.5}$ was on average $28 \mu \mathrm{g} \mathrm{m}^{-3}$ during the winter and spring, and as low as $13 \mu \mathrm{g} \mathrm{m}^{-3}$ during the summer. $\mathrm{PM}_{2.5-10}$ was highest during the fall, $29 \mu \mathrm{g} \mathrm{m}^{-3}$ and lowest during the summer, $11 \mu \mathrm{g} \mathrm{m}^{-3}$. The aerosol scattering coefficient at $520 \mathrm{~nm}$ wavelength was highest during the winter period $\left(80.7 \mathrm{Mm}^{-1}\right)$ accompanied by an absorption coefficient of $8.5 \mathrm{Mm}^{-1}\left(\sim 1.3 \mu \mathrm{g} \mathrm{m}^{-3}\right.$ black carbon). Particle number concentrations (20-800 nm) were highest $\left(5900 \mathrm{~cm}^{-3}\right)$ due to strong new particle formation during the summer season, while the lowest concentrations $\left(3300 \mathrm{~cm}^{-3}\right)$ were observed during autumn, when nucleation was reduced. The fine fraction consisted of OC ( $45 \%$ during the spring, $14 \%$ during the summer), sulphates (44\% during the summer, $20 \%$ during the spring) and ammonia (20\% during the summer, $8 \%$ during the spring).

The local summer (December-February) had the most distinct planetary boundary layer (PBL) evolution on most days. A very shallow aerosol layer was observed during the night and an increase up to $2-3 \mathrm{~km}$ during the day on average. The maximum layer thickness was about $5 \mathrm{~km}$. This period was the cloudiest period of the year and in contrast winter (JuneAugust) was almost totally unclouded. Strong and complex multi-layered structure of the aerosol was observed throughout the year, most frequently in autumn (March-May). Winter and partly spring (September-November) showed mostly a stable aerosol layer up to $1-3 \mathrm{~km}$ height and also the diurnal variation was the weakest in winter.

India: the seasonal variation of the aerosol characteristics was very distinct in Gual Pahari. The highest concentrations were observed during the winter $\left(\mathrm{PM}_{10}\right.$ mean $=322 \mu \mathrm{g} \mathrm{m}^{-3}$ ) and the lowest during the rainy season $\left(\mathrm{PM}_{10}\right.$ mean $\left.=93 \mu \mathrm{g} \mathrm{m}^{-3}\right)$. During the pre-monsoon (March-June) surface concentrations began to decrease as the temperatures increased thus intensifying the natural convection. The coarse mode contribution increased to 40$50 \%$ due to dust events. During the monsoon season (JulySeptember), aerosol concentrations decreased by $50-70 \%$ compared to the pre-monsoon season, depending on the total seasonal rainfall. OM, EC, nitrate, sulphate, and ammonium had highest concentrations during the dry season. OM dominated the fine mass; it represented $60 \%$ of the fine mass during the wet season and around $50 \%$ during the dry season. During the wet season higher relative contributions of EC and sulphate were observed. During the dry season the contribution of ammonium and nitrate increased. Equivalent black carbon concentrations alone averaged to $17.7 \mu \mathrm{g} \mathrm{m}^{-3}$. In the post-monsoon season (October-November) the fine fraction started to dominate the aerosol characteristics with 
total aerosol number concentration averaging $24000 \mathrm{~cm}^{-3}$. During winter the night- and day time temperatures had their lowest values, thus decreasing natural convection and the boundary layer height.

Brazil: aerosol physical properties were measured at a pristine Amazonian forest site from February 2008 to January 2011. A strong seasonal behaviour was observed, with greater aerosol loadings during the dry season (JulyNovember) as compared to the wet season (DecemberJune). During the wet season, aerosol scattering $(450 \mathrm{~nm})$ and absorption $(637 \mathrm{~nm})$ coefficients averaged, respectively, $14 \pm 22$ and $0.9 \pm 0.8 \mathrm{Mm}^{-1}$, increasing to $58 \pm 58 \mathrm{Mm}^{-1}$ and $4.1 \pm 3.8 \mathrm{Mm}^{-1}$ during the dry season, correspondingly. From wet to dry season, integrated aerosol number concentrations increased approximately by a factor of two. During the wet season, the Aitken mode $(\sim 30-100 \mathrm{~nm})$ was prominent, suggesting the presence of secondary aerosol. In contrast, during the dry season the accumulation mode (100$500 \mathrm{~nm}$ ) dominates the aerosol size spectra, indicating the presence of primary and/or aged aerosol.

$\mathrm{PM}_{2.5}$ and $\mathrm{PM}_{2.5-10}$ samples were taken from February to June (wet season) and from August to September (dry season) in 2008. The mass of fine particles averaged $2.4 \mu \mathrm{g} \mathrm{m}^{-3}$ during the wet season and $4.2 \mu \mathrm{g} \mathrm{m}^{-3}$ during the dry season. The average coarse aerosol mass concentration during wet and dry periods was 7.9 and $7.6 \mu \mathrm{g} \mathrm{m}^{-3}$, respectively. The overall chemical composition of fine and coarse mass did not show any seasonality, with the largest fraction of fine and coarse aerosol mass explained by organic carbon (OC). The average OC to mass ratio was 0.4 and 0.6 in fine and coarse aerosol modes, respectively. $44 \%$ of fine total carbon mass was assigned to biomass burning, $43 \%$ to secondary organic aerosol (SOA), and $13 \%$ to volatile species that are difficult to apportion. The carbon fraction represented by biomass burning and SOA were $35 \%$ and $49 \%$ during the wet season, and $71 \%$ and $25 \%$ during the dry season, respectively. In the coarse mode, primary biogenic aerosol particles (PBAP) dominated the carbonaceous aerosol mass. The PBAP concentration averaged $2.4-1.6 \mu \mathrm{g} \mathrm{m}^{-3}$, with higher values during the wet season, up to $7 \mu \mathrm{g} \mathrm{m}^{-3}$.

China: The number concentration of nucleation mode particles showed a clear monthly variation with the minimum mean value of about $1000 \mathrm{~cm}^{-3}$ in July and August 2008 and a maximum mean value of $10000 \mathrm{~cm}^{-3}$ in March 2008. The nucleation events peaked in spring and early summer and reached a minimum in summertime. During these particle formation events, the number concentration of the nucleation mode rose up to $10000 \mathrm{~cm}^{-3}$. Due to particles growth, the mean number concentration of Aitken mode particles was higher during spring and early summer. The total particle number concentration was higher in spring months and lower in summer months, and the monthly mean concentration varied from about 6000 to $20000 \mathrm{~cm}^{-3}$.

Lidar measurements revealed that the top height of the aerosol layer was around $900 \mathrm{~m}$ above ground for all seasons, only slightly higher during the summer months. Frequently, elevated aerosol layers were observed, especially during winter and spring. A mean aerosol optical depth (AOD) of 0.95 was observed for air masses arriving from the North China Plain. In contrast, the mean AOD was only about 0.42 for northerly air masses.

\section{E9 Air quality and local climate interactions inside and outside Europe}

Applying a mix of available technical and non-technical reduction measures of short-lived climate forcing components and air pollutants can give a co-beneficial climate and air quality mitigation. These measures used in several assessments on global and regional scale, e.g. for Europe and the Arctic, gave a $50 \%$ reduction in integrated forcing from short-lived climate forcing components by applying maximum feasible reductions while even lower forcing can be reached by less stringent sulphur emission reductions outside Europe.

When stringent air pollution control measures are implemented worldwide, the present-day negative total aerosol top-of-the-atmosphere radiative forcing will be reduced by $50 \%$ by 2030 . Climate change thereafter will be controlled to a larger extent by changes in greenhouse gas emissions. The net effect of increasing GHG concentrations and lower aerosol concentrations is a global annual mean equilibrium temperature increase of approximately $2.2 \mathrm{~K}$. If additional emission controls are applied only to the industrial sources including power plants but not on the domestic and transportation sectors the predicted temperature increase is $1.9 \mathrm{~K}$. Increasing GHG concentrations alone leads to a temperature response of $1.2 \mathrm{~K}$. As aerosols strongly impact surface forcings the consequences for precipitation increases associated with global warming are even stronger.

By 2100 , the response of natural aerosol to changes in climate could cause a direct radiative forcing feedback of up to $1 \mathrm{Wm}^{-2}$. This feedback includes changes in dust, wildfires, biogenic secondary organic aerosol, and sulphate aerosols formed from marine biota emissions of dimethyl sulphide (DMS) gas. At present there is not enough information to allow an estimate of the indirect radiative effect of these changes in natural aerosols. However, local effects have been estimated, and could be several Watts per square meter. Thus, the response of natural aerosol emissions to changes in climate could have significant effects on local climate and air quality.

Large averaged July $\mathrm{O}_{3}$ changes of $+8.9 \mathrm{ppb}$ and $-3.5 \mathrm{ppb}$ are predicted for the IPCC A2 and B1 emissions scenarios, respectively, under present-day climate for Europe for 2050. Climate change (IPCC SRES A2 2050s) alone causes Julyaverage $\mathrm{O}_{3}$ increases of up to $2 \mathrm{ppb}$ in western and southern Europe, due largely to increased isoprene emissions.

Substantial fine PM decreases are predicted for the B1 emissions scenario in both summer and winter. 
Contrastingly, large localized PM increases are predicted for the A2 emissions scenario due to increases in nitrate, POA and BC, with a strong seasonal and regional dependence. Climate change alone causes small domain-average PM changes, but notable local increases in some PM species due to reduced precipitation and increase in biogenic SOA.

These results highlight the potential impact of future climate change on air pollution and vice versa of air-qualitydriven mitigation strategies on climate.

\section{E10 The impact of aerosols and trace gases on cloud droplet activation, cloud lifetime, and extent (the aerosol indirect effects)}

The aerosol indirect effects on climate, i.e. their influence on cloud properties and precipitation, depend on aerosol properties and cloud microphysics as well as on meteorological conditions. Before EUCAARI, the uncertainties related to aerosol properties were similarly high as those related to cloud microphysics and meteorology. By synthesis of EUCAARI project results and related studies, the uncertainty of key parameters in aerosol properties and cloud microphysics could be reduced by about $50 \%$ (aerosol particle hygroscopicity, size distribution, number concentration, dilution ratio, effective radius, etc.).

With regard to cloud droplet activation, cloud lifetime, and extent, aerosol properties and cloud microphysics appear now well constrained relative to the uncertainties of meteorological conditions (updraft velocities, spatial inhomogeneity, etc.). In particular, the effective hygroscopicity of aerosol particles, i.e. their ability to absorb water vapour and to form cloud droplets, can be efficiently approximated by a single hygroscopicity parameter $(\kappa)$. This parameter is easy to calculate from aerosol chemical composition data. EUCAARI extensive observations have been extremely useful to constrain $\kappa$ values for air mass conditions in Europe. We showed that, on average, it is limited to fairly narrow value ranges for continental and marine boundary layer aerosols $(0.3 \pm 0.2$ vs. $0.7 \pm 0.2$; Pringle et al., 2010$)$. Thus, the current knowledge of $\mathrm{CCN}$ properties can be used as a constraint rather than a tuning parameter in climate models (Heintzenberg and Charlson, 2009).

One of the key questions in current research on air quality - climate interactions are the direct and indirect climate effects of black carbon in carbonaceous combustion aerosols. Reductions in black carbon emissions are often perceived as an attractive global warming mitigation option (e.g. Bond and Sun, 2005; Jacobson, 2010; Kopp and Mauzerall, 2010). However, carbonaceous combustion aerosol can also act as cloud condensation nuclei and thus cool the climate by increasing cloud albedo (Koch et al., 2011). Recent studies suggest that that carbonaceous combustion aerosol accounts for a large portion of the increase in the atmospheric abundance of cloud condensation nuclei since pre-industrial times (Bauer et al., 2010; Spracklen et al., 2011). This aspect must be considered to ensure that black carbon emissions controls have the desired net effect on climate.

\section{E11 Interactions between the aerosol cycle, the water cycle, and the biosphere}

The precipitation response and thus the hydrological sensitivity differ strongly for greenhouse gas (GHG) forcing and aerosol (AE) forcings. We find a hydrological sensitivity for the GHG simulation of $1.96 \% / \mathrm{K}$ and $2.81 \% / \mathrm{K}$ for the $\mathrm{AE}$ simulation. As a result the precipitation increase is strongly enhanced when aerosol forcings are considered (e.g. GHG: $+0.07 \mathrm{~mm} \mathrm{~d}^{-1}$; GHG+AE: $+0.15 \mathrm{~mm} \mathrm{~d}^{-1}$. However, expected future air pollution mitigations, as considered in this study, will reverse this. Decreasing aerosol emissions in the future can lead to an even stronger increase in precipitation as can be expected from GHG forcing alone. This effect is estimated to be strengthened by further feedbacks between GHG driven precipitation increase and aerosol wet removal (Iversen et al., 2010). The implied reduced atmospheric residence time of aerosols is estimated larger for the presentday (year 2000) aerosol emissions than it would have been if aerosols were kept at pre-industrial levels. The aerosol cooling effect is thus reduced by the increased GHG, causing reinforcement of the GHG driven global warming.

Changes in climate extremes may have severe implications for food supply and human security. The type, frequency and intensity of extreme events are expected to change as climate changes. In a warmer future climate, there will be an increased risk of more intense, more frequent and longerlasting heat waves. Summer drying and more intense precipitation in winter is expected as well. This trend might be enhanced by future reduction in aerosol emissions. Aerosols reduce solar insolation and thus cool the surface during daytime and exert a warming effect during nighttime, damping temperature extremes and the diurnal amplitude. Aerosols decrease the evaporation rate and increase the stability in the boundary layer (Paeth and Feichter, 2006). This affects precipitation amount and distribution. In addition, aerosol particles influence cloud microphysics and precipitation formation. As shown by Paeth and Feichter (2006), high aerosol loading damps extreme values of temperature and precipitation, so we expect more extreme conditions if applying stricter air pollution measures and reducing aerosol emissions.

Results were analyzed focusing on extreme values of temperature and precipitation. Indicators for moderate weather extremes have been introduced which take place on larger temporal and spatial scales and are, therefore, suitable for analyses of global model results (Sillmann, 2009). We conducted simulations in which only GHG concentrations are changed or only aerosol emissions are changed to disentangle the importance of both individual forcing agents. 
A future reduction of aerosol pollutants results in:

- warmer temperature minima in higher latitudes;

- higher temperature maxima over continents and $\mathrm{NH}$ oceans;

- the occurrence of tropical nights extends polewards;

- dry spells decrease slightly in the desert belt, the Sahara and Arabian peninsula, but increase significantly over Amazonia, southern Africa and Australia.

- 5-day precipitation increases in Monsoon regions and higher NH latitudes.

- Wet days decrease over Amazonas region, southern Africa and Australia and increase over Indian and WestAfrican monsoon regions and over high- and midlatitudes of the $\mathrm{NH}$.

\section{E12 Aerosol interactions in the Earth System}

EUCAARI has advanced our understanding of the interactions and feedbacks in the Earth System, which involve aerosol processes and properties. We have assessed the role of climate change as a driver of changes in anthropogenic aerosols as well as the strength of climate feedbacks involving aerosol species. The uncertainties in these feedbacks have partly been quantified through a multi-model approach and by undertaking the first ever review and synthesis of the available literature covering observational and modeling studies.

Our review of aerosol feedbacks in the Earth system concludes that by 2100, the response of natural aerosol to changes in climate could cause a direct radiative forcing feedback of up to $1 \mathrm{~W} \mathrm{~m}^{-2}$ (Carslaw et al., 2010). This feedback includes changes in dust, wildfires, biogenic secondary organic aerosol, and sulphate aerosols formed from marine biota emissions of dimethyl sulphide (DMS) gas. At present there is not enough information to allow an estimate of the indirect radiative effect of these changes in natural aerosols. However, local effects have been estimated, and could be several Watts per square metre. Thus, the response of natural aerosol emissions to changes in climate could have significant effects on local climate.

Advances have been made during the EUCAARI project concerning the impact of changes in marine and terrestrial biogenic emissions. The ECHAM and HadGEM2-ES climate models have been updated and used to simulate the climate response to these changing emissions. The results suggest that any thermostat involving DMS or biogenic volatile organic compound emissions in a future climate is weaker than suggested by previous studies. Although ECHAM and HadGEM2-ES disagree on many aspects of the DMS feedback, both models suggest that DMS emissions respond to climate change in a limited way. Moreover the change in cloud condensation nucleus concentrations associated with a change in DMS may also be small.

Changes in sea-spray aerosol are likely to occur in regions of sea ice retreat at high northern latitudes. In the Southern Hemisphere the acceleration of wind speeds, due most likely to the appearance of the Antarctic ozone hole, has been predicted in a model to cause large increases in sea spray aerosol production, causing a localized cooling that may have counteracted greenhouse gas-induced warming over the past 2-3 decades. The climate feedback associated with changes in dust emissions remains ambiguous, but is likely to be an important factor in local changes in climate, and possibly in nutrient supply to the ocean biota.

\section{Appendix F}

\section{EUCAARI Partners}

\begin{tabular}{|c|c|}
\hline Partner & Country \\
\hline HELSINGIN YLIOPISTO & Finland \\
\hline $\begin{array}{l}\text { CENTRE NATIONAL DE LA RECHERCHE SCIENTIFIQUE } \\
\text { (CNRS) }\end{array}$ & France \\
\hline $\begin{array}{l}\text { MAX PLANCK GESELLSCHAFT ZUR FOERDERUNG DER } \\
\text { WISSENSCHAFTEN E.V. }\end{array}$ & Germany \\
\hline $\begin{array}{l}\text { LEIBNIZ INSTITUT FUER TROPOSPHAERENFORSCHUNG } \\
\text { e.V. }\end{array}$ & Germany \\
\hline CONSIGLIO NAZIONALE DELLE RICERCHE & Italy \\
\hline EIDGENOESSISCHE TECHNISCHE HOCHSCHULE ZUERICH & Switzerland \\
\hline $\begin{array}{l}\text { NEDERLANDSE ORGANISATIE VOOR TOEGEPAST NATU- } \\
\text { URWETENSCHAPPELIJK ONDERZOEK - TNO }\end{array}$ & The Netherlands \\
\hline $\begin{array}{l}\text { KONINKLIJK NEDERLANDS METEOROLOGISCH INSTI- } \\
\text { TUUT (KNMI) }\end{array}$ & The Netherlands \\
\hline UNIVERSITY OF LEEDS & United Kingdom \\
\hline LUNDS UNIVERSITET & Sweden \\
\hline PANNON EGYETEM & Hungary \\
\hline ILMATIETEEN LAITOS & Finland \\
\hline $\begin{array}{l}\text { European Community represented by the European Commission - } \\
\text { Directorate General JRC }\end{array}$ & $\mathrm{EU}$ \\
\hline MET OFFICE & United Kingdom \\
\hline NORSK INSTITUTT FOR LUFTFORSKNING & Norway \\
\hline METEOROLOGISK INSTITUTT & Norway \\
\hline NATIONAL UNIVERSITY OF IRELAND, GALWAY & Ireland \\
\hline PAUL SCHERRER INSTITUT & Switzerland \\
\hline UNIVERSITETET I OSLO & Norway \\
\hline $\begin{array}{l}\text { FOUNDATION FOR RESEARCH AND TECHNOLOGY HEL- } \\
\text { LAS }\end{array}$ & Greece \\
\hline $\begin{array}{l}\text { USTAV CHEMICKYCH PROCESU - AKADEMIE VED CESKE } \\
\text { REPUBLIKY }\end{array}$ & Czech Republic \\
\hline CENTRE NATIONAL DE RECHERCHES METEO- & France \\
\hline ROLOGIQUES METEO FRANCE & \\
\hline FORSCHUNGSZENTRUM JUELICH GMBH & Germany \\
\hline NORTH-WEST UNIVERSITY & South Africa \\
\hline THE ENERGY AND RESOURCES INSTITUTE & India \\
\hline KOBENHAVNS UNIVERSITET & Denmark \\
\hline UNIVERSITY OF EAST ANGLIA & United Kingdom \\
\hline ITÄ-SUOMEN YLIOPISTO & Finland \\
\hline THE UNIVERSITY OF MANCHESTER & United Kingdom \\
\hline ASSOCIACAO DOS PESQUISADORES DO EXPERIMENTO & Brazil \\
\hline $\begin{array}{l}\text { DE GRANDE ESCALA DA BIOSFERA-ATMOSFERA NA } \\
\text { AMAZONIA - APLBA }\end{array}$ & \\
\hline AKTSIASELTS AIREL & Estonia \\
\hline UNIVERSITY OF BIRMINGHAM & United Kingdom \\
\hline DEUTSCHES ZENTRUM FUER LUFT- UND RAUMFAHRT E.V. & Germany \\
\hline UNIVERSITY OF CRETE & Greece \\
\hline THE HEBREW UNIVERSITY OF JERUSALEM & Israel \\
\hline $\begin{array}{l}\text { INTERNATIONAL INSTITUTE FOR APPLIED SYSTEM } \\
\text { ANALYSIS - IIASA }\end{array}$ & Austria \\
\hline STOCKHOLMS UNIVERSITET & Sweden \\
\hline UNIWERSYTET WARSZAWSKI & Poland \\
\hline UNIVERSIDADE DE AVEIRO & Portugal \\
\hline TARTU UELIKOOL & Estonia \\
\hline
\end{tabular}


M. Kulmala et al.: Integrating aerosol research from nano to global scales

$\begin{array}{ll}\text { JOHANNES GUTENBERG UNIVERSITAET MAINZ } & \text { Germany } \\ \text { PEKING UNIVERSITY } & \text { China } \\ \text { CHINESE ACADEMY OF METEOROLOGICAL SCIENCES } & \text { China } \\ \text { PANEPISTIMIO AIGAIOU } & \text { Greece } \\ \text { COMMISSARIAT A L'ENERGIE ATOMIQUE } & \text { France } \\ \text { FORSKNINGSCENTER RISOE } & \text { Denmark } \\ \text { DEUTSCHER WETTERDIENST } & \text { Germany }\end{array}$

Acknowledgements. Main part of the work in this paper has been funded with FP6 project EUCAARI (Contract 34684). This work was performed in the framework of the Research Infrastructure Action under the FP6 "Structuring the European Research Area" Programme, EUSAAR Contract No. RII3-CT-2006-026140. The financial support by the Academy of Finland Centre of Excellence program (project No. 1118615) is gratefully acknowledged. CNRS and Métófrance partners acknowledge the financial support of Agence Nationale de la Recherche under the AEROCLOUDS proposal. This research has received funding from ERC Advanced Grant ATMNUCLE No. 227463.

Edited by: W. T. Sturges

\section{References}

Abdul-Razzak, H. and Ghan, S. J.: A parameterization of aerosol activation 2. Multiple aerosol types, J. Geophys. Res., 105, 6837-6844, 2000.

Althausen, D., Engelmann, R., Baars, H., Heese, B., Ansmann, A., Müller, D., and Komppula, M.: Portable Raman Lidar PollyXT for automated profiling of aerosol backscatter, extinction, and depolarization, J. Atmos. Ocean. Technol., 26, 2366-2378, 2009.

Ammann, M. and Pöschl, U.: Kinetic model framework for aerosol and cloud surface chemistry and gas-particle interactions - Part 2: Exemplary practical applications and numerical simulations, Atmos. Chem. Phys., 7, 6025-6045, doi:10.5194/acp-7-60252007, 2007.

Anderson, H. R.: Air pollution and mortality, Atmos. Environ., 43, 142-152, 2009.

Andreae, M. O.: Correlation between cloud condensation nuclei concentration and aerosol optical thickness in remote and polluted regions, Atmos. Chem. Phys., 9, 543-556, doi:10.5194/acp-9-543-2009, 2009.

Andreae, M. O. and Rosenfeld, D.: Aerosol-cloud-precipitation interactions. Part 1. The nature and sources of cloud-active aerosols, Earth-Sci. Rev., 89, 13-41, 2008.

Andrejczuk, M., Grabowski, W. W., Malinowski, S. P., and Smolarkiewicz, P. K.: Numerical simulation of cloud-clear air interfacial mixing: Homogeneous versus inhomogenous mixing, J. Atmos. Sci., 66, 2493-2500, 2009.

Ansmann, A. and Mülle, D.: Lidar and Atmospheric Aerosol Particles, in Lidar, Springer Series in Optical Sciences, edited by: Weitkamp, C., Springer Berlin, Heidelberg, Germany, 102, 105$141,2005$.

Ansmann, A., Tesche, M., Althausen, D., Muller, D., Seifert, P., Freudenthaler, V., Heese, B., Wiegner, M. , Pisani, G., Knippertz, P., and Dubovik, O.: Influence of Saharan dust on cloud glaciation in southern Morocco during the Saharan Mineral Dust Experiment, J. Geophys. Res., 113, D04210, doi:10.1029/2007JD008785, 2008.
Ansmann, A., Baars, H., Tesche, M., Muller, D., Althausen, D., Engelmann, R., Pauliquevis, T., and Artaxo, P.: Dust and smoke transport from Africa to South America: Lidar profiling over Cape Verde and the Amazon rainforest, Geophys. Res. Lett., 36, 11, 802, doi:10.1029/2009GL037923, 2009.

Anttila T., Kerminen, V.-M., and Lehtinen, K. E. J.: Parameterizing the formation rate of new particles: the effect of nuclei selfcoagulation, J. Aerosol Sci., 41, 621-636, 2010.

Arabas, S. and Pawlowska, H.: Preliminary validation of a kappabased CCN activation model with EUCAARI-IMPCT airborne aerosol observations, EUCAARI Annual Meeting, Helsinki, Finland, 2010

Arabas, S. and Pawlowska, H.: Adaptive method of lines for multicomponent aerosol condensational growth and cloud droplet activation, Geosci. Model Dev., 4, 15-31, doi:10.5194/gmd-4-152011, 2011.

Arden Pope III, C. and Dockery, D. W.: Health effects of fine particulate air pollution: lines that connect, J. Air Waste Manage. Assoc., 56, 709-742, 2006.

Arneth, A., Unger, N., Kulmala, M., and Andreae, M. O.: Clean the air, heat the planet, Science, 326, 672-673, 2009.

Arneth, A., Harrison, S. P., Zaehle, S., Tsigaridis, K., Menon, S., Bartlein, P. J., Feichter, J., Korhola, A., Kulmala, M., O'Donnell, D., Shurgers, G., Sorvari, S., and Vesala, T.: Terrestial biogeochemical feedbacks in the climate system, Nature Geoscience, 3, 525-532, 2010.

Asa-Awuku, A., Engelhart, G. J., Lee, B. H., Pandis, S. N., and Nenes, A.: Relating CCN activity, volatility, and droplet growth kinetics of beta-caryophyllene secondary organic aerosol, Atmos. Chem. Phys., 9, 795-812, doi:10.5194/acp-9-795-2009, 2009.

Asmi, E., Sipilä, M., Manninen, H. E., Vanhanen, J., Lehtipalo, K, Gagne, S., Neitola, K., Mirme, A., Mirme, S., Tamm, E., Uin, J., Komsaare, K., Attoui, M., and Kulmala, M.: Results of first air ion spectrometer calibration and intercomparison workshop, Atmos. Chem. Phys., 9, 141-154, doi:10.5194/acp-9-141-2009, 2009.

Asmi, A., Wiedensohler, A., Laj, P., Fjaeraa, A.-M., Sellegri, K., Birmili, W., Weingartner, E., Baltensperger, U., Zdimal, V., Zikova, N., Putaud, J.-P., Marinoni, A., Tunved, P., Hansson, H.C., Fiebig, M., Kiveks, N., Lihavainen, H., Asmi, E., Ulevicius, V., Aalto, P. P., Swietlicki, E., Kristensson, A., Mihalopoulos, N., Kalivitis, N., Kalapov, I., Kiss, G., de Leeuw, G., Henzing, B., Harrison, R. M., Beddows, D., O’Dowd, C., Jennings, S. G., Flentje, H., Weinhold, K., Meinhardt, F., Ries, L., and Kulmala, M.: Number size distributions and seasonality of submicron particles in Europe 2008-2009, Atmos. Chem. Phys., 11, 5505-5538, doi:10.5194/acp-11-5505-2011, 2011.

Aumont, O., Bopp, L., and Schulz, M.: What does temporal variability in aeolian dust deposition contribute to sea-surface iron and chlorophyll distributions?, Geophys. Res. Lett., 35, L07607, doi:07610.01029/02007GL031131, 2008.

Balkanski, Y., Schulz, M., Claquin, T., and Guibert, S.: Reevaluation of mineral aerosol radiative forcings suggests a better agreement with satellite and AERONET data, Atmos. Chem. Phys., 7, 81-95, doi:10.5194/acp-7-81-2007, 2007.

Barley, M. H. and McFiggans, G.: The critical assessment of vapour pressure estimation methods for use in modelling the formation of atmospheric organic aerosol, Atmos. Chem. Phys., 10, 749- 
767, doi:10.5194/acp-10-749-2010, 2010.

Barley, M. H., Topping, D. O., Jenkin, M. E., and McFiggans, G.: Sensitivities of the absorptive partitioning model of secondary organic aerosol formation to the inclusion of water, Atmos. Chem. Phys., 9, 2919-2932, doi:10.5194/acp-9-2919-2009, 2009.

Barley, M. H., Topping, D., Lowe, D., Utembe, S., and McFiggans, G.: The sensitivity of secondary organic aerosol (SOA) component partitioning to the predictions of component properties - Part 3: Investigation of condensed compounds generated by a near-explicit model of VOC oxidation, Atmos. Chem. Phys. Discuss., 11, 21055-21090, doi:10.5194/acpd-11-210552011, 2011.

Bauer, S. E., Menon, S., Koch, D., Bond, T. C., and Tsigaridis, K.: A global modeling study on carbonaceous aerosol microphysical characteristics and radiative effects, Atmos. Chem. Phys., 10, 7439-7456, doi:10.5194/acp-10-7439-2010, 2010.

Beddows, D. C. S. and Harrison, R. M.: Comparison of average particle number emission factors for heavy and light duty vehicles derived for rolling chasses dynamometer and field studies, Atmos. Environ., 42, 7954-7966, 2008.

Bellouin, N., Boucher, O., Haywood, J., and Reddy, M. S.: Global estimate of aerosol direct radiative forcing from satellite measurements, Nature, 438, 1138-1141, doi:10.1038/nature04348, 2005.

Bellouin, N., Boucher, O., Haywood, J., Johnson, C., Jones, A., Rae, J., and Woodward, S.: Improved representation of aerosols for HadGEM2, Hadley Centre Technical Note No. 73, 242 pp., 2007.

Bellouin, N., Jones, A., Haywood, J., and Christopher, S. A.: Updated estimate of aerosol direct radiative forcing from satellite observations and comparison against the Hadley Centre climate model, J. Geophys. Res., 113, D10205, doi:10.1029/2007JD009385, 2008.

Bergman, T., Kerminen, V.-M., Korhonen, H.,Lehtinen, K. E. J., Makkonen, R., Arola, A., Mielonen, T., Romakkaniemi, S., Kulmala, M., and Kokkola, H.: Evaluation of a sectional aerosol microphysics module SALSA implementation in ECHAM-HAM aerosol climate model, Geosci. Model Dev. Discuss., in press, 2011.

Bergström, R. and Simpson, D.: Organic aerosol modelling in EMEP: Recent Developments, in: Transboundary Particulate Matter in Europe, Status Report 4/2010, The Norwegian Institute for Air Research (NILU), Kjeller, Norway, 2010.

Bergström, R., Denier van der Gon, H. A. C., Prév^t, A. S. H., Yttri, K. E., and Simpson, D.: Modelling of organic aerosols over Europe (2002-2007) using a volatility basis set (VBS) framework with application of different assumptions regarding the formation of secondary organic aerosol, Atmos. Chem. Phys. Discuss., in preparation, 2011.

Berndt, T., Böge, O., Stratmann, F., Heintzenberg, J., and Kulmala, M.: Rapid formation of sulfuric acid particles at nearatmospheric conditions, Science, 307, 698-700, 2005.

Berndt, T., Stratmann, F., Sipilä, M., Vanhanen, J., Petäjä, T., Mikkilä, J., Grüner, A., Spindler, G., Lee Mauldin III, R., Curtius, J., Kulmala, M., and Heintzenberg, J.: Laboratory study on new particle formation from the reaction $\mathrm{OH}+\mathrm{SO}_{2}$ : influence of experimental conditions, $\mathrm{H}_{2} \mathrm{O}$ vapour, $\mathrm{NH}_{3}$ and the amine tert-butylamine on the overall process, Atmos. Chem. Phys., 10,
7101-7116, doi:10.5194/acp-10-7101-2010, 2010.

Berresheim, H., Elste, T., Plass-Dülmer, C., Eisele, F., and Tanner, D. J.: Chemical ionization mass spectrometer for long-term measurements of atmospheric $\mathrm{OH}$ and $\mathrm{H}_{2} \mathrm{SO}_{4}$, Int. J. Mass Spectrom., 202, 91-109, 2000.

Bilde M., Svenningsson, S., Mønster, J., and Rosenørn, T.: EvenOdd Alternation of Evaporation Rates and Vapor Pressures of C3-C9 Dicarboxylic Acid Aerosols, Environ. Sci. Technol., 37, 1371-1378, 2003.

Birmili, W., Schepanski, K., Ansmann, A., Spindler, G., Tegen, I., Wehner, B., Nowak, A., Reimer, E., Mattis, I., Müller, K., Brüggemann, E., Gnauk, T., Herrmann, H., Wiedensohler, A., Althausen, D., Schladitz, A., Tuch, T., and Löschau, G.: A case of extreme particulate matter concentrations over Central Europe caused by dust emitted over the southern Ukraine, Atmos. Chem. Phys., 8, 997-1016, doi:10.5194/acp-8-997-2008, 2008.

Bloss, C., Wagner, V., Jenkin, M. E., Vokamer, R., Bloss, W. J., Lee, J. D., Heard, D. E., Wirtz, K., Martin-Reviejo, M., Rea, G., Wenger, J. C., and Pilling, M. J.: Development of a detailed chemical mechanism (MCMv3.1) for the atmospheric oxidation of aromatic hydrocarbons, Atmos. Chem. Phys., 5, 641-664, doi:10.5194/acp-5-641-2005, 2005.

Bohn, B., Rohrer, F., Brauers, T., and Wahner, A.: Actinometric measurements of $\mathrm{NO}_{2}$ photolysis frequencies in the atmosphere simulation chamber SAPHIR, Atmos. Chem. Phys., 5, 493-503, doi:10.5194/acp-5-493-2005, 2005.

Bonasoni, P., Laj, P. , Angelini, F., Arduini, J., Bonafè, U., Calzolari, F., Cristofanelli, P., Decesari, S., Facchini, M. C., Fuzzi, S. , Gobbi, G. P., Maione, M., Marinoni, A., Petzold, A., Roccato, F., Roger, J.-C., Sellegri, K., Sprenger, M., Venzac, H., Verza, G. P., Villani, P., and Vuillermoz, E.: The ABC-Pyramid Atmospheric Research Observatory in Himalaya for aerosol, ozone and halocarbon measurements, Sci. Total Environ., 391, 252-261, 2008.

Bonasoni, P., Laj, P., Marinoni, A., Sprenger, M., Angelini, F., Arduini, J., Bonafè, U., Calzolari, F., Colombo, T., Decesari, S., Di Biagio, C., di Sarra, A. G., Evangelisti, F., Duchi, R., Facchini, MC., Fuzzi, S., Gobbi, G. P., Maione, M., Panday, A., Roccato, F., Sellegri, K., Venzac, H., Verza, GP., Villani, P., Vuillermoz, E., and Cristofanelli, P.: Atmospheric brown clouds in the Himalayas: first two years of continuous observations at the Nepal Climate Observatory-Pyramid (5079 m), Atmos. Chem. Phys., 10, 7515-7531, doi:10.5194/acp-10-7515-2010, 2010.

Bond, T. C. and Sun H.: Can reducing black carbon emissions counteract global warming? Environ. Sci. Technol., 39, 5921-5926 doi:10.1021/es0480421, 2005.

Booth, A. M., Markus, T., McFiggans, G., Percival, C. J., McGillen, M. R., and Topping, D. O.: Design and construction of a simple Knudsen Effusion Mass Spectrometer (KEMS) system for vapour pressure measurements of low volatility organics, Atmos. Meas. Tech., 2, 355-361, doi:10.5194/amt-2-355-2009, 2009.

Booth, A. M., Barley, M. H., Topping, D. O. , McFiggans, G., Garforth, A., and Percival, C. J.: Solid state and sub-cooled liquid vapour pressures of substituted dicarboxylic acids using Knudsen Effusion Mass Spectrometry (KEMS) and Differential Scanning Calorimetry, Atmos. Chem. Phys., 10, 4879-4892, doi:10.5194/acp-10-4879-2010, 2010.

Booth, A. M., Barley, M. H., Topping, D. O., McFiggans, G., Garforth, A., and Percival, C. J.: Solid state and sub-cooled liquid vapour pressures of substituted aromatic compounds, Atmos. 
Chem. Phys. Discuss., in preparation, 2011a.

Booth, A. M., Montague, W. J., Barley, M. H., Topping, D. O., McFiggans, G., Garforth, A., and Percival, C. J.: Solid state and subcooled liquid vapour pressures of cyclic aliphatic dicarboxylic acids, Atmos. Chem. Phys., 11, 655-665, doi:10.5194/acp-11655-2011, 2011b.

Boulon, J., Sellegri, K., Venzac, H., Picard, D., Weingartner, E., Wehrle, G., Collaud Coen, M., Bütikofer, R., Flückiger, E., Baltensperger, U., and Laj, P.: New particle formation and ultrafine charged aerosol climatology at a high altitude site in the Alps (Jungfraujoch, $3580 \mathrm{~m}$ a.s.l., Switzerland), Atmos. Chem. Phys., 10, 9333-9349, doi:10.5194/acp-10-9333-2010, 2010.

Boulon, J., Sellegri, K., Hervo, M., Picard, D., Pichon, J.-M., Fréville, P., and Laj, P.: Investigation of nucleation events vertical extent: a long term study at two different altitude sites, Atmos. Chem. Phys., 11, 5625-5639, doi:10.5194/acp-11-56252011, 2011.

Boville, B. A., Rasch, P. J., Hack, J. J., and McCaa, J. R.: Representation of clouds and precipitation processes in the Community Atmosphere Model version 3 (CAM3), J. Climate, 19, 2184-2198, 2006.

Brasseur, G. P. and Roeckner R.: Impact of improved air quality on the future evolution of climate, Geophys. Res. Lett., 32, L23704, doi:10.1029/2005GL023902, 2005.

Brus, D., Hyvärinen, A.-P., Viisanen, Y., Kulmala, M., and Lihavainen, H.: Homogeneous nucleation of sulfuric acid and water mixture: experimental setup and first results, Atmos. Chem. Phys., 10, 2631-2641, doi:10.5194/acp-10-2631-2010, 2010.

Bryan, G. H. and Fritsch, J. M.: A benchmark simulation for moist nonhydrostatic numerical models, Mon. Weather Rev., 130, 2917-2928, 2002.

Buchholz, A.: Secondary Organic Aerosols: Chemical Aging, Hygroscopicity, and Cloud Droplet Activation, Doktorarbeit, Mathematisch-Naturwissenschaftliche Fakultät, Universität zu Köln, Köln, 128 pp., 2010.

Burrows, J. P., Platt, U., and Borrell, P. (Eds.): The Remote Sensing of Tropospheric Composition from Space, 536 pp., Springer-Verlag Berlin Heidelberg, ISBN:978-3-642-14790-6, doi:10.1007/978-3-642-14791-3, 2011.

Carslaw, K., Boucher, O., Spracklen, D., Mann, G., Rae, J., Woodward, S., and Kulmala, M.: Aerosol in the Earth System: A review of processes and feedbacks, Atmos. Chem. Phys., 10, 1701-1737, doi:10.5194/acp-10-1701-2010, 2010.

Cavalli, F., Viana, M., Yttri, K. E., Genberg, J., and Putaud, J. P.: Toward a standardised thermal-optial protocol for measuring atmospheric organic and elemental carbon: the EUSAAR protocol, Atmos. Meas. Tech., 3, 79-89, doi:10.5194/amt-3-79-2010, 2010.

Ceburnis, D., Garbaras, A., Szidat, S., Rinaldi, M., Fahrni, S., Perron, N., Wacker, L., Leinert, S., Remeikis, V., Facchini, M. C., Prévôt, A. S. H., Jennings, S. G., Ramonet, M., and O'Dowd, C. D.: Quantification of the carbonaceous matter origin in submicron marine aerosol by ${ }^{13} \mathrm{C}$ and ${ }^{14} \mathrm{C}$ isotope analysis, Atmos. Chem. Phys., 11, 8593-8606, doi:10.5194/acp-11-85932011, 2011.

Charlson, R. J., Langner, J., and Rodhe, H.: Sulfate aerosol and climate, Nature, 348, 22-22, 1990.

Charlson, R. J., Schwartz, S. E., Hales, J. M., Cess, R. D., Coakley, J. A., Hansen, J. E., and Hofmann, D. J.: Climate forcing by anthropogenic aerosols, Science, 255, 423-430, 1992.

Chirico, R., DeCarlo, P. F., Heringa, M. F., Tritscher, T., Richter, R., Prévôt, A. S. H., Dommen, J., Weingartner, E., Wehrle, G., Gysel, M., Laborde, M., and Baltensperger U.: Impact of aftertreatment devices on primary emissions and secondary organic aerosol formation potential from in-use diesel vehicles: results from smog chamber experiments, Atmos. Chem. Phys., 10, 11545-11563, doi:10.5194/acp-10-11545-2010, 2010.

Chou, C., Stetzer, O., Weingartner, E., Jurányi, Z., Kanji, Z. A., and Lohmann, U.: Ice nuclei properties within a Saharan dust event at the Jungfraujoch in the Swiss Alps, Atmos. Chem. Phys., 11, 4725-4738, doi:10.5194/acp-11-4725-2011, 2011.

Christner, B. C., Morris, C. E., Foreman, C. M., Cai, R. M., and Sands, D. C.: Ubiquity of biological ice nucleators in snowfall, Science, 319, 1214-1214, 2008.

Clegg, S. L., Kleeman, M. J., Griffin, R. J., and Seinfeld, J. H.: Effects of uncertainties in the thermodynamic properties of aerosol components in an air quality model - Part 2: Predictions of the vapour pressures of organic compounds, Atmos. Chem. Phys., 8, 1087-1103, doi:10.5194/acp-8-1087-2008, 2008a.

Clegg, S. L., Kleeman, M. J., Griffin, R. J., and Seinfeld, J. H.: Effects of uncertainties in the thermodynamic properties of aerosol components in an air quality model - Part 1: Treatment of inorganic electrolytes and organic compounds in the condensed phase, Atmos. Chem. Phys., 8, 1057-1085, doi:10.5194/acp-81057-2008, 2008b.

Clegg, S. L. and Wexler, A. S.: Densities and apparent molar volumes of atmospherically important electrolyte solutions. I. The solutes $\mathrm{H}_{2} \mathrm{SO}_{4}, \mathrm{HNO}_{3}, \mathrm{HCl}, \mathrm{Na}_{2} \mathrm{SO}_{4}, \mathrm{NaNO}_{3}, \mathrm{NaCl}$, $\left(\mathrm{NH}_{4}\right)_{2} \mathrm{SO}_{4}, \mathrm{NH}_{4} \mathrm{NO}_{3}$, and $\mathrm{NH}_{4} \mathrm{Cl}$ from 0 to $50^{\circ}$, including extrapolations to very low temperature and to the pure liquid state, and $\mathrm{NaHSO}_{4}, \mathrm{NaOH}$ and $\mathrm{NH}_{3}$ at $25^{\circ}$, J. Phys. Chem. A, 2011, 115, 3393-3460, doi:10.1021/jp108992a, 2011a.

Clegg, S. L. and Wexler, A. S.: Densities and Apparent Molar Volumes of Atmospherically Important Electrolyte Solutions. 2. The Systems $\mathrm{H}^{+}-\mathrm{HSO}_{4}^{-}-\mathrm{SO}_{4}^{2-}-\mathrm{H}_{2} \mathrm{O}$ from 0 to $3 \mathrm{~mol} \mathrm{~kg}^{-1}$ as a Function of Temperature and $\mathrm{H}^{+}-\mathrm{NH}_{4}^{+}-\mathrm{HSO}_{4}^{-}-\mathrm{SO}_{4}^{2-}-\mathrm{H}_{2} \mathrm{O}$ from 0 to $6 \mathrm{~mol} \mathrm{~kg}^{-1}$ at $25{ }^{\circ} \mathrm{C}$ Using a Pitzer Ion Interaction Model, and $\mathrm{NH}_{4} \mathrm{HSO}_{4}-\mathrm{H}_{2} \mathrm{O}$ and $\left(\mathrm{NH}_{4}\right)_{3} \mathrm{H}\left(\mathrm{SO}_{4}\right)_{2}-\mathrm{H}_{2} \mathrm{O}$ over the Entire Concentration Range, J. Phys. Chem. A, 2011, 115, 3461-3474, doi:10.1021/jp1089933, 2011b.

Collaud Coen, M., Weingartner, E., Apituley, A., Ceburnis, D., Fierz-Schmidhauser, R., Flentje, H., Henzing, J. S., Jennings, S. G., Moerman, M., Petzold A., Schmid, O., and Baltensperger, U.: Minimizing light absorption measurement artifacts of the Aethalometer: evaluation of five correction algorithms, Atmos. Meas. Tech., 3, 457-474, doi:10.5194/amt-3-457-2010, 2010.

Collett, K. S., Piketh, S. J., and Ross, K. E.: An assessment of the atmospheric nitrogen budget on the South African Highveld, South African J. Sci., 106, 5/6, doi:10.4102/sajs.v106i5/6.220, 2010.

Collins, W. J., Sitch, S., and Boucher, O.: How vegetation impacts affect climate metrics for ozone precursors, J. Geophys. Res., 115, D23308, doi:10.1029/2010JD014187, 2010.

Crumeyrolle, S., Manninen, H. E., Sellegri, K., Roberts, G., Gomes, L., Kulmala, M., Weigel, R., Laj, P., and Schwarzenboeck, A.: New particle formation events measured on board the ATR-42 aircraft during the EUCAARI campaign, Atmos. Chem. Phys., 10, 6721-6735, doi:10.5194/acp-10-6721-2010, 2010. 
Crumeyrolle, S., Schwarzenboeck, A., Roger, J. C., Sellegri, K., Burkhart, J. F., Stohl, A., Gomes, L., Quennehen, B., Roberts, G., Weigel, R., Villani, P., Pichon, J. M., Bourrianne, T., and Laj, P.: Overview of aerosol properties associated with air masses sampled by the ATR-42 during the EUCAARI campaign (2008), Atmos. Chem. Phys. Discuss., in preparation, 2011.

de Leeuw, G., Andreas, E. L., Anguelova, M. D., Fairall, C. W., Lewis, E. R,. O’Dowd, C.D., Schulz, M., and Schwartz, S. E.: Production flux of sea-spray aerosol, Rev. Geophys., 49, RG2001, doi:10.1029/2010RG000349, 2011a.

de Leeuw, G., Kinne, S., Leon, J. F., Pelon, J., Rosenfeld, D., Schaap, M., Veefkind, P. J., Veihelmann, B., Winker, D. M., and von Hoyningen-Huene, W.: Retrieval of aerosol properties, in: The remote sensing of tropospheric composition from space, edited by: Burrows, J. P., Platt, U., and Borrell, P., 536 pp., Springer-Verlag Berlin Heidelberg 2011, ISBN: 978-3-64214790-6, 359-313, doi:10.1007/978-3-642-14791-3, 2011 b.

DeCarlo, P. F., Kimmel, J. R., Trimborn, A., Northway, M. J., Jayne, J. T., Aiken, A. C., Gonin, M., Fuhrer, K., Horvath, T., Docherty, K. S., Worsnop, D. R., and Jimenez, J. L.: Field-deployable, high-resolution, time-of-flight aerosol mass spectrometer, Anal. Chem., 78, 8281-8289, 2006.

Decesari, S., Facchini, M. C., Mircea, M., Cavalli, F., Emblico, L., Fuzzi, S., Moretti, F., and Tagliavini, E.: Source attribution of water-soluble organic aerosol by nuclear magnetic resonance spectroscopy, Environ. Sci. Technol., 41, 2479-2484, 2007.

Decesari, S., Finessi, E., Paglione, M., Dall'Osto, O’Dowd, C., M., Hillamo, R., Carbone, S., Kiendler-Scharr, A., Prévôt, A., Swietlicki, E., Worsnop. D. R., and Facchini, M. C.: Novel insights into secondary organic aerosol formation and ageing from nuclear magnetic resonance (NMR) spectroscopy, Atmos. Chem. Phys. Discuss., in preparation, 2011a.

Decesari, S., Finessi, E., Rinaldi, M., Paglione, M., Fuzzi, S., Stephanou, E. G., Tziaras, T., Spyros, A., Ceburnis, D., O’Dowd, C. D., Dall'Osto, M., Harrison, R. M., Allan, J. D., Coe, H., and, Facchini M. C.: Primary and secondary marine organic aerosols over the North Atlantic Ocean during the MAP experiment, J. Geophys. Res., 116, D22210, doi:10.1029/2011JD016204, $2011 b$.

Denier van der Gon, H. A. C., Visschedijk, A. J. H., Johansson, C., Hedberg Larsson, E., Harrison, R., and Beddows, D.: Sizeresolved pan European anthropogenic particle number iInventory, EUCAARI Deliverable report D141 (available on request from EUCAARI project office), 2009.

Denier van der Gon, H.A.C, Visschedijk, A., van der Brugh, H., and Dröge, R.: A high resolution European emission data base for the year 2005, TNO report TNO-034-UT-2010-01895_RPTML, Utrecht, The Netherlands, 2010.

Denier van der Gon, H. A. C., Visschedijk, A. J. H., Dröge, R., Johansson, C., and Klimont, Z.: A high resolution emission inventory of particulate elemental carbon and organic carbon for Europe in 2005, EUCAARI special issue, Atmos. Chem. Phys. Discuss., in preparation, 2011a.

Denier van der Gon, H. A. C., Visschedijk, A., Johansson, C., Ntziachristos, L., and Harrison, R. M.: Size-resolved Pan-European Anthropogenic Particle Number Inventory, EUCAARI special issue, Atmos. Chem. Phys. Discuss., in preparation, $2011 \mathrm{~b}$.

Dentener, F., Stevenson, D., Cofala, J., Mechler, R., Amann, M., Bergamaschi, P., Raes, F., and Derwent, R.: The impact of air pollutant and methane emission controls on tropospheric ozone and radiative forcing: CTM calculations for the period 19902030, Atmos. Chem. Phys., 5, 1731-1755, doi:10.5194/acp-51731-2005, 2005.

Dentener, F., Kinne, S., Bond, T., Boucher, O., Cofala, J., Generoso, S., Ginoux, P., Gong, S., Hoelzemann, J. J., Ito, A., Marelli, L., Penner, J. E., Putaud, J.-P., Textor, C., Schulz, M., van der Werf, G. R., and Wilson, J.: Emissions of primary aerosol and precursor gases in the years 2000 and 1750 prescribed data-sets for AeroCom, Atmos. Chem. Phys., 6, 4321-4344, doi:10.5194/acp6-4321-2006, 2006.

Deuzé, J.-L., Goloub, P., Herman, M., Marchand, A., Perry, G., Tanré, D., and Susana, S.: Estimate of the aerosols properties over the ocean with POLDER, J. Geophys. Res., 105, 1532915346, 2000.

Diehl, K., Matthias-Maser, S., Jaenicke, R., and Mitra, S. K.: The ice nucleating ability of pollen. Part II: Laboratory studies in immersion and contact freezing modes, Atmos. Res., 61, 125-133, 2002.

Djikaev, Y. S.: Effect of the surface-stimulated model on the kinetics of homogeneous crystal nucleation in droplets, J. Phys. Chem. A, 112, 6592-6600, 2008.

Donahue, N. M., Robinson, A. L., Stanier, C. O., and Pandis, S. N.: Coupled partitioning, dilution, and chemical aging of semivolatile organics, Environ. Sci. Technol., 40, 2635-2643, 2006.

Donahue, N. M., Epstein, S. A., Pandis, S. N., and Robinson, A. L.: A two-dimensional volatility basis set: 1. organic-aerosol mixing thermodynamics, Atmos. Chem. Phys., 11, 3303-3318, doi:10.5194/acp-11-3303-2011, 2011.

Drewnick, F., Hings, S. S., DeCarlo, P., Jayne, J. T., Gonin, M., Fuhrer, K., Weimer, S., Jimenez, J. L., Demerjian, K. L., Borrmann, S., and Worsnop, D. R.: A new time-of-flight aerosol mass spectrometer (TOF-AMS) - Instrument description and first field deployment, Aerosol Sci. Technol., 39, 637-658, 2005.

Dubuisson, P., Frouin, R., Dessailly, D., Duforêt, L., Léon, J.-F., Moss, K., and Antoine, D.: Estimation of aerosol altitude from reflectance ratio measurements in the $\mathrm{O} 2 \mathrm{~A}$-band, Remote Sens. Environ., 113, 1899-1911, 2008.

Duplissy, J., Gysel, M., Alfarra, M. R., Dommen, J., Metzger, A., Prévôt, A. S. H., Weingartner, E., Laaksonen, A., Raatikainen, T., Good, N., Turner, S. F, McFiggans, G., and Baltensperger, U.: Cloud forming potential of secondary organic aerosol under near atmospheric conditions, Geophys. Res. Lett., 35, L03818, doi:10.1029/2007GL031075, 2008.

Dusek, U., Frank, G. P., Curtius, J., Drewnick, F., Schneider, J., Kurten, A., Rose, D., Andreae, M. O., Borrmann, S., and Pöschl, U.: Enhanced organic mass fraction and decreased hygroscopicity of cloud condensation nuclei $(\mathrm{CCN})$ during new particle formation events, Geophys. Res. Lett., 37, L03804, doi:10.1029/2009GL040930, 2010.

Dutcher, C. S., Wexler, A. S., and Clegg, S. L.: Surface tensions of inorganic multicomponent aqueous electrolyte solutions and melts, J. Phys. Chem., A, 114, 12216-12230, 2010.

Duynkerke, P. G. and Driedonks, A. G. M.: A model for the turbulent structure of the stratocumulus topped atmospheric boundary layer, J. Atmos. Sci., 44, 43-64, doi:10.1175/15200469(1987)044<0043:AMFTTS>2.0.CO;2, 1987.

Ehn M., Junninen, H., Petäjä, T., Kurten, T., Kerminen, V.-M., 
Schobesberger, S., Manninen, H. E., Ortega, I. K., Vehkamäki, H., Kulmala, M., and Worsnop D. R.: Composition and temporal behavior of ambient ions in the boreal forest, Atmos. Chem. Phys., 10, 8513-8530, doi:10.5194/acp-10-8513-2010, 2010.

Engelhart G. J., Asa-Awuku, A., Nenes, A., and Pandis, S. N.: CCN activity and droplet growth kinetics of fresh and aged monoterpene secondary organic aerosol, Atmos. Chem. Phys., 8, 39373949, doi:10.5194/acp-8-3937-2008, 2008.

Engelhart, G. J., Moore, R. H., Nenes, A., and Pandis, S. N.: Cloud condensation nuclei activity of isoprene secondary organic aerosol, J. Geophys. Res., 116, D02207, doi:10.1029/2010JD014706, 2011.

Fierz-Schmidhauser, R., Zieger, P., Gysel, M., Kammermann, L., DeCarlo, P. F., Baltensperger, U., and Weingartner E.: Measured and predicted aerosol light scattering enhancement factors at the high alpine site Jungfraujoch, Atmos. Chem. Phys., 10, 23192333, doi:10.5194/acp-10-2319-2010, 2010.

Finessi, E., Moretti, F., Facchini, M. C., Baltensperger, U., Dommen, J., Mentel, T., and Decesari, S: Novel insights into secondary organic aerosol formation and ageing from nuclear magnetic resonance (NMR) spectroscopy, Atmos. Chem. Phys. Discuss., in preparation, 2011a.

Finessi, E., Decesari, S., Paglione, M., Giulianelli, L., Carbone, C., Gilardoni, S., Fuzzi, S., Saarikoski, S., Raatikainen, T., Hillamo, R., Allan, J., Mentel, Th. F., Tiitta, P., Laaksonen, A., Petäjä, T., Kulmala, M., Worsnop, D. R., and Facchini, M. C.: Determination of the biogenic secondary organic aerosol fraction in the boreal forest by AMS and NMR measurements, Atmos. Chem. Phys. Discuss., 11, 22619-22662, doi:10.5194/acpd-11-226192011, 2011 b.

Fors, E., Swietlicki, E., Kristenson, A., and Svenningsson, B. M.: Development of an H-TDMA for long-term unattended measurement of the hygroscopic properties of atmospheric aerosol particles, Atmos. Meas. Tech., 2, 313-318, doi:10.5194/amt-2-3132009, 2009.

Fountoukis, C., Racherla, P. N., Denier van der Gon, H. A. C., Polymeneas, P., Charalampidis, P. E., Pilinis, C., Wiedensohler, A., Dall'Osto, M., O'Dowd, C., and Pandis, S. N.: Evaluation of a three-dimensional chemical transport model (PMCAMx) in the European domain during the EUCAARI May 2008 campaign, Atmos. Chem. Phys., 11, 10331-10347, doi:10.5194/acp11-10331-2011, 2011a.

Fountoukis, C., Riipinen, I., Denier van der Gon, H. A. C., Charalampidis, P. E., Pilinis, C., and Pandis, S. N.: Simulating ultrafine particle formation in Europe using a regional CTM: Contribution of primary emissions versus secondary formation to aerosol number concentrations, in preparation, 2011b.

Fowler, D., Pilegaard, K., Sutton, M. A., Ambus, P., Raivonen, M., Duyzer, J., Simpson, D., Fagerli, H., Fuzzi, S., Schjoerring, J. K., Granier, C. , Neftel, A. , Isaksen, I. S. A., Laj, P., Maione, M., Monks, P. S. Burkhardt, J., Daemmgen, U., Neirynck, J., Personne, E. , Butterbach-Bahl, K., Flechard, C. ., Tuovinen, J. P. , Coyle, M., Gerosa, G. Loubet, B., Altimir, N. , Gruenhage, L., Ammann, C., Cieslik, S., Paoletti, E., Mikkelsen, T. N., Ro-Poulsen, H., Cellier, P., Cape, J. N., Horváth, L., Loreto, F., Niinemets, U., Palmer, P. I., Rinne, J., Misztal, P., Nemitz, E., Nilssona, S., Pryor, D., Gallagher, M. W., Vesala, T., Skiba, U., Brüggemann, N., Zechmeister-Boltenstern, S., Williams, J., O’Dowd, C, Facchini, M. C., de Leeuw, G., Flossmann, A. I.,
Chaumerliac, N., and Erisman, J. W.: Atmospheric composition change: Ecosystems-atmosphere interactions. Atmos. Environ., 43, 5193-5267, doi:10.1016/j.atmosenv.2009.07.068, 2009.

Fricke, W., Barrie, L. A., and Schleyer, R. (Eds.): The German Contribution to the WMO/GAW Program: Upon the 225th anniversary of GAW Hohenpeissenebrg Observatory, GAW Report 167, (WMO TD No. 1336), 2007.

Frosch, M., Zardini, A. A., Platt, S. M., Muller, L., Reinnig, M.C., Hoffmann, T., and Bilde, M.: Thermodynamic properties and cloud droplet activation of a series of oxo-acids, Atmos. Chem. Phys., 10, 5873-5890, doi:10.5194/acp-10-5873-2010, 2010.

Frosch, M., Prisle, N. L., Bilde, M., Varga, Z., and Kiss, G.: Joint effect of organic acids and inorganic salts on cloud droplet activation, Atmos. Chem. Phys., 11, 3895-3911, doi:10.5194/acp11-3895-2011, 2011.

Gagné S., Laakso, L., Petäjä, T., Kerminen, V.-M., and Kulmala, M.: Analysis of one year of Ion-DMPS data from the SMEAR II station, Finland, Tellus, 60B, 318-329, 2008.

Gagné, S., Nieminen, T., Kurtén, T., Manninen, H. E., Petäjä, T., Laakso, L., Kerminen, V.-M., Boy, M., and Kulmala, M.: Factors influencing the contribution of ion-induced nucleation in a boreal forest, Finland, Atmos. Chem. Phys., 10, 3743-3757, doi:10.5194/acp-10-3743-2010, 2010.

Garstang, M., Tyson, M., Swap, R., Edwards, M., Kållberg, P., and Lindesay, J. A.: Horizontal and vertical transport of air over southern Africa, J. Geophys. Res., 101, 23721-23736, 1996.

Gaydos, T. M., Pinder, R. W., Koo, B., Fahey, K. M., and Pandis, S. N.: Development and application of a three-dimensional aerosol chemical transport model, PMCAMx, Atmos. Environ., 41, 2594-2611, 2007.

Ge, X, Wexler, A. S., and Clegg, S. L.: Atmospheric Amines Part II. Thermodynamic properties and gas/particle partitioning, Atmos. Environ. 45, 561-577, 2011.

Genberg, J., Hyder, M., Stenström, K., Bergström, R., Simpson, D., Fors, E. O., Jönsson, J. Å., and Swietlicki, E.: Source apportionment of carbonaceous aerosol in southern Sweden, Atmos. Chem. Phys., 11, 11387-11400, doi:10.5194/acp-1111387-2011, 2011.

Gilardoni, S., Vignati, E., Cavalli, F., Putaud, J. P., Larsen, B. R., Karl, M., Stenström, K., Genberg, J., Henne, S., and Dentener, F.: Better constraints on sources of carbonaceous aerosols using a combined ${ }^{14} \mathrm{C}$ macro tracer analysis in a European rural background site, Atmos. Chem. Phys., 11, 5685-5700, doi:10.5194/acp-11-5685-2011, 2011.

Grenier, H. and Bretherton, C. S.: A moist parameterization for large-scale models and its application to subtropical cloudtopped marine boundary layers, Mon. Weather Rev., 129, $357-$ 377, 2001.

Gu, L., Baldocchi, D., Verma, S. B., Black, T. A., Vesala, T., Falge, E. M., and Dowty, P. R.: Advantages of diffuse radiation for terrestrial ecosystem productivity, J. Geophys. Res., 107, 4050, doi:10.1029/2001JD001242, 2002.

Gunthe, S. S., King, S. M., Rose, D., Chen, Q., Roldin, P., Farmer, D. K., Jimenez, J. L., Artaxo, P., Andreae, M. O., Martin, S. T., and Pöschl, U.: Cloud condensation nuclei in pristine tropical rainforest air of Amazonia: size-resolved measurements and modeling of atmospheric aerosol composition and CCN activity, Atmos. Chem. Phys., 9, 7551-7575, doi:10.5194/acp-9-75512009, 2009. 
Halloran, P. R., Bell, T. G., and Totterdell, I. J.: Can we trust empirical marine DMS parameterisations within projections of future climate?, Biogeosciences, 7, 1645-1656, doi:10.5194/bg-71645-2010, 2010.

Hamburger, T., McMeeking, G., Minikin, A., Birmili, W., Dall'Osto, M., O’Dowd, C., Flentje, H., Henzing, B., Junninen, H., Kristensson, A., de Leeuw, G., Stohl, A., Burkhart, J. F., Coe, H., Krejci, R., and Petzold, A.: Overview of the synoptic and pollution situation over Europe during the EUCAARILONGREX field campaign, Atmos. Chem. Phys., 11, 10651082, doi:10.5194/acp-11-1065-2011, 2011.

Hamed, A., Birmili, W., Joutsensaari, J., Mikkonen, S., Asmi, A., Wehner, B., Spindler, G., Jaatinen, A., Wiedensohler, A., Korhonen, H., Lehtinen, K. E. J., and Laaksonen, A.: Changes in the production rate of secondary aerosol particles in Central Europe in view of decreasing $\mathrm{SO}_{2}$ emissions between 1996 and 2006, Atmos. Chem. Phys., 10, 1071-1091, doi:10.5194/acp-10-10712010, 2010.

Hand, J. L. and Malm, W. C.: Review of aerosol mass scattering efficiencies from ground-based measurements since 1990, J. Geophys. Res., 112, D16203, doi:10.1029/2007JD008484, 2007.

Hansson, H.-C.: Particles and soot connecting climate change and air pollution abatement, Chem. Eng. Trans., 22, 185-190, 2010.

Hao, L. Q., Yli-Pirilä, P., Tiitta, P., Romakkaniemi, S., Vaattovaara, P., Kajos, M. K., Rinne, J., Heijari, J., Kortelainen, A., Miettinen, P., Kroll, J. H., Holopainen, J. K., Smith, J. N., Joutsensaari, J., Kulmala, M., Worsnop, D. R., and Laaksonen, A.: New particle formation from the oxidation of direct emissions of pine seedlings, Atmos. Chem. Phys., 9, 8121-8137, doi:10.5194/acp9-8121-2009, 2009.

Hao, L. Q., Romakkaniemi, S., Yli-Pirilä, P., Joutsensaari, J., Kortelainen, A., Kroll, J. H., Miettinen, P., Vaattovaara, P., Tiitta, P., Jaatinen, A., Kajos, M. K., Holopainen, J. K., Heijari, J., Rinne, J., Kulmala, M., Worsnop, D. R., Smith, J. N., and Laaksonen, A.: Mass yields of secondary organic aerosols from the oxidation of $\alpha$-pinene and real plant emissions, Atmos. Chem. Phys., 11, 1367-1378, doi:10.5194/acp-11-1367-2011, 2011.

Hari, P. and Kulmala, M.: Station for Measuring Ecosystem - Atmosphere Relations (SMEAR II), Boreal Env. Res., 10, 315-322, 2005.

Haywood, J. and Schulz, M.: Causes of the reduction in uncertainty in the anthropogenic radiative forcing of climate between IPCC (2001) and IPCC (2007), Geophys. Res. Lett., 34, L20701, doi:10.1029/2007GL030749, 2007.

Heintzenberg, J. and Charlson, R. J.: Clouds in the Perturbed Climate System - their Relationship to Energy Balance, Atmospheric Dynamics, and Precipitation, MIT Press, Cambridge, USA, 2009.

Henne, S., Klausen, J., Junkermann, W., Kariuki, J. M., Aseyo, J. O., and Buchmann, B.: Representativeness and climatology of carbon monoxide and ozone at the global GAW station Mt. Kenya in equatorial Africa, Atmos. Chem. Phys., 8, 3119-3139, doi:10.5194/acp-8-3119-2008, 2008.

Henne, S., Brunner, D., Folini, D., Solberg, S., Klausen, J., and Buchmann, B.: Assessment of parameters describing representativeness of air quality in-situ measurement sites, Atmos. Chem. Phys., 10, 3561-3581, doi:10.5194/acp-10-3561-2010, 2010.

Henrich, F., Siebert, H., Jäkel, E., Shaw, R. A., and Wendisch, M.: Collocated measurements of boundary layer cloud microphysical and radiative properties: A feasibility study, J. Geophys. Res., 115, D24214, doi:10.1029/2010JD013930, 2010.

Hildebrandt, L., Engelhart, G. J., Mohr, C., Kostenidou, E., Lanz, V. A., Bougiatioti, A., DeCarlo, P. F., Prévôt, A. S. H., Baltensperger, U., Mihalopoulos, N., Donahue, N. M., and Pandis, S. N.: Aged organic aerosol in the Eastern Mediterranean: the Finokalia Aerosol Measurement Experiment - 2008, Atmos. Chem. Phys., 10, 4167-4186, doi:10.5194/acp-10-4167-2010, 2010.

Hirsikko, A., Nieminen, T., Gagné, S., Lehtipalo, K., Manninen, H. E., Ehn, M., Hõrrak, U., Kerminen, V.-M., Laakso, L., McMurry, P. H., Mirme, A., Mirme, S., Petäjä, T., Tammet, H., Vakkari, V., Vana, M., and Kulmala, M.: Atmospheric ions and nucleation: a review of observations, Atmos. Chem. Phys., 11, 767798, doi:10.5194/acp-11-767-2011, 2011.

Hoek, G., Brunekreef, B., Goldbohm, S., Fischer, P., and van den Brandt, P. A,.: Association between mortality and indicators of traffic-related air pollution in the Netherlands: a cohort study, Lancet, 360, 1203-9, 2002.

Holben, B. N., Eck, T. F., Slutsker, I., Tanre, D., Buis, J. P., Setzer, A., Vermote, E., Reagan, J. A., Kaufman, Y. F., Nakajima, T., Lavenu, F., Jankowiak, I., and Smirnov, A.: AERONET-a federated instrument network and data archive for aerosol characterization, Remote Sens. Environ., 66, 1-16, 1998.

Holben, B. N., Tanre, D., Smirnov, A., Eck, T. F., Slutsker, I., Abuhassan, N., Newcomb, W. W., Schafer, J. S., Chatenet, B., Lavenu, F., Kaufman, Y. J., Castle, J. V., Setzer, A., Markham, B., Clark, D., Frouin, R., Halthore, R., Karneli, A., O’Neill, N. T., Pietras, C., Pinker, R. T., Voss, K., and Zibordi, G.: An emerging ground-based aerosol climatology: Aerosol optical depth from AERONET, J. Geophys. Res.-Atmos., 106, 12067-12097, 2001.

Hoose, C., Kristjánsson, J. E., Iversen, T., Kirkevåg, A., Seland, Ø., and Gettelman, A.: Constraining cloud droplet number concentration in GCMs suppresses the aerosol indirect effect, Geophys. Res. Lett. 36, L12807, doi:10.1029/2009GL038568, 2009.

Hoose, C., Kristjánsson, J. E., Arabas, S., Boers, R., Pawlowska, H., Puygrenier, V., Siebert, H., and Thouron, O.: Parameterization of in-cloud vertical velocities for cloud droplet activation in coarsegrid models: Analysis of observations and cloud resolving model results, $5 \mathrm{pp}$. In: Proceedings of the AMS 13th Conference on Cloud Physics and 13th Conference on Atmospheric Radiation, 28 June-2 July 2010, Portland, Oregon, USA, Am. Meteorol. Soc., http://ams.confex.com/ams/pdfpapers/170866.pdf, 2010a.

Hoose, C., Kristjánsson, J. E., and Burrows, S. M.: How important is biological ice nucleation in clouds on a global scale?, Environ. Res. Lett., 5, doi:10.1088/1748-9326/5/2/024009, 2010b.

Hoose, C., Kristjánsson, J. E., Chen, J.-P., and Hazra, A.: A classical-theory-based parameterization of heterogeneous ice nucleation by mineral dust, soot and biological particles in a global climate model, J. Atmos. Sci., 67, 2483-2503, 2010c.

Hõrrak, U., Aalto, P. P., Salm, J., Komsaare, K., Tammet, H., Mäkelä, J. M., Laakso, L., and Kulmala, M.: Variation and balance of positive air ion concentrations in a boreal forest, Atmos. Chem. Phys., 8, 655-675, doi:10.5194/acp-8-655-2008, 2008.

Hourdin, F., Musat, I., Bony, S., Braconnot, P., Codron, F., Dufresne, J. L., Fairhead, L., Filiberti, M. A., Friedlingstein, P., Grandpeix, J. Y., Krinner, G., Levan, P., Li, Z. X., and Lott, F.: The LMDZ4 general circulation model: climate performance 
and sensitivity to parametrized physics with emphasis on tropical convection, Clim. Dynam., 27, 787-813, 2006.

Hyvärinen, A.-P., Lihavainen, H., Komppula, M., Panwar, T. S., Sharma, V. P., Hooda, R. K., and Viisanen, Y.: Aerosol measurements at the Gual Pahari EUCAARI station: preliminary results from first year in-situ measurements, Atmos. Chem. Phys. 10, 7241-7252, doi:10.5194/acp-10-7241-2010, 2010.

Hyvärinen, A.-P., Raatikainen, T., Brus, D., Komppula, M., Panwar, T. S., Hooda, R. K., Sharma, V. P., and Lihavainen, H.: Effect of the summer monsoon on aerosols at two measurement stations in Northern India - Part 1: PM and BC concentrations, Atmos. Chem. Phys., 11, 8271-8282, doi:10.5194/acp-11-82712011, 2011a.

Hyvärinen, A.-P., Raatikainen, T., Komppula, M., Mielonen, T., Sundström, A.-M., Brus, D., Panwar, T. S., Hooda, R. K., Sharma, V. P., de Leeuw, G., and Lihavainen, H.: Effect of the summer monsoon on aerosols at two measurement stations in Northern India - Part 2: Physical and optical properties, Atmos. Chem. Phys., 11, 8283-8294, doi:10.5194/acp-11-82832011, 2011b.

IPCC: The Scientific Basis. A report of Working Group I of the Intergovernmental Panel on Climate Change. in: Climate Change 2007: The Physical Science Basis. Contribution of Working Group I to the Fourth Assessment Report of the Intergovernmental Panel on Climate Change, edited by: Solomon, S., 2007.

Isaksen, I. S. A., Granier, C., Myhre, G., Berntsen, T. K., Dalsren, S. B., Gauss, M., Klimont, Z., Benestad, R., Bousquet, P., Collins, W., Cox, T., Eyring, V., Fowler, D., Fuzzi, S., Jöckel, P., Laj, P., Lohmann, U., Maione, M., Monks, P., Prévôt, A. S. H., Raes, F., Richter, A., Rognerud, B., Schulz, M., Shindell, D., Stevenson, D. S., Storelvmo, T., Wang, W.-C., van Weele, M., Wild, M., and Wuebbles, D.: Atmospheric composition change: Climate-chemistry interactions, Atmos. Environ., 43, 5138-5192, doi:10.1016/j.atmosenv.2009.08.003, 2009.

Iversen, T, Kirkevåg, A., Seland, Ø., Debernard, J., Kristjansson, J. E., and Hoose, C.: Assessing Impacts of Aerosol Processes on Equilibrium Climate Sensitivity. In: Air Pollution Modeling and Its Application XX, edited by: Steyn, D. G. and Rao, S. T., Springer, Dordrecht, The Netherlands, 493-497, doi:10.1007/978-90-481-3812-8, 2010.

Jacobson, M. Z.: Short term effects of controlling fossil fuel soot, biofuel soot and gases, and methane on climate, Arctic ice, and air pollution health, J. Geophys. Res., 115, D14209, doi:10.1029/2009JD013795, 2010.

Janhäll, S., Andreae, M. O., and Pöschl, U.: Biomass burning aerosol emissions from vegetation fires: particle number and mass emission factors and size distributions, Atmos. Chem. Phys., 10, 1427-1439, doi:10.5194/acp-10-1427-2010, 2010.

Jayne, J. T., Leard, D. C., Zhang, X. F., Davidovits, P., Smith, K. A., Kolb, C. E., and Worsnop, D. R.: Development of aerosol mass spectrometer for size and composition analysis of submicron particles, Aerosol Sci. Technol., 33, 49-70, 2000.

Jenkin, M. E., Saunders, S. M., Wagner, V., and Pilling, M. J.: Protocol for the development of the Master Chemical Mechanism, MCM v3 (Part B): tropospheric degradation of aromatic volatile organic compounds, Atmos. Chem. Phys., 3, 181-193, doi:10.5194/acp-3-181-2003, 2003.

Jimenez, J. L., Canagaratna, M. R., Donahue, N. M., Prévôt, A. S. H., Zhang, Q., Kroll, J. H., DeCarlo, P. F., Allan, J. D., Coe,
H., Ng, N. L., Aiken, A. C., Docherty, K. S., Ulbrich, I. M., Grieshop, A. P., Robinson, A. L., Duplissy, J., Smith, J. D., Wilson, K. R., Lanz, V. A., Hueglin, C., Sun, Y. L., Tian, J., Laaksonen, A., Raatikainen, T., Rautiainen, J., Vaattovaara, P., Ehn, M., Kulmala, M., Tomlinson, J. M., Collins, D. R., Cubison, M. J., Dunlea, E. J., Huffman, J. A., Onasch, T. B., Alfarra, M. R., Williams, P. I., Bower, K., Kondo, Y., Schneider, J., Drewnick, F., Borrmann, S., Weimer, S., Demerjian, K., Salcedo, D., Cottrell, L., Griffin, R., Takami, A., Miyoshi, T., Hatakeyama, S., Shimono, A., Sun, J. Y., Zhang, Y. M., Dzepina, K., Kimmel, J. R., Sueper, D., Jayne, J. T., Herndon, S. C., Trimborn, A. M., Williams, L. R., Wood, E. C., Middlebrook, A. M., Kolb, C. E., Baltensperger, U., and Worsnop, D. R.: Evolution of Organic Aerosols in the Atmosphere, Science, 326, 1525-1529, doi:10.1126/science.1180353, 2009.

Johansson, C., Hedberg, E., Boman, C., Denier van der Gon, H., and Visschedijk, A.: Particle number emission factors for residential biomass burning, ITM report 176, Department of Applied Environmental Science, Stockholm university, December 2008.

Jones, A., Haywood, J. M., and Boucher, O.: Aerosol forcing, climate response and climate sensitivity in the Hadley Centre climate model, J. Geophys. Res., 112, D20211, doi:10.1029/2007JD008688, 2007.

Jung J.-G., Pandis S. N., and Adams P. J.: Evaluation of nucleation theories in a sulfur-rich environment, Aerosol Sci. Technol., 42, 495-504, 2008.

Jung, J.-G., Fountoukis, C., Adams, P. J., and Pandis, S. N.: Simulation of in situ ultrafine particle formation in the Eastern United States using PMCAMx-UF, J. Geophys. Res., 115, D03203, doi:10.1029/2009JD012313,, 2010.

Junninen, H., Ehn, M., Petäjä, T., Luosujärvi, L., Kotiaho, T., Kostiainen, R., Rohner, U., Gonin, M., Fuhrer, K., Kulmala, M., and Worsnop, D. R.: A high-resolution mass spectrometer to measure atmospheric ion composition, Atmos. Meas. Tech., 3, 10391053, doi:10.5194/amt-3-1039-2010, 2010.

Jurányi, Z., Gysel, M., Weingartner, E., DeCarlo, P. F., Kammermann, L., and Baltensperger, U.: Measured and modelled cloud condensation nuclei number concentration at the high alpine site Jungfraujoch, Atmos. Chem. Phys., 10, 7891-7906, doi:10.5194/acp-10-7891-2010, 2010.

Kahn, R. A., Nelson, D. L., Garay, M. J., Levy, R. C., Bull, M. A., Diner, D. J., Martonchik, J. V., Paradise, S. R., Hansen, E. G., and Remer, L. A.: MISR aerosol product attributes and statistical comparisons with MODIS, IEEE T. Geosci. Remote, 47, 40954114, 2009.

Kahnert, M., Lazaridis, M., Tsyro, S., and Torseth, K.: Requirement for developing a regional monitoring capacity for aerosols in Europe with EMEP, J. Environ. Monitor., 6, 646-655, 2004.

Kahnt, A., Iinuma, Y., Böge, O., Heinold, A., and Herrmann, H.: Denuder sampling techniques for the determination of gas-phase carbonyl compounds: a comparison and characterisation of insitu and ex-situ derivatisation methods, J. Chromatogr. B, 879, 1402-1411, doi:10.1016/j.jchromb.2011.02.028, 2011.

Kammermann, L., Gysel, M., Weingartner, E., and Baltensperger, U.: 13-month climatology of the aerosol hygroscopicity at the free tropospheric site Jungfraujoch (3580 m a.s.1.), Atmos. Chem. Phys., 10, 10717-10732, doi:10.5194/acp-10-107172010, 2010.

Kanakidou, M., Myriokefalitakis, S., Tsigaridis, K., Mihalopoulos, 
N., Querol, X. and Alastuey, A.: Natural and Anthropogenic contributions to particulate matter in southern Europe, EUCAARI, Helsinki, Report Series in Aerosol Science part A (vol 99), Proceedings of 2008 EUCAARI Annual Meeting Helsinki 17-21 Novermber 2008, edited by: Lappalainen, H. K., Asmi, A., Nieminen, T., and Kulmala, M., 121-126, 2008.

Kazil, J., Harrison, R. G., and Lovejoy, E. R.: Tropospheric new particle formation and the role of ions, Space Sci. Rev., 137, 241255, 2008.

Kazil, J., Stier, P., Zhang, K., Quaas, J., Kinne, S., O’Donnell, D., Rast, S., Esch, M., Ferrachat, S., Lohmann, U., and Feichter, J.: Aerosol nucleation and its role for clouds and Earth's radiative forcing in the aerosol-climate model ECHAM5-HAM, Atmos. Chem. Phys., 10, 10733-10752, doi:10.5194/acp-1010733-2010, 2010.

Kerminen, V.-M. and Kulmala, M.: Analytical formulae connecting the real and the "apparent" nucleation rate and the nuclei number concentration for atmospheric nucleation events, J. Aerosol Sci., 33, 609-622, 2002.

Kerminen, V.-M., Anttila, T., Petäjä, T., Laakso, L., Gagné, S., Lehtinen, K. E. J., and Kulmala, M.: Charging state of the atmospheric nucleation mode: Implications for separating neutral and ion-induced nucleation, J. Geophys. Res., 112, D21205, doi:10.1029/2007JD008649, 2007.

Kerminen, V.-M., Petäjä, T., Manninen, H. E., Paasonen, P., Nieminen, T., Sipilä, M., Junninen, H., Ehn, M., Gagné, S., Laakso, L., Riipinen, I., Vehkamäki, H., Kurten, T., Ortega, I. K., Dal Maso, M., Brus, D., Hyvärinen, A., Lihavainen, H., Leppä, J., Lehtinen, K. E. J., Mirme, A., Mirme, S., Hõrrak, U., Berndt, T., Stratmann, F., Birmili, W., Wiedensohler, A., Metzger, A., Dommen, J., Baltensperger, U., Kiendler-Scharr, A., Mentel, T. F., Wildt, J., Winkler, P. M., Wagner, P. E., Petzold, A., Minikin, A., Plass-Dülmer, C., Pöschl, U., Laaksonen, A., and Kulmala, M.: Atmospheric nucleation: highlights of the EUCAARI project and future directions, Atmos. Chem. Phys., 10, 10829-10848, doi:10.5194/acp-10-10829-2010, 2010.

Kiendler-Scharr, A., Zhang, Q., Hohaus, T., Kleist, E., Mensah, A., Mentel, T. F., Spindler, C., Uerlings, R., Tillmann, R., and Wildt, J.: Aerosol Mass Spectrometric Features of Biogenic SOA: Observations from a Plant Chamber and in Rural Atmos. Environ., Environ. Sci. Technol., 43, 8166-8172, doi:10.1021/es901420b, 2009a.

Kiendler-Scharr, A., Wildt, J., Dal Maso, M., Hohaus, T., Kleist, E., Mentel, T. F., Tillmann, R., Uerlings, R., Schurr, U., and Wahner, A.: New particle formation in forests inhibited by isoprene emissions, Nature, 461, 381-384, doi:10.1038/nature08292, 2009b.

King, S. M., Rosenoern, T. , Shilling, J. E., Chen, Q., Wang, Z., Biskos, G., McKinney, K. A., Pöschl, U., and Martin, S. T.: Cloud droplet activation of mixed organic-sulfate particles produced by the photooxidation of isoprene, Atmos. Chem. Phys., 10, 3953-3964, doi:10.5194/acp-10-3953-2010, 2010.

Kinne, S.: Aerosol direct forcing with an AERONET touch, Atmos. Environ., in preparation, 2011.

Kirkby, J., Curtius, J., Almeida, J., Dunne, E., Duplissy, J., Ehrhart, S., Franchin, A., Gagne, S., Ickes, L., Kurten, A., Kupc, A., Metzger, A., Riccobono, F., Rondo, L., Schobesberger, S., Tsagkogeorgas, G., Wimmer, D., Amorim, A., Bianchi, F., Breitenlechner, M., David, A., Dommen, J., Downard, A., Ehn, M., Flagan, R. C., Haider, S., Hansel, A., Hauser, D., Jud, W., Junni- nen, H., Kreissl, F., Kvashin, A., Laaksonen, A., Lehtipalo, K., Lima, J., Lovejoy, E. R., Makhmutov, V., Mathot, S., Mikkila, J., Minginette, P., Mogo, S., Nieminen, T., Onnela, A., Pereira, P., Petaja, T., Schnitzhofer, R., Seinfeld, J. H., Sipila, M., Stozhkov, Y., Stratmann, F., Tome, A., Vanhanen, J., Viisanen, Y., Vrtala, A., Wagner, P. E., Walther, H., Weingartner, E., Wex, H., Winkler, P. M., Carslaw, K. S., Worsnop, D. R., Baltensperger, U., Kulmala, M.:Role of sulphuric acid, ammonia and galactic cosmic rays in atmospheric aerosol nucleation, Nature, 476, 429433, doi:10.1038/nature10343, 2011.

Kirkevåg, A., Iversen, T., Seland, Ø., Debernard, J. B., Storelvmo, T., and Kristjansson, J. E.: Aerosol-cloud-climate interactions in the climate model CAM-Oslo, Tellus 60A, 492-512, doi:10.1111/j.1600-0870.2008.00313.x., 2008.

Kiss, G., Tombacz, E., Varga, B., Alsberg, T., and Persson, L.: Estimation of the average molecular weight of humic-like substances isolated from fine atmospheric aerosol, Atmos. Environ. 37, 3783-3794, 2003.

Kleipool, Q. L., Dobber, M. R., de Haan, J. F., and Levelt, P. F.: Earth surface reflectance climatology from 3 years of OMI data, J. Geophys. Res., 113, D18308, doi:10.1029/2008JD010290, 2008.

Kloster, S., Dentener, F., Feichter, J., Raes, F., van Aardenne, J., Roeckner, E., Lohmann, U., Stier, P., and Swart, R.: Influence of future air pollution mitigation strategies on total aerosol radiative forcing, Atmos. Chem. Phys., 8, 6405-6437, doi:10.5194/acp-86405-2008, 2008.

Kloster, S., Dentener, F., Feichter, J., Raes, F., Lohmann, U., Roeckner, E., and Fischer-Bruns, I.: A GCM study of future climate response to aerosol pollution, Reductions, Clim Dynam., doi:10.1007/s00382-009-0573-0, 2009.

Koch, K., Schulz, M., Kinne, S., Bond, T. C., Balkanski, Y., Bauer, S., Berntsen, T., Boucher, O., Chin, M., Clarke, A., De Luca, N., Dentener, F., Diehl, T., Dubovik, O., Easter, R., Fahey, D. W., Feichter, J. , Fillmore, D. , Freitag, S., Ghan, S., Ginoux, P., Gong, S., Horowitz, L., Iversen, T., Kirkevåg, A., Klimont, Z., Kondo, Y., Krol, M., Liu, X., McNaughton, C., Miller, R., Montanaro, V. , Moteki, N. ,Myhre, G., Penner, J. E., Perlwitz, J., Pitari, G., Reddy, S., Sahu, L., Sakamoto, H. , Schuster, G. , Schwarz, J. P., Seland, Ø., Spackman, J. R., Stier, P., Takegawa, N., Takemura, T., Textor, C., van Aardenne, J. A., and Zhao, Y.: Evaluation of black carbon estimations in global aerosol models, Atmos. Chem. Phys. 9, 9001-9026, doi:10.5194/acp-9-9001-2009, 2009.

Kokhanovsky, A. and de Leeuw, G. (Eds.): Satellite aerosol remote sensing over land, Springer, ISBN 978-3-540-69396-3, 388 pp., 2009.

Kokhanovsky, A. A., Platnick, S., and King, M. D.: Remote sensing of terrestrial clouds from space using backscattering and thermal emission techniques, edited by: Burrows, J. P., Platt, U., and Borrell, P., in: The remote sensing of tropospheric composition from space, physics of earth and space environments, Springer-Verlag Berlin Heidelberg, Germany, doi:10.1007/9783-642-14791-3, 2011.

Kokkola, H., Korhonen, H., Lehtinen, K. E. J., Makkonen, R., Asmi, A., Järvenoja, S., Anttila, T., Partanen, A.-I., Kulmala, M., Järvinen, H., Laaksonen, A., and Kerminen, V.-M.: SALSA - a Sectional Aerosol module for Large Scale Applications, Atmos. Chem. Phys., 8, 2469-2483, doi:10.5194/acp-8-2469-2008, 
2008.

Kolmonen, P., Sogacheva, L., Sundström, A.-M., Rodriguez, E., and de Leeuw, G.: The AATSR dual view algorithm for global multi-year retrieval of aerosol optical properties over land, special issue on Remote Sensing of Aerosols and Clouds: Techniques and Applications, Atmos. Res., in preparation, 2011.

Komppula, M., Mielonen, T., Arola, A., Korhonen, K., Lihavainen, H., Hyvärinen, A.-P., Baars, H., Engelmann, R., Althausen, D., Ansmann, A., Müller, D., Panwar, T. S., Hooda, R. K., Sharma, V. P., Kerminen, V.-M., Lehtinen, K. E. J., and Viisanen, Y.: One year of Raman-lidar measurements in Gual Pahari EUCAARI site close to New Delhi in India: seasonal characteristics of the aerosol vertical structure, Atmos. Chem. Phys. Discuss., 10, 31123-31151, doi:10.5194/acpd-10-31123-2010, 2010.

Koop, T., Bookhold, J., Shiraiwa, M., and Pöschl, U.: Glass transition and phase state of organic compounds: dependency on molecular properties and implications for secondary organic aerosols in the atmosphere, Phys. Chem. Chem. Phys., 13, 19238-19255, 2011.

Koponen, I. K., Riipinen, I. Hienola, A., Kulmala M., and Bilde, M.: Thermodynamic properties of succinic, glutaric and malonic acids: evaporation rates and vapor pressures, Environ. Sci. Technol., 41, 3926-3933, 2007.

Kopp, R. E. and Mauzerall, D. L.: Assessing the climatic benefits of black carbon mitigation, Proc. Natl. Acad. Sci. USA, 107, 26, 11703-11708, doi:10.1073/pnas.0909605107, 2009.

Kristensson, A,, Rosenorm, T., and Bilde, M.: Cloud droplet activation of amino acid aerosol particles, J. Phys. Chem., A, 114, 379-386, 2010.

Krol, M., Houweling, S., Bregman, B., van den Broek, M., Segers, A., van Velthoven, P., Peters, W., Dentener, F., and Bergamaschi, P.: The two-way nested global chemistry-transport zoom model TM5: algorithm and applications, Atmos. Chem. Phys., 5, 417432, doi:10.5194/acp-5-417-2005, 2005.

Kroll J. H., Donahue, N. M., Jimenez, J. L., Kessler, S. H., Canagaratna, M. R., Wilson, K. R., Altieri, K. E., Mazzoleni, L. R., Wozniak, A. S., Bluhm, H., Mysak, E. R., Smith, J. D., Kolb, C. E., and Worsnop, D. R.: Carbon oxidation state as a metric for describing the chemistry of atmospheric organic aerosol, Nature Chem., 3, 133-139, doi:10.1038/nchem.948, 2011.

Kulmala, M., Suni, T., Lehtinen, K. E. J., Dal Maso, M., Boy, M., Reissell, A., Rannik, U., Aalto, P., Keronen, P., Hakola, H., Back, J. B., Hoffmann, T., Vesala, T., and Hari, P.: A new feedback mechanism linking forests, aerosols, and climate, Atmos. Chem. Phys., 4, 557-562, doi:10.5194/acp-4-557-2004, 2004a.

Kulmala, M., Vehkamäki, H., Petäjä, T., Dal Maso, M., Lauri, A., Kerminen, V.-M., Birmili, W., and McMurry, P. H.: Formation and growth rates of ultrafine atmospheric particles: A review of observations, J. Aerosol Sci., 35, 143-176, 2004b.

Kulmala, M., Lehtinen K. E. J., and Laaksonen, A.: Aluster activation theory as an explanation of the linear dependence between formation rate of $3 \mathrm{~nm}$ particles and sulphuric acid concentration, Atmos. Chem. Phys., 6, 787-793, doi:10.5194/acp-6-787-2006, 2006.

Kulmala, M., Riipinen, I., Sipilä, M., Manninen, H. E., Petäjä, T., Junninen, H., Dal Maso, M., Mordas, G., Mirme, A., Vana, M., Hirsikko, A., Laakso, L., Harrison, R. M., Hanson, I., Leung, C., Lehtinen, K. E. J., and Kerminen, V.-M.: Toward direct measurement of atmospheric nucleation, Science, 318, 89-92, 2007a.
Kulmala, M., Mordas, G., Petäjä, T., Grönholm, T., Aalto, P.P., Vehkamäki, H., Hienola, A. I, Herrmann, E., Sipilä, M., Riipinen, I., Manninen, H. E., Hämeri, K., Stratman, F., Bilde, M., Winkler, P. M., Wolfram, B., and Wagner, P. E.: The Condensation Particle Counter Battery (CPCB): A new tool to investigate the activation properties of nanoparticles, J. Aerosol Sci., 38, 289-304, 2007b.

Kulmala, M., Asmi, A., Lappalainen, H. K., Carslaw, K. S., Pöschl, U., Baltensperger, U., Hov, Ø., Brenquier, J.-L., Pandis, S. N., Facchini, M. C., Hansson, H.-C., Wiedensohler, A., and O'Dowd, C. D.: Introduction: European Integrated project on Aerosol Cloud Climate and Air Quality interactions (EUCAARI) - integrating aerosol research from nano to global scales, Atmos. Chem. Phys., 9, 2825-2841, doi:10.5194/acp-92825-2009, 2009.

Kulmala, M.; Riipinen, I., Nieminen, T., Hulkkonen, M., Sogacheva, L., Manninen, H. E., Paasonen, P., Petäjä, T., Dal Maso, M., Aalto, P. P., Viljanen, A., Usoskin, I., Vainio, R., Mirme, S., Mirme, A., Minikin, A., Petzold, A., Hõrrak, U., Plaß-Dülmer, C., Birmili, W., Kerminen, V.-M.: Atmospheric data over a solar cycle: no connection between galactic cosmic rays and new particle formation, Atmos. Chem. Phys., 10, 18851898, doi:10.5194/acp-10-1885-2010, 2010.

Kupiainen, K. and Klimont, Z.: Primary Emissions of Fine Carbonaceous Particles in Europe. Atmos. Environ., 41, 2156-2170, 2007.

Kurtén T., Loukonen, V., Vehkamäki, H., and Kulmala, M.: Amines are likely to enhance neutral and ion-induced sulfuric acid-water nucleation in the atmosphere more effectively than ammonia, Atmos. Chem. Phys., 8, 4095-4103, doi:10.5194/acp-8-4095-2008, 2008.

Laakso, L., Gagne, S., Petäjä, T., Hirsikko, A., Aalto, P. P., Kulmala, M., and Kerminen, V.-M.: Detecting charging state of ultrafine particles: instrumental development and ambient measurements, Atmos. Chem. Phys., 7, 1333-1345, doi:10.5194/acp-7-13332007, 2007.

Laakso, L., Laakso, H., Aalto, P. P., Keronen, P., Petäjä, T., Nieminen, T., Pohja, T., Siivola, E., Kulmala, M., Kgabi, N., Molefe, M., Mabaso, D., Phalatse, D., Pienaar, K., and Kerminen, V.-M.: Basic characteristics of atmospheric particles, trace gases and meteorology in a relatively clean Southern African Savannah environment, Atmos. Chem. Phys., 8, 4823-4839, doi:10.5194/acp-8-4823-2008, 2008.

Laakso, L., Vakkari, V., Laakso, H., Virkkula, A., Kulmala, M., Beukes, J. P., van Zyl, P. G., Pienaar, J. J., Chiloane, K., Gilardoni, S., Vignati, E., Wiedensohler, A., Tuch, T., Birmili, W., Piketh, S., Collett, K., Fourie, G. D., Komppula, M., Lihavainen, H., de Leeuw, G., and Kerminen, V.-M.: South African EUCAARI - measurements: a site with high atmospheric variability, Atmos. Chem. Phys. Discuss., 10, 3069130729, doi:10.5194/acpd-10-30691-2010, 2010.

Labonnote, L., Riedi, J., Waquet, F., and POLDER Aerosol/Cloud Teams: Remote Sensing of Cloud and Aerosol over Cloud from Multi-Viewing Polarized Measurements, in Hyperspectral Imaging and Sensing of the Environment, OSA Technical Digest (CD), Optical Society of America, paper HWB2, 2009.

Laj, P., Klausen, J., Bilde, M., Plaß-Duelmer, C., Pappalardo, G., Clerbaux, C, Baltensperger, U., Hjorth, J., Simpson, D., Reimann, S., Coheur, P.-F., Richter, A., De Mazie, M., Rudich, 
Y., McFiggans, G., Torseth, K., Wiedensohler, A., Morin, S., Schulz, M., Allan, J. D., Attie, J.-L., Barnes, I., Birmili, W., Cammas, J. P., Dommen, J., Dorn, H.-P., Fowler, D., Fuzzi, S., Glasius, M., Granier, C., Hermann, M., Isaksen, I. S. A., Kinne, S., Koren, I., Madonna, F., Maione, M., Massling, A., Moehler, O., Mona, L., Monks, P. S., Mueller, D., Mueller, T., Orphal, J., Peuch, V.-H., Stratmann, F., Tanre, D., Tyndall, F., Abo Riziqmm, A., Van Roozendael, M., Villani P., Wehner, B., Wex, H., and Zardini, A. A.: Measuring atmospheric composition change, Atmos. Environ, 43, 5351-5414, doi:10.1016/j.atmosenv.2009.08.020, 2009.

Lang-Yona, N., Rudich, Y., Mentel, T. F., Bohne, A., Buchholz, A., Kiendler-Scharr, A., Kleist, E., Spindler, C., Tillmann, R., and Wildt, J.: The chemical and microphysical properties of secondary organic aerosols from Holm Oak emissions, Atmos. Chem. Phys., 10, 7253-7265, doi:10.5194/acp-10-7253-2010, 2010.

Lanz, V. A., Alfarra, M. R., Baltensperger, U., Buchmann, B., Hueglin, C., and Prévôt, A. S. H.: Source apportionment of submicron organic aerosols at an urban site by factor analytical modelling of aerosol mass spectra, Atmos. Chem. Phys., 7, 1503-1522, doi:10.5194/acp-7-1503-2007 2007.

Lanz, V. A., Alfarra, M. R., Baltensperger, U., Buchmann, B., Hueglin, C., Szidat, S., Wehrli, M. N., Wacker, L., Weimer, S., Caseiro, A., Puxbaum, H., and Prévôt, A. S. H.: Source attribution of submicron organic aerosols during wintertime inversions by advanced factor analysis of aerosol mass spectra, Environ. Sci. Technol., 42, 214-220, 2008.

Lanz, V. A., Prévôt, A. S. H., Alfarra, M. R., Weimer, S., Mohr, C., DeCarlo, P. F., Gianini, M. F. D., Hueglin, C., Schneider, J., Favez, O., D'Anna, B., George, C., and Baltensperger, U.: Characterization of aerosol chemical composition with aerosol mass spectrometry in Central Europe: an overview, Atmos. Chem. Phys., 10, 10453-10471, doi:10.5194/acp-10-10453-2010, 2010.

Lee, B. H., Kostenidou, E., Hildebrandt, L., Riipinen, I., Engelhart, G. J., Mohr, C., DeCarlo, P. F., Mihalopoulos, N., Prevot, A. S. H., Baltensperger, U., and Pandis, S. N.: Measurement of the ambient organic aerosol volatility distribution: application during the Finokalia Aerosol Measurement Experiment (FAME2008), Atmos. Chem. Phys., 10, 12149-12160, doi:10.5194/acp10-12149-2010, 2010.

Lehtinen, K. E. J., Dal Maso, M., Kulmala, M., and Kerminen, V.M.: Estimating nucleation rates from apparent particle formation rates and vice-versa: Revised formulation of the KerminenKulmala equation, J. Aerosol Sci., 38, 988-994, 2007.

Lehtipalo, K., Sipilä, M., Riipinen, I., Nieminen, T. and Kulmala, M.: Analysis of atmospheric neutral and charged molecular clusters in boreal forest using pulse-height CPC, Atmos. Chem. Phys., 9, 4177-4184, doi:10.5194/acp-9-4177-2009, 2009.

Leppä, J., Kerminen, V.-M., Laakso, L., Korhonen, H., Lehtinen, K. E. J., Gagne, S., Manninen, H. E., Nieminen, T., and Kulmala, M.: Ion-UHMA: a model for simulating the dynamics of neutral and charged aerosol particles, Boreal Environ. Res., 14, 559575, 2009.

Levy, R. C., Remer, L. A., Kleidman, R. G., Mattoo, S., Ichoku, C., Kahn, R., and Eck, T. F.: Global evaluation of the Collection 5 MODIS dark-target aerosol products over land, Atmos. Chem. Phys., 10, 10399-10420, doi:10.5194/acp-10-10399-2010, 2010. Lohmann, U. and Hoose, C.: Sensitivity studies of different aerosol indirect effects in mixed-phase clouds, Atmos. Chem. Phys. 9, 8917-8934, doi:10.5194/acp-9-8917-2009, 2009.

Lohmann, U., Stier, P., Hoose, C., Ferrachat, S., Roeckner, E., and Zhang, J.: Cloud microphysics and aerosol indirect effects in the global climate model ECHAM5-HAM, Atmos. Chem. Phys., 7, 3425-3446, doi:10.5194/acp-7-3425-2007, 2007.

Loukonen, V., Kurten, T., Ortega, I. K, Vehkamäki, H., Padua, A. A. H., Sellegri, K., and Kulmala, M.: Enhancing effect of dimethylamine in sulfuric acid nucleation in the presence of watera computational study, Atmos. Chem. Phys., 10, 4961-4974, doi:10.5194/acp-10-4961-2010, 2010.

Lüönd, F., Stetzer, O., Welti, A., and Lohmann, U.: Experimental study on the ice nucleation ability of size selected kaolinite particles in the immersion mode, J. Geophys. Res. 115, D14201, doi:10.1029/2009JD012959, 2010.

Makkonen R., Asmi, A., Korhonen, H., Kokkola, H., Järvenoja, S., Räisänen, P., Lehtinen, K. E. J., Laaksonen, A., Kerminen,V.M., Järvinen, H., Lohmann, U., Bennartz, R., Feichter, J., and Kulmala, M.: Sensitivity of aerosol concentrations and cloud properties to nucleation and secondary organic distribution in ECHAM5-HAM global circulation model, Atmos. Chem. Phys., 9, 1747-1766, doi:10.5194/acp-9-1747-2009, 2009.

Makkonen, R., Asmi, A., Kerminen, V.-M., Boy, M., Arneth, A., Hari, P., and Kulmala, M.: Air pollution control and decreasing new particle formation lead to strong climate warming, Atmos. Chem. Phys. Discuss., 11, 25991-26007, doi:10.5194/acpd-1125991-2011, 2011.

Mann, G.W., Carslaw, K. S. , Spracklen, D. V., Ridley, D. A , Manktelow, P. T., Chipperfield, M. P., Pickering, S. J., and Johnson C. E.: Description and evaluation of GLOMAP-mode: a modal global aerosol microphysics model for the UKCA composition-climate model, Geosci. Model Dev., 3, 519-551, doi:10.5194/gmd-3-519-2010, 2010.

Manninen, H. E., Nieminen, T., Riipinen, I., Yli-Juuti, T., Gagné, S., Asmi, E., Aalto, P. P., Petäjä, T., Kerminen, V.-M., and Kulmala, M.: Charged and total particle formation and growth rates during EUCAARI 2007 campaign in Hyytiälä, Atmos. Chem. Phys., 9, 4077-4089, doi:10.5194/acp-9-4077-2009, 2009a.

Manninen, H. E., Petäjä, T., Asmi, E., Riipinen, I., Nieminen, T., Mikkilä, J., Hõrrak, U., Mirme, A., Mirme, S., Laakso, L., Kerminen, V.-M., and Kulmala, M.: Long-term field measurements of charged and neutral clusters using Neutral cluster and Air Ion Spectrometer (NAIS), Boreal Environ. Res., 14, 591-605, 2009b.

Manninen, H. E., Nieminen, T., Asmi, E., Gagné, S., Häkkinen, S., Lehtipalo, K., Aalto, P., Vana, M., Mirme, A., Mirme, S., Hõrrak, U., Plass-Dülmer, C., Stange, G., Kiss, G., Hoffer, A., Töro, N., Moermann, M., Henzing, B., de Leeuw, G., Brinkenberg, M., Kouvarakis, G.N., Bougiatioti, K., Mihalopoulos, N., O'Dowd, C., Ceburnis, D., Arneth, A., Svenningsson, B., Swietlicki, E., Tarozzi, L., Decesari, S., Facchini, M.C., Birmili, W., Sonntag, A., Wiedensohler, A., Boulon, J., Sellegri, K., Laj, P., Gysel, M., Bukowiecki, N., Weingartner, E., Laaksonen, A., Hamed, A., Joutsensaari, J., Petäjä, T., Kerminen, V.-M., and Kulmala, M.: EUCAARI ion spectrometer measurements at 12 European sites - analysis of new-particle formation events, Atmos. Chem. Phys., 10, 7907-7927, doi:10.5194/acp-10-7907-2010, 2010.

Marcolli, C., Gedamke, S., Peter, T., and Zobrist, B.: Efficiency of immersion mode ice nucleation on surrogates of mineral dust, Atmos. Chem. Phys., 7, 5081-5091, doi:10.5194/acp-7-5081- 
2007, 2007

Martin, S. T., Andreae, M. O., Althausen, D., Artaxo, P., Baars, H., Borrmann, S., Chen, Q., Farmer, D. K., Guenther, A., Gunthe, S. S., Jimenez, J. L., Karl, T., Longo, K., Manzi, A., Mller, T., Pauliquevis, T., Petters, M. D., Prenni, A. J., Pöschl, U., Rizzo, L. V., Schneider, J., Smith, J. N., Swietlicki, E., Tota, J., Wang, J., Wiedensohler, A., and Zorn, S. R.: An overview of the Amazonian Aerosol Characterization Experiment 2008 (AMAZE-08), Atmos. Chem. Phys., 10, 11415-11438, doi:10.5194/acp-1011415-2010, 2010.

Massling, A., Niedermeier, N., Hennig, T., Fors, E. O., Swietlicki, E., Ehn, M., Hämeri, K., Villani, P., Laj, P., Good, N., McFiggans, G., and Wiedensohler, A.: Results and recommendations from an intercomparison of six Hygroscopicity-TDMA systems, Atmos. Meas. Tech., 4, 485-497, doi:10.5194/amt-4-485-2011, 2011.

McFiggans, G., Topping, D. O., and Barley, M. H.: The sensitivity of secondary organic aerosol component partitioning to the predictions of component properties - Part 1: A systematic evaluation of some available estimation techniques, Atmos. Chem. Phys., 10, 10255-10272, doi:10.5194/acp-10-10255-2010, 2010.

McMeeking, G. R., Hamburger, T., Liu, D., Flynn, M., Morgan, W. T., Northway, M., Highwood, E. J., Krejci, R., Allan, J. D., Minikin, A., and Coe, H.: Black carbon measurements in the boundary layer over western and northern Europe, Atmos. Chem. Phys., 10, 9393-9414, doi:10.5194/acp-10-9393-2010, 2010,

Mentel, T. F., Wildt, J., Kiendler-Scharr, A., Kleist, E., Tillmann, R., Dal Maso, M., Fisseha, R., Hohaus, T., Spahn, H., Uerlings, R., Wegener, R., Griffiths, P. T., Dinar, E., Rudich, Y., and Wahner, A.: Photochemical production of aerosols from real plant emissions, Atmos. Chem. Phys., 9, 4387-4406, doi:10.5194/acp9-4387-2009, 2009.

Merikanto, J., Spracklen, D. V., Mann, G. W., Pickering, S. J., and Carslaw, K. S.: Impact of nucleation on global CCN, Atmos. Chem. Phys., 9, 8601-8616, doi:10.5194/acp-9-8601-2009, 2009.

Merikanto, J., Spracklen D. V., Pringle K. J., and Carslaw K.: Effects of boundary layer particle formation on cloud droplet number and changes in cloud albedo from 1850 to 2000, Atmos. Chem. Phys., 10, 695-705, doi:10.5194/acp-10-695-2010, 2010.

Metzger, A., Verheggen, B., Dommen, J., Duplissy, J., Prévôt, A. S., Weingartner, E., Riipinen, I., Kulmala, M., Spracklen, D. V., Carslaw, K. S., and Baltensperger, U.: Evidence for the role of organics in aerosol particle formation under atmospheric conditions, P. Natl. Acad. Sci., 107, 6646-6651, 2010.

Michaud, V., El Haddad, I., Yao Liu, Sellegri, K., Laj, P., Villani, P., Picard, D., Marchand, N., and Monod, A.: In-cloud processes of methacrolein under simulated conditions - Part 3: Hygroscopic and volatility properties of the formed secondary organic aerosol, Atmos. Chem. Phys., 9, 5119-5130, doi:10.5194/acp-95119-2009, 2009

Mikhailov, E., Vlasenko, S., Martin, S. T., Koop, T., and Pöschl, U.: Amorphous and crystalline aerosol particles interacting with water vapour: conceptual framework and experimental evidence for restructuring, phase transitions and kinetic limitations, Atmos. Chem. Phys., 9, 9491-9522, doi:10.5194/acp-9-9491-2009, 2009

Mirme, A., Tamm, E., Mordas, G., Vana, M., Uin, J., Mirme, S., Bernotas, T., Laakso, L., Hirsikko, A., and Kulmala, M.: A wide- range multi-channel Air Ion Spectrometer, Boreal Environ. Res., 12, 247-264, 2007

Mirme, S., Mirme, A., Minikin, A., Petzold, A., Hrrak, U., Kerminen, V.-M., and Kulmala, M.: Atmospheric sub-3 nm particles at high altitudes, Atmos. Chem. Phys., 10, 437-451, doi:10.5194/acp-10-437-2010, 2010.

Monge, M. E., D’Anna, B., Mazri, L., Giroir-Fendler, A., Ammann, M., Donaldson, D. J., and George, C.: Light changes the atmospheric reactivity of soot, Proc. Natl. Acad. Sci. USA, 107, 6605-6609, doi:10.1073/pnas.0908341107, 2010a.

Monge, M. E., D’Anna, B., and George, C.: Nitrogen dioxide removal and nitrous acid formation on titanium oxide surfaces-an air quality remediation process?, Phys. Chem. Chem. Phys., 12, 8992-8999, doi:10.1039/b925785c, 2010b.

Monks, P. S., Granier, C., Fuzzi, S., Stohl, A., Williams, M. L., Akimoto, H., Amann, M., Baklanov, A., Baltensperger, U., Bey, I., Blake, N., Blake, R. S., Carslaw, K., Cooper, O. R., Dentener, F., Fowler, D. , Fragkou, E., Frost, G. J., Generoso, S., Ginoux, P., Grewe, V., Guenther, A., Hansson, H. C., Henne, S., Hjorth, J., Hofzumahaus, A., Huntrieser, H., Isaksen, I. S. A., Jenkin, M. E., Kaiser, J., Kanakidou, M., Klimont, Z., Kulmala, M., Laj, P., Lawrence, M. G., Lee, J. D., Liousse, C. Maione, M., Mciggans, G., Metzger, A., Mieville, A., Moussiopoulos, N., Orlando, J. J., O'Dowd, C. D., Palmer, P. I., Parrish, D. D., Petzold, A., Platt, U., Pöschl, U., Prévôt, A. S. H., Reeves, C. E., Reimann, S. , Rudich, Y. , Sellegri, K., Steinbrecher, R., Simpson, D., ten Brinkt, H., Theloke, J., vander Werf, G. R., Vautard, R., Vestreng, V., Vlachokostas, C., and von Glasow, R.: Atmospheric composition change Global and regional air quality. Atmos. Environ., 43, 5268-5350, doi:10.1016/j.atmosenv.2009.08.021, 2009.

Morgan, W. T., Allan, J. D., Bower, K. N., Esselborn, M., Harris, B., Henzing, J. S., Highwood, E. J., Kiendler-Scharr, A., McMeeking, G. R., Mensah, A. A., Northway, M. J., Osborne, S., Williams, P. I., Krejci, R., and Coe, H.: Enhancement of the aerosol direct radiative effect by semi-volatile aerosol components: airborne measurements in North-Western Europe, Atmos. Chem. Phys., 10, 8151-8171, doi:10.5194/acp-10-8151-2010, 2010a.

Morgan, W. T., Allan, J. D., Bower, K. N., Highwood, E. J., Liu, D., McMeeking, G. R., Northway, M. J., Williams, P. I., Krejci, R., and Coe, H.: Airborne measurements of the spatial distribution of aerosol chemical composition across Europe and evolution of the organic fraction, Atmos. Chem. Phys., 10, 4065-4083, doi:10.5194/acp-10-4065-2010, 2010 b.

Myhre, G., Berglen, T. F., Johnsrud, M., Hoyle, C. R., Berntsen, T. K., Christopher, S. A., Fahey, D., Isaksen, I. S. A., Jones, T. A., Kahn, R. A., Loeb, N., Quinn, P., Remer, L., Schwarz, J. P., and Yttri, K. E.: Modelled radiative forcing of the direct aerosol effect with multi-observation evaluation, Atmos. Chem. Phys., 9, 1365-1392, doi:10.5194/acp-9-1365-2009, 2009.

Müller, L.: The Chemistry of Formation and Evolution of Biogenic Secondary Organic Aerosols in the Atmosphere - A Mass Spectrometric Study, Johannes Gutenberg-University of Mainz, $\mathrm{PhD}$ thesis, Germany, 2010.

Müller, L., Reinnig, M. C., Naumann, K. H., Saathoff, H., Mentel, T. F., Donahue, N. M., and Hoffmann, T.: Formation of $3-$ methyl-1,2,3-butanetricarboxylic acid via gas phase oxidation of pinonic acid - a mass spectrometric study of SOA aging, Atmos. 
Chem. Phys. Discuss., 11, 19443-19476, doi:10.5194/acpd-1119443-2011, 2011.

Myriokefalitakis, S., Vrekoussis, M., Tsigaridis, K., Wittrock, F., Richter, A., Brühl, C., Volkamer, R., Burrows, J. P., and Kanakidou, M.: The influence of natural and anthropogenic secondary sources on the glyoxal global distribution, Atmos. Chem. Phys., 8, 4965-4981, doi:10.5194/acp-8-4965-2008, 2008.

Myriokefalitakis, S., Vignati, E., Tsigaridis ,K., Papadimas, C., Sciare, J., Mihalopoulos, N., Facchini, M. C., Rinaldi, M., Dentener, F. J., Ceburnis, D., Hatzianastasiou, N., O’Dowd, C. D., van Weele, M., and Kanakidou, M.: Global modelling of the oceanic source of organic aerosols, Adv. Meteorol., 2010, 939171, doi:10.1155/2010/939171, 2010.

Myriokefalitakis, S., Tsigaridis, K., Mihalopoulos, N., Sciare, J., Nenes, A., Kawamura, K., Segers, A., and Kanakidou, M.: In-cloud oxalate formation in the global troposphere: a 3-D modeling study, Atmos. Chem. Phys., 11, 5761-5782, doi:10.5194/acp-11-5761-2011, 2011.

Nannoolal, Y., Rarey, J., Ramjugernath, D., and Cordes, W.: Estimation of pure component properties. Part 1, Estimation of the normal boiling point of non-electrolyte organic compounds via group contributions and group interactions, Fluid Phase Equilibr., 226, 45-63, 2004.

Nannoolal, Y., Rarey, J., and Ramjugernath, D.: Estimation of pure component properties. Part 3. Estimation of the vapor pressure of non-electrolyte organic compounds via group contributions and group interactions, Fluid Phase Equilibr., 269, 117-133, 2008.

Ndour, M., Conchon, P., D'Anna, B., Ka, O., and George, C.: Photochemistry of mineral dust surface as a potential atmospheric renoxification process, Geophys. Res. Lett., 36, L05816, doi:10.1029/2008g1036662, 2009a.

Ndour, M., Nicolas, M., D’Anna, B., Ka, O., and George, C.: Photoreactivity of $\mathrm{NO}_{2}$ on mineral dusts originating from different locations of the Sahara desert, Phys. Chem. Chem. Phys., 11, 1312-1319, doi:10.1039/b806441e, 2009b.

Nemitz, E., Prévôt, A. S. H., Äijälä, M., Allan, J. D., Baltensperger, U., Berresheim, H., Carbone, S., Canagaratna, M. R., Canonaco, F., Capes, G., Ceburnis, D., Choularton, T., Coe, H., Cubison, M. J., Dall'Osto, M., Di Marco, C. F., DeCarlo, P. F., Ehn, M., Eriksson, A., Freney, E., Herrmann, H., Jimenez, J. L., Hildebrandt, L., Juninen, H., Kiendler-Scharr, A., Laaksonen, A., Lanz, V. A., McFiggans, G., Mensah, A., Mentel, T. F., Mohr, C., O’Dowd, C., Ortega, A., Ovadnevaite, J., Pagels, J., Pandis, S. N., Phillips, G. J., Poulain, L., Raatikainen, T., Saarikoski, S., Sellegri, K., Spindler, G., Sueper, D., Swietlicki, E., Tiitta, P., Worsnop, D. R., European submicron aerosol chemical composition derived from a campaign-based Aerosol Mass Spectrometer network, in preparation, 2011.

Neuman, J. A., Nowak, J. B., Brock, C. A., Trainer, M., Fehsenfeld, F. C., Holloway, J. S., Hubler, G., Hudson, P. K., Murphy, D. M., Nicks, D. K., Orsini, D., Parrish, D. D., Ryerson, T. B., Sueper, D. T., Sullivan, A., and Weber, R.: Variability in ammonium nitrate formation and nitric acid depletion with altitude and location over California, J. Geophys. Res.-Atmos., 108, 4557, doi:10.1029/2003jd003616, 2003.

Ng, N. L., Canagaratna, M. R., Zhang, Q., Jimenez, J. L., Tian, J., Ulbrich, I. M., Kroll, J. H., Docherty K. S., Chhaabra, P. S., Bahreini, R., Murphy, S. M., Seinfeld, J. H., Hildebrandt, L., Donahue, N. M., DeCarlo, P. F., Lanz, V. A., Prévôt, A.
S. H., Dinar, E., Rudich, Y., and Worsnop, D. R.: Organic aerosol components observed in northern hemispheric datasets from Aerosol Mass Spectrometry, Atmos. Chem. Phys., 10, 4625-4641, doi:10.5194/acp-10-4625-2010, 2010.

Nicolet, M., Stetzer, O., Lüönd, F., Möhler, O., and Lohmann, U.: Single ice crystal measurements during nucleation experiments with the depolarization detector IODE, Atmos. Chem. Phys., 10, 313-325, doi:10.5194/acp-10-313-2010, 2010.

Niedermeier, D., Hartmann, S., Shaw, R. A., Covert, D., Mentel, T. F., Schneider, J., Poulain, L., Reitz, P., Spindler, C., Clauss, T., Kiselev, A., Hallbauer, E., Wex, H., Mildenberger, K., and Stratmann, F.: Heterogeneous freezing of droplets with immersed mineral dust particles - measurements and parameterization, Atmos. Chem. Phys., 10, 3601-3614, doi:10.5194/acp-10-36012010, 2010.

Nieminen, T., Paasonen, P., Manninen, H. E., Sellegri, K., Kerminen, V.-M., and Kulmala, M.: Parameterization of ion-induced nucleation rates based on ambient observations, Atmos. Chem. Phys., 11, 3393-3402, doi:10.5194/acp-11-3393-2011, 2011

Nieto-Gligorovski, L., Net, S., Gligorovski, S., Zetzsch, C., Jammoul, A., D'Anna, B., and George, C.: Interactions of ozone with organic surface films in the presence of simulated sunlight: impact on wettability of aerosols, Phys. Chem. Chem. Phys., 10, 2964-2971, doi:10.1039/b717993f, 2008.

O’Dowd, C. D., Langmann, B., Varghese, S., Scannell, C., Ceburnis, D., and Facchini, M. C.: A combined organic-inorganic sea-spray source function, Geophys. Res. Lett., 35, L01801, doi:10.1029/2007GL030331, 2008.

O'Dowd, C. D., Monahan, C., and Dall-Osto, M.: On the occurrence of open ocean particle production and growth events, Geophys. Res. Lett., 37, L19805, doi:10.1029/2010GL044679, 2010.

O'Donnell, D.: Towards the Assessment of the Climate Effects of Secondary Organic Aerosols, PhD Thesis, University of Hamburg, Germany, 2009.

O'Donnell, D., Tsigaridis, K., and Feichter, J.: Estimating the direct and indirect effects of secondary organic aerosols using ECHAM5-HAM, Atmos. Chem. Phys., 11, 8635-8659, doi:10.5194/acp-11-8635-2011, 2011.

Ortega, I. K., Kurtén, T., Vehkamäki, H., and Kulmala, M.: The role of ammonia in sulfuric acid ion induced nucleation, Atmos. Chem. Phys., 8, 2859-2867, doi:10.5194/acp-8-2859-2008, 2008.

Paasonen, P., Nieminen, T., Asmi, E., Manninen, H. E., Petäjä, T., Plass-Dülmer, C., Flentje, H., Birmili, W., Wiedensohler, A., Hõrrak, U., Metzger, A., Hamed, A., Laaksonen, A., Facchini, M. C., Kerminen, V.-M., and Kulmala, M.: On the roles of sulphuric acid and low-volatile orgnanic vapours in the initial steps of atmospheric new particle formation, Atmos. Chem. Phys., 10, 11223-11242, doi:10.5194/acp-10-11223-2010, 2010.

Paeth, H. and Feichter, J.: Greenhouse gas versus aerosol forcing and African climate response, Clim. Dynam., 26, 35-54, 2006.

Pankow, J. F. and Barsanti, K. C.: The carbon number-polarity grid: A means to manage the complexity of the mix of organic compounds when modeling atmospheric organic particulate matter, Atmos. Environ., 43, 2829-2835, 2009.

Paulsen, D., Dommen, J., Kalberer, M., Prévôt, A. S. H., Richter, R., Sax, M., Steinbacher, M., Weingartner, E., and Baltensperger, U.: Secondary organic aerosol formation by irradiation of 1,3,5trimethylbenzene- $\mathrm{NO}_{\mathrm{x}}-\mathrm{H}_{2} \mathrm{O}$ in a new reaction chamber for at- 
mospheric chemistry and physics, Environ. Sci. Technol., 39, 2668-2678, 2005.

Petters, M. D. and Kreidenweis, S. M.: A single parameter representation of hygroscopic growth and cloud condensation nucleus activity, Atmos. Chem. Phys., 7, 1961-1971, doi:10.5194/acp-71961-2007, 2007.

Petäjä, T., Mauldin, III, R. L., Kosciuch, E., McGrath, J., Nieminen, T., Paasonen, P., Boy, M., Adamov, A., Kotiaho, T., and Kulmala, M.: Sulfuric acid and $\mathrm{OH}$ concentrations in a boreal forest site, Atmos. Chem. Phys., 9, 7435-7448, doi:10.5194/acp9-7435-2009, 2009.

Pfrang, C., Shiraiwa, M., and Pöschl, U.: Coupling aerosol surface and bulk chemistry with a kinetic double layer model (K2-SUB): oxidation of oleic acid by ozone, Atmos. Chem. Phys., 10, 45374557, doi:10.5194/acp-10-4537-2010, 2010.

Pfrang, C., Shiraiwa, M., and Pöschl, U.: Chemical ageing and transformation of diffusivity in semi-solid multi-component organic aerosol particles, Atmos. Chem. Phys., 11, 7343-7354, doi:10.5194/acp-11-7343-2011, 2011.

Philippin, S., Laj, P., Putaud, J.-P., Wiedensohler, A., de Leeuw, G., Fjaeraa, A. M., Platt, U., Baltensperger, U., and Fiebig, M.: EUSAAR - An Unprecedented Network of Aerosol Observation in Europe, Earozoru Kenkyu, JAAST, 24, 78-83, 2009.

Pierce, J. R., Theodoritsi, G., Adams, P. J., and Pandis, S. N.: Parameterization of the effect of sub-grid scale aerosol dynamics on aerosol number emission rates, J. Aerosol Sci., 40, 385-393, doi:10.1016/j.jaerosci.2008.11.009, May 2009.

Pikridas, M., Bougiatioti, A., Hildebrandt, L., Engelhart, G. J., Kostenidou, E., Mohr, C., Prévôt, A. S. H., Kouvarakis, G., Zarmpas, P., Burkhart, J. F., Lee, B. H., Psichoudaki, M., Mihalopoulos, N., Pilinis, C., Stohl, A., Baltensperger, U., Kulmala, M., and Pandis, S. N.: The Finokalia Aerosol Measurement Experiment-2008 (FAME-08): an overview, Atmos. Chem. Phys., 10, 6793-6806, doi:10.5194/acp-10-6793-2010, 2010.

Piters, A. J. M., Buchmann, B., Brunner, D., Cohen, R., Lambert, J.-C., de Leeuw, G., Stammes, P., van Weele, M., and Wittrock, F.: Data quality and validation of satellite measurements of atmospheric composition, edited by: Burrows, J. P., Platt, U., and Borrell, P., The Remote Sensing of Tropospheric Composition from Space, Physics of Earth and Space Environments, 536 pp., Springer-Verlag Berlin Heidelberg 2011, ISBN: 978-3-64214790-6, doi:10.1007/978-3-642-14791-3, 315-364, 2011.

Pope III, C. A. and Dockery, D. W.: Health effects of fine particulate air pollution: Lines that connect, J. Air Waste Manage. Assoc., 56, 709-742, 2006.

Pozzoli, L., Janssens-Maenhout, G., Diehl, T., Bey, I., Schultz, M. G., Feichter, J., Vignati, E., and Dentener, F.: Reanalysis of tropospheric sulphate aerosol and ozone for the period 1980-2005 using the aerosol-chemistry-climate model ECHAM5-HAMMOZ, Atmos. Chem. Phys., 11, 95639594,doi:10.5194/acpd-11-10191-2011, 2011.

Prenni, A. J., Petters, M. D., and Kreidenweiss, S. M.: Relative roles of biogenic emissions and Saharan dust as ice nuclei in the Amazon basin, Nature Geosci., 2, 401-404, 2009.

Prévôt, A. S. H., Canonaco, F., Lanz, V.A, Nemitz, E., Äijälä, M., Allan, J. D., Baltensperger, U., Berresheim, H., Carbone, S., Canagaratna, M. R., Canonaco, F., Capes, G., Ceburnis, D., Choularton, T., Coe, H., Cubison, M. J., Dall'Osto, M., Di Marco, C. F., DeCarlo, P. F., Ehn, M., Eriksson, A., Freney,
E., Herrmann, H., Jimenez, J. L., Hildebrandt, L., Juninen, H., Kiendler-Scharr, A., Laaksonen, A., Lanz, V. A., McFiggans, G., Mensah, A., Mentel, T. F., Mohr, C., O’Dowd, C., Ortega, A., Ovadnevaite, J., Pagels, J., Pandis, S. N., Phillips, G. J., Poulain, L., Raatikainen, T., Saarikoski, S., Sellegri, K., Spindler, G., Sueper, D., Swietlicki, E., Tiitta, P., and Worsnop, D. R.: European submicron organic aerosol composition and characteristics derived from a campaign-based Aerosol Mass Spectrometer network, in preparation, 2011.

Pringle, K. J., Tost, H., Pozzer, A., Pöschl, U., and Lelieveld, J.: Global distribution of the effective aerosol hygroscopicity parameter for CCN activation, Atmos. Chem. Phys., 10, 52415255, doi:10.5194/acp-10-5241-2010, 2010.

Prisle, N. L., Raatikainen, T., Laaksonen, A., and Bilde, M.: Surfactants in cloud droplet activation: mixed organic-inorganic particles, Atmos. Chem. Phys., 10, 5663-5683, doi:10.5194/acp-105663-2010, 2010.

Prisle, N. L., Raatikainen, T., Sorjamaa, R., Svenningsson, B., Laaksonen, A., and Bilde, M.: Surfactant partitioning in cloud droplet activation: a study of C8, C10, C12 and C14 normal fatty acid sodium salts, Tellus, 60B, 416-431, doi:10.1111/j.16000889.2008.00352.x, 2008.

Putaud, J. P., Van Dingenen, R., Bruggemann, E., Facchini, M. C., Decessari, S., Fuzzi, S., Gehrig, R., Huglin, C., Laj, P., Lorbeer, G., Maenhaut, W., Mihalopoulos, N., Muller, K., Querol, X., Rodriguez, S., Schneider, J., Spindler, G., ten Brink, H., Torseth, K., and Wiedensohler, A.: European aerosol phenomenology2: Chemical characteristics of particulate matter at kerbside, urban, rural and background sites in Europe, Atmos. Environ., 38, 2579-2595, 2004.

Pöschl, U.: Gas-particle interactions of tropospheric aerosols: Kinetic and thermodynamic perspectives of multiphase chemical reactions, amorphous organic substances, and the activation of cloud condensation nuclei, Atmos. Res., 101, 562-573, doi:10.1016/j.atmosres.2010.12.018, 2011.

Pöschl, U., Rudich, Y., and Ammann, M.: Kinetic model framework for aerosol and cloud surface chemistry and gas-particle interactions - Part 1: General equations, parameters, and terminology, Atmos. Chem. Phys., 7, 5989-6023, doi:10.5194/acp-75989-2007, 2007.

Pöschl, U., Martin, S. T., Sinha, B., Chen, Q., Gunthe, S. S., Huffman, J. A., Borrmann, S., Farmer, D. K., Garland, R. M., Helas, G., Jimenez, J. L., King, S. M., Manzi, A., Mikhailov, E., Pauliquevis, T., Petters, M. D., Prenni, A. J., Roldin, P., Rose, D., Schneider, J., Su, H., Zorn, S. R., Artaxo, P., and Andreae, M. O.: Rainforest aerosols as biogenic nuclei of clouds and precipitation in the Amazon, Science, 429, 1513-1516, 2010.

Quaas, J., Ming, Y., Menon, S., Takemura, T., Wang, M., Penner, J. E., Gettelman, A., Lohmann, U., Bellouin, N., Boucher, O., Sayer, A. M., Thomas, G. E., McComiskey, A., Feingold, G., Hoose, C., Kristjánsson, J. E., Liu, X., Balkanski, Y., Donner, L. J., Ginoux, P. A., Stier, P., Grandey, B., Feichter, J., Sednev, I., Bauer, S. E., Koch, D., Grainger, R. G., Kirkevåg, A., Iversen, T., Seland, Ø., Easter, R., Ghan, S. J., Rasch, P. J., Morrison, H., Lamarque, J.-F., Iacono, M. J., Kinne, S., and Schulz, M.: Aerosol indirect effects - general circulation model intercomparison and evaluation with satellite data, Atmos. Chem. Phys., 9, 8697-8717, doi:10.5194/acp-9-8697-2009, 2009.

Raatikainen, T. and Laaksonen, A.: A simplified treatment of sur- 
factant effects on cloud drop activation, Geosci. Model Dev., 4, 107-116, doi:10.5194/gmd-4-107-2011, 2011.

Rae, J. G. L., Johnson, C. E., Bellouin, N., Boucher, O., Haywood, J. M., and Jones, A.,: Sensitivity of global sulphate aerosol production to changes in oxidant concentrations and climate, J. Geophys. Res., 112, D10312, doi:10.1029/2006JD007826, 2007.

Raes, F. and Seinfeld, J. H.: Climate change and air pollution abatement: A bumpy road, Atmos. Environ., 43, 5132-5133, 2009.

Reddington, C. L., Carslaw, K. S., Spracklen, D. V., Frontoso, M. G., Collins, L., Merikanto, J., Minikin, A., Hamburger, T., Coe, H., Kulmala, M., Aalto, P., Flentje, H., Plass-Dülmer, C., Birmili, W., Wiedensohler, A., Wehner, B., Tuch, T., Sonntag, A., O’Dowd, C. D., Jennings, S. G., Dupuy, R., Baltensperger, U., Weingartner, E., Hansson, H.-C., Tunved, P., Laj, P., Sellegri, K., Boulon, J., Putaud, J.-P., Gruening, C., Swietlicki, E., Roldin, P., Henzing, J. S., Moerman, M., Mihalopoulos, N., Kouvarakis, G., Ždímal, V., Zíková, N., Marinoni, A., Bonasoni, P., and Duchi, R.: Primary versus secondary contributions to particle number concentrations in the European boundary layer, Atmos. Chem. Phys., 11, 12007-12036, doi:10.5194/acp-11-12007-2011, 2011.

Reutter, P., Su, H., Trentmann, J., Simmel, M., Rose, D., Gunthe, S. S., Wernli, H., Andreae, M. O., and Pöschl, U.: Aerosoland updraft-limited regimes of cloud droplet formation: influence of particle number, size and hygroscopicity on the activation of cloud condensation nuclei (CCN), Atmos. Chem. Phys., 9, 7067-7080, doi:10.5194/acp-9-7067-2009, 2009.

Riedi, J., Marchant, B., Platnick, S., Baum, B., Thieuleux, F., Oudard, C., Parol, F., Nicolas, J.-M., and Dubuisson, P.: Cloud thermodynamic phase inferred from merged POLDER and MODIS data. Atmos. Chem. Phys., 7, 14103-14137, doi:10.5194/acp-7-14103-2007, 2007.

Riipinen, I., Svenningsson, B. , Bilde, M., Gaman, A., Lehtinen, K. E. J., and Kulmala, M.: A method for determing thermophysical properties of organic material in aqueous solutions: succinic acid, Atmos. Res., 82, 579-590, 2006.

Riipinen, I., Sihto, S.-L., Kulmala, M., Arnold, F., Dal Maso, M., Birmili, W., Saarnio, K., Teinilä, K., Kerminen, V.-M., Laaksonen, A., and Lehtinen, K. E. J.: Connections between atmospheric sulphuric acid and new particle formation during QUEST III-IV campaigns in Heidelberg and Hyytiälä, Atmos. Chem. Phys., 7, 1899-1914, doi:10.5194/acp-7-1899-2007, 2007a.

Riipinen, I., Koponen, I. K., Frank, G. P., Hyvarinen, A.-P., Vanhanen, J., Lihavainen, H., Lehtinen, K. E. J., Bilde, M., and Kulmala, M.: Adipic and Malonic Acid Aqueous Solutions: Surface Tensions and Saturation Vapor Pressures, J. Phys. Chem., A, 111, 12995-13002, 2007b.

Rinne, J., Bäck, J., and Hakola, H.: Biogenic volatile organic compound emissions from the Eurasian taiga: current knowledge and future directions, Boreal Environ. Res., 14, 807-826, 2009.

Roberts, G. C. and Nenes, A.: A Continuous-Flow Streamwise Thermal-Gradient CCN Chamber for Atmospheric Measurements, Aerosol Sci. Technol., 39, 206-221, 2005.

Roberts, G. C., Day, D. A., Russell, L. M., Dunlea, E. J., Jimenez J. L., Tomlinson, J. M., Collins, D. R., Shinozuka, Y., and Clarke, A. D.: Characterization of particle cloud droplet activity and composition in the free troposphere and the boundary layer during INTEX-B, Atmos. Chem. Phys., 10, 6627-6644, doi:10.5194/acp-10-6627-2010, 2010.

Roberts, G. C., Gomes, L., Brenguier, J.-L., Apituley, A., Wilson,
K., Boers, R., Donovan, D. P., Pelon, J., Josset, D. B., Boquet, M., Coe, H., and Trembath J.: Assessing aerosol-cloud interactions linking multi-platform observations and remote sensing, in preparation, 2011.

Robinson, A. L., Donahue, N. M., Shrivastava, M. K., Weitkamp, E. A., Sage, A. M., Grieshop, A. P., Lane, T. E., Pierce, J. R., and Pandis, S. N.: Rethinking organic aerosols: Semivolatile emissions and photochemical aging, Science, 315, 1259-1262, 2007.

Roeckner, E., Bäuml, G., Bonaventura, Brokopf, L. R., Esch, M., Giorgetta, M., Hagemann, S., Kirchner, I., Kornblueh, L., Manzini, E., Rhodin, A., Schlese, U., Schulzweida, U., and Tompkins, A.: The atmospheric general circulation model ECHAM5, part I: Model description, Technical Report 349, Max-Planck-Institute for Meteorology, Hamburg, Germany, 2003.

Rogers, D. C.: Development of a Continuous Flow Thermal Gradient Diffusion Chamber for Ice Nucleation Studies, Atmos. Res., 22, 149-181, 1988.

Rohrer, F., Bohn, B., Brauers, T., Bruning, D., Johnen, F. J., Wahner, A., and Kleffmann, J.: Characterisation of the photolytic HONO-source in the atmosphere simulation chamber SAPHIR, Atmos. Chem. Phys., 5, 2189-2201, doi:10.5194/acp-5-21892005, 2005.

Rouviere, A., DeCarlo, P. F., Schlierf, A., Favez, O., D’Anna, B., George, C., Prévôt, A., and Ammann, M.: Photosensitized aging of succinic acid aerosol, Geochim. Cosmochim. Acta, 73, A1125-A1125, 2009.

Russchenberg, H. W. J., Bosveld, F., Swart, D., ten Brink, H., de Leeuw, G., Uijlenhoet, R., Arbesser-Rastburg, B., van der Marel, H., Ligthart, L., Boers, R., and Apituley, A.: Groundbased atmospheric remote sensing in The Netherlands; European outlook, IEICE Transactions on Communications, E88-B(6), 2252-2258; doi:10.1093/ietcom/e88-b.6.2252, 2005.

Schlosser, E., Bohn, B., Brauers, T., Dorn, H. P., Fuchs, H., Haseler, R., Hofzumahaus, A., Holland, F., Rohrer, F., Rupp, L. O., Siese, M., Tillmann, R., and Wahner, A.: Intercomparison of two hydroxyl radical measurement techniques at the atmosphere simulation chamber SAPHIR, J. Atmos. Chem., 56, 187-205, doi:10.1007/s10874-006-9049-3, 2007.

Schulz, M.: Constraining model estimates of the aerosol radiative forcing, Habilitation thesis presented to Universite Pierre et Marie Curie, Paris VI, December 2007.

Schulz, M., Textor, C., Kinne, S., Balkanski, Y., Bauer, S., Berntsen, T., Berglen, T., Boucher, O., Dentener, F., Guibert, S., Isaksen, I. S. A., Iversen, T., Koch, D., Kirkevåg, A., Liu, X., Montanaro, V., Myhre, G., Penner, J. E., Pitari, G., Reddy, S., Seland, Ø., Stier, P., and Takemura, T.: Radiative forcing by aerosols as derived from the AeroCom present-day and pre-industrial simulations, Atmos. Chem. Phys., 6, 5225-5246, doi:10.5194/acp-6-5225-2006, 2006.

Schwartz, S. E., Charlson,R. J., Kahn, R. A., Ogren, J. A., and Rodhe, H.: Why hasn't Earth warmed as much as expected?, J. Climate, 23, 2453-2464, 2010.

Schwarz, J. P., Spackman, J. R., Gao, R. S., Watts, L. A., Stier, P., Schulz, M., Davis, S. M., Wofsy, S. C., and Fahey, D. W.: Global-scale black carbon profiles observed in the remote atmosphere and compared to models, Geophys. Res. Lett., 37, L18812, doi:10.1029/2010GL044372, 2010.

Seifert, A. and Beheng, K. D.: A two-moment cloud microphysics 
parameterization for mixed- phase clouds. Part I: Model description, Meteorol. Atmos. Phys., 92, 45-66, 2006.

Seinfeld, J. H. and Pandis, S. N.: Atmos. Chem. Phys.: From Air Pollution to Climate Change, John Wiley \& Sons, New York, USA, 1326 pp., 1998.

Seland, Ø., Iversen, T., Kirkevåg, A., and Storelvmo, T.: On basic shortcomings of aerosol-climate interactions in atmospheric GCMs, Tellus, 60A, 459-491, 2008.

Sellegri, K., Laj, P., Peron, F., Dupuy, R., Legrand, M., Preunkert, S., Putaud, J.-P., Cachier, H., and Ghermandi, G.: Mass balance of winter time free tropospheric aerosol at the Puy de Dôme (France), J. Geophys. Res., 108, 4333, doi:10.1029/2002JD002747, 2003a.

Shen, X. J., Sun, J. Y., Zhang, Y. M., Wehner, B., Nowak, A., Tuch, T., Zhang, X. C., Wang, T. T., Zhou, H. G., Zhang, X. L., Dong, F., Birmili, W., and Wiedensohler, A.: First longterm study of particle number size distributions and new particle formation events of regional aerosol in the North China Plain, Atmos. Chem. Phys., 11, 1565-1580, doi:10.5194/acp-11-15652011, 2011.

Shinozuka, Y., Clarke, A. D., DeCarlo, P. F., Jimenez, J. L., Dunlea, E. J., Roberts, G. C., Tomlinson, J. M., Collins, D. R., Howell, S. G., Kapustin, V. N., McNaughton, C. S., and Zhou, J.: Aerosol optical properties relevant to regional remote sensing of $\mathrm{CCN}$ activity and links to their organic mass fraction: airborne observations over Central Mexico and the US West Coast during MILAGRO/INTEX-B, Atmos. Chem. Phys., 9, 6727-6742, doi:10.5194/acp-9-6727-2009, 2009.

Shiraiwa, M., Pfrang, C., and Pöschl, U.: Kinetic multi-layer model of aerosol surface and bulk chemistry (KM-SUB): the influence of interfacial transport and bulk diffusion on the oxidation of oleic acid by ozone, Atmos. Chem. Phys., 10, 3673-3691, doi:10.5194/acp-10-3673-2010, 2010.

Shiraiwa, M., Garland, R. M., and Pöschl, U.: Kinetic double-layer model of aerosol surface chemistry and gas-particle interactions (K2-SURF): Degradation of polycyclic aromatic hydrocarbons exposed to $\mathrm{O}_{3}, \mathrm{NO}_{2}, \mathrm{H}_{2} \mathrm{O}, \mathrm{OH}$ and $\mathrm{NO}_{3}$, Atmos. Chem. Phys., 9, 9571-9586, doi:10.5194/acp-9-9571-2009, 2009.

Shiraiwa, M., Ammann, M., Koop, T., and Pöschl, U: Gas uptake and chemical aging of semi-solid organic aerosol particles, $\mathrm{P}$. Natl. Acad. Sci. USA, 108, 11003-11008, 2011a.

Shiraiwa, M., Sosedova, Y., Rouviere, A., Yang, H, Zhang, Y., Abbatt, J. P. D., Ammann, M., and Pöschl, U.: The role of long-lived reactive oxygen intermediates in the reaction of ozone with aerosol particles, Nature Chem., 3, 291-295, doi:10.1038/NCHEM.988, 2011b.

Sihto, S.-L., Kulmala, M., Kerminen, V.-M., Dal Maso, M., Petäjä, T., Riipinen, I., Korhonen, H., Arnold, F., Janson, R., Boy, M., Laaksonen, A., and Lehtinen, K. E. J.: Atmospheric sulphuric acid and aerosol formation: implications from atmospheric measurements for nucleation and early growth mechanisms, Atmos. Chem. Phys., 6, 4079-4091, doi:10.5194/acp-6-4079-2006, 2006.

Sillmann, J. and Croci-Maspoli, M.: Present and future atmospheric blocking and its impact on European mean and extreme climate, Geophys. Res. Lett., 36, L10702, doi:10.1029/2009GL038259, 2009.

Simpson, D., Winiwarter, W., Börjesson, G., Cinderby, S., Ferreiro, A., Guenther, A., Hewitt, C. N., Janson, R., Khalil, M. A. K.,
Owen, S., Pierce, T. E., Puxbaum, H., Shearer, M., Skiba, U., Steinbrecher, R., Tarrasón, L., and Öquist, M. G.: Inventorying emissions from Nature in Europe, J. Geophys. Res., 104D, 81138152, 1999.

Simpson, D., Yttri, K., Klimont, Z., Kupiainen, K., Caseiro, A., Gelencsér, A., Pio, C., and Legrand, M.: Modeling Carbonaceous Aerosol over Europe. Analysis of the CARBOSOL and EMEP EC/OC campaigns, J. Geophys. Res., 112, D23S14, doi:10.1029/2006JD008158, 2007.

Simpson, D., Benedictow, A., Berge, H., Bergstrm, L. D. Emberson, R., Fagerli, H., Gauss, M., Hayman, G., Jenkin, M., Jonson, J., Nyíri, A., Richter, C., Semeena, V., Tsyro, S., Valdebenito, A., and Wind, P.: The EMEP MSC-W Chemical Transport model I: Model description, Atmos. Chem. Phys. Discuss., submitted, 2011.

Sipilä, M., Lehtipalo, K., Kulmala, M., Petäjä, T., Junninen, H., Aalto, P. P., Manninen, H. E., Kyrö, E.-M., Asmi, E., Riipinen, I., Curtius, J., Kurten, A., Borrmann, S., and O'Dowd, C. D. O.: Applicability of condensation particle counters to measure atmospheric clusters, Atmos. Chem. Phys., 8, 4049-4060, doi:10.5194/acp-8-4049-2008, 2008.

Sipilä, M., Lehtipalo, K., Attoui, M., Neitola, K., Petäjä, T., Aalto, P. P., O'Dowd, C. D., and Kulmala, M.: Laboratory verification of PH-CPC's ability to monitor atmospheric sub-3nm clusters, Aerosol Sci. Technol., 43, 126-135, 2009.

Sipilä M., Berndt, T., Petäjä, T., Brus, D., Vanhanen, J., Stramann, F., Patokoski, J., Mauldin, III R. L., Hyvärinen, A.-P., Lihavainen, H., and Kulmala, M.: The role of sulfuric acid in atmospheric nucleation, Science, 327, 1243-1246, 2010.

Sneep, M., Ityaksov, D., Aben, I., Linnartz, H., and Ubachs, W.: Temperature-dependent cross sections of $\mathrm{O}_{2}-\mathrm{O}_{2}$ collisioninduced absorption resonances at 477 and $577 \mathrm{~nm}$, J. Quant. Spectrosc. Ra., 98, 405-424, 2006.

Sneep, M., de Haan, J. F., Stammes, P., Wang, P., Vanbauce, C., Joiner, J., Vasilkov, A. P., and Levelt, P. F.: Three-way comparison between OMI and PARASOL cloud pressure products, J. Geophys. Res., 113, D15S23, doi:10.1029/2007JD008694, 2008.

Sosedova, Y., Rouviere, A., Bartels-Rausch, T., and Ammann, M.: UVA/Vis-induced nitrous acid formation on polyphenolic films exposed to gaseous $\mathrm{NO}_{2}$, Photochem. Photobiol. Sci. 10, 16801690, doi:10.1039/C1PP05113J, 2011.

Spindler, C.: Charakterisierung Biogener Sekundärer Organischer Aerosole mit Statistischen Methoden, doctoral thesis, Fachbereich Mathematik und Naturwissenschaften, Bergischen Universität Wuppertal, Wuppertal, Germany, 163 pp., 2010.

Spracklen, D., Carslaw, K., Kulmala, M., Kerminen, V.-M., Mann, G., and Sihto, S.-L.: The contribution of boundary layer nucleation events to total particle concentrations on regional and global scales, Atmos. Chem. Phys., 6, 5631-5648, doi:10.5194/acp-6-5631-2006, 2006.

Spracklen, D. V., Bonn, B., and Carslaw, K. S.: Boreal Forests, Aerosols and the Impacts on Clouds and Climate, Philos. Trans. Roy. Soc. A, 366, 4613-4626, doi:10.1098/rsta.2008.0201, 2008a.

Spracklen, D. V., Carslaw, K. S., Kulmala, M., Kerminen, V.-M., Sihto, S.-L., Riipinen, I., Merikanto, J., Mann, G. W., and Chipperfield, M. P., Wiedensohler, A., Birmili, W., and Lihavainen, H.: Contribution of particle formation to global cloud conden- 
sation nuclei concentrations, Geophys. Res. Lett., 35, L06808, doi:10.1029/2007GL033038, 2008b.

Spracklen, D. V-, Carslaw, K. S., Merikanto, J., Mann, G. W., Reddington, C. L., Pickering S., Ogren, J. A., Andrews, E., Baltensperger, U., Weingartner, E., Boy, M., Kulmala, M., Laakso, L., Lihavainen, H., Kivekäs, N., Komppula, M., Mihalopoulos, N., Kouvarakis, G., Jennings, S. G., O’Dowd, C. D., Birmili, W., Wiedensohler, A., Weller, R., Gras, J., Laj, P., Sellegri, K., Bonn, B., Krejci, R., Laaksonen, A., Hamed, A., Minikin, A., Harrison, R. M., Talbot, R., and Sun, J.: Explaining global surface aerosol number concentrations in terms of primary emissions and particle formation, Atmos. Chem. Phys., 10, 47754793, doi:10.5194/acp-10-4775-2010, 2010.

Spracklen, D. V., Carslaw, K. S., Pöschl, U., Rap, A., and Forster, P. M.: Global cloud condensation nuclei influenced by carbonaceous combustion aerosol, Atmos. Chem. Phys., 11, 9067-9087, doi:10.5194/acp-11-9067-2011, 2011.

Staudt, M. and Bertin, N.: Light and temperature dependence of the emission of cyclic and acyclic monoterpenes from holm oak (Quercus ilex L.) leaves, Plant Cell Environ., 21, 385-395, 1998.

Stemmler, K., Ndour, M., Elshorbany, Y,. Kleffmann, J., D’Anna, B., George, C., Bohn, B., and Ammann, M.: Ligth induced conversion of nitrogen dioxide into nitrous acid on submicron humid acid aerosol, Atmos. Chem. Phys., 7, 4237-4248, doi:10.5194/acp-7-4237-2007, 2007.

Stetzer, O., Baschek, B., Lüönd, F., and Lohmann, U.: The Zurich Ice Nucleation Chamber (ZINC) - A new instrument to investigate atmospheric ice formation, Aerosol Sci. Tech., 42, 64-74, 2008.

Stier, P., Feichter, J., Kinne, S., Kloster, S., Vignati, E., Wilson, J., Ganzeveld, L., Tegen, I., Werner, M., Balkanski, Y., Schulz, M., Boucher, O., Minikin, A., and Petzold, A.: The aerosolclimate model ECHAM5-HAM, Atmos. Chem. Phys., 5, 11251156, doi:10.5194/acp-5-1125-2005, 2005.

Stier, P., Seinfeld, J. H., Kinne, S., and Boucher, O.: Aerosol absorption and radiative forcing, Atmos. Chem. Phys., 7, 52375261, doi:10.5194/acp-7-5237-2007, 2007.

Stohl, A., Forster, C., Frank, A., Seibert, P., and Wotawa, G.: Technical note: The Lagrangian particle dispersion model FLEXPART version 6.2, Atmos. Chem. Phys., 5, 2461-2474, doi:10.5194/acp-5-2461-2005, 2005.

Storelvmo, T., Kristjánsson, J. E., and Lohmann, U.: Aerosol influence on mixed-phase clouds in CAM-Oslo, J. Atmos. Sci., 65, 3214-3230, 2008.

Styler, S. A., Brigante, M., D’ Anna, B., George, C., and Donaldson, D. J.: Photoenhanced ozone loss on solid pyrene films, Phys. Chem. Chem. Phys., 11, 7876-7884, doi:10.1039/b904180j, 2009.

Su, H., Rose, D., Cheng, Y. F., Gunthe, S. S. Massling, A., Stock, M., Wiedensohler, A., Andreae, M. O., and Pöschl, U.: Hygroscopicity distribution concept for measurement data analysis and modeling of aerosol particle mixing state with regard to hygroscopic growth and CCN activation, Atmos. Chem. Phys., 10, 7489-7503, doi:10.5194/acp-10-7489-2010, 2010.

Swart, R.: A good climate for clean air: Linkages between climate change and air pollution - An editorial essay, Clim. Change, 66, 263-269, 2004.

Swietlicki, E.,Hansson, H.-C., Hämeri, K., Svenningsson, B., Massling, A., McFiggans, G., McMurry, P.H., Petäjä, T., Tunved,
P., Gysel, M., Topping, D., Weingartner, E., Baltensperger, U., Rissler, J., Wiedensohler, A., and Kulmala, M.: Hygroscopic Properties of Sub-Micrometer Atmospheric Aerosol Particles Measured with H-TDMA Instruments in Various Environments - A Review, Tellus B, 60, 432-469, 2008.

Swietlicki, E. et al. (EUCAARI H-TDMA team): Hygroscopic Properties of Sub-Micrometer Atmospheric Aerosol Particles from Long-term Measurements with H-TDMA Instruments across Europe 2008-2009, Atmos. Chem. Phys. Discuss., EUCAARI Special Issue, in preparation, 2011.

Szidat, S., Jenk, T. M., Synal, H.-A., Kalberer, M., Wacker, L., Hajdas, I., Kasper-Giebl, A., and Baltensperger, U.: Contributions of fossil fuel, biomass-burning, and biogenic emissions to carbonaceous aerosols in Zurich as traced by ${ }^{14} \mathrm{C}$, J. Geophys. Res., 111, D07206, doi:10-1029/2005JD006590, 2006.

Szidat, S., Prévôt, A. S. H., Sandradewi, J., Alfarra, M. R., Synal, H.-A., Wacker, L., and Baltensperger U.: Dominant impact of residential wood burning on particulate matter in Alpine valleys during winter, Geophys. Res. Lett., 34, L05820, doi:10.1029/2006GL028325, 2007.

Textor, C., Schulz, M., Guibert, S., Kinne, S., Balkanski, Y., Bauer, S., Bernstsen, T., Berglen, T., Bourcher, O., Chin, M., Dentener, F., Diehl, T., Easter, R., Feichter, H., Fillmore, D., Ghan, S., Ginoux, P., Gong, S., Kristjansson, J. E., Krol, M., Lauer, A., Lamarque, J. F., Liu, X., Montanaro, V., Myhre, G., Penner, J. E., Pitari, G., Reddy, S., Seland, O., Stier, P., Takemura, T., and Tie, X.: Analysis and quantification of the diversities of aerosol life cycles within AeroCom, Atmos. Chem. Phys., 6, 1777-1813, doi:10.5194/acp-6-1777-2006, 2006.

Topping, D. O., Lowe, D., and McFiggans, G.: Partial Derivative Fitted Taylor Expansion: An efficient method for calculating gas-liquid equilibria in atmospheric aerosol particles: 1. Inorganic compounds, J. Geophys. Res., 114, D04304, doi:10.1029/2008JD010099, 2009.

Topping, D. O., Barley, M. H., and McFiggans, G.: The sensitivity of Secondary Organic Aerosol component partitioning to the predictions of component properties - Part 2: Determination of particle hygroscopicity and its dependence on "apparent" volatility, Atmos. Chem. Phys., 11, 7767-7779, doi:10.5194/acp-11-77672011, 2011a.

Topping, D., Lowe, D., and McFiggans, G.: Partial Derivative Fitted Taylor Expansion: an efficient method for calculating gas/liquid equilibria in atmospheric aerosol particles - Part 2: Organic compounds, Geosci. Model Dev. Discuss., 4, 1755-1791, doi:10.5194/gmdd-4-1755-2011, $2011 \mathrm{~b}$.

Torres, O., Tanskanen, A., Veihelmann, B., Ahn, C., Braak, R., Bhartia, P. K., Veefkind, P., and Levelt, P.: Aerosols and surface UV products from Ozone Monitoring Instrument observations: An overview, J. Geophys. Res., 112, D24S47, doi:10.1029/2007JD008809, 2007.

Tunved, P., Hansson H.-C., Kerminen, V.-M., Ström, J. M. D., Lihavainen, H., Viisanen, Y., Aalto, P., Komppula, M., and Kulmala, M. :High natural aerosol loading over boreal forests, Science, 312, 261-263, 2006.

Tunved, P., Ström, J., Kulmala, M., Kerminen, V.-M., Dal Maso, M., Svennignsson, B., Lunder, C., and Hansson H.-C.: The natural aerosol over Northern Europe and its relation to anthropogenic emissions - Implications of important climate feedbacks, Tellus, 60B, 473-484, 2008. 
Tunved, P., Partridge, D. G., and Korhonen, H.: New trajectorydriven aerosol and chemical process model Chemical and Aerosol Lagrangian Model (CALM), Atmos. Chem. Phys., 10, 10161-10185, doi:10.5194/acp-10-10161-2010, 2010.

Ulbrich, I. M., Canagaratna, M. R., Zhang, Q., Worsnop, D. R., and Jimenez, J. L.: Interpretation of organic components from Positive Matrix Factorization of aerosol mass spectrometric data, Atmos. Chem. Phys., 9, 2891-2918, doi:10.5194/acp-9-2891-2009, 2009.

UNECE, UNECE Convention on Long-range Transboundary Air Pollution aims to reduce Black Carbon emissions, Geneva, available online at: www.unece.org/press/pr2010/10env_p20e.htm, last access: 15 June 2011, 2010.

UNEP Integrated assessment of Black Carbon and tropospheric ozone, ISBN: 978-92-807-3142-2, Job. No: DEW/1352/NA, http://www.unep.org/dewa/, Report by the Co-Chairs of the Ad Hoc Expert Group on Black Carbon, ECE/EB.AIR/2010/7, available online at: http://www.unece.org/env/documents/2010/eb/eb/ ece.eb.air.2010.7.e.pdf, 2011.

Vaattovaara, P., Räsänen, M., Kühn, T., Joutsensaari, J., and Laaksonen, A.: A method for detecting the presence of organic fraction in nucleation mode sized particles, Atmos. Chem. Phys., 5, 3277-3287, doi:10.5194/acp-5-3277-2005, 2005.

Vakkari, V., Laakso, H., Kulmala, M., Laaksonen, A., Mabaso, D., Molefe, M., Kgabi, N., and Laakso, L.: New particle formation events in semi-clean South African savannah, Atmos. Chem. Phys., 11, 3333-3346, doi:10.5194/acp-11-3333-2011, 2011.

Van Dingenen, R., Raes, F., Putaud, J.-P., Baltensperger, U., Charron, A., Facchini, M. C., Decesari, S., Fuzzi, S., Gehrig, R., Hansson, H.-C., Harrison, R. M., Huglin, C., Jones, A. M., Laj, P., Lorbeer, G., Maenhaut, W., Palmgren, F, Querol, X., Rodriguez, S., Schneider, J., ten Bring, H., Tunved, P., Torseth, K., Wehner, B., Weingartner, E., Wiedensohler, A., and Wahlin, P.: A European aerosol phenomenology - 2.: physical characteristics of particulate matter at kerbside, urban, rural and background sites in Europe, Atmos. Environ., 38, 2561-2577, 2004.

Vanhanen, J., Mikkilä, J., Sipilä, M., Manninen, H. E., Lehtipalo, K., Siivola, E., Petäjä, T., and Kulmala, M.: Particle Size Magnifier for nano-CN detection, Aerosol Sci. Technol., 45, 533-542, 2011.

Venzac, H., Sellegri, K., Villani, P., Picard, D., and Laj, P.: Seasonal variation of aerosol size distributions in the free troposphere and residual layer at the puy de Dôme station, France, Atmos. Chem. Phys., 9, 1465-1478, doi:10.5194/acp-9-1465-2009, 2009.

Vlasenko, A., Huthwelker, T., Gaggeler, H. W., and Ammann, M.: Kinetics of the heterogeneous reaction of nitric acid with mineral dust particles: an aerosol flowtube study, Phys. Chem. Chem. Phys., 11, 7921-7930, 2009.

Wehner, B., Siebert, H., Ansmann, A., Ditas, F., Seifert, P., Stratmann, F., Wiedensohler, A., Apituley, A., Shaw, R. A., Manninen, H. E., and Kulmala, M.: Observations of turbulence-induced new particle formation in the residual layer, Atmos. Chem. Phys., 10, 4319-4330, doi:10.5194/acp-10-4319-2010, 2010.
Wiedensohler, A., Birmili, W., Nowak, A., Sonntag, A., Weinhold, K., Merkel, M., Wehner, B., Tuch, T., Pfeifer, S., Fiebig, M., Fjäraa, A. M., Asmi, E., Sellegri, K., Depuy, R., Venzac, H., Villani, P., Laj, P., Aalto, P., Ogren, J. A., Swietlicki, E., Roldin, P., Williams, P., Quincey, P., Hüglin, C., Fierz-Schmidhauser, R., Gysel, M., Weingartner, E., Riccobono, F., Santos, S., Grüning, C., Faloon, K., Beddows, D., Harrison, R. M., Monahan, C., Jennings, S. G., O’Dowd, C. D., Marinoni, A., Horn, H.-G., Keck, L., Jiang, J., Scheckman, J., McMurry, P. H., Deng, Z., Zhao, C. S., Moerman, M., Henzing, B., and de Leeuw, G.: Particle mobility size spectrometers: harmonization of technical standards and data structure to facilitate high quality long-term observations of atmospheric particle number size distributions, Atmos. Meas. Tech. Discuss., 3, 5521-5587, doi:10.5194/amtd-3-55212010, 2010.

Winkler, P. M., Steiner, G., Vrtala, A., Vehkamäki, H., Noppel, M., Lehtinen, K. E. J., Reischl, G. P., Wagner, P. E., and Kulmala, M.: Heterogeneous nucleation experiments bridging the scale from molecular ion clusters to nanoparticles, Science, 319, 1374-1377, 2008.

Yttri, K. E., Simpson, D., Stenström, K., Puxbaum, H., and Svendby, T.: Source apportionment of the carbonaceous aerosol in Norway - quantitative estimates based on ${ }^{14} \mathrm{C}$, thermal-optical and organic tracer analysis, Atmos. Chem. Phys., 11, 9375-9394, doi:10.5194/acp-11-9375-2011, 2011a.

Yttri, K. E., Simpson, D., Nøjgaard, J. K., Kristensen, K., Genberg, J., Stenström, K., Swietlicki, E., Hillamo, R., Aurela, M., Bauer, H., Offenberg, J. H., Jaoui, M., Dye, C., Eckhardt, S., Burkhart, J. F., Stohl, A., and Glasius, M.: Source apportionment of the summer time carbonaceous aerosol at Nordic rural background sites, Atmos. Chem. Phys. Discuss., 11, 16369-16416, doi:10.5194/acpd-11-16369-2011, 2011 b.

Zardini, A. A. and Krieger, U. K.: Evaporation kinetics of a nonspherical, levitated aerosol particle using optical resonance spectroscopy for precision sizing, Optics Express, 17, 4659-4669, 2009.

Zardini, A. A., Riipinen, I., Koponen, I. K., Kulmala, M., and Bilde, M: Evaporation of ternary inorganic/organic aqueous droplets: Sodium chloride, succinic acid and water, J. Aerosol Sci., 41, 760-770, 2010.

Zelenay, V., Monge, M. E., D’Anna, B., George, C., Styler, S. A., Huthwelker, T., and Ammann, M.: Increased steady state uptake of ozone on soot due to UV/Vis radiation, J. Geophys. Res., 116, D11301, doi:10.1029/2010JD015500, 2011.

Zhang, F., Zhou, L. X., Novelli, P. C., Worthy, D. E. J., Zellweger, C., Klausen, J., Ernst, M., Steinbacher, M., Cai, Y. X., Xu, L., Fang, S. X., and Yao, B.: Evaluation of in situ measurements of atmospheric carbon monoxide at Mount Waliguan, China, Atmos. Chem. Phys., 11, 5195-5206, doi:10.5194/acp-11-51952011, 2011. 